\title{
MICROPROPAGATION TECHNOLOGY IN EARLY PHASES OF COMMERCIAL SEED POTATO PRODUCTION
}

Krzysztof Pruski 
Promotoren: Prof. dr. ir. P.C. Struik

Hoogleraar in de Gewasfysiologie

Prof. dr. J. Nowak

Professor in Horticulture, Virginia Polytechnic Institute and State University, Blacksburg, USA

Co-promotor: Dr. G.-J. de Klerk

Senior-onderzoeker weefselkweek,

Proefstation voor Plant \& Omgeving, Lisse

Samenstelling promotiecommissie:

Dr. R.J. Howard (Crop Diversification Centre South, Brooks, Canada)

Dr. S. Blade (Crop Diversification Centre North, Edmonton, Canada)

Prof. dr. L.H.W. van der Plas (Wageningen Universiteit)

Prof. dr. ir. R.G.F. Visser (Wageningen Universiteit)

Dr. ir. I. Mastenbroek (NAK, Emmeloord) 


$$
\text { ponos20!, 3060 }
$$

\title{
MICROPROPAGATION TECHNOLOGY IN EARLY PHASES OF COMMERCIAL SEED POTATO PRODUCTION
}

\author{
Krzysztof Pruski
}

\section{Proefschrift}

ter verkrijging van de graad van doctor op gezag van de rector magnificus van Wageningen Universiteit, prof. dr. ir. L. Speelman in het openbaar te verdedigen op woensdag 31 oktober 2001 des namiddags te vier uur in de Aula.

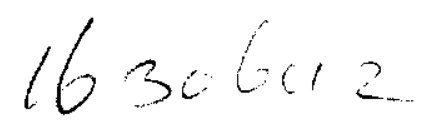


Krzysztof Pruski

Micropropagation technology in early phases of commercial seed potato production. Krysztof Pruski - [S.L. : s.n.]. I11

Thesis Wageningen University. - With ref.-

With summaries in English and Dutch.

ISBN: 90-5808-499-X

Subject headings: Solanum tuberosum L.; seed production / Solanum tuberosum L.; in vitro propagation. 


\section{Propositions}

1. The seed potato industry in the province of Alberta (Canada) will be enhanced by the introduction of microtubers in the seed production system.

(this thesis)

2. Jasmonates stimulate the production of potato microtubers and their performance in the greenhouse production of minitubers.

(this thesis)

3. Genotypic responses to in vitro conditions may determine the success or failure of the introduction of the method to a new cultivar.

4. GMO potato can be a public enemy or a friend.

5. The Dutch seed potato system helped the potato to colonize the world.

6. The small fruit industry in Alberta should be linked closer to the seed potato industry for mutual economic benefits.

7. Micropropagation is blooming in China and can significantly change the economy of the Three Gorges Region on Yangtse River in China.

8. Organic agriculture began as an ideology, but it cannot meet today's needs.

Propositions belonging to the $\mathrm{PhD}$ thesis of Krzysztof Pruski

Micropropagation technology in early phases of commercial seed potato production

Wageningen, 31 October 2001. 


\section{Abstract}

Pruski, Krzysztof, 2001. Micropropagation technology in early phases of commercial seed potato production. PhD thesis, Wageningen University and Research Centre, Wageningen, The Netherlands, $166 \mathrm{pp}$., English and Dutch summaries.

Micropropagation (in vitro propagation) has been introduced to seed potato production programmes more than two decades ago. The research reported in this thesis studied possibilities of improvements to micropropagation methods commonly used in commercial laboratories. The focus was placed on seed potato growers in Western Canada who either produce the tissue culture plant material themselves and use it for the production of minitubers (nuclear tubers) in their own operations, or acquire it prior to planting.

The autotrophic micropropagation (in $\mathrm{CO}_{2}(1500 \mathrm{ppm})$ enriched atmosphere, no sucrose in the medium) of Russet Burbank variety showed its usefulness for the small commercial laboratories where often the full sterility is difficult to maintain. Autotrophically grown cultures produced stems very similar to conventionally grown in vitro cultures (no significant differences in length, number of nodes and dry weight). Also, the conventionally propagated cultures benefited from $\mathrm{CO}_{2}$ enrichment during the 4 week growing period by a $20 \%$ increase in the number of nodes per stem and a $50 \%$ increase in stem dry weight (doubled stem length).

The use of continuous low red light $(690 \mathrm{~nm})$ at $3 \mu \mathrm{mol} \mathrm{m} \mathrm{s}^{-2} \mathrm{~s}^{-1}$ PPFD and $30 \mathrm{~g} \mathrm{l}^{-1}$ sucrose in the medium during the in vitro low temperature $\left(4^{\circ} \mathrm{C}\right)$ storage of potato cultures were beneficial for maintenance of vigorous, high quality cultures with a high re-grow capacity. In small tissue culture laboratories, installation of a simple low light device in the regular refrigerator would improve maintenance of the high quality of the stored cultures.

Significantly better production of microtubers (number of tubers and weight) was observed on solid (agar) than on liquid media, and under the $8 \mathrm{~h}$ photoperiod (SD) compared to no light. Microtubers derived from SD were greenish and seemed less juvenile than the tubers from $0 \mathrm{~h}$ light. Such microtubers performed better in the field or the greenhouse than microtubers produced in darkness. The $16 \mathrm{~h}$ photoperiod was inhibitory to the production of microtubers. The production of microtubers in all six commercial varieties tested in the studies benefited from SD. Tuber bulking rates were lower in the darkness than under the SD. Independently of the variety, fewer microtubers per explant with significantly lower weights, were produced under $0 \mathrm{~h}$ photoperiod than in SD. Production of microtubers in all three Russet varieties and in Sangre was superior to this of Shepody and Atlantic.

Effects of jasmonic acid (JA) on in vitro tuberization of potato were also variety specific. Varieties Amisk, Russet Burbank, Sangre and Umatilla Russet produced the highest number of microtubers per nodal cutting (1.0 - 1.7) and their tubers were also the largest with $70-75 \%$ of microtubers in the $>0.1 \mathrm{~g}$ size category. Results with Shepody were inconsistent and Atlantic produced the lowest number of tubers per nodal cutting. Amisk, Atlantic and Umatilla Russet benefited (significantly higher total tuber weight, percentage and weight of microtubers $>0.1 \mathrm{~g}$ ) from JA supplement to the tuberization medium (JAMed), but not from the pre-conditioning treatment (JAPret). However, none of these varieties clearly benefited from any JA treatments under light. Russet Burbank and Sangre also benefited from the JA supplement in the dark, although stock plantlet conditioning (JAPret) was more effective than the JA supplement to the tuberization medium (JAMed). Shepody did not show any benefits of JA on microtuberization, neither under dark or light conditions. The double treatment with JA (JAPret and JAMed) in light reduced production of microtubers comparing to the control and the individual JA treatments. 
The greenhouse/field performance of microtubers was highly dependent on JA conditioning of plantlets prior to in vitro tuberization, presence of JA in tuberization media, the photoperiod during tuberization and the dormancy release treatment. Although plantlets of all five tested cultivars performed well in the greenhouse, the microtuber performance was variety dependent, so were the responses to JA. JA conditioning of stock plants prior to taking explants for tuberization was beneficial for minituber production and it can be proposed as a treatment enhancing the quality of microtubers and their performance in the greenhouse production of minitubers. In the field, the results with JA were inconclusive; stock plantlets pre-treated with JA (JAPret) enhanced the Pre-elite tuber production in Russet Burbank by approximately $40 \%$ but significantly lowered it in Shepody by $17 \%$. In the greenhouse, the three Russet varieties responded best to JA treatments producing results comparable to in vitro plantlets in production of minitubers whereas microtubers of Shepody produced inconclusive results and variety Atlantic performance was poor. The varietal responses were similar in the field studies, however, yield and the number of Pre-elite tubers produced from microtubers were less than $50 \%$ of these from plantlets. SD during in vitro tuberization was an important factor (irrespective of other treatments) in producing microtubers which then performed well in the greenhouse and in the field. Microtubers produced in dark performed poorly. Although Rindite proved to be very effective in microtuber dormancy release in greenhouse conditions, more studies are required to provide evidence that the product is safe to use with microtubers. No severe damage to microtubers treated with Rindite was observed when microtubers were from $8 \mathrm{~h}$ light tuberization treatment (minimal damage to tubers from the dark treatment). In the field situation, GA gave better results in dormancy release. In all three Russet varieties, the highest number and yield of Pre-elite tubers were obtained when the microtubers were soaked in $100 \mathrm{ppm}$ solution of GA prior to field planting.

Optimalization of commercial production of disease/virus-free propagules in the seed potato system encompasses various aspects of micropropagation technology. These include improvements in mass multiplication phase, storage of cultures and the use of microtubers in the system. Microtubers of the Russet varieties can be successfully used to speed up the multiplication in the seed potato system, in the greenhouse production of minitubers.

Key words: Solanum tuberosum L., in vitro plantlet, in vitro tuberization, microtubers, minitubers, tuber bulking, photoperiod, in vitro storage, jasmonates, micropropagation, seed production. 


\section{Preface}

This thesis is a result of a five years research programme on the utilization of micropropagation techniques in the production of elite seed potatoes. Unless stated otherwise, experiments were performed at the Crop Diversification Centre North (CDCNorth) in Edmonton, Alberta, Canada. The data were processed, the published/submitted manuscripts prepared and the thesis written at the Nova Scotia Agricultural College, Truro, Nova Scotia, Canada. Most of the research funding came from the Alberta Agriculture Food and Rural Development (AAFRD), Edmonton, Alberta, Canada.

Special acknowledgement is extended to AAFRD for granting me a two-year educational leave to pursue my PhD study at the Wageningen University and Research Centre (WUR), The Netherlands.

First and foremost, I would like to thank my promotor, Dr. Paul C. Struik for giving me the opportunity to pursue this degree. I am thankful for his day-to-day guidance (internet), unreserved support, effort, patience and advice he provided to me throughout the process. I am very grateful to Dr. Jerzy Nowak, my other promotor, for his encouragement, enthusiasm, day-to-day help, and his vivid expression of continuous interest in my work, and his friendship over these last few years. Thank you Jerzy for being the invisible drive behind the work I was doing. You were instrumental in organizing the whole project. Without your strong believe in me this thesis would not have been completed. A very special Thank You to both of you, Paul and Jerzy, for sparing your precious time editing and improving the manuscript.

I would like to thank my co-promotor Dr. Geert-Jan de Klerk (editor-in-chief of Plant Cell, Tissue and Organ Culture) for his interest in my study and for his help in editing the manuscript.

I am indebted to Drs Stanford Blade (director of CDCNorth) and Ron Howard (director of CDCSouth) for their continuous support in my $\mathrm{PhD}$ educational leave. Special thanks are due to Mr. Alan Hall, director of the Plant Industry Division of AAFRD, who was instrumental in granting me the educational leave.

There are many people who have been professionally involved in the work reported herein. I would like to thank them all for their assistance. To Jeff Richards for the completion of the preliminary experiment of Chapter 5. To Patricia Duplessis of CDCNorth, for her supervision of the experimental plots and for creating an accurate data collection system. Special thanks are due to Tina Lewis, also of CDCNorth, for her excellent assistance in arranging the laboratory experiments and data collection.

I would also like to thank Linda Stewart, Katherine Andrew and Leah Maskewich, 
the summer assistants, for their excellence in maintaining of greenhouse and field plots, and data collection.

At Wageningen University, the help of Gon van Laar is highly acknowledged by putting the thesis in a consistent lay-out and conducting a last editorial round.

My family has been very supportive throughout the time period of the work reported here. I thank them for allowing me to pursue this work. I thank them for being so patient and understanding during this time. To Gefu, my wife, whose patience, support and love allowed me to put this thesis together, I wish to express my everlasting sense of gratitude and love. Thank you. I dedicate this thesis to you. 


\section{Contents}

1. General introduction

2. Role of micropropagation in horticultural and horticulture related crops for cold regions in Canada

3. Photoautotrophic micropropagation of Russet Burbank potato (Solanum tuberosum L.)

4. Sucrose and light effects on in vitro cultures of potato (Solanum tuberosum L.), chokecherry (Prunus virginiana L.) and Saskatoon berry (Amelanchier alnifolia Nutt.) during low temperature storage

5. Jasmonate effects on in vitro tuberization and tuber bulking in two potato cultivars (Solanum tuberosum L.) under different media and photoperiod conditions

6. Jasmonate effects on in vitro tuberization of potato (Solanum tuberosum L.) varieties under light and dark conditions

7. Jasmonate as a potato plantlets and microtubers conditioner for greenhouse and field planting

8. Microplantlets and microtubers in the seed potato production system of Alberta, Canada

9. General discussion

Summary

Samenvatting 
Chapter 1

General introduction 


\section{General introduction}

\subsection{Micropropagation}

The growth of isolated plant organs such as shoot tips, root tips, anthers and pollen, cells and protoplasts in culture on defined and semi-defined media in the absence of contaminating micro-organisms is called micropropagation, propagation in vitro or tissue culture propagation. All of the offspring from a single mother plant will be genetically identical and are members of a group called clone (similarly to the conventional vegetative propagation by cuttings). Micropropagation is not limited by season or by the weather. Laboratory propagation permits year round production and scheduling since tissue culture plants are grown in "season-controlled" growth rooms, where environmental conditions are set for optimal regeneration and growth. Tissue culture propagation provides opportunity for mass-production of uniform, pathogen free plants.

In potato, micropropagation became an essential component of the seed production systems providing disease/virus-free plants in early phases of multiplication. Tissue cultured plantlet or in vitro produced plantlet is the most common type of propagule used in the seed potato system around the world. Microtubers or in vitro produced tubers are another type of propagule which could also be utilized in the production of pathogen-free seed potato material. Microtubers are small $(0.02-0.70 \mathrm{~g})$ tubers produced from nodal cuttings or on complete plantlets using a specific growing medium (Hussey \& Stacey, 1984; Estrada et al., 1986; Garner \& Blake, 1989; Lillo, 1989; Struik \& Lommen, 1990; Ranalli et al., 1994). Utilization of microtubers has been postulated in the elite seed potato production systems by several authors, for almost two decades (Hussey \& Stacey, 1981; Estrada et al., 1986, Coltman \& Kostichka, 1993). Despite their advantage over microplants in storage and exchange (Estrada $e t$ al., 1986), microtubers have not been accepted as propagules of choice by the industry (Lommen, 1995; Struik \& Wiersema, 1999). However, in recent years, due to increasing demand for more high quality, disease-free seed material, the potato industry started considering a new type of propagule which could supplement the existing tissue cultured plantlet. More attention has been turned to micro- and minitubers. Recently, several new production protocols have been developed, giving better yields of larger microtubers (Struik \& Wiersema, 1999). Most of them, however, require either special equipment (Ranalli, 1997; Struik \& Wiersema, 1999) and/or frequent media exchanges which increase cost and labour demand and may lead to culture infection. Also, these systems have not been fully validated in the industrial settings. 


\section{Chapter 1}

The research work presented in this thesis is focused on an economical, commercial production of microtubers and its utilization in the early stages of seed potato programmes.

\subsection{The potato plant, its morphology and reproduction}

Potato (Solanum tuberosum L.) is an annual plant, $30-100 \mathrm{~cm}$ tall (depending on the variety and environmental conditions under which the crop is grown), producing three different types of stems: the normal stems (either sprouts or leafy stems), the stolons (the underground stems on which tubers are produced) and the tubers. Apical and axillary buds are present on all three types. If the internal and external conditions are favourable these buds potentially can produce one of the three types of stems again (Lommen, 1995). This phenomenon can be used in vegetative propagation of potato.

The normal (main) stems give support to leaves. These stems often branch and are (after proper induction and dry matter partitioning permitting) capable of producing inflorescences which by the end of the growing season produce berries that contain true seeds. Stolons (the underground stems (rhizomes), developed from axillary buds) have scale leaves and a hooked tip, and grow horizontally below the soil surface. Tubers, which in fact are severely shortened and thickened stems, usually form on stolons' tips and their branches. Roots in potato plants develop adventitiously, usually on leafy stems and stolons. Recently, Cutter (1992) and Struik \& Wiersema (1999) provided a detailed morphology of the potato plant.

Seed tubers are the most common source of plant material in potato reproduction. Approximately $15 \%$ of the total area under potato cultivation around the world is used for the production of seed tubers (FAO, 2000). However, the conventional seed tuber production system has several potential problems, since the seed tubers are successively produced from other seed tubers, which over the long period of time leads to high incidence of seed-borne diseases and occurrence of tubers not carrying all characteristics of the parent plant. Potato plants can be produced from other types of propagation material including protoplasts, callus and explants from different tissues (Evans et al., 1981), dissected meristems (Wang \& Hu, 1980), cuttings or stem segments (i.e., shoot tips, nodal cuttings (Goodwin et al. 1980; Bryan et al., 1981), stem cuttings and true potato seeds (Umaerus, 1987).

Since the genetic stability and the production of uniform, true-to-type plant material is important for the industry, the multiplication methods which utilize nodal or apical cuttings and tubers are preferred in seed potato production. New plants are produced from existing buds assuring identical genetic make-up of the parent plants (Lommen, 1995). 


\subsection{Distribution and importance}

Potato is one of the world's major food crops next to rice, wheat and corn. Its worldwide production is close to 300 million tonnes $(t)$ on approximately 20 million hectares (ha) (42 million acres) in 140 countries (FAO, 2000). In Canada, potato is the most important vegetable crop, accounting for about $60 \%$ of all vegetable farm cash income (over CAD $\$ 700$ million, CAD\$ $1.00=\sim$ US $\$ 0.65$ ). Over the last few years the potato sales at farm gate in Canada rose steadily (by $17 \%$ in 1998 and by $16 \%$ in 1999 season) due mainly to increased production, expanding markets and better prices (Statistics Canada, 2001). The 2000 production in Canada was over 4.5 million tonnes and was concentrated in the Atlantic region ( $45 \%$ - over 2 million t per year). The summary of Canadian potato production is shown in Table 1.

The two prairie provinces, Alberta and Manitoba, significantly expanded their production over the last decade. In the province of Alberta, due to two new processing plants (McCain Foods Ltd. and Lamb-Weston, Inc.) built near Taber, Alberta, the planting area under potato production is in a state of rapid expansion, from 13,000 ha $(28,000$ acres) in 1998 to 21,000 ha $(51,000$ acres) in 2000 (Clive Schaupmeyer, personal communication, Statistics Canada 2001). This expansion requires corresponding increase in high quality seed potato production.

Table 1. Canadian potato production in 2000. Area and production of potatoes in Canada, by Province (Statistics Canada, January 2001).

\begin{tabular}{lrrrr}
\hline & $\begin{array}{c}\text { Area } \\
\text { Planted } \\
\text { Provinces }\end{array}$ & $\begin{array}{c}\text { Area } \\
\text { Harvested } \\
{[\mathrm{ha}]}\end{array}$ & $\begin{array}{r}\text { Yield } \\
{\left[\mathrm{tha}^{-1}\right]}\end{array}$ & $\begin{array}{c}\text { Total } \\
\text { Production } \\
{[\mathrm{t}]}\end{array}$ \\
\hline CANADA (total) & $\mathbf{1 6 4 , 4 0 0}$ & $\mathbf{1 5 8 , 1 0 0}$ & $\mathbf{2 8 . 9 3}$ & $\mathbf{4 , 5 6 8 , 6 0 0}$ \\
Newfoundland & 200 & 200 & 20.50 & 4,100 \\
Prince Edward Island (P.E.I.) & 44,100 & 43,700 & 30.27 & $1,322,700$ \\
Nova Scotia & 2,100 & 2,100 & 26.95 & 56,600 \\
New Brunswick & 22,300 & 22,300 & 28.53 & 636,200 \\
Quebec & 17,800 & 17,400 & 26.12 & 454,100 \\
Ontario & 17,700 & 16,100 & 21.35 & 343,000 \\
Manitoba & 31,600 & 29,900 & 29.19 & 872,700 \\
Saskatchewan & 3,800 & 3,700 & 29.89 & 110,600 \\
Alberta & 21,400 & 19,300 & 34.75 & $\mathbf{6 7 0 , 7 0 0}$ \\
British Columbia & 3,400 & 3,400 & 28.79 & 97,900 \\
\hline
\end{tabular}




\section{Chapter 1}

Since a high percentage of potatoes produced in Canada are processed (close to $35 \%$ ), the varieties (cultivars) are often grown according to the demands of processing companies. Although the choice of varieties differs between provinces, there is a number of cultivars commonly grown across Canada. The cultivars Russet Burbank and Shepody together comprise close to $90 \%$ of the potatoes processed for French fries in the country and they are grown in all potato producing provinces in Canada.

The seed potato industry in Canada is a multi-million venture, with sales of about CAD\$ 100 million annually. In Alberta only, seed potato sales are around CAD $\$ 11$ million. With new processors in the area, new markets opening in Asia (i.e., China, Japan, Taiwan), other export markets expanding (including Cuba and Mexico), sales of seed potato may double in the near future.

At present, the base for seed potato production in Canada is the Pre-elite potato tuber. Pre-elite tubers are predominantly produced from greenhouse grown nuclear seed tubers derived from tissue cultured (in vitro) plantlets. This thesis is focused on the production and performance of microtubers, one of the new types of propagules that can be utilized in seed potato production.

\subsection{The Canadian seed potato system}

The basic requirement for plantlets is the disease/virus - free status. This minimizes disease incidence in later generations and assures high quality of the seed. Major seed borne diseases in Canada include:

1. Fungal diseases: Late blight (Phytophthora infestans), Early blight (Alternaria solani), Gray mold (Botrytis cinerea), Seed piece decay (Fusarium spp., also Rhizoctonia solani, Pythium spp.) and Powdery scab (Spongospora subterranea);

2. Bacterial diseases: Bacterial ring rot (Clavibacter michiganesis subsp. sepedonicus (Corynebacterium sepedonicum)), Common scab (Streptomyces scabies), Black leg (Erwinia carotovora var. atroseptica), Seed piece decay (Erwinia carotovora) and Bacterial soft rot (Ervinia carotovora var. carotovora); and

3. Viruses, viroids and mycoplasmas including the mosaic viruses (PVY, PVA), potato leafroll virus (PLRV) and the latent viruses (PVS and PVX).

Plantlets are produced in the tissue laboratory(ies) and then planted to special, vector-proof greenhouses, to produce nuclear tubers. Figure 1 illustrates the seed potato system in Canada. The system is a standard across the country. Growers follow strictly the regulations and inspections of the Canadian seed potato system. Table 2 illustrates the area of seed potato plantings which passed all the necessary inspections in each of the provinces. 
Prince Edward Island (P.E.I.) is the largest producer of potatoes in Canada including potatoes for seed. Table 3 presents the P.E.I. production summary of hectares passed by class and major potato varieties.

\section{Nuclear stock, disease-free tissue-cultured tubers and/or transplants}

\begin{tabular}{|c|c|c|}
\hline $\begin{array}{l}\text { PRE-ELITE (PE) } \\
\nabla\end{array}$ & $\begin{array}{l}\text { Tuber unit planting: } \\
\text { Field inspections: } \\
\text { Disease tolerance: } \\
\text { Varietal mixture: }\end{array}$ & $\begin{array}{l}100 \% \\
3 \\
0 \% \\
0 \%\end{array}$ \\
\hline $\begin{array}{l}\text { ELITE } 1 \text { (E 1) } \\
\nabla\end{array}$ & $\begin{array}{l}\text { Tuber unit planting: } \\
\text { Field inspections: } \\
\text { Disease tolerance: } \\
\text { Varietal mixture: }\end{array}$ & $\begin{array}{l}100 \% \\
3 \\
0 \% \\
0 \%\end{array}$ \\
\hline $\begin{array}{l}\text { ELITE } 2 \text { (E 2) } \\
\nabla\end{array}$ & $\begin{array}{l}\text { Tuber unit planting: } \\
\text { Field inspections: } \\
\text { Disease tolerance: } \\
\text { Varietal mixture: }\end{array}$ & $\begin{array}{l}100 \% \\
3 \\
0 \% \\
0 \%\end{array}$ \\
\hline $\begin{array}{l}\text { ELITE } 3 \text { (E 3) } \\
\nabla\end{array}$ & $\begin{array}{l}\text { Field inspections: } \\
\text { Disease tolerance: } \\
\text { Varietal mixture: }\end{array}$ & $\begin{array}{l}3 \\
0.25 \% \\
0 \%\end{array}$ \\
\hline $\begin{array}{l}\text { ELITE } 4 \text { (E 4) } \\
\nabla\end{array}$ & $\begin{array}{l}\text { Field inspections: } \\
\text { Disease tolerance: } \\
\text { Varietal mixture: }\end{array}$ & $\begin{array}{l}2 \\
0.25 \% \\
0 \%\end{array}$ \\
\hline $\begin{array}{l}\text { FOUNDATION (F) } \\
\nabla\end{array}$ & $\begin{array}{l}\text { Field inspections: } \\
\text { Disease tolerance: } \\
\text { Varietal mixture: }\end{array}$ & $\begin{array}{l}2 \\
0.50 \% \\
0.05 \%\end{array}$ \\
\hline CERTIFIED (C) & $\begin{array}{l}\text { Field inspections: } \\
\text { Disease tolerance: } \\
\text { Varietal mixture: }\end{array}$ & $\begin{array}{l}2 \\
2 \% \\
0.10 \%\end{array}$ \\
\hline
\end{tabular}

Figure 1. The Canadian seed potato system including seed classes and field inspection standards (Advisory Committee on Potatoes, 1993). 


\section{Chapter 1}

Table 2. Canadian Certified Seed Potatoes - Area passing inspection, February 20, 2001 (http://www.agr.ca/misb/infohortseedpotato.html).

\begin{tabular}{lr}
\hline Canada and the Provinces & Area [ha] \\
\hline CANADA (total) & $\mathbf{2 8 , 0 6 0}$ \\
Newfoundland & 47 \\
Prince Edward Island (P.E.I.) & 7,099 \\
Nova Scotia & 206 \\
New Brunswick & 6,585 \\
Quebec & 2,057 \\
Ontario & 414 \\
Manitoba & 3,903 \\
Saskatchewan & 2,128 \\
Alberta & 4,766 \\
British Columbia & 855 \\
\hline
\end{tabular}

Table 3. The 2000 seed potato crop summary of the major cultivars grown in Prince Edward Island by hectares [ha] and variety (PEIDAF, 2000).

\begin{tabular}{lrrrrrrrr}
\hline & \multicolumn{7}{c}{ SEED } & \multicolumn{2}{c}{ CLASS } \\
\cline { 2 - 9 } VARIETY & PE & \multicolumn{1}{c}{ E 1 } & \multicolumn{1}{c}{ E 2 } & E 3 & \multicolumn{1}{c}{ E 4 } & \multicolumn{1}{c}{ F } & \multicolumn{1}{c}{ C } & Total \\
\hline Shepody & 5.12 & 25.4 & 167.2 & 209.1 & 266.4 & 499.3 & 1.2 & $1,173.72$ \\
Superior & 1.33 & 12.2 & 29.9 & 224.6 & 382.4 & 473.8 & 41.9 & $1,166.13$ \\
Russet Burbank & 3.04 & 25.3 & 151.9 & 376.7 & 372.7 & 170.7 & 0 & $1,100.34$ \\
Atlantic & 3.87 & 27.9 & 93.2 & 316.7 & 167.8 & 102.0 & 22.0 & 733.47 \\
Yukon Gold & 0.83 & 5.9 & 15.5 & 35.8 & 126.2 & 276.5 & 254.9 & 715.63 \\
Russet Norkotach & 0.66 & 0 & 3.5 & 6.0 & 460.3 & 9.6 & 0 & 480.06 \\
Kennebec & 0.61 & 1.9 & 20.4 & 41.5 & 124.6 & 234.8 & 53.9 & 477.71 \\
Chieftain & 0.56 & 3.1 & 30.5 & 62.7 & 69.1 & 35.0 & 0 & 200.96 \\
Goldrush & 0.14 & 1.2 & 18.1 & 58.4 & 14.4 & 16.4 & 2.9 & 111.54 \\
Snowden & 0 & 2.7 & 11.7 & 8.8 & 63.3 & 18.2 & 0 & 104.70 \\
\hline
\end{tabular}

\subsection{The conventional seed tuber production system in Alberta, Canada}

The traditional seed tuber multiplication system, where the new generations of seed tubers are produced from carefully selected (the clonal selection), healthy, true-to-type seed tubers, is not used as such any more in Alberta. Although the later generations of seed are still produced that way, the initial material comes from tissue culture. Almost two decades ago, following Canada's eastern provinces (New Brunswick and P.E.I.), 
the province of Alberta adopted the seed potato production system which utilizes in vitro produced plantlets as starting material. Two crops of minitubers (nuclear tubers) are produced from the plantlets in the greenhouse per year, one in June (from March planting) and the second in October (from June planting). Production of nuclear tubers during winter months is not economical in Alberta, due to short day (length $6-7 \mathrm{hrs}$ ) and low temperatures (often down to $-35^{\circ} \mathrm{C}$ ). After harvest, the nuclear tubers are graded and then stored over winter in the cooler at $4^{\circ} \mathrm{C}+/-1^{\circ} \mathrm{C}$. The next growing season, they are planted to the field giving by the end of the season the Pre-elite generation. The Pre-elite tubers are used for further multiplication giving subsequent generations of seed tubers in following seasons (Figure 1).

Since the greenhouse production of minitubers (nuclear seed) in Alberta is seasonal (March - October), the laboratory owners realized that they are experiencing heavy workload periods followed by so called dead seasons. Moreover, for a part of the year their tissue culture facilities are under-utilized. Throughout the year, an uneven distribution of work is a major problem in tissue culture laboratories producing plantlets for greenhouse plantings (Jensen, 1996). Also, with the growing demand for high quality seed (see Section 1.2) growers started looking for more efficient ways to produce both, nuclear and Pre-elite tubers. Thus, microtubers (in vitro produced tubers) could become a useful alternative for handling such a production and/or could become a valuable addition to the existing in vitro plantlet system. As mentioned earlier, several authors presented a potential for microtubers and minitubers in seed potato production systems since the propagules appear suitable for use in the first year of the seed program in which the number of conventional field multiplications is to be reduced drastically (Lommen, 1995; Ranalli, 1997). Both types of propagules can be planted directly to the field (Ahloowalia, 1994; Ranalli et al. 1994). Earlier studies also showed that along with in vitro plantlets, microtubers can be successfully used for speeding up multiplication at the start of seed programs (Mastenbroek \& Eising, 1987; Jones, 1988). Wiersema et al., (1987) stated that both, in vitro plantlets and microtubers, perform well when they are planted under protected conditions in the production of nuclear- or minitubers. When used as transplants in the field, their performance was also found satisfactory (Wattimena et al., 1983).

\subsection{Production of in vitro plantlets}

Several tissue culture techniques for potato have been developed over the last two decades. Hussey \& Stacey (1981) reported a successful micropropagation of potato and its usefulness in rapid multiplication of the seed. Goodwin et al. (1980) under laboratory conditions, showed multiplication of $10-25$ fold over the 8 week period. 
The technique is mainly used to obtain the disease/virus-free plant material and then rapidly propagate it. If virus elimination is needed, cultures are initiated from meristems (dissected portions of the meristematic region of a shoot tip) from plants often exposed to a heat treatment prior to culturing. The meristems are placed on the nutrient medium for plant regeneration. They grow into plantlets (approx. $6-8$ weeks) and then the disease tests are performed on them. Once the disease/virus-free status is determined, the meristem derived plantlets are used for further, rapid multiplication. For this phase, when large numbers of healthy plantlets are required, the nodal cuttings are commonly used (Hussey \& Stacey, 1981; Marinus, 1985).

\subsection{Production of microtubers}

Microtubers or in vitro tubers are produced in vitro from nodal cuttings or on complete plantlets using a specific growing medium under specific external conditions. Several researchers have shown suitability of microtubers in elite seed potato production systems more than a decade ago (Hussey \& Stacey, 1981; Estrada et al., 1986; Garner \& Blake, 1989; Lillo, 1989; Coltman \& Kostichka, 1993). Microtubers have two important advantages over the plantlets: they are easy to store and easy to transport. Moreover, microtubers do not all have to be produced just before use (unlike plantlets), making it possible to evenly organize the laboratory production over time (Struik \& Wiersema, 1999). As mentioned earlier, in the most in vitro production protocols, the generated microtubers are small and not uniform $(0.02-0.70 \mathrm{~g}$ or $3-10$ $\mathrm{mm}$ in diameter) (Hussey \& Stacey, 1984; Estrada et al., 1986, Struik \& Lommen, 1990). Due to the lack of uniformity in the microtuber induction and the bulking processes, their physiological age as well as the length of the dormancy period may vary (Leclerc et al., 1995; Coleman \& Coleman, 2000). Consequently, not all microtubers uniformly sprout and produce vigorous plants after planting. Microtubers, in general, are very dormant and require a long period of time before they sprout (Struik \& Wiersema, 1999). It has been found that the length of microtuber dormancy is cultivar dependent and can be regulated by storage temperatures (Tabori et al., 1999). Reduction in microtuber dormancy can be achieved by modifying microtuber induction media and/or applying various dormancy release treatments after harvest. Coleman \& Coleman (2000) reported significant reduction in duration of microtuber dormancy in three commercial potato varieties (Russet Burbank, Shepody and Kennebec) by increasing sucrose content in tuberization medium to $16 \%$ under $8 \mathrm{hr}$ photoperiod. A $24 \mathrm{hr}$ treatment with bromoethane vapours resulted in a rapid

dormancy release of freshly harvested microtubers (Coleman \& Coleman, 2000). Several authors reported a successful use of Rindite (Denny, 1945) in microtuber 
dormancy release (Nasiruddin \& Blake, 1997; Kim et al., 1999). However, there is a controversy associated with the use of Rindite for microtubers since reports indicated detrimental effects of the product on microtubers (Struik \& Wiersema, 1999). Tábori et al. (1999) reported that dormancy of microtubers strongly depended on cultivar (four cultivars were tested in their studies) and in some cases on the photoperiod treatment applied during tuberization. There was no significant difference in duration of dormancy between different tuber-size groups, but the release from dormancy increased significantly with a decrease in tuber size (Tábori et al., 1999).

At present, the commercial production of nuclear and Pre-elite seed tubers in Alberta (as well as in other parts of Canada) is based on tissue culture plantlets only. This situation is mainly due to limited information on greenhouse and field performance comparison between microtubers and plantlets (Joung et al., 1993; Ranalli et al., 1994; Lê, 1999). Due to a recent, rapid expansion of potato acreage in the Province of Alberta, some of the plantlet and nuclear seed producers turned to microtubers as a supplement to plantlet type of the propagule which can be used successfully in the early stages of seed production. This is the first step towards inclusion of new types of propagules into the seed potato system in Alberta.

\subsection{The research project}

The project was funded by Potato Growers of Alberta and the Alberta Agriculture Research Institute and Alberta Agriculture Food and Rural Development. The main objectives of the project were:

1. To study the microtuber production and its uses in seed potato programmes,

2. To study the possibilities of producing large number of microtubers in an efficient and economical way which can be used either as an alternative to in vitro plantlets or along with the plantlet method, and

3. To determine performance of microtubers in the greenhouse and on the field in comparison to plantlets.

The results may also contribute to the development of new production systems for potato seed tubers. The existing tissue culture protocols for microtuber production were developed predominantly to study hormonal/environmental regulation of potato tuberization. A commercial application of this technology requires a reliable, highly efficient system for a rapid production of microtubers.

In search for an efficient method for the production of microtubers the research moved towards tuber inducing substances (e.g., jasmonates). There are several reports that jasmonates (JAs), particularly the jasmonic acid (JA), are highly effective in 
promoting production of microtubers (Koda et al., 1991; Van den Berg \& Ewing, 1991; Pelacho \& Mingo-Castel, 1991; Ravnikar et al., 1992; Pruski et al. 1993; Kreft et al., 1997; Jackson, 1999; Pruski et al., 2001). Van den Berg \& Ewing (1991) in their review, already reported that jasmonates, naturally occurring growth regulators, perform regulatory roles in growth inhibition and senescence, and that their activity is specific.

The project first describes some adjustments on the methodology of in vitro culturing and then focuses on the effects of jasmonates on in vitro tuberization of potato and on finding practical methods of transplanting microtubers to the greenhouse and to the field. It describes and analyses effects of techniques used during production of microtubers including tuber formation and plantlet's growth and development. It also describes methods of transplanting microtubers to the greenhouse and to the field and analyses their performance in yield of nuclear and Pre-elite tubers.

\subsection{The structure of the thesis}

The first part of the thesis is focused on the role of micropropagation in the development of horticulturally important crops in the cold regions of Canada. Chapter 2 describes the state of tissue culture propagation in Alberta and in the other prairie provinces of Canada including recent research on micropropagation in selected horticulture and horticulture related crops. It also describes contributions of the micropropagation (tissue culture) technology to conservation of plants native to the Canadian prairies (including local potato clones), contributions to the introduction of new horticultural crops to this region and to the development of the multi-million potato industry in Alberta. In Chapter 3 the autotrophic propagation of potato cultures is described which may have practical implications in the production of vigorous plantlets during the mass multiplication phase. Chapter 4 focuses on the short-term low temperature storage of cultures of various crops including potato, which is an important part of the day-to-day scheduling in the tissue culture laboratory. In Chapter 5 , the in vitro tuberization of two potato cultivars is described, focusing on jasmonic acid (JA) as a tuberization agent and on the effects of various photoperiods and media on microtuber production. Chapter 6 is a continuation of Chapter 5 and it examines suitability of six commercial potato cultivars to the in vitro tuberization method. In Chapter 7, the performance of microtubers in the greenhouse and in the field is described with a focus on yield of minitubers and Pre-elite tubers. Performance of microtubers is compared to performance of in vitro plantlets. Chapter 8 reviews the system for the production of seed tubers in Alberta including use of plantlets and microtubers. The general discussion, Chapter 9, first describes the role the tissue 
culture propagation plays in delivering high quality, disease-free plant material, moving later to research on finding optimum conditions for mass multiplication (including autotrophic culturing) as well as for a short term, low temperature storage of cultures. The discussion on search for optimum conditions for microtuber production focuses on the photoperiod and JA effects on in vitro tuberization and further performance of these microtubers in the greenhouse and in the field. Responses of several commercial potato cultivars to in vitro tuberization are also discussed including the microtuber performance description of these cultivars in the production of minitubers in the greenhouse and Pre-elite tubers on the field.

\section{References}

Advisory Committee on Potatoes, 1993. Atlantic Canada Potato Guide. Atlantic Agriculture, Publication 1300/93, Agdex \#257/13, 57 pp.

Agriculture and Agri-Food Canada (AAFC), 2000. Canadian Certified Seed Potatoes for 2000 - Area passing inspection, from (http://www.agr.ca/misb/infohortseedpotato.html), accessed Feb. 20, 2001.

Ahloowalia, B.S., 1994. Production and performance of potato mini-tubers. Euphytica 75: 163-172.

Bryan, J.E., M.T. Jackson, M. Quevedo B. \& N. Melendez G., 1981. Single-node cuttings, a rapid multiplication technique for potatoes. CIP slide training series. Series I: Rapid Multiplication Techniques. Guide-Book 2. International Potato Center (CIP), Lima, 8 pp.

Coleman, W.K. \& S.E. Coleman, 2000. Modification of potato microtuber dormancy during induction and growth in vitro and ex vitro. American Journal of Potato Research 77: 103-110.

Coltman, R. \& C. Kostichka, 1993. Performance of minitubers produced from microshoots $v s$ microtubers. American Potato Journal 70: 803-804 (abstract).

Cutter, E.G., 1992. Structure and development of the potato plant. In: P.M. Harris (Ed.), The Potato Crop. The Scientific Basis for Improvement. Second Edition. Chapman \& Hall, London, pp. 65-161.

Denny, F.E., 1945. Synergistic effects of three chemicals in the treatment of dormant potato tubers to hasten germination. Contr Boyce Thompson Institute of Plant Research 14: 1-14.

Estrada, R., P. Tovar \& J.H. Dodds, 1986. Induction of in vitro tubers in a broad range of potato genotypes. Plant Cell, Tissue and Organ Culture 7: 3-10.

Evans, D.A., W.R. Sharp \& C.E. Flick, 1981. Plant regeneration from cell cultures. Horticulture Reviews 3: 214-314.

FAO, 2000. FAO Yearbook Production, 1999. Food and Agriculture Organization of the United Nations, Rome.

Garner, N. \& J. Blake, 1989. The induction and development of potato microtubers in vitro on media free of growth regulating substances. Annals of Botany 63: 663-674. 


\section{Chapter 1}

Goodwin, P.B., Y.C. Kim \& T. Adisarwanto, 1980. Propagation of potato by shoot-tip culture. 1. Shoot multiplication. Potato Research 23: 9-18.

Hussey, G. \& N.J. Stacey, 1981. In vitro propagation of potato (Solanum tuberosum L.). Annals of Botany 48: 787-796.

Hussey, G. \& N.J. Stacey, 1984. Factors affecting the formation of in vitro tubers of potato (Solanum tuberosum L.). Annals of Botany 53: 565-578.

Jackson S.D., 1999. Multiple signalling pathways control tuber induction in potato. Plant Physiology 119: 1-8.

Jones, E.D., 1988. A current assessment of in vitro culture and other rapid multiplication methods in North America and Europe. American Potato Journal 65: 209-220.

Jensen, L.C., 1996. The small lab's perspective of technology used in commercial increase of Solanum tuberosum by micropropagation. In Vitro Cellular and Developmental Biology Plant 32: 34 (abstract).

Joung, H., J.H. Jeon, S.W. Park \& H.S. Kim, 1993. The impact of mass-produced potato microtubers on Korean potato agriculture. American Potato Joumal 70: 819-820 (abstract).

Kim, S.Y., J.K. Kim, K.H. Choi, Y.H. Joung \& H. Joung, 1999. Effects of Rindite on breaking dormancy of potato microtubers. American Journal of Potato Research 76: 5-8.

Koda, Y., Y. Kikuta, H. Tazaki, Y. Tsuhino, S. Sakamura, \& T. Yoshihara, 1991. Potato tuber-inducing activities of jasmonic acid and related compounds. Phytochemistry 30: 1435-1438.

Leclerc, Y., D.J. Donnelly, W.K. Coleman \& R.R. King, 1995. Microtuber dormancy in three potato cultivars. American Potato Journal 72: 215-223.

Lê, C.L., 1999. In vitro microtuberization: an evaluation of culture conditions for the production of virus-free potatoes. Potato Research 42: 489-498.

Lillo, C., 1989. A simple two-phase system for efficient in vitro tuberization in potato. Norwegian Journal of Agricultural Science 3: 23-27.

Lommen, W.J.M., 1995. Basic studies on the production and performance of potato minitubers. PhD thesis Landbouw Universiteit Wageningen, the Netherlands, $181 \mathrm{pp}$.

Marinus, J., 1985. "In Vitro" Multiplication of Potatoes: Description of Methods and Experience in The Netherlands. CABO, Wageningen, $21 \mathrm{pp}$.

Mastenbroek, I. \& J. Eising, 1987. Optimum production of tubers from in-vitro plantlets. Abstracts $10^{\text {th }}$ Triennial Conference of the European Association for Potato Research, Aalborg, Denmark, pp. 123-124.

Nasinddin, K.M. \& J. Blake, 1997. Effect of Rindite on storage behavior, dormancy break and sprout growth of potato microtubers (cv. Desiree). American Potato Journal 74: 325 330.

PEIDAF, 2000. Prince Edward Island Seed Potato 2000 Certification List and growers Directory. Prince Edward Island Department of Agriculture and Forestry, Charlottetown, 
PEI, Canada.

Pelacho, A.M. \& A.M. Mingo-Castel, 1991. Jasmonic acid induces tuberization of potato stolons cultured in vitro. Plant Physiology 97: 1253-1255.

Pruski, K., J. Nowak \& T. Lewis, 1993. Jasmonates and photoperiod effect on microtuber production in two potato cultivars. In Vitro Cellular and Developmental Biology - Plant 29: 69(abstract).

Pruski, K., T. Astatkie \& J. Nowak, 2001. Jasmonate effects on in vitro tuberization and tuber bulking in two potato cultivars (Solanum tuberosum L.) under different media and photoperiod conditions. In Vitro Cellular and Developmental Biology - Plant (accepted).

Ranalli, P., F. Bassi, G. Ruaro, P. Del Re, M. Di Candilo \& G. Mandolino, 1994. Microtuber and minituber production and field performance compared with normal tubers. Potato Research 37: 383-391.

Ranalli, P., 1997. Innovative propagation methods in seed tuber multiplication programmes. Potato Research 40: 439-453.

Ravinkar, M., B. Vilhar \& N. Gogala, 1992. Stimulatory effects of jasmonic acid on potato node and protoplast culture. Journal of Plant Growth Regulation 11: 29-33.

Statistics Canada, 2000. Canadian Potato Production, July 2000. Agriculture Division.

Statistics Canada, 2001. Canadian Potato Production, January 2001. Agriculture Division.

Struik, P.C. \& W.J.M. Lommen, 1990. Production, storage and use of micro- and minitubers. Proceedings of the $11^{\text {th }}$ Triennial Conference of the European Association for Potato Research (EAPR), Edinburgh, UK, pp. 122-133.

Struik, P.C. \& S.G. Wiersema, 1999. Seed Potato Technology. Wageningen Pers, Wageningen, $383 \mathrm{pp}$.

Tábori, K.M., J. Dobránszki, \& A. Ferenczy, 1999. Some sprouting characteristics of microtubers. Potato Research 42: 611-617.

Umaerus, M., 1987. True potato seed. Proceedings 10th Triennial Conference of the European Association for Potato Research, Aalborg, Denmark, pp. 72-102.

Van den Berg, J.H. \& E.E. Ewing, 1991. Jasmonates and their role in plant growth and development with special reference to the control of potato tuberization: A review. American Potato Journal 68: 781-794.

Wang, P.J. \& C.Y. Hu, 1980. Regeneration of virus-free plants through in vitro culture. Advances in Biochemical Engineering 18: 61-99.

Wattimena, G., B. McCown \& G. Weis, 1983. Comparative field performance of potatoes from microculture. American Potato Journal 60: 27-33.

Wiersema, S.G., R. Cabello, P. Tovar \& J.H. Dodds, 1987. Rapid seed multiplication by planting into beds micro tubers and in vitro plants. Potato Research 30: 117-120. 


\section{Chapter 2}

Role of micropropagation in horticultural and horticulture

related crops for cold regions in Canada 


\section{Role of micropropagation in horticultural and horticulture related crops for cold regions in Canada}

Micropropagation is a valuable tool in mass propagation of high quality plant material. Since its origin it has played an important role in the development and conservation of horticultural crops in cold climates. It has been commercially applied to a variety of different crops in regions with such climates including vegetables (i.e., potato), a variety of fruit crops (mostly berry crops), and a range of ornamental plants including annuals, perennials and woody ornamentals. The most important aspect of the micropropagation technology is the pathogen-free status of plants propagated via this method. Also, the technology has been invaluable in conservation of species native to northern regions. The application of somatic embryogenesis to high-value clonal forestry is modernizing the reforestation programmes.

Most of the Canadian territory is placed above $49^{\circ} \mathrm{N}$ and is considered to be a "cold climate" area. The seasons can be separated distinctly into spring, summer, fall and winter. These climatic periods also affect the commercial production of horticultural crops, with the majority of activities spaced between the end of February and midNovember. In turn, it directly affects production schedules in the tissue culture laboratories making it seasonal, with a heavy workload concentration during winter and early spring (November until the end of April) on preparation of the in vitro propagated plant material for spring and early summer plantings.

This chapter reviews the use of tissue culture propagation in the commercial production of several horticultural and horticulture related crops grown in northern regions of Canada and some of the recent research on micropropagation of these crops.

\subsection{Potato}

As mentioned in the previous chapter (Section 1.2), potato is the most important vegetable crop in Canada, accounting for about $60 \%$ of all vegetable farm cash (Statistics Canada, 2001). Potato is a cool-season crop and it grows well in the Prairie Provinces of Canada (Alberta, Saskatchewan and Manitoba) and the northern parts of New Brunswick and Prince Edward Island (Schaupmeyer, 1992; Advisory Committee on Potatoes, 2001). Cool nights and warm days with high intensity light during summer months make the Canadian prairies an ideal site for potato production. Cool night temperatures are important for dry matter accumulation in the tubers and with high light intensity, tuber initiation and development start early (Menzel, 1980; Machackova et al., 1998). In addition, the harsh winter conditions on the prairies 
(temperatures often drop as low as to $-35^{\circ} \mathrm{C}$ ) help in natural elimination of most of the soil borne pathogens.

The commercial production of potato in northern countries and regions including Canada and the Canadian prairies relies heavily on micropropagation. In vitro plantlets (Jones, 1988; Lommen, 1995; Struik \& Wiersema, 1999) are commonly used for speeding up multiplication of disease-free material in elite seed potato programmes. After the final multiplication stage, the plantlets are used for the production of seed tubers. This step is usually carried out in greenhouses resulting in the production of minitubers (nuclear tubers). In some operations, the plantlets are also used for the production of microtubers in vitro, which have a potential to be integrated into seed potato programmes (Lillo, 1989; Struik \& Lommen, 1990; Lommen, 1995; Khuri \& Moorby, 1996; Struik \& Wiersema, 1999). In Canada, the plantlets are the base for the seed potato programmes, microtubers being in experimental stage only.

The last decade research on micropropagation in seed potato production, in Canada touches various aspects. Quality improvement of potato plantlets and speeding the multiplication phases are at the top of the list. The above are closely associated with optimalization of environmental conditions for culture growth (including photoautotrophic culturing), and the production and utilization of microtubers in seed potato systems, germplasm storage, and exchange (including preservation of native to northern regions, prairie potato cultivars). Also, a considerable amount of work is spent on breeding and introduction of new cultivars to the market. In search of faster growth of cultures and better adaptation to environmental stresses (i.e., during transplanting), the in vitro bacterization of potato plantlets with a pseudomonad bacterium, Pseudomonas spp. strain PsJN, has been investigated recently (Nowak et al., 1999). It has been observed that nodal cuttings taken from plantlets inoculated with Pseudomonas spp. strain PsJN and subjected to in vitro tuberization set more microtubers than cuttings from control plantlets (non-bacterized). Moreover, the inoculated plantlets and microtubers showed better greenhouse and field transplant survival than nonbacterized controls. Also, the above study has demonstrated that in vitro bacterized plantlets, as well as the minitubers inoculated prior to planting, gave significantly higher tuber yields, produced fewer stolons (but these stolons set tubers) developing large tubers, and developed smaller and faster senescing tops than the non-bacterized controls. The controls produced more stolons but most of them failed to set tubers (Nowak et al., 1999). Recently, several authors reported growth-promoting effects of rhizobacteria on in vitro cultures of potato and other plants (Nowak et al., 1995; Dunbar, 1997; Bensalim et al., 1998).

Another area of research on potato micropropagation in Canada has been the photoautotrophic culturing of potato plantlets, also called the autotrophic micro- 
propagation. The method is based on growing plantlets on the nutrient medium in the absence of sucrose and in $\mathrm{CO}_{2}$ enriched atmosphere. It offers a few important advantages including a possibility to significantly reduce microbial contamination of cultures since sucrose in the medium is either omitted or in low concentration. This allows the use of larger size, loosely capped vessels, which in turn could generate significant savings in spending on labour in the laboratory. High percentage of transplant survival is very common with autotrophic cultures since the propagules do not require a strict acclimatization phase to outside conditions as do conventionally micropropagated plantlets (Kozai, 1989). The method is attractive for seed potato growers, the owners of small tissue culture laboratories who either use the plantlets in their own operations in greenhouses, or supply potato plantlets directly to other seed potato growers. Since most of these laboratories are located within the immediate vicinity of seed potato production fields (growers' sites), cross contamination of cultures is more likely to happen. Autotrophic production of plantlets could be an alternative for these laboratories where the aseptic conditions are difficult to maintain. Several studies were undertaken in the area, with encouraging results, investigating aspects ranging from determining and optimizing factors affecting $\mathrm{CO}_{2}$ fixation in micropropagated plantlets (Desjardins, 1995a; 1995b) to practical applications of the method to micropropagation of cv. Russet Burbank (Pruski et al., 1991a).

Considerable time has been dedicated to research on utilization of microtubers in the seed potato production systems (Coleman et al., 2001) with emphasis on microtuber dormancy (Leclerc et al., 1995; Coleman \& Coleman, 2000). Significant reductions in the duration of microtubers dormancy were obtained in cultivars commonly used by the processing industry (Kennebec, Russet Burbank and Shepody) by modifying induction media and applying various dormancy-release treatments after harvest, with or without prior storage (Coleman \& Coleman, 2000). These researches also indicated that an $8 \mathrm{~h}$ photoperiod, instead of continuous darkness during microtuber induction and development, increased microtuber yield while reducing dormancy duration. It has been also reported that photoperiod during in vitro tuberization significantly enhances subsequent yield of greenhouse-grown potato tubers (Seabrook et al., 1995).

Small commercial micropropagation laboratories in Western Canada usually store their stock cultures for up to 3 months, either in refrigerators or small coolers with low light, at $4^{\circ} \mathrm{C}+1-1^{\circ} \mathrm{C}$. In order to optimize the storage conditions, some of the research projects focused on effects of low light, sucrose concentration in the medium, and the length of the storage period at $4^{\circ} \mathrm{C}$ on capacity to re-grow of in vitro cultures of potato (Pruski et al, 2000b). It has been found that sucrose was essential for the low temperature maintenance of vigorous stock plants of potato and the low light significantly 
improved quality of the stored cultures (Pruski et al., 2000b). In recent work, Dr. Seabrook and co-workers (2001) utilized micropropagation techniques to segregate somatic embryos in potato, essential part of the breeding programme at Potato Research Centre in Fredericton, New Brunswick. Considerable differences in regeneration capacity between aseptically grown seedlings of three potato cultivars and three wild species of Solanum, were observed. Data from these experiments suggest that regeneration of somatic embryos is under nuclear control (Seabrook et al., 2001).

\subsection{Fruit crops}

The number of fruit crops grown on Canadian prairies and northern regions of other Provinces of Canada is limited due to unfavourable climatic conditions. Harsh winters and relatively short-growing seasons (in some parts less than 100 frost-free days) allow growers to commercially grow only fruit species well adapted to these areas. As a result, the prairie fruit industry has been developed based predominantly on berry crops including strawberries, raspberries, Saskatoon berries (Amelanchier alnifolia Nutt.), chokecherries (Prunus virginiana L.) and pincherries ( $P$. pensylvanica L.f). Although strawberry and raspberry have been commercially produced on the Canadian prairies for more than 100 years, the commercial introduction of the Saskatoon berry, chokecherry and pincherry is just two decades old. All three species are native to North America (Hosie, 1973; St-Pierre, 1993, 1997) and well adapted to severe winter conditions of Canadian prairies. All three are small to medium size shrubs and all three are members of the Rose family, Saskatoon berry being related to apples (St-Pierre, 1997) and both cherries closely related to each other and to domesticated cherries, plums, apricots and peaches (St-Pierre, 1993; Shiell et al., 1996).

Micropropagation has been instrumental in upgrading these species to a commercial fruit status on the Prairies. Domestication of these species was based solely on the selection of superior clones from native wild shrubs (Davidson et al., 1991; Davidson and St-Pierre, 1993; St-Pierre, 1993). As a result, the initial number of stock plants was very limited and this was the restraining factor in commercial introduction of these selections to orchardists. Moreover, the selections are considered "difficult-toroot", especially Saskatoons, and the conventional propagation via cuttings failed to produce adequate numbers of plants. Harris (1980) initiated research work on micropropagtion of the most common selection of the Saskatoon berry 'Smoky'. This research continued resulting in the micropropagation protocol for several cultivars of the Saskatoon (Pruski et al., 1990; Pruski et al., 1991b) and making possible a rapid expansion of the small fruit industry in the Prairie Provinces. In Alberta alone, from just under 300 acres (120 ha) in 1985 the area planted under Saskatoons rose to about 
1100 acres (500 ha) in 1994 (Alberta Agriculture, 2001) and close to 1500 acres (700 ha) in 2000 (Lloyd Hausher, personal communication). Area planted in Saskatchewan and Manitoba is estimated for 600 acres (275 ha) each (AgVentures, 1996). In search of new fruit crops for the Canadian prairies growers turned their interest to native cherries. Besides their ornamental value, the chokecherry and pincherry selections made over the last two decades have relatively large fruits that are suitable for processing. In 1995 the fruit processing demand was estimated to be 4,000,000 lbs (1816 tonnes) for the chokecherries alone, with a supply of approximately $500,000 \mathrm{lbs}$ (230 tonnes) (Verreault, 1996). The fruit growers in Western Canada are currently considering these two species as new crops which could be commercially grown in the severe climate of the Prairies. To make a large scale cultivation and an effective breeding viable, an efficient multiplication method of the superior clones had to be established. Research conducted on cultivar selection and propagation of these two related species (Pruski et al., 1992; Schroeder, 1996) resulted in the micropropagation protocol (Pruski et al., 2000a) facilitating delivery of a high number of plants to the market. Moreover, the micropropagation techniques used for Saskatoon berry and the two native cherries are presently used in conservation of other native fruit species for the Prairie Provinces. Recently, the Saskatoon berry has been successfully introduced to eastern provinces of Canada including Nova Scotia and New Brunswick.

\subsection{Hardwood forest and shelterbelt species}

Out of the number of different research projects conducted in the area of woody plant micropropagation across Canada, important results were recently obtained in the field of reforestation. Production of seedlings and plantlets for forestry and shelterbelts in Canada is often grouped with horticultural crops since the production is taking place in greenhouses. The Canadian Forest Service-Atlantic Forestry Centre (Natural Resources Canada), Fredericton, New Brunswick, Canada has been established about 20 years ago, initially, to service northern parts of eastern provinces with research on coniferous species for reforestation. At present, its programmes serve all the provinces of Canada, providing research on development of propagation and cultivation methods for the forest industries. Micropropagation is used for various programmes including application of somatic embryogenesis in high-value clonal forestry. It has been found that the deployment of the highly valuable, superior clones in clonal forestry can be achieved inexpensively by mass serial rooting of cuttings from juvenile donor plants produced from cryo-preserved (stored in liquid nitrogen) embryonic cultures (Park et al., 1998). Somatic embryogenesis (SE) in conifers is a recent advance in vegetative propagation and offers an efficient method for the cloning of genetically improved 


\section{Chapter 2}

trees. Dunstan and co-workers (1995) reported about 150 woody species and related hybrids to which the method was applied successfully. For several spruce and larch species, the SE technique has been sufficiently refined to be applied in commercial tree improvement programmes (Park et al., 1993; Adams et al., 1994). The development of superior tree "varieties" was, for most conifers, not previously possible due to inability to produce the same genotypes consistently over time. By using SE in conjunction with cryo-preservation, it is possible to develop genetically improved varieties consistently by defrosting and re-propagating the frozen embryonic clones after genetic testing has shown which clones are the best performers. The SE system for conifers involves the induction of embryonal suspensor mass (ESM) tissue from embryos that have been removed from seed and cultured in vitro on defined growth medium. Once ESM tissue is formed, the tissue can be sub-cultured indefinitely. At this stage, the ESM tissue is cryo-stored until the latter part of the screening process is completed. ESM tissue can be then transferred to proprietary embryo maturation and desiccation steps to allow germination and plant formation. Following field evaluations of these plants, elite lines can be identified and larger scale production begun with the cryo-preserved ESM tissue. Practically, a limitless amount of ESM tissue

Selected parents from genetic tests

Controlled pollination

Induction of somatic embryogenesis (SE)

$$
\begin{aligned}
& \text { Cryo-preservation } \\
& \downarrow \text { (field testing) } \downarrow
\end{aligned}
$$

Retrieval of best clones

Propagation of juvenile donor plants

by somatic embryogenesis

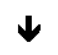

Mass vegetative multiplication

by serial rooting of cuttings

Deployment in clonal forestry
Figure 1. Illustration of a clonal forestry strategy based on somatic embryogenesis (SE) and cryo-preservation (Park et al., 1998). 
can be stored, thawed, proliferated, and re-stored, the SE system offers the potential for mass propagation of clonal plants which consistently grow like seedlings, with uniform needle and shoot characteristics. Park and co-workers (1998) found that induction of SE in white spruce (Picea glauca), one of the most important species in Canadian forest industries, is under strong genetic control. The genetic effects in subsequent maturation and germination phases were much less pronounced, suggesting that the induction phase of SE can be manipulated by breeding. Researchers cryopreserved the embryonic clones from this experiment for 3 and 4 years. The assessment of morphological in vitro development and ex vitro survival and growth characters demonstrated general stability of the cryo-preserved clones (Park et al., 1998). Following years of laboratory experiments and field tests the clonal forestry strategy was outlined (Figure 1). The above process has already been commercialised for spruce SE by Silvagen, a Vancouver (BC, Canada) located biotech company (Polonenko, 1998).

Micropropagation has been instrumental in research on propagation of mature larch (Larix) trees. Larch is another important species widely used by the forestry industries across northern regions of the American continent. For the different Larix species, there is interest in obtaining propagules with juvenile growth behaviour (as for seedlings) from selected adult trees (Ewald, 1998). Micropropagation of mature trees is often, with some exceptions, more difficult than in vitro propagation of juvenile material such as zygotic embryos or seedlings. It is difficult to establish proliferation or embryogenic culture from adult trees. If propagation is achieved via organ formation or organ development, production is often lower than in cultures initiated from juvenile plant material (Ewald, 1998). Bonga \& von Aderkas (1992) described different rejuvenation pre-treatments of material (destined for micropropagation) from mature Larix trees including grafting, pruning, growth regulator treatments and etiolation. Although the number of clonal lines that can be propagated in vitro (at present) is small, the results are encouraging and may lead to the propagation of adult larch trees on a large (commercial) scale (Ewald, 1998).

In vitro organogenesis and somatic embryogenesis have also been studied in several species of aspen including Populus nigra $\times$ P. maximowiczi (Park \& Son, 1989), giving base for developmental work for other poplar hybrids important for Canadian paper industries. Research on tree species for the Prairies is focused on shelterbelt plants. The Prairie Farm Rehabilitation Administration (PFRA-Agriculture Agri-Food Canada, Indian Head, Saskatchewan, Canada), working closely with producers, farm groups and government promotes diversification into new crops (including fruits such as chokecherry - Section 2.1 , value added processing and shelterbelt planning and seedling distribution (including aspen, willow (Salix sp.) and birch (Betula sp.)). 


\section{Chapter 2}

Although somatic embryogenesis (SE) has many advantages for mass propagation and genetic improvement of hardwood forest trees, a number of limitations in several species still remains to be overcome before embryogenic system can be applied for operational production of propagules (Merkle, 1995). The limiting factor is poor conversion to plantlets; often embryos produce microshoots which are difficult to root. Thus, treatments such as cold stratification and desiccation (mimicking pre-germination conditions in the seed) can have a significant effect with somatic embryos. Recent growing success of SE in combination with cryo-preservation (better conversion to plantlets) provides a base for development of a mass propagation method for superior and valuable clones of many forest and shelterbelt hardwood species (Merkle, 1995; Park et al., 1998).

\subsection{Overview and conclusions}

Although the text in this chapter reviewed the selected crops (the recent research including) only, the contribution of micropropagation to the development, introduction of these crops to cold regions and their mass production is indisputable. Without in vitro techniques, the seed potato programmes would be crippled, leaving growers unable to produce high quality seed for the competitive world markets, a number of fruit crops presently available on the Prairies would not exist and the mass propagation of high quality tree clones would not be possible. Micropropagation changed the way growers used to propagate and produce plants. Across the Prairies and in Eastern Canada more than a dozen tissue culture laboratories have been established over the last decade. In Alberta alone, there are eight small, private laboratories (certified by Canadian Food Inspection Agency) producing potato plantlets for the seed programme $(400,000$ plantlets per year), and two laboratories producing plantlets $(350,000$ 500,000 plantlets per year) of several fruit species, ornamental plants (including orchids and native lilies) and woody species (including aspen and birch) (Patricia Duplessis, personal communication; Arden Delidais - D'nA Gardens, personal communication). Micropropagation also significantly contributed to conservation of native to northern regions ornamental and fruit species (Pruski et al., 1991c; Pruski et al., 2000).

The list of horticultural crops where micropropagation has played a role in their commercial development is long. For many people associated with the horticulture industry in the cold regions of Canada micropropagation provided new ways of handling the production of plant material and/or in some cases (for example, small native fruits) it created the whole industry. 


\section{References}

Adams, G.W., M.G. Doiron \& Y.S. Park, 1994. Commercialization potential of somatic embryogenesis in black spruce tree improvement. Forestry Chronicles 70: 593-598.

Advisory Committee on Potatoes, 2001. Potato crop: Variety, weed and pest control guide. Atlantic Provinces Agriculture Services Co-ordinating Committee, Agdex 257, Publication $1300 \mathrm{~A}$.

AgVentures, 1996. Commercial Saskatoon Berry Industry. Agriculture Business Profiles, Agdex 238/830-1, Alberta Agriculture (AAFRD) Publication.

Alberta Agriculture (Alberta Agriculture Food and Rural Development-AAFRD), 2001. Commercial Saskatoon Berry Industry. See www.agric.gov.ab.ca/agdex/200/238_8301.html [accessed May 7, 2001].

Bensalim, S., J. Nowak \& S.K. Asiedu, 1998. Temperature and pseudomonad bacterium effects on in vitro and ex vitro performance of 18 clones of potato. American Journal of Potato Research 75: 145-152.

Bonga, J.M. \& P. von Aderkas, 1992. Initiation of organogenesis and embryogenesis in mature material. In: Bonga, J.M. \& P. von Aderkas (Eds.), In vitro culture of trees. Kluwer Academic Publishers, The Netherlands, Monograph: 95-107.

Coleman, W.K. \& S.E. Coleman, 2000. Modification of potato microtuber dormancy during induction and growth in vitro and ex vitro. American Journal of Potato Research 77: 103110.

Coleman, W.K., D.J. Donnelly \& S.E. Coleman, 2001. Potato microtubers as research tools: A review. American Journal of Potato Research 78: 47-55.

Davidson, C.G., R.J. Enns \& M. Reimer, 1991. Tree Fruit Production for the Prairie Provinces. Communication Branch, Agriculture Agri-Food Csanada, Ottawa, ON, Canada, Publication 1866/E.

Davidson, J.G.N. \& R.G. St-Pierre, 1993. Saskatoon cultivars (new or revised). In: J.N. Cummins (Ed.), Register of New Fruit Varieties. International Registration Authority for Genus Amelanchier, Brooks \& Olmo, pp. 1-4.

Desjardins, Y., 1995a. Factors affecting $\mathrm{CO}_{2}$ fixation in striving to optimize photoautotrophy in micropropagated plantlets. Plant Tissue Culture and Biotechnology 1: 13-25.

Desjardins, Y., 1995b. Overview of factors influencing photosynthesis of micropropagated plantlets and their effect on acclimatization. In: F. Carré \& P. Chagvardieff (Eds.), Proceedings of the International Symposium on Ecophysiology and Photosynthetic in vitro Cultures. CEA, Aix-en-Provençe, France, pp. 145-160.

Dunbar, C., 1997. Utilization of seaweed-extract and plant growth promoting rhizobacterium in greenhouse production of minitubers. MSc Thesis, Biology Department, Dalhousie University, Halifax, NS, Canada.

Dunstan, I., T. Tautorus \& T.A. Thorpe, 1995. Somatic embryogenesis in woody plants. In: 


\section{Chapter 2}

T.A. Thorpe (Ed.), In vitro embryogenesis in plants. Kluwer Academic Publishers, The Netherlands, pp. 471-538.

Ewald, D., 1998. Review: Advances in tissue culture of adult Jarch. In Vitro Cellular and Developmental Biology - Plant 34: 325-330.

Harris, R.E., 1980. Propagation of Amelanchier, Amelanchier alnifolia Nutt. cv. Smoky in vitro. Western Canadian Society for Horticultural Science 19: 32-34.

Hosie, R.C., 1973. Service berries. In: Native Trees of Canada. Canadian Forestry Service, Department of the Environment, Ottawa, Canada, pp. 235-236.

Jones, E.D., 1988. A current assessment of in vitro culture, and other rapid multiplication methods in North America and Europe. American Potato Journal 65: 209-220.

Khuri, S. \& J. Moorby, 1996. Nodal segments or microtubers as explants for in vitro microtuber production of potato. Plant Cell, Tissue and Organ Culture 45: 215-222.

Kozai, T., 1989. Autotrophic micropropagation - A novel method. In Vitro Cellular and Developmental Biology - Plant 25: 21 (abstract).

Lillo, C., 1989. A simple two-phase system for efficient in vitro tuberization in potato. Norwegian Journal of Agricultural Science 3: 23-27.

Leclerc, Y., D.J. Donnelly, W.K. Coleman \& R.R. King, 1995. Microtuber dormancy in three potato cultivars. American Potato Journal 72: 215-223.

Lommen, W.J.M., 1995. Basic studies on the production and performance of potato minitubers. $\mathrm{PhD}$ thesis, Wageningen Agricultural University, The Netherlands, $181 \mathrm{pp}$.

Machackova, I., T. Konstantinova, L.I. Segeeva, V.N. Lozhnikova, S.A. Golyankovskaya, N.D. Dudko, J. Eder \& N.P. Aksenova, 1998. Photoperiodic control of growth, development and phytohormone balance in Solanum tuberosum L. Physiologia Plantarum 102: 272-278.

Menzel, C.M., 1980. Tuberization in potato at high temperatures: responses to gibberellin and growth inhibitors. Annals of Botany 56: 1329-1330.

Merkle, S.A., 1995. Strategies for dealing with limitations of somatic embryogenesis in hardwood trees. Plant Tissue Culture and Biotechnology 1: 112-121.

Nowak, J., S. Bensalim, C.D. Smith, C. Dunbar, S.K. Asiedu, A. Madani, G. Lazarovits, D. Northcott \& A.V. Sturz, 1999. Behaviour of plant material issued from in vitro bacterization. Potato Research 42: 505-519.

Nowak, J., S.K. Asiedu, G. Lazarovits, V. Pillay, A. Stewart, C. Smith \& Z. Liu, 1995. Enhancement of in vitro growth and transplant stress tolerance of potato and vegetable plantlets co-cultured with a plant growth promoting thizobacterium. In: F. Carré \& P. Chagvardieff (Eds.), Proceedings of the International Symposium on Ecophysiology and Photosynthetic in vitro Cultures. CEA, Aix-en-Provençe, France, pp. 173-180.

Park, Y.G. \& S.H. Son, 1989. In vitro organogenesis and somatic embryogenesis from punctured leaf of Populus nigra $\times$ P. maximowiczi. Plant Cell, Tissue and Organ Culture 
15: 95-105.

Park, Y.S., S.E. Pond \& J.M. Bonga, 1993. Initiation of somatic embryogenesis in white spruce (Picea glauca): genetic control, culture treatment effects, and implication for tree breeding. Theoretical and Applied Genetics 86: 427-436.

Park, Y.S., J.D. Barrett \& J.M. Bonga, 1998. Application of somatic embryogenesis in highvalue clonal forestry: deployment, genetic control, and stability of cryo-preserved clones. In Vitro Cellular and Developmental Biology - Plant 34: 231-239.

Polonenko, D.R., 1998. Challenges and issues in scaling up commercial production of conifer somatic embryos. In Vitro Cellular and Developmental Biology - Plant 34: 34, SP-1017 (abstract).

Pruski, K., J. Nowak \& G. Grainger, 1990. Micropropagation of four cultivars of Saskatoon berry (Amelanchier alnifolia Nutt.). Plant Cell, Tissue and Organ Culture 21: 103-109.

Pruski, K., S. Pietucha \& M. Mirza, 1991a. Autotrophic micropropagation of potato (Solanum tuberosum L.). In Vitro Cellular and Developmental Biology - Plant 27: 44A (abstract).

Pruski, K., M. Mohyuddin \& G. Grainger, 1991b. Saskatoon berry (Amelanchier alnifolia Nutt.). In: Y.P.S. Bajaj (Ed.), Biotechnology in Agriculture and Forestry. Springer-Verlag, Berlin Heidelberg, Vol 16 Trees III, pp. 164-179.

Pruski, K., M. Mohyuddin \& G. Grainger, 1991c. Role of micropropagation in the development of horticulturally important crops in cold regions. Third International Symposium on Cold Region Development, Extended Abstracts, Edmonton, Alberta, Canada, p. 39.

Pruski, K., T. Lewis \& M. Mirza, 1992. Micropropagation of chokecherry and pincherry (Prunus virginiana and P. pensylvanica). HortScience 27: 571 (021 abstract).

Pruski, K., T. Lewis, T. Astatkie \& J. Nowak, 2000a. Micropropagation of chokecherry (Prunus virginiana L.) and pincherry ( $P$. pensylvanica L.) cultivars. Plant Cell, Tissue and Organ Culture 63: 93-100.

Pruski, K., T. Kozai, T. Lewis, T. Astatkie \& J. Nowak, 2000b. Sucrose and light effects on in vitro cultures of potato (Solanum tuberosum L.), chokecherry (Prunus virginiana L.) and Saskatoon berry (Amelanchier alnifolia Nutt.) during low temperature storage. Plant Cell, Tissue and Organ Culture 63: 215-221.

Schaupmeyer, C., 1992. Alberta Potato Production Guide. Alberta Agriculture Publications (AAFRD).

Schroeder, W.R., 1996. Chokecherry cultivars for the prairies. In: Proceedings Chokecherry Workshop, PFRA Shelterbelt Centre, Indian Head, Saskatchewan, Canada, pp. 18-21.

Seabrook, J.E.A., J.E. Percy, L.K. Douglas \& G.C.C. Tai, 1995. Photoperiod in vitro affects subsequent yield of greenhouse-grown potato tubers. American Potato Journal 72: 365374.

Seabrook, J.E.A., L.K. Douglas \& C.C. Tai, 2001. Segregation for somatic embryogenesis in potato. Proceeding $85^{\text {th }}$ Annual Meeting of the Potato Association of America, St 


\section{Chapter 2}

Augustine, FL, USA, abstract 28.

Shiell, K.J., B. Weir \& R.G. St-Pierre, 1996. The Pincherry, a guide for growers. Department of Horticultural Science, University of Saskatchewan, Saskatoon, Canada, 2 pp.

Statistics Canada, 2001. Canadian Potato Production, January 2001. Agriculture Division.

St-Pierre, R.G., 1993. The Chokecherry, a guide for growers. Department of Horticultural

Science, University of Saskatchewan, Saskatoon, Canada, 2 pp.

St-Pierre, R.G., 1997. Growing Saskatoons, a manual for orchardists. Department of Horticultural Science, University of Saskatchewan, Saskatoon, Canada, 1 p.

Struik, P.C. \& W.J.M. Lommen, 1990. Production, storage and use of micro- and minitubers. Proceedings of the $11^{\text {th }}$ Triennial Conference of the European Association for Potato Research (EAPR), Edinburgh, UK, pp. 122-133.

Struik, P.C. \& S.G. Wiersema, 1999. Seed Potato Technology. Wageningen Pers, The Netherlands, 383 pp.

Verreault, A., 1996. Harvest of wild black cherries (Chokecherries). In: Proceedings Chokecherry Workshop, PFRA Shelterbelt Centre, Indian Head, Saskatchewan, Canada, pp. 30-33. 
Chapter 3

\section{Photoautotrophic micropropagation of Russet Burbank potato} (Solanum tuberosum L.)*

${ }^{*}$ Pruski, K., T. Astatkie, M. Mirza \& J. Nowak, 2001. Photoautotrophic micropropagation of Russet Burbank potato (Solanum tuberosum L.). Plant Cell, Tissue and Organ Culture (accepted). 


\title{
3. Photoautotrophic micropropagation of Russet Burbank potato (Solanum tuberosum L.)
}

\begin{abstract}
The photoautotrophic micropropagation of potato cv. Russet Burbank was investigated. Single node microcuttings were grown for four weeks on MS medium with or without sucrose $\left(30 \mathrm{~g}^{-1}\right)$ in the growth room at $21 / 19^{\circ} \mathrm{C}$ day/night temperature, with $16 \mathrm{~h}$ photoperiod at $150 \mu \mathrm{mol} \mathrm{m} \mathrm{s}^{-1}$, with or without supplemental $\mathrm{CO}_{2}$ at $1500 \mu_{\mathrm{II}}^{-1}$. A $20 \%$ increase in the number of nodes per stem (from 7.5 to 9.4 ) and a $50 \%$ increase in stem dry weight was observed in cultures grown on media with sucrose and in $\mathrm{CO}_{2}$ enriched atmosphere comparing to the conventionally micropropagated cultures or the cultures grown photoautotrophically on media without sucrose but in air supplemented with $1500 \mu \mathrm{CO}_{2} \mathrm{l}^{-1}$. Stems of these cultures (from media with sucrose and in $\mathrm{CO}_{2}$ enriched air) almost doubled in length the stems of cultures from the other two treatments. No significant differences were observed between Control (MS medium supplemented with sucrose, $30 \mathrm{~g} \mathrm{l}^{-1}$ ) and photoautotrophic cultures coming from MS medium with no sucrose grown under $1500 \mu \mathrm{I} \mathrm{CO}_{2} \mathrm{l}^{-1}$. Photoautotrophic cultures produced stems averaging $43.3 \mathrm{~mm}$, with 7 nodes and weighing $9.2 \mathrm{mg}$ (dry), very similar to conventionally grown in vitro cultures ( $47.9 \mathrm{~mm}$ with 7.55 nodes, 9.7 $\mathrm{mg}$ dry weight). Growers may consider photoautotrophic culturing of potato in areas where the high sterility levels are difficult to maintain. Supplementing air in the growth room up to $1500 \mu \mathrm{CO}_{2} \mathrm{l}^{-1}$ could be beneficial for potato plantlet production even on media containing sucrose since it significantly improved quality, size and biomass of produced plantlets, speeding up the multiplication.
\end{abstract}

Key words: $\quad \mathrm{CO}_{2}$ enrichment, in vitro, nodal microcuttings, Solanum tuberosum $\mathrm{L}$.

Abbreviations: $\mathrm{CO}_{2}$-carbon dioxide, MS - Murashige and Skoog (1962) medium, PPFD - photosynthetic photon flux density

\subsection{Introduction}

Since its origins, tissue culture propagation of plants has been heterotrophic. Sugars are added to the growing media as a source of carbon (Murashige \& Skoog, 1962; Jones, 1988). Over the last two decades, attempts have been made to develop new culture containers allowing good gas exchange, including penetration of exogenous carbon dioxide inside the vessels (Kozai et al., 1987; Desjardins, 1995). High concentrations of carbon dioxide in the growing environment allowed in vitro plants to grow either photoautotrophically (without sugar in the medium), or photomixtrophically (with sugar present) (Kozai et al., 1987; Hayashi et al., 1995). The benefits of the 
photoautotrophic cultures are usually associated with the use of large size, loosely capped, vessels, reduction of microbial contamination, lower humidity inside vessels, and overall better plantlets' quality; photoautotrophically produced propagules do not require acclimatization prior to transplanting and usually establish better than the traditionally micropropagated ones (Kozai et al., 1987; Fujiwara et al., 1995; Van Huylenbroeck \& Debergh, 1996). Traditionally propagated tissue cultured plantlets in many aspects are similar to shade-plants. Leaves have poorly developed mesophyll (palisade cells absent or very small), with large intercellular spaces (Smith et al., 1986), and a low number of stomata; abnormally functioning (Donnelly \& Vidaver, 1984; Van Huylenbroeck \& Debergh, 1996). This leads to poor control over water loss of in vitro plantlets, which in turn, could cause significant losses during acclimatization (Kozai et al., 1987; Van Huylenbroeck \& Debergh, 1996).

In vitro plantlets are commonly used for speeding up multiplication of disease-free material in elite seed potato programmes (Jones, 1988; Struik \& Wiersema, 1999). After the final multiplication stage the plantlets are used for the production of seed tubers. This step is usually carried out in greenhouses resulting in the production of minitubers (also called nuclear tubers). In Western Canada, several commercial tissue culture laboratories supply potato plantlets directly to the growers. Since most of these laboratories are located within an immediate vicinity of seed potato production fields (seed potato growers' sites) often in very dusty areas, contamination of cultures with air-borne pathogens is more likely to happen. Owners of these laboratories showed interest in methods that will reduce risk of contamination and provide high quality, vigorous cultures. Photoautotrophic production of plantlets could be an alternative. With reduced levels or no sugar in the medium, a loss of in vitro plantlets to bacterial or fungal contaminants is reduced to a minimum. This study describes effects of $\mathrm{CO}_{2}$ enrichment and sucrose in the medium on the production of potato plantlets cultivar Russet Burbank.

\subsection{Materials and methods}

Tissue cultured plantlets of Russet Burbank, derived from the potato germplasm bank at Crop Diversification Centre North, Edmonton, Alberta, Canada were used as a source of virus-free material. The plantlets were multiplied as single-node explants on hormone-free MS (Murasige \& Skoog, 1962) medium (Sigma-Aldrich Canada Ltd., Oakville, Ontario, Canada) with standard vitamins. Sucrose $\left(30 \mathrm{~g} \mathrm{l}^{-1}\right)$ was used as a carbon source and the media were solidified with $6 \mathrm{~g} \mathrm{l}^{-1}$ agar (Difco, Detroit, MI, USA). The pH was adjusted to 5.7 before autoclaving. Media were dispensed to GA7 Magenta vessels (Magenta Corp., Chicago, IL, USA) and autoclaved. Sixteen (4×4) 
single-node explants were placed in each vessel. Cultures were incubated for 4 weeks in an environmental chamber (Conviron S10h, Winnipeg, Manitoba, Canada) at $20^{\circ} \mathrm{C}$ $+/-1^{\circ} \mathrm{C}, 16 \mathrm{~h}$ photoperiod at $150 \mu \mathrm{mol} \mathrm{m} \mathrm{s}^{-1}$ mixed fluorescent (F40T12 tubes, General Electric (GE), USA) and incandescent illumination (40 W, GE, USA). At the end of the 4-week period, the plantlets were cut into single-node explants and placed on fresh MS medium in GA7 Magenta jars for further multiplication. The process was repeated until the required number of plantlets for the photoautotrophic experiments was achieved.

To examine the effects of sucrose and $\mathrm{CO}_{2}$ on growth of Russet Burbank, singlenode explants (with one leaf) taken from four-week old plantlets were divided into two groups and transferred (apical and basal nodes were discarded) onto $50 \mathrm{ml}$ agar media: ( $i$ ) the same hormone-free MS medium as above, and (ii) the MS medium (with standard vitamins) but without sucrose. Sixteen $(4 \times 4)$ single-node explants were placed in each vessel and the vessels were capped with lids equipped with $0.22 \mu \mathrm{m}$ filters. Both groups of cultures were incubated for 4 weeks in: (i) the same environmental growth room and under the same conditions as described above, and (ii) in the environmental growth chamber (Conviron CMP3023, Winnipeg, Manitoba, Canada) at $21 / 19^{\circ} \mathrm{C}$ day/night temperature, $16 \mathrm{~h}$ photoperiod at $150 \mu \mathrm{mol} \mathrm{m} \mathrm{m}^{-2} \mathrm{~s}^{-1}$ mixed fluorescent (FT72112/CW/VHO tubes, Philips, USA) and incandescent illumination (40 W, GE, USA) supplemented with $1500 \mu \mathrm{CO}_{2} \mathrm{l}^{-1}$. After 4 weeks the number of nodes (leaves), shoot length and dry weight were recorded. The statistical model for this experiment was Split-Plot with three Shelf blocks (top, middle and bottom), two $\mathrm{CO}_{2}$ whole-plot treatments (Control-Air, $340 \mu \mathrm{CO}_{2} \mathrm{l}^{-1}$; and $1500 \mu \mathrm{CO}_{2} \mathrm{I}^{-1}$ ), two Sucrose sub-plot treatments (MS with no sucrose and MS with $30 \mathrm{~g} \mathrm{l}^{-1}$ sucrose), and eight replications (vessels). The response variables were shoot length [mm], number of leaves/nodes and dry weight of stems [mg]. The residuals were examined (using model adequacy checking methods discussed, e.g., in Montgomery (2001)) to determine the validity of constant variance and normal distribution of the error terms' assumptions for all response variables. These assumptions for number of nodes (leaves) and stem dry weights were valid, and a square-root transformation was necessary for shoot length. The analysis was completed using Proc Mixed of SAS, which uses the appropriate whole plot and subplot errors for testing the effects (Littell et al., 1996). The least square means comparisons (with Tukey adjustment to control the experiment wise error rate) of the four $\mathrm{CO}_{2}$ and Sucrose combinations were completed. The interaction effect between $\mathrm{CO}_{2}$ and Sucrose was also sliced by $\mathrm{CO}_{2}$ (the effect of Sucrose was tested within control as well as $1500 \mu \mathrm{CO}_{2} 1^{-1}$ ). 


\section{Chapter 3}

\subsection{Results and discussion}

Table 1 summarizes analysis of variance results in terms of $P$-values for shoot length, number of nodes and dry weight of stems. With the exception of the $P$-value for $\mathrm{CO}_{2} \times$ Sucrose interaction for dry weight, $P$-values of all the other parameters were less than $1 \%$.

Table 2 illustrates the effects of sucrose in the medium and $\mathrm{CO}_{2}$ enrichment on the above responses. Since the experiments were conducted in fully controlled environment, the $1 \%$ level of significance was applied to obtain letter groupings. After 4 weeks of culture, no significant differences were observed between Control (MS medium supplemented with sucrose, $30 \mathrm{~g} \mathrm{l}^{-1}$ ) and photoautotrophic cultures coming from MS medium with no sucrose grown under $1500 \mu \mathrm{CO}_{2} \mathrm{I}^{-1}$. Cultures grown photoautotrophically with no sucrose but in extra $\mathrm{CO}_{2}$ in atmosphere produced stems averaging $43.3 \mathrm{~mm}$, with 7 nodes and weighing $9.2 \mathrm{mg}$ (dry), similar to conventional in vitro cultures grown on medium with sucrose (Table 2). The leaves of photoautotrophic cultures had lighter green colour comparing to leaves of plantlets coming from the regular MS media with sucrose. However, the leaf hairs on plantlets' leaves grown with extra $\mathrm{CO}_{2}$ atmosphere and no sucrose in the medium were in abundance comparing to regular plantlets.

There was a significant increase in shoot length, number of nodes and dry weight observed in plantlets grown on media with sucrose under $\mathrm{CO}_{2}$ enrichment (Table 2). The stems almost doubled in length compared to the shoots from the conventionally micropropagated cultures or the cultures grown on media without sucrose but in 1500 $\mu \mathrm{CO}_{2} \mathrm{l}^{-1}$. The number of nodes increased about $20 \%$ (from 7.5 to 9.4 nodes per stem). An increase of $50 \%$ was observed in stem dry weight in cultures grown on media with sucrose in $\mathrm{CO}_{2}$ enriched atmosphere (Table 2). Fujiwara et al. (1995)

Table 1. Analysis of variance results for shoot length, number of nodes, and dry weight of stems. $P$-values for main effects of $\mathrm{CO}_{2}$ and sucrose, and the interaction effect of $\mathrm{CO}_{2}$ and sucrose.

\begin{tabular}{lccc}
\hline \multirow{2}{*}{$\begin{array}{l}\text { Source } \\
\text { of Variation }\end{array}$} & Shoot length & Number of nodes & Dry weight \\
\cline { 2 - 4 } $\mathrm{CO}_{2}$ & 0.003 & 0.007 & 0.001 \\
Sucrose & 0.001 & 0.001 & 0.001 \\
$\mathrm{CO}_{2} \times$ Sucrose & 0.002 & 0.001 & 0.014 \\
Sucrose within $1500 \mu \mathrm{CO}_{2} 1^{-1}$ & 0.001 & 0.001 & 0.001 \\
Sucrose within Control CO 2 & 0.001 & 0.001 & 0.001 \\
\hline
\end{tabular}


Table 2. Effects of sucrose and $\mathrm{CO}_{2}$ enriched atmosphere on growth of cultures of Russet Burbank. Least squares means for $\mathrm{CO}_{2}$ and sucrose treatment combinations with Tukey's adjustment for multiple comparisons.

\begin{tabular}{|c|c|c|c|c|}
\hline \multicolumn{2}{|l|}{ Treatments } & \multicolumn{3}{|c|}{ Parameters } \\
\hline $\mathrm{CO}_{2}$ & Sucrose & $\begin{array}{c}\text { Average } \\
\text { shoot length } \\
{[\mathrm{mm}]}\end{array}$ & $\begin{array}{l}\text { Average number } \\
\text { of nodes per stem }\end{array}$ & $\begin{array}{c}\text { Average dry } \\
\text { weight of stem } \\
\text { [mg] }\end{array}$ \\
\hline Control & No & $18.7 c^{*}$ & $4.61 \mathrm{c}$ & $4.8 \mathrm{c}$ \\
\hline Control & Yes, $30 \mathrm{~g} \mathrm{l}^{-1}$ & $47.9 \mathrm{~b}$ & $7.55 \mathrm{~b}$ & $9.7 \mathrm{~b}$ \\
\hline $1500 \mu \mathrm{l} \mathrm{l^{-1 }}$ & No & $43.3 \mathrm{~b}$ & $7.58 \mathrm{~b}$ & $9.2 \mathrm{~b}$ \\
\hline $1500 \mu \mathrm{l}^{-1}$ & Yes, $30 \mathrm{~g} \mathrm{l}^{-1}$ & $74.1 \mathrm{a}$ & $9.38 \mathrm{a}$ & $14.9 \mathrm{a}$ \\
\hline
\end{tabular}

* Means followed by the same letter are not significantly different at the $1 \%$ level of significance.

observed a significant increase in dry weight of potato cultures cv. Benimaru under $\mathrm{CO}_{2}$-enriched conditions when sucrose in the media was reduced to $15 \mathrm{~g} \mathrm{l}^{-1}$. Increase in growth of in vitro shoots/plantlets is a result of enhanced photosynthesis which, in turn, is affected by several factors including $\mathrm{CO}_{2}$ concentration (Desjardins, 1995), sucrose concentration in media (Fujiwara et al., 1992), the number of air exchanges and the lighting cycle (Hayashi et al., 1995).

As expected, the shortest stems with the lowest number of nodes and the lowest dry weight were observed in cultures grown on media without sucrose and with no extra $\mathrm{CO}_{2}$ in air (Table 2). Cultures visibly suffered from lack of carbon (small, pale green leaves) and their growth was significantly reduced.

Results from our study indicate that the photoautotrophic propagation can successfully be used in micropropagation of potato plantlets and could be recommended to seed potato growers and laboratory owners especially in places where the aseptic conditions are difficult to maintain. Plantlets produced photoautotrophically on media without sucrose were very similar to those produced traditionally (Table 2). On the other hand, growers may consider using extra $\mathrm{CO}_{2}$ in their growth rooms for potato plantlet production even on media containing sucrose since the combination of these two factors significantly improved quality, size and biomass of produced plantlets, thus speeding up the multiplication. Economically, the technique also seems feasible since at current price level for one in vitro plantlet, CAD\$ $0.65-0.85$ (CAD\$ $1.00=$ US\$ 0.65), the $\mathrm{CO}_{2}$ enrichment in the growth room can be accommodated. 


\section{Chapter 3}

\section{References}

Desjardins, Y., 1995. Factors affecting $\mathrm{CO}_{2}$ fixation in striving to optimize photoautotrophy in micropropagated plantlets. Plant Tissue Culture and Biotechnology 1: 13-25.

Donnelly, D.J. \& W.E. Vidaver, 1984. Leaf anatomy of red raspberry transferred from culture to soil. Journal of the American Society for Horticultural Science 109: 172-176.

Fujiwara, K., S. Kira \& T. Kozai, 1992. Time course of $\mathrm{CO}_{2}$ exchange of potato cultures in vitro with different sucrose concentrations in the culture medium. Journal of Agricultural Meteorology 48: 49-56.

Fujiwara, K., S. Kira \& T. Kozai, 1995. Contribution of photosynthesis to dry weight increase of in vitro potato cultures under different $\mathrm{CO}_{2}$ concentrations. Acta Horticulturae 393: 119-126.

Hayashi, M., K. Fujiwara, T. Kozai, M. Tateno \& Y. Kitaya, 1995. Effects of lighting cycle on daily $\mathrm{CO}_{2}$ exchange and dry weight increase of potato plantlets cultured in vitro photoautotrophically. Acta Horticulturae 393: 213-218.

Jones, E.D., 1988. A current assessment of in vitro culture, and other rapid multiplication methods in North America and Europe. American Potato Journal 65: 209-220.

Kozai, T., Y. Iwanami \& K. Fujiwara, 1987. Environment control for mass propagation of tissue cultured plantlets. (1) Effects of $\mathrm{CO}_{2}$ enrichment on the plantlet growth during the multiplication stage. Plant Tissue Culture Letters 4: 22-26.

Littell, R.C., G.A. Milleken, W.W. Stroup \& R.D. Wolfinger, 1996. SAS System for Mixed Models. SAS Institute Inc., Cary NC, 633 pp.

Montgomery, D.C., 2001. Design and Analysis of Experiments. Fifth edition, Wiley, New York.

Murashige, T. \& F. Skoog, 1962. A revised medium for rapid growth and bioassays with tobacco tissue cultures. Physioiogia Plantarum 15: 473-497.

Smith, M.A.L., J.P. Palta \& B.H. McCown, 1986. Comparative anatomy and physiology of microcultured seedlings and greenhouse-grown Asian white birch. Journal of American Society for Horticultural Science 111: 437-442.

Struik, P.C. \& S.G. Wiersema, 1999. Seed Potato Technology. Wageningen Pers, The Netherlands, 383 pp.

Van Huylenbroeck, J.M. \& P.C. Debergh, 1996. Physiological aspects in acclimatization of micropropagated plantlets. Plant Tissue Culture and Biotechnology 2: 136-141. 


\section{Chapter 4}

Sucrose and light effects on in vitro cultures of potato (Solanum tuberosum L.), chokecherry (Prunus virginiana L.) and Saskatoon berry (Amelanchier alnifolia Nutt.) during low temperature storage $^{*}$

" Pruski K., T. Kozai, T. Lewis, T. Astatkie \& J. Nowak, 2000. Sucrose and light effects on in vitro cultures of potato (Solanum tuberosum L.), chokecherry (Prunus virginiana L.) and Saskatoon berry (Amelanchier alnifolia Nutt.) during low temperature storage. Plant Cell, Tissue and Organ Culture 63: 215-221. 


\title{
4. Sucrose and light effects on in vitro cultures of potato (Solanum tuberosum L.), chokecherry (Prunus virginiana L.) and Saskatoon berry (Amelanchier alnifolia Nutt.) during low temperature storage
}

\begin{abstract}
Cultures of potato (Solanum tuberosum) $\mathrm{cv}$. Atlantic, chokecherry (Prunus virginiana L.) cv. Garrington and Saskatoon berry (Amelancher alnifolia Nutt.) cv. Northline grown in vitro for 3 weeks at $24 / 22^{\circ} \mathrm{C}, 16 \mathrm{~h}$ photoperiod, $150 \mu \mathrm{mol} \mathrm{m} \mathrm{m}^{-2} \mathrm{~s}^{-1}$ photosynthetic photon flux density (PPFD) mixed fluorescent/incandescent light were stored for 6,9 and 12 weeks at $4^{\circ} \mathrm{C}$ under 0 (darkness) and $3 \mu \mathrm{mol} \mathrm{m}^{-2} \mathrm{~s}^{-1}$ PPFD (690 nm red light continuous illumination). Growth regulators free MSMO medium either with or without $30 \mathrm{~g} \mathrm{I}^{-1}$ sucrose was used to store the cultures. All cultures retained capacity to re-grow after storage. Tested factors, sucrose, light and the length of the storage period had an impact on shoot quality and regrowth capacity of the cultures. For either light treatment sucrose was essential for the low temperature maintenance of vigorous stock plants of potato, if stored for over 6 weeks. Chokecherry and Saskatoon cultures stored well without sucrose, although chokecherry benefited from sucrose in the storage medium when the stock cultures were kept at the low temperature for 12 weeks. Low light significantly improved quality of the stored potato cultures, but had very little effect on both chokecherry and Saskatoon berry cultures. The woody plant cultures grew during storage, and the longer the stock plants were stored, the more vigorous cultures they generated. The results indicate that growers can successfully use their existing facilities, small refrigerators and coolers with low light intensity, set at $4^{\circ} \mathrm{C}$, for short term storage of potato, chokecherry and Saskatoon berry cultures. The potato cultures, which are known to be sensitive to prolonged low temperature storage, should be frequently monitored and sub-cultured as required. On the other hand, the woody plant stock cultures do not require any special attention when kept at $4^{\circ} \mathrm{C}$ and re-grow the most vigorous shoots if stored for at least 12 weeks.
\end{abstract}

Key words: in vitro storage, capacity to re-grow, Solanum tuberosum L., Prunus virginiana L., Amelanchier alnifolia Nutt.

Abbreviations BAP - 6-benzylaminopurine, MSMO - Murashige \& Skoog's minimal organic medium, PPFD - photosynthetic photon flux density 


\section{Chapter 4}

\subsection{Introduction}

In Western Canada, several commercial tissue culture laboratories supply plantlets of potato, chokecherry and Saskatoon berry, sold directly to the growers. All these crops are important to local economies (Statistics Canada, 1998; Hosie, 1979; Pruski et al., 1992; St-Pierre, 1993; St-Pierre et al., 1997). To stay competitive and adjust propagation scheduling to the market demands, some of these laboratories store large number of stock cultures for various periods of time. Low-temperature storage of the in vitro stock material, commonly used in conservation of plant germplasm (Bessembinder $e t$ al., 1993; Withers \& Engelmann, 1998), is being recommended. This method, if properly adjusted to specific genotypes, can substantially reduce labour and media costs (Mullin \& Schlegel, 1976; Westcott, 1981a, b; Withers \& Engelmann, 1998).

Common factors which need to be adjusted are: temperature, light illumination (photosynthetic photon flux density or PPFD), and medium composition (Heines et al., 1992; Hansen \& Kristiansen 1997; Kubota et al., 1995; Kubota \& Kozai 1993, 1994, 1995; Marino et al., 1985). Small commercial micropropagation laboratories in Western Canada usually store their stock cultures for up to 3 months, either in refrigerators or small coolers with low light, at $4^{\circ} \mathrm{C}+1-1^{\circ} \mathrm{C}$. Thus, the objective of this study was to determine the effect of light, sucrose concentration in the medium, and the length of the storage period at $4^{\circ} \mathrm{C}$ on capacity to re-grow of in vitro cultures of potato (Solanum tuberosum L.), chokecherry (Prunus virginiana L.) and Saskatoon berry (Amelanchier alnifolia Nutt.).

\subsection{Materials and methods}

\section{Plant material, media, culture storage and treatments}

Plantlets of potato (cv. Atlantic), chokecherry (cv. Garrington) and Saskatoon berry (cv. Northline) were grown in vitro for 4 weeks in a growth-room at $24 / 22^{\circ} \mathrm{C}$ day/night temperature, $16 \mathrm{hr}$ photoperiod, $150 \mu \mathrm{mol} \mathrm{m} \mathrm{m}^{-2} \mathrm{~s}^{-1}$ PPFD mixed fluorescent/incandescent light. Murashige \& Skoog (1962) based minimal organic media (MSMO) with the vitamins as described by Linsmaier \& Skoog (1965), supplemented with $2.22 \mu \mathrm{M}$ of 6-Benzylaminopurine (BAP) were used for chokecherry and Saskatoon berry (Pruski et al., 1990), and without BAP for potato. Media were solidified with $7 \mathrm{~g} \mathrm{l}^{-1}$ agar (Difco Laboratories, Detroit, MI, USA). GA7 Magenta vessels (Sigma, St. Louis, MO, USA), containing $50 \mathrm{ml}$ medium per vessel, were used to grow and store the cultures. Individual shoots separated from vigorously growing four-week-old cultures of chokecherry and Saskatoon berry, and shoot tops taken from three-week-old 
cultures of potato, were placed onto MSMO media $+/-30 \mathrm{~g} \mathrm{l}^{-1}$ of sucrose and moved to cold rooms at $4^{\circ} \mathrm{C}+/-1^{\circ} \mathrm{C}$, with and without low red light illumination $(690 \mathrm{~nm}, 3$ $\mu \mathrm{mol} \mathrm{m} \mathrm{m}^{-2} \mathrm{~s}^{-1}$ PPFD, provided by miniature red lights, HML-35 (LL42485), Hudson's Bay Co., ON, Canada) for 6, 9, and 12 weeks. To start with uniform cultures, before storage, individual shoots were shortened to about $10 \mathrm{~mm}$ for chokecherries (on average $70 \mathrm{mg}$ fresh weight (Fwt), 8 leaves/stem) and Saskatoons (30 mg Fwt, 5 leaves/stem), and $40 \mathrm{~mm}$ for potatoes (130 mg Fwt, 6 leaves per stem). Four shoots were placed in each GA7 Magenta vessel, 8 vessels per each treatment per species. After each storage period, shoots were subcultured on MSMO media of the same composition as for storage, and grown for 4 weeks in a growth-room at $24 / 22^{\circ} \mathrm{C} \mathrm{d} / \mathrm{n}$ temperature, $16 \mathrm{~h}$ photoperiod, $150 \mu \mathrm{mol} \mathrm{m} \mathrm{m}^{-2} \mathrm{~s}^{-1}$ PPFD.

For each species, the analysed response variables were: length of individual shoots and their fresh weight measured (Fwt1) after storage and after 4 weeks on re-growth media (Fwt2), number of leaves per stem after storage, number of yellow leaves per stem after storage, number of stems per culture after the re-growth period, and relative growth rate (RGR) after re-growth calculated as $\mathrm{RGR}=(\mathrm{Fwt} 2-\mathrm{Fwt1}) / \mathrm{Fwt} 1$.

\section{Statistical methods}

For each of the eight performance indicator responses listed above, a three-factor (sucrose $(\mathrm{S})$, light $(\mathrm{Li})$ and storage length (Le)) factorial design was used. For each response, validity of the model (normal distribution and constant variance assumptions on the experimental error terms) was confirmed by examining the residuals as described in Montgomery (1997). Only the number of yellow leaves after storage for potato (where the values were mainly zeros and ones) failed normality in its original as well as transformed scale and was excluded from this report.

For each response least squares means comparisons of the 12 treatment combinations (sucrose - yes/no, light - yes/no, storage length 6, 9, 12 weeks) were conducted to generate letter groupings. This was done for all responses, even if some did not have a significant three-factor interaction, to present the averages from all treatment combinations. Since the experiments were conducted in a controlled lab environment, the $1 \%$ level of significance was used in all analyses. Separate analyses were completed for each species using SAS (SAS Institute, Inc., 1989).

\subsection{Results and discussion}

All tested factors, the presence of sucrose in storage media (S), the continuous low intensity red light illumination ( $\mathrm{Li}$ ) and the length of storage period at $4^{\circ} \mathrm{C}(\mathrm{Le})$, had 


\section{Chapter 4}

significant effect $(P<0.01)$ on most of the parameters (response variables) for chokecherry, Saskatoon berry and potato cultures (Table 1A, B and C). Table 1 summarizes all the analysis of variance results, indicating the statistical design, the significance or non-significance (in terms of $P$-values) of the main as well as the interaction effects for the different plant species. Table 2 presents least squares means, along with their letter groupings, to reveal the best treatments (for 12 treatment combinations) for all responses from chokecherry. Tables 3 and 4 show the same for Saskatoon berry and potato, respectively.

As shown in Table 1, none of the responses for chokecherry had a significant threefactor interaction, $S \times$ LixLe. However, the interaction effect between light and storage length was significant for fresh weight after re-growth (Fwt2), length of shoots after re-growth, number of shoots and the relative growth rate (RGR). The number of shoots and their length after re-growth were also significantly affected by the interaction of sucrose (S) and length of storage (Le). This interaction was also significant for fresh weight after re-growth period (Fwt2) and the number of yellow leaves after storage. The interaction between sucrose and light was significant for RGR only (Table 1). The main effects of sucrose and light were significant for the number of yellow leaves per stem of chokecherry cultures after storage. The sucrose effect alone was significant for shoot length after storage only. None of the effects was significant for fresh weight after storage (Fwt1), which suggests that all the 12 treatment combinations would produce the same average Fwt1 for chokecherry cultures.

Table 2 presents the least squares means for the responses in chokecherry. The presence of sucrose in the storage medium gave significantly higher shoot fresh weight (Fwt2) in re-grown cultures when the shoots originated from 12 weeks of storage. Under the shorter storage period, sucrose had either no effect (6 weeks storage) or even a negative effect ( 9 weeks in dark) on the post storage culture performance of this species. Number of shoots per culture re-grown from chokecherry shoots stored for 12 weeks on medium with sucrose was also the highest (Table 2). Re-growth of cultures after 12-week storage was the fastest (compared to 6 and 9 weeks) and means comparison of the relative growth rate (RGR) after the re-growth period confirmed this observation. This could indicate that a prolonged exposure to the low temperature had reduced dormancy. RGR was the highest for the 12 week storage period irrespective of the presence of sucrose in the storage medium as long as the cultures were exposed to low light during storage (Table 2). Short storage (6 weeks), gave more vigorous cultures from the dark than from the light treatment. Mullin \& Schlegel (1976) showed that prolonged cold storage of strawberry cultures at $4^{\circ} \mathrm{C}$ induced vigorous plantlets during re-growth period. Sucrose in the medium also induced yellowing of lower leaves of chokecherry cultures. This, however, did not affect the capacity to re-grow 
Table 1. $P$-values for the main and interaction effects of sucrose (S), light $(\mathrm{Li})$ and length of $4^{\circ} \mathrm{C}$ storage (Le) on chokecherry (A), Saskatoon berry (B) and potato cultures (C).

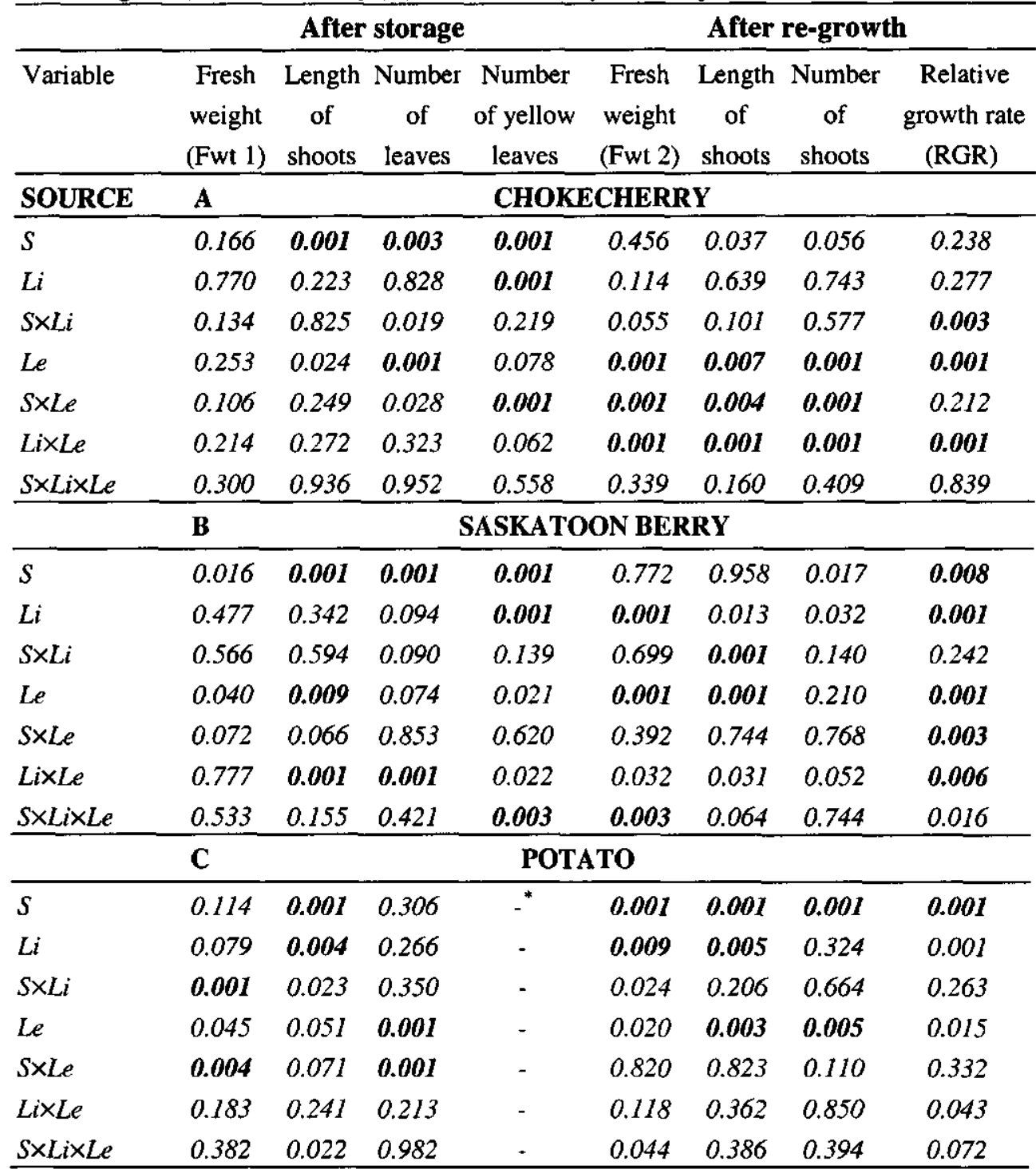

* There is no $P$-value for potato yellow leaf number after storage because the values were all zeroes and ones, and the normality assumption for the statistical model was not valid under the original as well as transformed scales. $P$-values less than $1 \%$ shown in bold.

$R G R=(F w t 2-F w t) / F w t 1$ 
Table 2. Chokecherry: sucrose $-\mathrm{S}$, light $-\mathrm{Li}$ and length of storage at $4^{\circ} \mathrm{C}-\mathrm{Le}(\mathrm{S} \times \mathrm{Li} \times \mathrm{Le})$ interaction. Least square means comparison of all responses.

\begin{tabular}{|c|c|c|c|c|c|c|c|c|c|c|}
\hline \multicolumn{3}{|c|}{ Treatment } & \multicolumn{4}{|c|}{ After storage } & \multicolumn{4}{|c|}{ After re-growth } \\
\hline$S$ & $\mathrm{Li}$ & (wks) & {$[\mathrm{mg}]$} & $\begin{array}{c}\text { Length } \\
\text { of } \\
\text { shoots } \\
\text { [mm] }\end{array}$ & $\begin{array}{c}\text { Number } \\
\text { of } \\
\text { leaves }\end{array}$ & $\begin{array}{c}\text { Number } \\
\text { of } \\
\text { yellow } \\
\text { leaves }\end{array}$ & {$[\mathrm{mg}]$} & $\begin{array}{c}\text { Length } \\
\text { of } \\
\text { shoots } \\
\text { [mm] }\end{array}$ & $\begin{array}{c}\text { Number } \\
\text { of } \\
\text { shoots }\end{array}$ & RGR \\
\hline No & Dark & 6 & $139.4 \mathrm{a}^{*}$ & $12.9 \mathrm{ab}$ & $10.3 \mathrm{a}$ & $3.0 \mathrm{c}$ & $849.1 \mathrm{~cd}$ & $25.3 \mathrm{a}$ & $5.8 \mathrm{c}$ & $5.4 \mathrm{~cd}$ \\
\hline No & Dark & 9 & $126.7 \mathrm{a}$ & $12.6 \mathrm{ab}$ & $9.6 \mathrm{a}$ & $5.3 b c$ & $507.1 \mathrm{ef}$ & $20.5 \mathrm{~cd}$ & $5.4 \mathrm{~cd}$ & $3.3 \mathrm{de}$ \\
\hline No & Dark & 12 & $112.9 \mathrm{a}$ & $12.0 \mathrm{ab}$ & $8.1 \mathrm{~b}$ & $5.0 \mathrm{bc}$ & $1024.7 \mathrm{c}$ & $21.0 \mathrm{~cd}$ & $5.7 \mathrm{c}$ & $8.7 b$ \\
\hline No & Light & 6 & $120.6 \mathrm{a}$ & $13.4 \mathrm{a}$ & $9.4 \mathrm{ab}$ & $4.4 \mathrm{c}$ & $621.6 \mathrm{de}$ & $24.1 \mathrm{ab}$ & $4.5 \mathrm{~d}$ & $4.7 \mathrm{~cd}$ \\
\hline No & Light & 9 & $129.6 \mathrm{a}$ & $11.6 \mathrm{~b}$ & $9.3 \mathrm{ab}$ & $8.1 \mathrm{a}$ & $698.6 \mathrm{de}$ & $24.1 \mathrm{ab}$ & $5.6 \mathrm{~cd}$ & $4.8 \mathrm{~cd}$ \\
\hline No & Light & 12 & $111.5 \mathrm{a}$ & $11.7 \mathrm{~b}$ & $7.8 \mathrm{~b}$ & $6.4 a b$ & $1495.0 \mathrm{~b}$ & $22.0 \mathrm{bc}$ & $6.9 \mathrm{bc}$ & $13.2 \mathrm{a}$ \\
\hline Yes & Dark & 6 & $132.4 a$ & $13.8 \mathrm{a}$ & $10.5 a$ & $8.8 \mathrm{a}$ & $853.9 \mathrm{~cd}$ & $25.3 a$ & $6.2 b c$ & $5.9 \mathrm{c}$ \\
\hline Yes & Dark & 9 & $125.6 \mathrm{a}$ & $13.3 \mathrm{a}$ & $9.1 \mathrm{ab}$ & $6.4 a b$ & 498.1ef & $19.5 \mathrm{~cd}$ & $4.9 \mathrm{~d}$ & $3.1 \mathrm{de}$ \\
\hline Yes & Dark & 12 & $119.3 \mathrm{a}$ & $13.8 \mathrm{a}$ & $9.0 \mathrm{ab}$ & $7.2 \mathrm{ab}$ & $1359.1 \mathrm{~b}$ & $21.3 \mathrm{bcd}$ & $7.6 a b$ & $10.8 \mathrm{ab}$ \\
\hline Yes & Light & 6 & $135.3 \mathrm{a}$ & $13.9 \mathrm{a}$ & $10.5 \mathrm{a}$ & $8.0 \mathrm{a}$ & 541.1ef & $18.8 \mathrm{~d}$ & $5.3 \mathrm{~cd}$ & $3.0 \mathrm{de}$ \\
\hline Yes & Light & 9 & $122.3 \mathrm{a}$ & $12.4 \mathrm{ab}$ & $9.8 \mathrm{a}$ & $8.6 \mathrm{a}$ & $360.1 \mathrm{f}$ & $20.8 \mathrm{~cd}$ & $3.9 \mathrm{~d}$ & $2.3 \mathrm{e}$ \\
\hline Yes & Light & 12 & $145.5 \mathrm{a}$ & $13.4 \mathrm{a}$ & $10.1 \mathrm{a}$ & $8.5 \mathrm{a}$ & $1767.3 \mathrm{a}$ & $24.6 \mathrm{a}$ & $8.9 \mathrm{a}$ & $12.0 \mathrm{a}$ \\
\hline
\end{tabular}

* Means followed by different letters are significantly different at the $1 \%$ level of significance. RGR (relative growth rate) $=($ Fwt $2-$ Fwt 1$) /$ Fwt 1 .

of chokecherry cultures after 12 week storage as indicated by RGR. The lowest RGR with chokecherry cultures were observed after the 9 weeks storage period regardless of sucrose and light treatments (Table 2).

Similar to effects of sucrose, light significantly improved the capacity to re-grow of chokecherry cultures, but only after 12 weeks of storage. The cultures re-grown from shoots stored for 12 weeks, produced the largest biomass (Fwt2) and had the highest RGR. Also, the most vigorous cultures were produced from this treatment since the highest number of shoots per re-grown culture was observed with shoots stored for 12 weeks (Table 2). The length of shoots and the number of leaves of chokecherry cultures after storage were similar in all treatment combinations (Table 2).

The Analysis of Variance summary results for Saskatoon berry shown in Table 1 indicate that the number of yellow leaves after storage and fresh weight of cultures after re-growth (Fwt2) had significant S $\times$ Li $\times$ Le interaction effect. The significant LixLe interaction effect was observed for length of shoots after storage, the number of leaves per stem after storage and for the relative growth rate (RGR). The $S \times L e$ 
interaction effect was significant only in RGR of Saskatoon berry cultures, and the $\mathrm{S} \times \mathrm{Li}$ interaction effect was significant only in shoot length after re-growth. None of the treatments had a significant effect on fresh weight after storage (Fwt1) and the number of shoots after re-growth (Table 1).

Similar to chokecherry, the RGR of Saskatoon berry cultures was the highest from cultures stored for 12 weeks, irrespective of the presence of sucrose in the storage medium and exposure to low light during storage (Table 3). The RGR of these cultures tripled and quadrupled RGRs of cultures stored for 6 and 9 weeks. Similar to chokecherry cultures, sucrose in the storage medium, especially with light, induced yellowing of lower leaves in Saskatoon cultures. This however, did not affect the capacity to re-grow of Saskatoon cultures after $12 \mathrm{wk}$ storage. The fresh weight after re-growth (Fwt2), number of shoots and RGR were the highest after 12 weeks of cold storage. Also, the presence of sucrose in the storage medium enhanced the number of leaves during storage when stored under low light (Table 3). Having either light or sucrose significantly improved length of shoots in re-grown cultures after 9 week

Table 3. Saskatoon berry: sucrose - $\mathrm{S}$, light $-\mathrm{Li}$ and length of storage at $4^{\circ} \mathrm{C}-\mathrm{Le}$ (S×LixLe) interaction. Least square means comparison of all responses.

\begin{tabular}{|c|c|c|c|c|c|c|c|c|c|c|}
\hline \multicolumn{3}{|c|}{ Treatment } & \multicolumn{2}{|c|}{ After storage } & \multicolumn{6}{|c|}{ After re-growth } \\
\hline$S$ & $\mathrm{Li}$ & [wks] & Fwt 1 & $\begin{array}{c}\text { Length } \\
\text { of } \\
\text { shoots } \\
{[\mathrm{mm}]}\end{array}$ & $\begin{array}{c}\text { Number } \\
\text { of } \\
\text { leaves }\end{array}$ & $\begin{array}{c}\text { Number } \\
\text { of } \\
\text { yellow } \\
\text { leaves }\end{array}$ & $\begin{array}{l}\text { Fwt } 2 \\
{[\mathrm{mg}]}\end{array}$ & $\begin{array}{c}\text { Length } \\
\text { of } \\
\text { shoots } \\
{[\mathrm{mm}]}\end{array}$ & $\begin{array}{c}\text { Number } \\
\text { of } \\
\text { shoots }\end{array}$ & RGR \\
\hline No & Dark & 6 & $57.4 \mathrm{~b}^{*}$ & $11.9 \mathrm{bcd}$ & $6.1 \mathrm{ab}$ & $0.7 \mathrm{~d}$ & $511.2 \mathrm{c}$ & $25.6 \mathrm{c}$ & $9.7 \mathrm{a}$ & $8.0 \mathrm{c}$ \\
\hline No & Dark & 9 & $57.8 \mathrm{~b}$ & $11.2 \mathrm{~d}$ & $5.8 \mathrm{ab}$ & $0.9 \mathrm{~d}$ & $388.7 \mathrm{c}$ & $27.9 \mathrm{c}$ & $8.6 \mathrm{ab}$ & $5.6 \mathrm{cc}$ \\
\hline No & Dark & 12 & $60.1 b$ & $10.9 \mathrm{~d}$ & $5.0 \mathrm{~cd}$ & $0.4 \mathrm{~d}$ & $1284.6 \mathrm{a}$ & $26.1 \mathrm{c}$ & $9.5 \mathrm{a}$ & $20.2 \mathrm{ab}$ \\
\hline No & Light & 6 & $61.2 b$ & $11.3 \mathrm{~cd}$ & $5.1 \mathrm{~cd}$ & $1.9 \mathrm{~cd}$ & $295.7 d$ & $22.3 d$ & $6.7 \mathrm{bc}$ & $3.8 \mathrm{e}$ \\
\hline No & Light & 9 & $59.0 \mathrm{~b}$ & $11.2 \mathrm{~cd}$ & $4.3 \mathrm{~d}$ & $2.4 \mathrm{c}$ & $455.9 \mathrm{bc}$ & $32.3 a b$ & $8.0 a b c$ & $6.6 \mathrm{cc}$ \\
\hline No & Light & 12 & $56.4 \mathrm{~b}$ & $12.8 \mathrm{bc}$ & $5.4 \mathrm{bc}$ & $3.8 \mathrm{ab}$ & $935.4 \mathrm{a}$ & $28.9 \mathrm{bc}$ & $8.3 a b c$ & $15.0 \mathrm{~b}$ \\
\hline Yes & Dark & 6 & $71.2 \mathrm{ab}$ & $13.6 \mathrm{~b}$ & $6.2 \mathrm{ab}$ & $1.4 \mathrm{~d}$ & $437.4 \mathrm{bc}$ & $27.5 \mathrm{c}$ & $8.3 \mathrm{abc}$ & $5.1 \mathrm{de}$ \\
\hline Yes & Dark & 9 & $71.0 \mathrm{ab}$ & $13.0 \mathrm{~b}$ & $6.6 \mathrm{a}$ & $2.6 \mathrm{bc}$ & $500.5 b$ & $34.3 \mathrm{a}$ & $6.8 \mathrm{bc}$ & $5.9 \mathrm{~cd}$ \\
\hline Yes & Dark & 12 & $52.1 \mathrm{~b}$ & $12.9 b c$ & $5.8 \mathrm{ab}$ & $2.4 \mathrm{c}$ & $1186.3 \mathrm{a}$ & $27.8 \mathrm{c}$ & 7.6abc & $21.7 \mathrm{a}$ \\
\hline Yes & Light & 6 & $77.8 \mathrm{a}$ & $11.0 \mathrm{~d}$ & $6.5 \mathrm{a}$ & $4.8 \mathrm{a}$ & $289.5 \mathrm{~d}$ & $21.2 \mathrm{~d}$ & $6.3 c$ & $2.6 \mathrm{e}$ \\
\hline Yes & Light & 9 & $68.2 \mathrm{ab}$ & $13.1 \mathrm{~b}$ & $5.3 b c$ & $4.5 \mathrm{a}$ & $315.2 \mathrm{~cd}$ & $27.0 \mathrm{c}$ & $6.9 \mathrm{bc}$ & $3.3 \mathrm{e}$ \\
\hline Yes & Light & 12 & $60.2 \mathrm{~b}$ & $15.8 \mathrm{a}$ & $6.7 \mathrm{a}$ & $4.8 \mathrm{a}$ & $1227.0 \mathrm{a}$ & $25.6 \mathrm{c}$ & $8.6 \mathrm{ab}$ & $19.2 \mathrm{ab}$ \\
\hline
\end{tabular}

"Means followed by different letters are significantly different at the $1 \%$ level of significance. RGR (relative growth rate $)=($ Fwt $2-$ Fwt1 $) /$ Fwt1 . 
storage period. The results indicate that for the production of vigorous Saskatoon berry and chokecherry cultures, stock plants should be stored at cool temperatures for at least 12 weeks (Tables 2 and 3; Pruski \& Lewis, 1996). The 12 weeks exposure to $4^{\circ} \mathrm{C}$ may be the minimum chilling requirement for these species to overcome dormancy (Vegis, 1964). Successful, above freezing storage of cultures has been reported for apple (Malus domestica) and Prunus spp. Shoots of both species were stored up to 52 weeks at $2^{\circ} \mathrm{C}$ and re-grew vigorous cultures after storage (Druat, 1985). Thus, growers can store their stock plantlets in a simple refrigerator on a regular growing medium.

For potato, $S \times L$ interaction effect was significant for fresh weight of cultures (Fwt1) and the number of leaves after storage; $\mathrm{S} \times \mathrm{Li}$ was significant for fresh weight after storage (Fwt1) only, and main effects of one or more of the factors were significant for the other responses (Table 1).

The presence of sucrose in the storage medium was very critical for the potato cultures. After storage, plantlets re-grown from stock plants kept on sucrose had approximately 2.5 times higher fresh weight and almost 5 times the shoot length at four weeks in culture, compared to the plantlets re-grown from stock plants kept on the medium without sucrose (Table 4). All RGR values calculated for potato cultures grown from the cultures stored on media without sucrose are negative. The positive RGR are only for cultures stored on media with sucrose, irrespective of the length of the storage period with exception to 9 weeks dark storage treatment (Table 4). In short-term treatments ( 6 and 9 weeks), cultures also benefited from the light during storage producing significantly higher RGR than those stored in dark. Cultures regrown from low intensity red light storage with no sucrose in the storage medium produced longer shoots with long internodes (Table 4). Miyashita et al. (1995) also described beneficial effects of low intensity red light illumination $\left(2-50 \mu \mathrm{mol} \mathrm{m}^{-2} \mathrm{~s}^{-1}\right)$ on growth of potato culture.

To summarize, all three factors, sucrose, light and the length of the storage period had an impact on capacity to re-grow of the cultures, relative growth rate (RGR) as well as on quality of shoots produced by these cultures. Irrespective of light, sucrose was essential for the low temperature maintenance of vigorous stock plants of potato if stored for more than six weeks. The chokecherry and Saskatoon cultures stored well without sucrose, although chokecherry benefited from sucrose in the storage medium when the stock cultures were kept at the low temperature for 12 weeks. Low light significantly improved quality of potato cultures but had very little effect on both chokecherry and Saskatoon berry cultures. Similar to an earlier study by Pruski et al. (1997), the woody plant cultures grew during storage, and the longer the stock plants were stored, the more vigorous cultures they re-grew. As mentioned earlier, this could indicate that a prolonged exposure to the low temperature had reduced dormancy. The 
Table 4. Potato: sucrose - S, light - $\mathrm{Li}$ and length of storage at $4^{\circ} \mathrm{C}-\mathrm{Le}(\mathrm{S} \times \mathrm{Li} \times \mathrm{Le})$ interaction. Least square means comparison of all responses.

\begin{tabular}{|c|c|c|c|c|c|c|c|c|c|}
\hline \multicolumn{3}{|c|}{ Treatment } & \multicolumn{3}{|c|}{ After storage } & \multicolumn{4}{|c|}{ After re-growth } \\
\hline$S$ & $\mathrm{Li}$ & [wks] & [mg] & $\begin{array}{c}\text { Length } \\
\text { of } \\
\text { shoots } \\
\text { [mm] }\end{array}$ & $\begin{array}{l}\text { Number } \\
\text { of leaves }\end{array}$ & [mg] & $\begin{array}{c}\text { Length } \\
\text { of } \\
\text { shoots } \\
\text { [mm] }\end{array}$ & $\begin{array}{c}\text { Number } \\
\text { of } \\
\text { shoots }\end{array}$ & RGR \\
\hline No & Dark & 6 & $181.6 \mathrm{c}^{*}$ & $42.8 \mathrm{~cd}$ & $8.0 \mathrm{ab}$ & $72.0 \mathrm{~d}$ & $9.1 \mathrm{~d}$ & $1.0 \mathrm{~d}$ & $-0.54 \mathrm{e}$ \\
\hline No & Dark & 9 & $170.5 \mathrm{~cd}$ & $43.1 \mathrm{~cd}$ & $7.8 \mathrm{bcd}$ & $64.0 \mathrm{~d}$ & $7.0 \mathrm{~d}$ & $1.0 \mathrm{~d}$ & $-0.58 \mathrm{e}$ \\
\hline No & Dark & 12 & $158.2 \mathrm{~cd}$ & & $7.0 \mathrm{e}$ & $64.0 \mathrm{~d}$ & $7.0 \mathrm{~d}$ & $1.0 \mathrm{~d}$ & $-0.56 \mathrm{e}$ \\
\hline No & Light & 6 & $191.9 b c$ & $42.6 \mathrm{~cd}$ & $8.6 a$ & $109.0 \mathrm{c}$ & $20.4 c$ & $1.1 \mathrm{~cd}$ & $-0.21 \mathrm{de}$ \\
\hline No & Light & 9 & $156.3 \mathrm{~cd}$ & $43.5 \mathrm{~cd}$ & $7.8 \mathrm{bc}$ & $69.8 \mathrm{~d}$ & $9.0 \mathrm{~d}$ & $1.0 \mathrm{~d}$ & $-0.52 \mathrm{e}$ \\
\hline No & Light & 12 & $209.1 \mathrm{ab}$ & $41.6 \mathrm{~cd}$ & $7.1 \mathrm{de}$ & $107.4 \mathrm{c}$ & $14.1 \mathrm{~cd}$ & $1.1 \mathrm{~cd}$ & $-0.35 \mathrm{e}$ \\
\hline Yes & Dark & 6 & $182.5 \mathrm{c}$ & $47.1 \mathrm{ab}$ & & $181.1 \mathrm{~b}$ & $57.8 \mathrm{ab}$ & $1.4 \mathrm{ab}$ & $0.20 \mathrm{bcd}$ \\
\hline Yes & Dark & 9 & $225.3 \mathrm{ab}$ & $49.9 \mathrm{a}$ & $7.4 \mathrm{cde}$ & $179.5 b$ & $50.8 \mathrm{~b}$ & $1.3 \mathrm{bcd}$ & $-0.08 \mathrm{cde}$ \\
\hline Yes & Dark & 12 & $233.7 \mathrm{a}$ & $47.2 \mathrm{ab}$ & $8.0 \mathrm{ab}$ & 243.3ab & $48.5 \mathrm{~b}$ & $1.7 \mathrm{a}$ & $0.29 \mathrm{bc}$ \\
\hline Yes & Light & 6 & $137.4 d$ & $40.8 d$ & $8.5 a$ & $257.0 \mathrm{a}$ & $58.8 \mathrm{a}$ & $1.5 \mathrm{ab}$ & $0.96 \mathrm{a}$ \\
\hline Yes & Light & 9 & $175.1 \mathrm{~cd}$ & $44.5 \mathrm{bc}$ & $7.3 \mathrm{de}$ & $182.3 b$ & $51.6 \mathrm{ab}$ & $1.3 \mathrm{bcd}$ & $0.45 b$ \\
\hline Yes & Light & 12 & $193.2 \mathrm{abc}$ & $47.9 \mathrm{a}$ & $7.9 \mathrm{bc}$ & $181.4 b$ & $54.8 \mathrm{ab}$ & $1.6 \mathrm{ab}$ & $0.15 \mathrm{bcd}$ \\
\hline
\end{tabular}

* Means followed by different letters are significantly different at the $1 \%$ level of significance. RGR (relative growth rate) $=($ Fwt $2-F w t 1) / F w t 1$.

number of yellow leaves in both, chokecherries and Saskatoon berries, was related to the presence of sucrose in the storage medium and the presence of light during storage. The more yellow leaves were observed on cultures (12 weeks storage on media with sucrose and under low light), the stronger capacity to re-grow they showed (Tables 2 and 3). In all three species tested, the number of shoots per re-grown culture was also related to the presence of sucrose in the medium, low light during storage and storage length. More vigorous cultures had more shoots and they were obtained from shoots stored on media with sucrose, under low light and for 12 weeks (Tables 2, 3 and 4).

The results indicate that the growers can successfully use their existing facilities, small refrigerators and coolers set at $4^{\circ} \mathrm{C}$ with low light, for short-term storage of potato, chokecherry and Saskatoon berry cultures. The potato cultures, which are known to be sensitive to prolonged low temperature storage (Westcott, 1981a, b), should be frequently monitored and sub-cultured as required. On the other hand, the woody plant stock cultures do not require any special attention when kept at $4^{\circ} \mathrm{C}$ and they can re-grow the most vigorous shoots if stored for at least 12 weeks. 


\section{Chapter 4}

\section{References}

Bessembinder, J.J.E., G. Staritski \& E.A. Zandvoort, 1993. Long-term in vitro storage of Colocasia esculenta under minimal growth conditions. Plant Cell, Tissue and Organ Culture 33: 121-127.

Druat, P., 1985. In vitro germplasm preservation technique for fruit trees. In: A. SchäferMenuhr (Ed.), In Vitro Techniques- Propagation and Long-term storage. M. Nijhoff/Junk for CEC, Dordrecht, pp. 167-171.

Hansen, J. \& K. Kristiansen, 1997. Short-term in vitro storage of Miscanthus $\times$ ogiformis Honda 'Giganteus' as affected by medium composition, temperature, and photon flux density. Plant Cell, Tissue and Organ Culture 49: 161-169.

Heines, R.D., N. Lange \& T.F. Wallace, 1992. Low-temperature storage of bedding-plants plugs. In: K. Kurata \& T. Kozai (Eds.), Transplant Production Systems. Kluwer Academic Publishers, The Netherlands, pp. 45-64.

Hosie, R.C., 1979. The Cherries and Plums. In: Native Trees of Canada. Fitzhenry \& Whiteside Ltd., Don Mills, Ontario, Canada, pp. 242-244.

Kubota, C. \& T. Kozai, 1993. Dim light contributed to the quality retention of broccoli plants in vitro during low temperature storage. Proceedings of $I^{\text {st }}$ Asia-Pacific Conference on Plant Cell Culture, Abstr. p. 31.

Kubota, C. \& T. Kozai, 1994. Low temperature storage for quality preservation and growth suppression of Broccoli plantlets cultured in vitro. HortScience 29: 1191-1194.

Kubota, C. \& T. Kozai, 1995. Low temperature storage of transplants at the light compensation point: air temperature and light intensity for growth suppression and quality preservation. Scienta Horticulturae 61: 193-204.

Kubota, C., G. Niu \& T. Kozai, 1995. Low temperature storage for production management of in vitro plants: effects of air temperature and light intensity on preservation of plantlet dry weight and quality during storage. Acta Horticulturae 393: 103-110.

Linsmaier, E.M. \& F. Skoog, 1965. Organic growth factor requirements of tobacco tissue cultures. Physiologia Plantarum 18: 100-127.

Marino, G., P. Posati \& F. Sagrati, 1985. Storage of in vitro cultures of Prunus rootstocks. Plant Cell, Tissue and Organ Culture 5: 73-78.

Miyashita, Y., Y. Kitaya, T. Kimura \& T. Kozai, 1995. Effect of red and far-red light on growth and morphology of potato plantlets in vitro: using light emitting diode as a light source for micropropagation. Acta Horticulturae 393: 710-715.

Montgomery, D.C., 1997. Design and Analysis of Experiments. Fourth edition. Wiley, New York.

Mullin, R.H. \& D.E. Schlegel, 1976. Cold storage maintenance of strawberry meristem plantlets. HortScience 11: 100-101.

Murashige, T. \& F. Skoog, 1962. A revised medium for rapid growth and bioassays with 
tobacco tissue cultures. Physiologia Plantarum 15: 473-497.

Pruski, K., J. Nowak \& G. Grainger, 1990. Micropropagation of four cultivars of Saskatoon berry (Amelanchier alnifolia Nutt.). Plant Cell, Tissue and Organ Culture 21: 103-109.

Pruski, K., T. Lewis \& M. Mirza, 1992. Micropropagation of chokecherry and pincherry (Prunus virginiana and Prunus pensylvanica). HortScience 27: 571 (021 abstract).

Pruski, K. \& T. Lewis, 1996. Effect of low temperature long-term storage on quality and regeneration capability of in vitro cultures. In Vitro Cellular and Developmental Biology Plant, 32: 75 (P-1036 abstract).

Pruski, K., T. Lewis \& T. Kozai, 1997. Sucrose and low light effects on in vitro cultures during cold storage. In Vitro Cellular and Developmental Biology - Plant 33: 50 (P-1023 abstract).

SAS Institute Inc., 1989. SAS/STAT User's Guide, Version 6, $4^{\text {th }}$ Edition, Volume 2. SAS Institute Inc., Cary NC, 846 pp.

Statistics Canada, 1998. Fruit and Vegetable Production. Statistics Canada, Agriculture Division, Horticulture Crop Unit, Ottawa, ON, February 1998.

St-Pierre, R.G., 1993. The Chokecherry, a guide for growers. Department of Horticultural Sciences, University of Saskatchewan, Saskatoon, SK, Canada.

St-Pierre, R.G., H. Tulloch \& C. Greuel, 1997. Growing Saskatoons, a manual for orchardists. Department of Horticultural Sciences, University of Saskatchewan, Saskatoon, SK, Canada.

Vegis, A., 1964. Dormancy in higher plants. Annual Reviews in Plant Physiology 15: $185-$ 201.

Westcott, R.J., 1981 a. Tissue culture storage of potato germplasm. 1. Minimal growth storage. Potato Research 24: 331-342.

Westcott, R.J., 1981b. Tissue culture storage of potato germplasm. 2. Use of growth retardants. Potato Research 24: 343-352.

Withers, L.A. \& F. Engelmann, 1998. In vitro conservation of plant genetic resources. In: A. Altman (Ed.), Agricultural Biotechnology. Marcel Dekker, Inc., New York, NY, pp. 57-88. 


\section{Chapter 5}

Jasmonate effects on in vitro tuberization and tuber bulking in two potato cultivars (Solanum tuberosum L.) under different media and photoperiod conditions*

"Pruski, K., T. Astatkie \& J. Nowak, 2001. Jasmonate effects on in vitro tuberization and tuber bulking in two potato bultivars (Solanum tuberosum L.) under different media and photoperiod conditions. In Vitro Cellular and Developmental Biology - Plant (accepted). 


\title{
5. Jasmonate effects on in vitro tuberization and tuber bulking in two potato cultivars (Solanum tuberosum L.) under different media and photoperiod conditions
}

\begin{abstract}
Jasmonic acid (JA) effects on in vitro tuberization of potato nodal explants cvs Sangre and Russet Burbank were tested under liquid and solid media conditions and 0,8 and $16 \mathrm{~h}$ photoperiod. Explants taken from stock plants grown on $2.5 \mu \mathrm{M}$ JA supplemented medium, tuberized first; particularly in darkness. The most pronounced benefits of the JA pretreatment were recorded under $16 \mathrm{~h}$ photoperiod, which is known to inhibit tuberization. Cultivar Sangre benefited from the JA pre-conditioning of stock plants more than Russet Burbank. Russet Burbank required JA supplement in tuberization media to reach the same degree of stimulation. Overall, microtubers produced either from JA pre-conditioned stock plants or on the JA containing tuberization media were more uniform and larger than from other treatments. Eight hours photoperiod was by far the best for the production of a high quality, uniform microtubers. JA conditioning of stock plants prior to taking explants for tuberization is being proposed as a treatment enhancing the quality of microtubers.
\end{abstract}

Key words: jasmonic acid, microtubers, liquid/solid media, photoperiod, repeated measures analysis

\subsection{Introduction}

Utilization of microtubers has been postulated in elite seed potato production systems by several authors since early eighties (Hussey \& Stacey, 1981; Estrada et al., 1986; Lillo, 1989; Coltman \& Kostichka, 1993). Despite their advantage over microplants in storage and exchange (Estrada et al., 1986), microtubers have not been accepted as propagules of choice by the industry (Lommen, 1995; Struik \& Wiersema, 1999). In most of the in vitro production protocols, the generated microtubers are small and not uniform $(0.02-0.70 \mathrm{~g}$ or $3-10 \mathrm{~mm}$ in diameter) (Hussey \& Stacey, 1984; Estrada et al., 1986; Struik \& Lommen, 1990; Lê, 1999). Tuber bulking under tissue culture conditions is restricted due to the lack of the development of a perimedullary tissue (Xu et al., 1998). Moreover, it is difficult to obtain more than one microtuber per plantlet or nodal explant (Struik \& Lommen, 1990; Struik \& Wiersema, 1999). Due to the lack of uniformity in the microtuber induction and the bulking processes, length of their dormancy period as well as their physiological age may vary (Leclerc et al., 1995; Tábori et al., 1999; Coleman \& Coleman, 2000). Consequently, not all microtubers uniformly sprout and produce vigorous plants after planting. 


\section{Chapter 5}

In recent years several new production protocols have been developed, giving better yields of larger tubers (Struik \& Wiersema, 1999). Most of them, however, require either special equipment (Ranalli, 1997; Struik \& Wiersema, 1999) and/or frequent media exchanges (Teisson \& Alvard, 1999) which may lead to culture infection. Also, to our knowledge, these systems have not been yet fully validated in the industrial settings.

It has been found that jasmonates play several physiological functions in plants, usually related to their stress adaptation and signalling in root-shoot communication (Koda, 1997; Jackson, 1999). In potato, jasmonates also induce tuberization (Van den Berg \& Ewing, 1991; Pelacho \& Mingo-Castel, 1991; Koda et al., 1991; Ravnikar et al., 1992). To our knowledge, jasmonate supplements in the media have not been tested neither in plantlet conditioning prior to tuberization, nor during the microtuber production per se. The objective of this study was to determine the effect of jasmonic acid on tuberization responses and tuber bulking in two potato cultivars under different media and light conditions.

\subsection{Materials and methods}

\section{In vitro culture and effects of jasmonate on plantlet growth}

Cultivar Kennebec was used in the Preliminary Experiment to determine the effect of jasmonic acid concentration in the culture medium on plantlet growth and biomass partitioning between roots and shoots. Disease-free, tissue cultured plantlets were obtained from the Plant Propagation Center of the New Brunswick Department of Agriculture, New Brunswick, Canada. Stem cuttings with one leaf node were taken from six-week old in vitro plantlets and cultured on a hormone free Murashige and Skoog, MS (Murashige \& Skoog, 1962) medium (Sigma-Aldrich Canada Ltd., Oakville, Ont., Canada) with standard vitamins, supplemented with jasmonic acid (JA) (Apex Organics Ltd., Leicaster, UK) in concentrations of 0.0, 0.5, 1.0, 2.5, 5.0, 10.0 and $25.0 \mu \mathrm{M}$. Sucrose $\left(30 \mathrm{~g} \mathrm{l}^{-1}\right)$ was used as a carbon source and the media were solidified with $0.6 \%$ agar (Difco, Detroit, MI, USA). All media were adjusted to $\mathrm{pH}$ 5.7 before autoclaving. Media were dispensed to $25 \times 150 \mathrm{~mm}$ test tubes, $10 \mathrm{ml}$ per tube. Eighteen replicates were used per JA concentration for a destructive determination of the plantlet growth responses. Cultures were grown in a growth room in a tissue culture laboratory of the Nova Scotia Agricultural College, Truro, NS, Canada, at $22 / 18^{\circ} \mathrm{C}$ day/night temperature, $16 \mathrm{~h}$ photoperiod, $150 \mu \mathrm{mol} \mathrm{m}^{-2} \mathrm{~s}^{-1}$ mixed fluorescent (F40T12 tubes, General Electric (GE), USA) and incandescent illumination (40 W, GE, USA). After 4 weeks of incubation, plantlets were harvested and number of 
nodes, stem length, root length and dry weight of stems and roots were determined.

\section{In vitro multiplication of plantlets for tuberization experiments}

Tissue cultured plantlets of two commercial potato cultivars, Russet Burbank and Sangre, derived from the potato germplasm bank at Crop Diversification Centre North, Edmonton, Alberta, Canada were used as a source of virus-free material. The plantlets were multiplied as single-node explants on $50 \mathrm{ml}$ hormone-free MS medium, in GA7 Magenta vessels (Magenta Corp., Chicago, IL, USA). Sixteen $(4 \times 4)$ single-node explants were placed in each vessel. Cultures were incubated for 4 weeks in an environmental chamber (Conviron S10h, Winnipeg, Manitoba, Canada) at $20^{\circ} \mathrm{C}+1-$ $1^{\circ} \mathrm{C}$ temperature with $16 \mathrm{~h}$ photoperiod, and light conditions as above. At the end of the 4-week period, the plantlets were cut into single-node explants and placed on fresh MS medium in GA7 Magenta jars for further multiplication. The process was repeated until the required number of plantlets for in vitro tuberization experiments was achieved. During the last transfer before in vitro tuberization experiments, single-node explants of both cultivars were divided into two groups and transferred onto agar media: 1) the same hormone-free MS medium as above (continuation of the multiplication stage) and 2) the MS medium (with standard vitamins) supplemented with $2.5 \mu \mathrm{M} \mathrm{JA}$ (this group of explants was labelled as JA pre-treated (JAP)). Both groups were incubated for four weeks under the conditions described above.

\section{In vitro tuberization}

Experiment 1. Effects of photoperiod, media (liquid $v s$ agar (solid)), and JA pretreatment of nodal cuttings on microtuber production were investigated. Nodal explants (with one leaf) were taken from four-week old plantlets grown on media with and without JA. Apical and basal nodes were discarded. Explants were placed on MS tuberization media supplemented with $80 \mathrm{~g} \mathrm{I}^{-1}$ sucrose and with (solid)/without (liquid) $0.6 \%$ agar. Fifty $\mathrm{ml}$ of agar (solid) and $15 \mathrm{ml}$ of liquid medium was dispensed per jar. Fifteen nodal cuttings were placed per jar. Cultures were incubated at $20^{\circ} \mathrm{C}$ with 0 (darkness), 8 and $16 \mathrm{~h}$ photoperiod at $50 \mu \mathrm{mol} \mathrm{m} \mathrm{m}^{-2} \mathrm{~s}^{-1}$ mixed fluorescent/incandescent light for 10 weeks. Every two weeks, $7 \mathrm{ml}$ of liquid $\mathrm{MS}$ medium with $80 \mathrm{~g} \mathrm{l}^{-1}$ of sucrose was added to each jar with cultures grown on liquid media. Beginning the second week after the nodal cuttings were placed on tuberization media, regular observations of cultures started every $7-10$ days. The number of induced tubers and the tuber bulking process were recorded. After 10 weeks microtubers were harvested, the number and weight of microtubers produced per nodal cutting were recorded. 
Experiment 2. This experiment was designed as a follow up to Experiment 1 to see whether the addition of JA to tuberization media further enhances microtuber production. Nodal explants taken from plants grown on media with or without JA were placed on: 1) the same tuberization medium as in Experiment 1, and 2) on MS medium with sucrose $80 \mathrm{~g} \mathrm{l}^{-1}$, supplemented with $2.5 \mu \mathrm{M} \mathrm{JA}$ and either solidified with $0.6 \%$ agar or liquid. Explants were grown in GA7 Magenta jars, 15 nodal cuttings per jar. Growing conditions, culture maintenance, data collection and record keeping followed the description outlined in Experiment 1.

\section{Statistical analysis}

Second order polynomial regression of average of 18 plantlets per treatment stem dry weight, root dry weight, and root to stem biomass ratio was used to determine the optimum JA concentration in the Preliminary Experiment (Figure 2). Analysis of variance was also used to evaluate JA concentration effect on number of nodes, stem and root length, stem and root dry weight and root to stem biomass ratio in this experiment (data not shown; some included in text). The statistical model for Experiment 1 was a four-factor factorial, and for Experiment 2 was a five-factor factorial. The four factors in Experiment 1 are cultivar (cv: RB - Russet Burbank and SA Sangre), jasmonic acid pre-treatment (JAP: yes and no), light ( 0,8 and 16 hours) and medium (liquid and solid). Experiment 2 has these four factors plus jasmonic acid in tuberization media (JAM: yes and no). The weight of each tuber at week 10 for Experiment 1 and at week 11 for Experiment 2 was used as a tuber weight response. The tuber numbers were recorded at 6 time points (week 2 through week 10 for Experiment 1 and week 2 through 11 for Experiment 2) repeatedly and analysed as repeated measures.

To meet constant variance and normal distribution assumption of the error terms, the cubic-root transformed values of the tuber weights were used. However, the assumptions were valid with the original values of tuber numbers. For the repeated measures analysis of the tuber numbers, sphericity assumption was rejected and hence, the $P$-values of the Wilks' $\lambda$ statistic (Crowder \& Hand, 1990) shown in Table 1 were used to test whether the effects remained the same in all weeks. All statistical analyses were done using SAS (SAS, 1996).

\subsection{Results}

The effects of jasmonic acid (JA) concentration in the culture medium on plantlet growth and biomass partitioning between roots and shoots are shown in Figures 1 and 
2. The longest stems with the highest number of nodes and the longest roots were produced by plantlets grown on media either without $\mathrm{JA}$ or low $(0.5$ and $1.0 \mu \mathrm{M}) \mathrm{JA}$ concentrations. Compared to the control, JA supplement ranging from 0.5 to $2.5 \mu \mathrm{M}$, significantly $(P<0.05)$ shortened roots $(7.4 v s 6.1-4.6 \mathrm{~cm})$ and stems $(8.6 v s 7.6-5.3$ $\mathrm{cm}$ ) (data not shown) and enhanced plantlet biomass (Figure 2). Plantlets grown on the JA media were also much sturdier, with thicker stems, extensively branched and larger root system (Figure 1), and higher root and shoot dry weight and root to stem biomass ratio (Figure 2). The JA concentrations higher than $2.5 \mu \mathrm{M}$ were detrimental to the cultures (Figures 1 and 2). At $2.5 \mu \mathrm{M}$ JA roots had significantly $(P<0.05)$ higher dry weight and root/stem ratio than plantlets from other treatments (Figure 2). Overall plantlet appearance also indicated that $2.5 \mu \mathrm{M}$ JA medium supplement was the most beneficial and thus this concentration was chosen for further experimentation (Experiments 1 and 2).

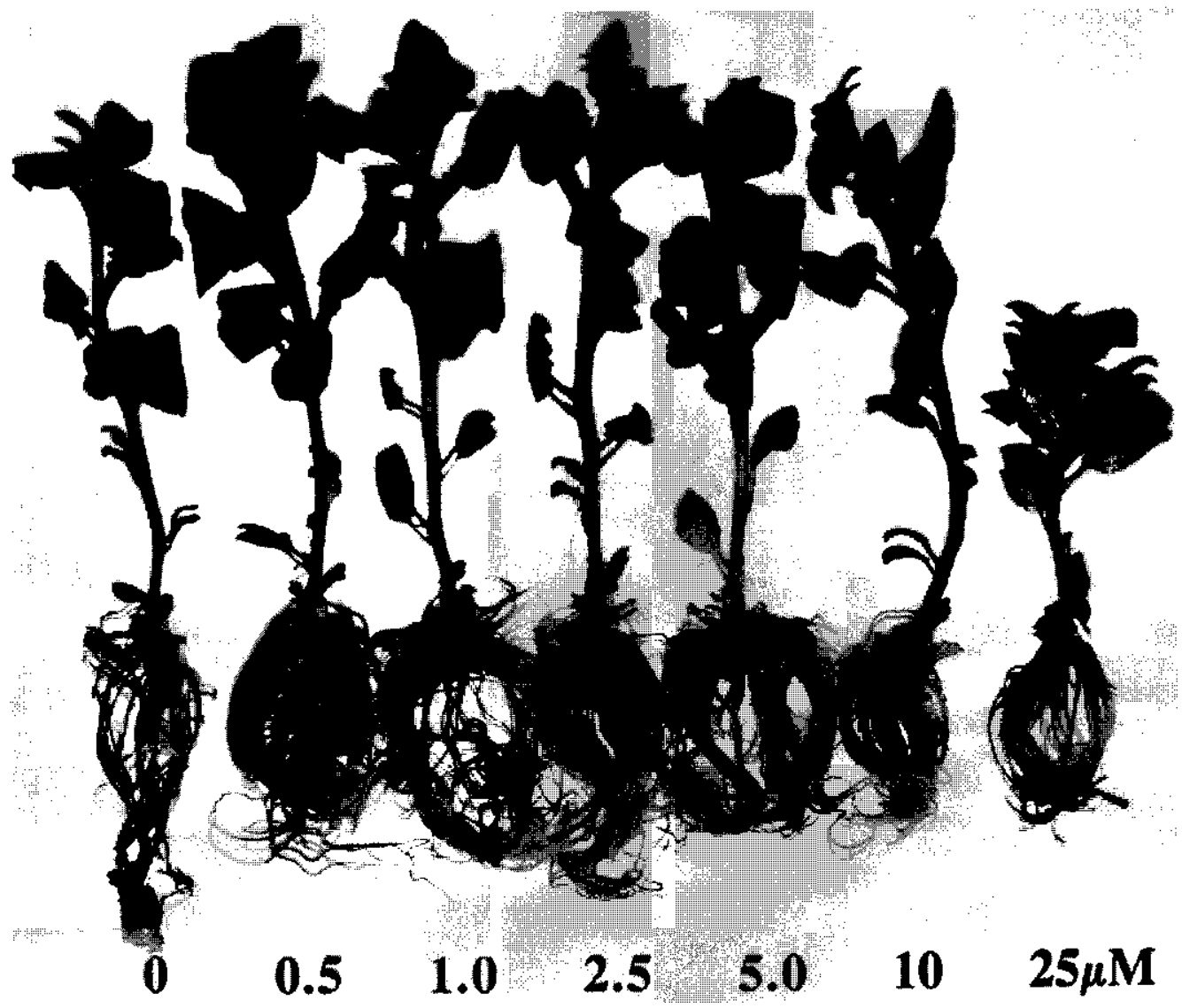

Figure 1. The effect of various concentrations of jasmonic acid (JA) on growth and root/shoot ratio of potato plantlets $\mathrm{c} v$. Kennebec. 
Chapter 5

Stem Dry Weight at JA Conc. of $2.5=64.7 \mathrm{mg}$

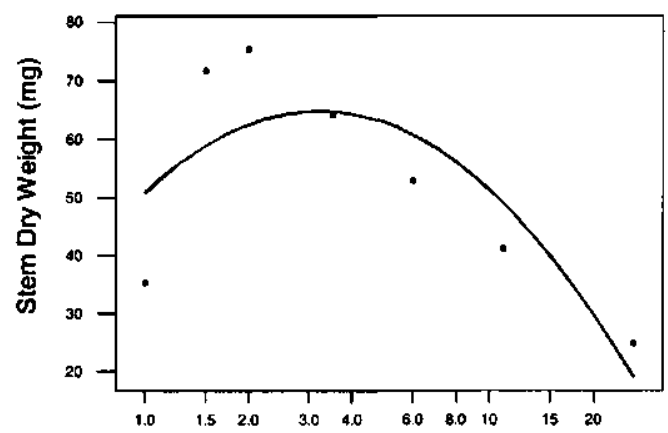

Root Dry Weight at JA Conc. of $2.5=68.2 \mathrm{mg}$

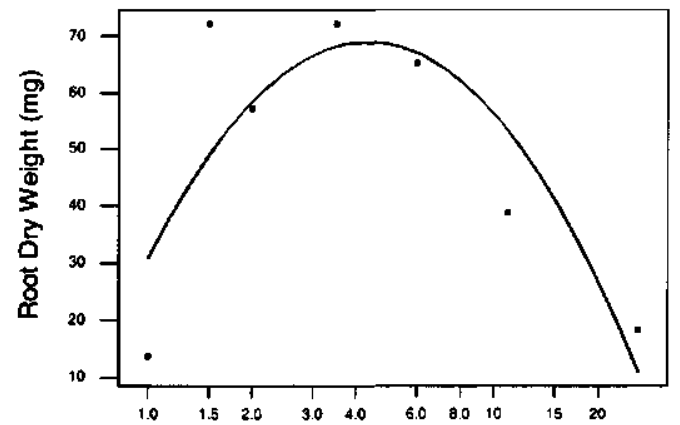

Root to Stem Dry Weight Ratio at JA Conc. of $2.5=1.1$

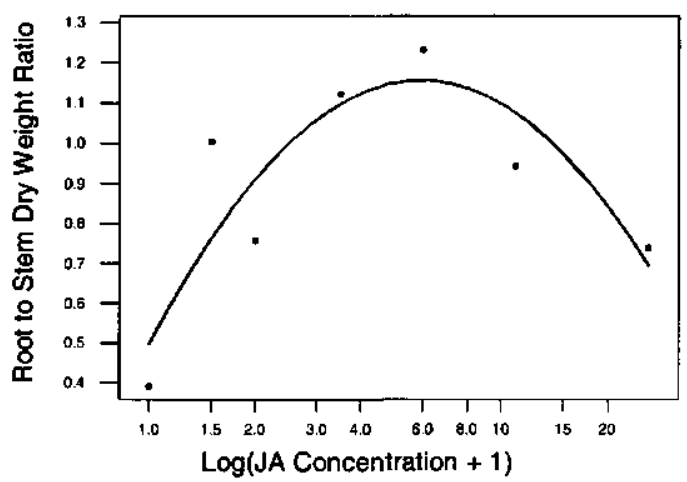

Figure 2. Plot of average stem dry weight [mg], root dry weight $[\mathrm{mg}]$ and root to stem dry weight ratio against $\log (\mathrm{JA}$ concentration +1$)$ together with second order polynomial fits. The average is based on 18 replications. JA concentrations in $\mu \mathrm{M}$. The estimate values for JA concentration of $2.5 \mu \mathrm{M}$ were calculated using the estimated equation. 
Table 1. $P$-values for main and interaction effects (by week) on number of microtubers produced per vessel. The multivariate analysis $P$-values for the number of microtubers are for the interaction between the source of variation and week (change over 10 or 11 weeks). Abbreviations: CV - cultivar, JAP - pre-treatment with jasmonic acid, JAM - jasmonic acid in media, $\mathrm{Li}$ - light/photoperiod, $\mathrm{M}$ - media (solid/liquid).

\begin{tabular}{|c|c|c|c|c|c|c|c|c|}
\hline \multirow{3}{*}{$\begin{array}{l}\text { Source of } \\
\text { Variation }\end{array}$} & \multicolumn{6}{|c|}{$P$-values } & \multirow{3}{*}{$\begin{array}{c}\text { Number of } \\
\text { microtuber } \\
\text { by week } \\
\text { Wilks' } \lambda \\
\text { ( } P \text {-values) }\end{array}$} & \multirow{3}{*}{$\begin{array}{c}\text { Weight of } \\
\text { microtuber } \\
\text { at week } 10 \\
\text { (harvest) } \\
\text { ( } P \text {-values) }\end{array}$} \\
\hline & Week & Week & Week & Week & Week & Week & & \\
\hline & 2 & 3 & 4 & 5 & 7 & 10 & & \\
\hline$C V$ & 0.006 & 0.001 & 0.001 & 0.001 & 0.001 & 0.004 & 0.001 & 0.565 \\
\hline$J A P$ & 0.001 & 0.013 & 0.173 & 0.109 & 0.264 & 0.803 & 0.894 & 0.139 \\
\hline$C V \times J A P$ & 0.331 & 0.020 & 0.290 & 0.114 & 0.066 & 0.264 & 0.192 & 0.273 \\
\hline$L i$ & 0.001 & 0.001 & 0.001 & 0.001 & 0.001 & 0.001 & 0.001 & 0.001 \\
\hline$C V \times L i$ & 0.016 & 0.001 & 0.001 & 0.001 & 0.379 & 0.003 & 0.001 & 0.001 \\
\hline$J A P \times L i$ & 0.001 & 0.070 & 0.001 & 0.053 & 0.050 & 0.126 & 0.001 & 0.126 \\
\hline$C V \times J A P \times L i$ & 0.040 & 0.001 & 0.064 & 0.374 & 0.290 & 0.518 & 0.001 & 0.613 \\
\hline$M$ & 0.024 & 0.007 & 0.783 & 0.292 & 0.001 & 0.001 & 0.001 & 0.001 \\
\hline$C V \times M$ & 0.001 & 0.080 & 0.338 & 0.001 & 0.001 & 0.001 & 0.001 & 0.01 \\
\hline$J A P \times M$ & 0.146 & 0.690 & 0.019 & 0.015 & 0.154 & 0.092 & 0.001 & 0.613 \\
\hline $\operatorname{Li} \times M$ & 0.001 & 0.369 & 0.001 & 0.001 & 0.001 & 0.001 & 0.001 & 0.001 \\
\hline$C V \times J A P \times M$ & 0.015 & 0.021 & 0.004 & 0.498 & 0.063 & 0.001 & 0.001 & 0.001 \\
\hline$C V \times L i \times M$ & 0.001 & 0.001 & 0.001 & 0.001 & 0.001 & 0.649 & 0.001 & 0.004 \\
\hline$J A P \times L i \times M$ & 0.507 & 0.588 & 0.844 & 0.843 & 0.676 & 0.254 & 0.338 & 0.039 \\
\hline$C V \times J A P \times L i \times M$ & 0.001 & 0.001 & 0.251 & 0.797 & 0.936 & 0.514 & 0.006 & 0.007 \\
\hline
\end{tabular}

Experiment 2: Main and 2-factor interactions only; 5-factor interaction in Table 3

\begin{tabular}{|c|c|c|c|c|c|c|c|c|}
\hline Source of Variation & Wk 2 & Wk 4 & Wk 6 & Wk 7 & Wk 8 & Wk 11 & Interaction & $\begin{array}{l}\text { Weight at } \\
\text { week } 11\end{array}$ \\
\hline CV & 0.001 & 0.170 & 0.155 & 0.440 & 0.610 & 0.001 & 0.001 & 0.106 \\
\hline JAP & 0.041 & 0.006 & 0.011 & 0.001 & 0.001 & 0.001 & 0.024 & 0.001 \\
\hline $\mathrm{CV} \times \mathrm{JAP}$ & 0.801 & 0.629 & 0.641 & 0.735 & 0.785 & 0.148 & 0.542 & 0.597 \\
\hline JAM & 0.923 & 0.004 & 0.607 & 0.015 & 0.230 & 0.364 & 0.001 & 0.001 \\
\hline $\mathrm{CV} \times \mathrm{JAM}$ & 0.202 & 0.017 & 0.036 & 0.004 & 0.001 & 0.001 & 0.011 & 0.327 \\
\hline JAP $\times$ JAM & 0.405 & 0.096 & 0.303 & 0.242 & 0.246 & 0.215 & 0.276 & 0.926 \\
\hline $\mathrm{Li}$ & 0.001 & 0.001 & 0.001 & 0.001 & 0.001 & 0.001 & 0.001 & 0.001 \\
\hline $\mathrm{CV} \times \mathrm{Li}$ & 0.001 & 0.007 & 0.001 & 0.008 & 0.006 & 0.001 & 0.001 & 0.001 \\
\hline JAP $\times L i$ & 0.003 & 0.845 & 0.948 & 0.017 & 0.039 & 0.237 & 0.044 & 0.004 \\
\hline $\mathrm{JAM} \times \mathrm{Li}$ & 0.778 & 0.098 & 0.444 & 0.708 & 0.745 & 0.001 & 0.001 & 0.001 \\
\hline $\mathbf{M}$ & 0.574 & 0.064 & 0.001 & 0.001 & 0.001 & 0.001 & 0.001 & 0.001 \\
\hline $\mathrm{CV} \times \mathrm{M}$ & 0.132 & 0.001 & 0.001 & 0.001 & 0.001 & 0.001 & 0.001 & 0.011 \\
\hline JAP $\times \mathbf{M}$ & 0.001 & 0.007 & 0.003 & 0.001 & 0.001 & 0.001 & 0.005 & 0.330 \\
\hline $\mathrm{JAM} \times \mathrm{M}$ & 0.670 & 0.053 & 0.004 & 0.015 & 0.370 & 0.287 & 0.051 & 0.097 \\
\hline LixM & 0.447 & 0.001 & 0.001 & 0.001 & 0.001 & 0.001 & 0.001 & 0.001 \\
\hline
\end{tabular}


Table 1 summarizes all the analysis of variance results, indicating the statistical design, the significance or non-significance (in terms of $P$-values) of the main as well as the interaction effects on weeks $2,3,4,5,7$, and 10 or 11 for tuber numbers and at harvest (week 10) for tuber weight. All tested factors, cultivar, jasmonic acid, photoperiod and type of medium used during in vitro tuberization had significant main and/or interaction effects on tuberization responses in both experiments (Table 1). The repeated measures analysis results (in terms of Wilks' $\lambda P$-values) were consistent over the growing period. Due to the large amount of space the table would have taken (for up to five-factor interaction), the results for Experiment 2 are shown for the main and two-factor interaction effects only (Table 1). All in all, the three-, four- and fivefactor interaction effects were similar to those in Experiment 1. Tables 2 and 3 present least square means of all treatment combinations, along with their letter groupings to reveal the best treatments for the number and weight (at harvest) of microtubers in Experiments 1 and 2, respectively. Table 4 shows a summary of the best treatment combinations for the number of microtubers produced per vessel at various weeks and their weights at harvest.

In Experiment 1, the number of microtubers per jar (15 nodal explants) at week 2 and 3 , and their weights at harvest (after 10 weeks in culture) had significant four- (Cultivar $\times \mathrm{JA}$ pre-treatment $\times$ Light $\times$ Medium; $\mathrm{CV} \times \mathrm{JAP} \times \mathrm{Li} \times \mathrm{M}$ ) and three-factor $(\mathrm{CV} \times \mathrm{JAP} \times \mathrm{M})$ interactions (Table 1). Following the completion of in vitro tuberization period (10 weeks), the highest number of microtubers per jar was produced from $\mathrm{cv}$. Sangre (SA) on media solidified with agar (solid), under $8 \mathrm{~h}$ photoperiod (Table 2 and Table 4, Experiment 1). Sangre produced significantly more tubers under $8 \mathrm{~h}$ light (24.7 per jar, or 1.65 per nodal explant) than Russet Burbank (RB) (17.7 per jar, or 1.18 per explant), although Sangre microtubers were smaller than Russet Burbank (150 vs $300 \mathrm{mg}$, respectively). The number of microtubers under $16 \mathrm{~h}$ photoperiod was significantly lower (6.0 - 9.7 for RB and 4.5 - 11.4 for SA) than under $8 \mathrm{~h}(8.6-17.7$ for RB and 10.6 - 24.7 for SA) (Tables 2 and 4, Experiment 1; Figure 3). Although the average weight of Russet Burbank microtubers was the highest in $8 \mathrm{~h}$ light, on solid media and from cuttings pre-treated with JA the difference was not significant (Tables 2 and 4, Experiment 1). The JA pre-treatment did not have a significant effect on the number of microtubers produced per nodal cutting in each cultivar under $8 \mathrm{~h}$ photoperiod on solid media (Table 2). On liquid media more microtubers were produced from plantlets pre-treated with JA. In darkness, the significant benefits of JA pretreatments were in Sangre on liquid medium (259.9 vs $177.5 \mathrm{mg}$ for pre-treated and non-pre-treated, respectively) (Table 2). In Russet Burbank JA pre-treatment only significantly enhanced the number of microtubers per jar on liquid medium (15.2 vs 11.8 for pre-treated and non-pre-treated, respectively). However, the average weight of 
Table 2. Least square means for the effect of media, JA pre-treatment (JAP) and photoperiod on the average number and fresh weight of microtubers per jar at the time of harvest (week 10 ) in Russet Burbank (RB) and Sangre (SA) - Experiment 1.

\begin{tabular}{|c|c|c|c|c|c|c|c|c|}
\hline \multirow{2}{*}{$\begin{array}{l}\text { Factor } \\
\text { Cultivar }\end{array}$} & \multirow[b]{2}{*}{ JAP } & \multirow[b]{2}{*}{ Medium } & \multicolumn{3}{|c|}{$\begin{array}{c}\text { Average number of } \\
\text { microtubers (week 10) }\end{array}$} & \multicolumn{3}{|c|}{$\begin{array}{c}\text { Average weight of } \\
\text { microtubers (week 10) [mg] }\end{array}$} \\
\hline & & & $\begin{array}{l}\text { Light } \\
0 \text { hrs }\end{array}$ & $\begin{array}{l}\text { Light } \\
8 \mathrm{hrs} \\
\end{array}$ & $\begin{array}{l}\text { Light } \\
16 \mathrm{hrs}\end{array}$ & $\begin{array}{l}\text { Light } \\
0 \text { hrs }\end{array}$ & $\begin{array}{l}\text { Light } \\
8 \text { hrs }\end{array}$ & $\begin{array}{l}\text { Light } \\
16 \text { hrs }\end{array}$ \\
\hline RB & Yes & Liquid & $15.2 \mathrm{a}^{*}$ & $13.7 \mathrm{c}$ & $9.7 \mathrm{a}$ & $117.3 \mathrm{c}$ & $284.8 \mathrm{ab}$ & $182.4 \mathrm{c}$ \\
\hline RB & Yes & Solid & $11.5 b$ & $16.3 b$ & $6.1 b$ & $85.3 d$ & $312.8 \mathrm{a}$ & $309.7 \mathrm{a}$ \\
\hline RB & No & Liquid & $11.8 \mathrm{~b}$ & $8.6 \mathrm{~d}$ & $6.0 \mathrm{~b}$ & $168.7 \mathrm{~b}$ & $280.7 \mathrm{ab}$ & $239.1 \mathrm{ab}$ \\
\hline RB & No & Solid & $17.8 \mathrm{a}$ & $17.7 \mathrm{~b}$ & $6.6 \mathrm{~b}$ & $70.8 d$ & $300.7 \mathrm{ab}$ & $196.1 \mathrm{c}$ \\
\hline SA & Yes & Liquid & $9.7 \mathrm{~b}$ & $10.6 \mathrm{~cd}$ & $4.5 b$ & $259.9 \mathrm{a}$ & $253.7 \mathrm{~b}$ & $240.8 \mathrm{ab}$ \\
\hline SA & Yes & Solid & $16.7 \mathrm{a}$ & $24.7 \mathrm{a}$ & $11.4 \mathrm{a}$ & $90.2 d$ & $149.1 d$ & $286.6 \mathrm{a}$ \\
\hline SA & No & Liquid & $11.7 \mathrm{~b}$ & $13.5 \mathrm{c}$ & $6.1 \mathrm{~b}$ & $177.5 b$ & $191.6 \mathrm{c}$ & $213.4 b c$ \\
\hline SA & No & Solid & $16.7 \mathrm{a}$ & $22.0 \mathrm{a}$ & $10.0 \mathrm{a}$ & $138.8 \mathrm{c}$ & $132.8 \mathrm{~d}$ & $278.2 \mathrm{a}$ \\
\hline
\end{tabular}

${ }^{*}$ Means within a column not followed by the same letter are significantly different at $5 \%$ level.

Table 3. Least square means for the effect of media, JA pre-treatment (JAP), JA in medium (JAM) and photoperiod on the average number and fresh weight of microtubers per jar at the time of harvest (week 11) in Russet Burbank (RB) and Sangre (SA) - Experiment 2.

\begin{tabular}{lllllccccc}
\hline & & & & \multicolumn{3}{c}{ Average number of } & \multicolumn{3}{c}{ Average weight of } \\
Factors & & & \multicolumn{3}{c}{ microtubers (wk 11) } & microtubers (wk 11) [mg] \\
\hline Culti & JAP & JAM & Media & Light & Light & Light & Light & Light & Light \\
var & & & & 0 hrs & $8 \mathrm{hrs}$ & $16 \mathrm{hrs}$ & $0 \mathrm{hrs}$ & $8 \mathrm{hrs}$ & $16 \mathrm{hrs}$ \\
\hline RB & Yes & Yes & Liquid & $13.1 \mathrm{bc}$ & $12.6 \mathrm{~d}$ & $8.3 \mathrm{ab}$ & $157.3 \mathrm{bc}$ & $234.9 \mathrm{bc}$ & $201.0 \mathrm{ab}$ \\
RB & Yes & Yes & Solid & $13.9 \mathrm{~b}$ & $17.4 \mathrm{~b}$ & $10.3 \mathrm{a}$ & $42.2 \mathrm{~g}$ & $245.5 \mathrm{~b}$ & $196.4 \mathrm{ab}$ \\
RB & Yes & No & Liquid & $9.9 \mathrm{de}$ & $8.0 \mathrm{f}$ & $6.7 \mathrm{~b}$ & $151.9 \mathrm{~cd}$ & $330.3 \mathrm{a}$ & $236.4 \mathrm{a}$ \\
RB & Yes & No & Solid & $7.7 \mathrm{de}$ & $19.3 \mathrm{ab}$ & $6.0 \mathrm{~b}$ & $54.0 \mathrm{f}$ & $134.3 \mathrm{e}$ & $108.5 \mathrm{c}$ \\
RB & No & Yes & Liquid & $11.7 \mathrm{bc}$ & $11.3 \mathrm{de}$ & $5.6 \mathrm{bc}$ & $120.1 \mathrm{~d}$ & $223.9 \mathrm{bc}$ & $264.2 \mathrm{a}$ \\
RB & No & Yes & Solid & $9.3 \mathrm{de}$ & $18.0 \mathrm{bc}$ & $6.7 \mathrm{~b}$ & $35.5 \mathrm{~g}$ & $256.2 \mathrm{ab}$ & $176.5 \mathrm{~b}$ \\
RB & No & No & Liquid & $8.5 \mathrm{de}$ & $11.3 \mathrm{de}$ & $8.0 \mathrm{ab}$ & $133.8 \mathrm{~cd}$ & $248.9 \mathrm{~b}$ & $234.4 \mathrm{a}$ \\
RB & No & No & Solid & $5.8 \mathrm{ef}$ & $21.8 \mathrm{a}$ & $4.2 \mathrm{c}$ & $48.9 \mathrm{fg}$ & $114.4 \mathrm{e}$ & $80.1 \mathrm{~d}$ \\
SA & Yes & Yes & Liquid & $3.4 \mathrm{f}$ & $8.6 \mathrm{f}$ & $3.5 \mathrm{c}$ & $340.9 \mathrm{a}$ & $193.6 \mathrm{~cd}$ & $164.4 \mathrm{~b}$ \\
SA & Yes & Yes & Solid & $17.4 \mathrm{a}$ & $16.3 \mathrm{c}$ & $8.4 \mathrm{ab}$ & $80.2 \mathrm{e}$ & $134.3 \mathrm{e}$ & $261.1 \mathrm{a}$ \\
SA & Yes & No & Liquid & $6.6 \mathrm{e}$ & $7.6 \mathrm{f}$ & $3.3 \mathrm{c}$ & $198.1 \mathrm{~b}$ & $212.4 \mathrm{bc}$ & $166.4 \mathrm{~b}$ \\
SA & Yes & No & Solid & $19.6 \mathrm{a}$ & $20.3 \mathrm{ab}$ & $8.9 \mathrm{ab}$ & $81.1 \mathrm{e}$ & $145.4 \mathrm{de}$ & $181.5 \mathrm{~b}$ \\
SA & No & Yes & Liquid & $10.7 \mathrm{~cd}$ & $7.0 \mathrm{f}$ & $2.7 \mathrm{c}$ & $201.7 \mathrm{~b}$ & $188.6 \mathrm{~cd}$ & $271.9 \mathrm{a}$ \\
SA & No & Yes & Solid & $12.5 \mathrm{~b}$ & $9.3 \mathrm{ef}$ & $5.6 \mathrm{bc}$ & $35.1 \mathrm{~g}$ & $84.6 \mathrm{f}$ & $255.5 \mathrm{a}$ \\
SA & No & No & Liquid & $7.3 \mathrm{e}$ & $6.1 \mathrm{f}$ & $6.5 \mathrm{~b}$ & $215.7 \mathrm{~b}$ & $134.4 \mathrm{e}$ & $164.6 \mathrm{~b}$ \\
SA & No & No & Solid & $8.3 \mathrm{~d}$ & $19.9 \mathrm{ab}$ & $4.1 \mathrm{c}$ & $71.5 \mathrm{ef}$ & $142.9 \mathrm{~d}$ & $189.7 \mathrm{ab}$ \\
\hline
\end{tabular}

"Means within a column not followed by the same letter are significantly different at $5 \%$ level. 


\section{Chapter 5}

microtuber in this treatment was reduced (Table 2).

Weekly tuberization responses in Experiment 1 indicate that microtubers were initiated first in Sangre in the second week on JA pre-treated nodal explants, on solid medium in the dark treatment (Table 4). Initiation of microtubers in Russet Burbank also started from microtubers pre-treated with JA in darkness, at week 3 but on liquid medium. At week 3, in Sangre the highest number of microtubers was recorded on both, liquid or solid media, in darkness, independently of JA pre-treatment. As of week 4 , the best production of mictotubers (number per vessel) was under $8 \mathrm{~h}$ photoperiod, on solid media independently of JA pre-treatment (Table 4, Experiment 1). At harvest (week 10), Sangre produced the highest number of microtubers per vessel ( 23.4 or 1.6 per explant) on solid medium, under $8 \mathrm{~h}$ photoperiod from either,

Table 4. The summary of the best treatment combinations for the number of microtubers produced per jar at various weeks in two potato cultivars, Russet Burbank (RB) and Sangre (SA). The best treatment combinations for fresh weight of microtubers at harvest are shown in the last column.

\section{Experiment 1}

\begin{tabular}{|c|c|c|c|c|c|c|c|}
\hline \multirow[t]{2}{*}{ Factor } & \multicolumn{6}{|c|}{ Average number of microtubers per jar } & \multirow{2}{*}{$\begin{array}{l}\text { Average fresh } \\
\text { weight of } \\
\text { microtubers } \\
\text { (wk 10) [mg] }\end{array}$} \\
\hline & Wk 2 & Wk 3 & Wk 4 & Wk 5 & Wk 7 & Wk 10 & \\
\hline Cultivar & SA & RB $\mathbf{S A}$ & RB & RB & RB $S A$ & SA & RB \\
\hline JAP & Yes & Yes either & No & Either & either & either & Yes \\
\hline Light & 0 & 0 & 8 & 8 & 8 & 8 & 8 \\
\hline Medium & Solid & Liq either & Solid & Solid & Solid & Solid & Solid \\
\hline Best Average & 2.5 & $4.7 \quad 5.7$ & 10.4 & 14.7 & 16.017 .2 & 23.4 & 312.8 \\
\hline \multicolumn{8}{|l|}{ Experiment 2} \\
\hline & Wk 2 & Wk 4 & Wk 6 & Wk 7 & Wk 8 & Wk 11 & $\begin{array}{c}\text { Weight } \\
\text { (wk 11) [mg] }\end{array}$ \\
\hline Cultivar & $\mathrm{SA}$ & RB & RB & $\mathrm{RB} \quad \boldsymbol{S A}$ & SA & $\mathrm{RB} \quad S A$ & $\mathrm{RB} \quad \boldsymbol{S A}$ \\
\hline JAP & Yes & Yes & Either & Yes & Either & No Yes/No & Yes \\
\hline JAM & No & Yes & Yes & Yes $N o$ & No & No & No \\
\hline Light & 0 & 0 & 8 & 8 & 8 & 8 & 80 \\
\hline Medium & Solid & Liquid & Solid & Solid & Solid & Solid & Liquid \\
\hline Best Average & 5.7 & 10.9 & 11.7 & 14.314 .6 & 16.8 & $21.8 \quad 20.1$ & $330.3 \quad 340.9$ \\
\hline
\end{tabular}

Values for cv. Sangre (SA) shown in italics, are the best averages not significantly different from those of Russet Burbank (RB).

The value of 20.1 for $\mathrm{cv}$. Sangre in week 11 is an average of two values from Table 3: 20.3 (yes/no JA, solid medium) and 19.9 (no/no JA, solid medium). 

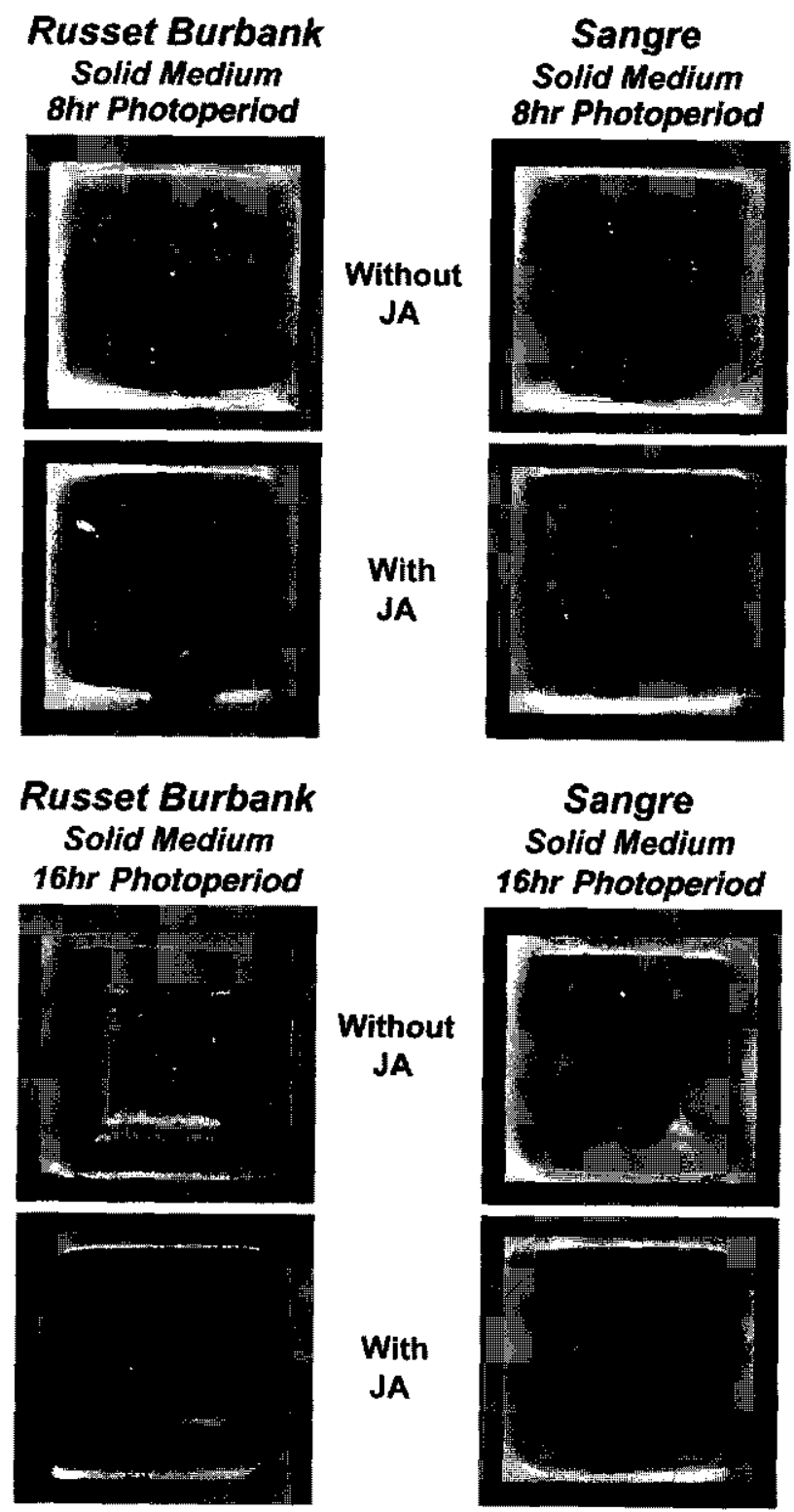

Figure 3. The effect of JA on production of microtubers in two potato cultivars, Russet Burbank and Sangre. Treatments: (1) with JA - from plantlets pre-treated with $2.5 \mu \mathrm{M} J A$ for 4 weeks; (2) without JA - control, not treated. Tuberization was carried out on media solidified with agar under 8 and $16 \mathrm{~h}$ photoperiods. Each photograph represents harvest from one Magenta vessel. 
JA-pretreated and non-treated microcuttings. On the average, Russet Burbank produced the largest microtubers $(312.8 \mathrm{mg}$ ) from JA pre-treated explants on solid medium under $8 \mathrm{~h}$ photoperiod (Tables 2 and 4, Experiment 1; Figure 3).

A detailed comparison of the treatment combinations from the 5-factor interaction (Cultivar $\times \mathrm{JA}$ pre-treatment $\times \mathrm{JA}$ in tuberization medium $\times$ Light $\times$ Medium type) on the number and weight of microtubers per jar at harvest of Experiment 2 is shown in Table 3. Similar to the Experiment 1, photoperiod had the most profound effect. In both cultivars, the average number of microtubers were the highest in the $8 \mathrm{~h}$ light treatments; on media solidified with agar in particular. Russet Burbank averaged 21.8 microtubers per jar (1.45 per explant from no/no JA treatment) and Sangre 20.3 (1.35 per explant from yes/no JA treatment) (Table 3). Microtubers derived either from the explants taken from stock plants grown on JA supplemented medium, or from a JA containing tuberization medium, had higher average weights than from other treatments (independently of cultivar or light regime). The benefits of jasmonate were the most pronounced on liquid media in Sangre, although jasmonic acid pre-treatment did not have a significant effect on the number of microtubers produced per explant in this treatment (Tables 3 and 4, Experiment 2). Compared to the individual JA treatments, plantlets from the double JA treatment (JAPret + JAMed) in $8 \mathrm{~h}$ light generally produced fewer microtubers in both varieties (Tables 3 and 4, Experiment 2).

As in Experiment 1, in Experiment 2, the first microtubers were initiated in Sangre (by the end of the second week) on explants derived from JA pre-treated stock plants, on solid tuberization media without JA supplement, in darkness (Table 4, Experiment 2). Microtuber initiation in Russet Burbank also first started from microcuttings pretreated with JA in darkness (at week 4), but on liquid media containing JA. Many stolon-like shoots were formed in Russet Burbank during the first three weeks of tuberization. By week 7 , there were no significant differences between cultivars regarding the number of microtubers per vessel (approximately 14.5) (Table 4, Experiment 2). Both, the JA pre-treatment of microcuttings and/or the presence of JA in tuberization media were beneficial to Russet Burbank. In Sangre, only the JA pretreatment of the stock plants enhanced the production of microtubers; JA supplement in tuberization media had no significant effect on the number of microtubers. By the end of the tuberization period ( 11 weeks), there were no significant differences between cultivars with regards to the number and weight of microtubers produced per vessel (Table 4, Experiment 2).

\subsection{Discussion}

Jasmonate pre-treatment of stock plants prior to taking nodal explants for tuberization, 
was an effective inducer of microtuber formation in both cultivars, Russet Burbank and Sangre. Sangre was more responsive, forming microtubers 1 - 2 weeks earlier than Russet Burbank. This JA responsiveness was particularly evident in Experiment 2, where JA supplement to the tuberization media benefited Russet Burbank explants, taken from the JA medium grown stock plants, but not Sangre. The JA induction of tuberization and tuber bulking was the most pronounced under the tuberization inhibiting $16 \mathrm{~h}$ photoperiod (Figure 3). It is possible that JA acted as gibberellins antagonist under these conditions (Jackson, 1999). The benefits of JA pre-treatment were less pronounced under short day $(8 \mathrm{~h})$ or darkness conditions. Stimulatory effects of JAs on in vitro tuberization and on potato stem node cultures have been also reported by Koda et al. (1991), Ravnikar et al. (1992) and others (Pruski et al., 1993; Kreft et al., 1997; Jackson, 1999). JAs are involved in control of leaf senescence in potato, which is closely associated with tuber induction (Van den Berg \& Ewing, 1991). According to the classical hypothesis of Gregory (1956) a substance(s) synthesized in potato leaves under short days is transported to the stolons and triggers tuber formation (Struik et al., 1987). These substance(s), later identified as jasmonates, have been investigated in tuberization research for several years. For example, Pelacho \& Mingo-Castel (1991), and Koda et al. (1991) reported JA induction of tuberization in potato stolons cultured in vitro. The JA pre-treatment of nodal cuttings used in our experiments may have a practical significance in triggering tuberization responses in commercial microtuber production systems. The JA concentration used as medium supplement $(2.5 \mu \mathrm{M})$ for growing stock plants as explant donors for tuberization, did not have a detrimental effect on plantlets growth, although it induced some symptoms of senescence after a 5 to 6-week-long exposure (i.e., a slight yellowing of leaves). A possible retention of JA in stems and/or leaves may have served as a trigger for the initiation of microtubers, once the nodal explants were placed on tuberization media.

Similar to Dobránszki \& Mandi (1993), and Ranalli (1997), we have observed beneficial effects of short days on the induction of in vitro tuberization, tuber uniformity and size. The first tubers were induced in darkness, on explants from JA conditioned stock plants, although tuber bulking rates were lower in the darkness than under the short photoperiod. Tubers derived from the short photoperiod treatment were green and seemed to be less juvenile than the tubers from dark treatments. Gopal et al. (1997) observed that such microtubers perform better in the field or greenhouse conditions than microtubers produced in darkness. Our studies indicate, that JA supplement in the tuberization media may elevate microtuber juvenility (K. Pruski $e t$ al., manuscript in preparation). 


\section{Chapter 5}

\section{References}

Coleman, W.K. \& S.E. Coleman, 2000. Modification of potato microtuber dormancy during induction and growth in vitro and ex vitro. American Journal of Potato Research 77: $103-$ 110.

Coltman, R. \& C. Kostichka, 1993. Performance of minitubers produced from microshoots vs microtubers. American Potato Journal 70: 803-804 (abstract).

Crowde, R.M.J. \& D.J. Hand, 1990. Analysis of Repeated Measures. Chapman and Hall, New York.

Dobránszki, J. \& M. Mandi, 1993. Induction of in vitro tuberization by short day period and dark treatment of potato shoots grown on hormone-free medium. Acta Biologica Hungarica 44: 411-420.

Estrada, R., P. Tovar, \& J.H. Dodds, 1986. Induction of in vitro tubers in a broad range of potato genotypes. Plant Cell, Tissue and Organ Culture 7: 3-10.

Gopal, J., J.L. Minocha \& J.S. Sidhu, 1997. Comparative performance of potato crops raised from microtubers induced in the dark versus microtubers induced in light. Potato Research 40: 407-412.

Gregory, L.E., 1956. Some factors for tuberization in the potato plant. American Journal of Botany 43: 281-288.

Hussey, G. \& N.J. Stacey, 1981. In vitro propagation of potato (Solanum tuberosum L.). Annals of Botany 48: 787-796.

Hussey, G. \& N.J. Stacey, 1984. Factors affecting the formation of in vitro tubers of potato (Solanum tuberosum L.). Annals Botany 53: 565-578.

Jackson, S.D., 1999. Multiple signalling pathways control tuber induction in potato. Plant Physiology 119: 1-8.

Koda, Y., Y. Kikuta, H. Tazaki, Y. Tsuhino, S. Sakamura, \& T. Yoshihara, 1991. Potato tuber-inducing activities of jasmonic acid and related compounds. Phytochemistry 30 : 1435-1438.

Koda, Y., 1997. Possible involvement of jasmonates in various morphogenic events. Physiologia Plantarum 98: 407-412.

Kreft, S., M. Ravinkar, P. Mesko, J. Pungercar, A. Umek, I. Kregar \& B. Strukelj, 1997. Jasmonic acid inducible aspartic proteinase inhibitors from potato. Phytochemistry 44: 1001-1006.

Leclerc, Y., D.J. Donnelly, W.K. Coleman \& R.R. King, 1995. Microtuber dormancy in three potato cultivars. American Potato Journal 72: 215-223.

Lê, C.L., 1999. In vitro microtuberization: An evaluation of culture conditions for the production of virus-free potatoes. Potato Research 42: 489-498.

Lillo, C., 1989. A simple two-phase system for efficient in vitro tuberization in potato. Norwegian Journal of Agricultural Science 3: 23-27. 
Lommen, W.J.M., 1995. Basic studies on the production and performance of potato minitubers. PhD thesis, Wageningen Agricultural University, The Netherlands, $181 \mathrm{pp}$.

Murashige, T. \& F. Skoog, 1962. A revised medium for rapid growth and bioassays with tobacco tissue cultures. Physiologia Plantarum 15: 473-497.

Pelacho, A.M. \& A.M. Mingo-Castel, 1991. Jasmonic acid induces tuberization of potato stolons cultured in vitro. Plant Physiology 97: 1253-1255.

Pruski, K., J. Nowak \& T. Lewis, 1993. Jasmonates and photoperiod effect on microtuber production in two potato cultivars. In Vitro Cellular and Developmental Biology - Plant 29: 69 (abstract).

Ravnikar, M., B. Vilhar \& N. Gogala, 1992. Stimulatory effects of jasmonic acid on potato node and protoplast culture. Journal of Plant Growth Regulation 11: 29-33.

Ranalli, P., 1997. Innovative propagation methods in seed tuber multiplication programmes. Potato Research 40: 439-453.

SAS Institute Inc., 1996. SAS/STAT Software: Changes and Enhancements through Release 6.11. SAS Institute Inc., Cary NC.

Struik, P.C., E.J. Boon \& D. Vreugdenhil, 1987. Effects of extracellular extracts from leaves on the tuberization of cuttings of potato (Solanum tuberosum L.). Plant Physiology 84: 214-217.

Struik, P.C. \& W.J.M. Lommen, 1990. Production, storage and use of micro- and minitubers. Proceedings of the $11^{\text {th }}$ Triennial Conference of the European Association for Potato Research (EAPR), Edinburgh, UK, pp. 122-133.

Struik, P.C. \& S.G. Wiersema, 1999. Seed Potato Technology. Wageningen Pers; The Netherlands, 383 pp.

Tábori, K.M., J. Dobránszki \& A. Ferenczy, 1999. Some sprouting characteristics of microtubers. Potato Research 42: 611-617.

Teisson, C. \& D. Alvard, 1999. In vitro production of microtubers in liquid medium using temporary immersion. Potato Research 42: 499-504.

Van den Berg, J.H. \& E.E. Ewing, 1991. Jasmonates and their role in plant growth and development with special reference to the control of potato tuberization: A review. American Potato Journal 68: 781-794.

Xu, X., D. Vreugdenhil \& A.A.M. van Lammeren, 1998. Cell division and cell enlargement during potato tuber formation: a comparison of in vitro and in vivo tuber development. Journal of Experimental Botany 49: 573-582. 


\section{Chapter 6}

Jasmonate effects on in vitro tuberization of potato (Solanum tuberosum $\mathbf{L}$.) varieties under light and dark conditions*

* Pruski, K., P. Duplessis, T. Astatkie, J. Nowak \& P.C. Struik, 2001. Jasmonate effects on in vitro tuberization of potato (Solanum tuberosum L.) varieties under light and dark conditions. Potato Research (accepted). 


\title{
6. Jasmonate effects on in vitro tuberization of potato (Solanum tuberosum $\mathbf{L}$.) varieties under light and dark conditions
}

\begin{abstract}
Effects of jasmonic acid (JA) on in vitro tuberization of six potato varieties, Amisk, Atlantic, Russet Burbank, Sangre, Shepody and Umatilla Russet, were examined in two independent experiments, under light $(8 \mathrm{~h})$ and dark conditions. Stock plantlets were multiplied via single node cuttings, on a hormone-free MS medium with vitamins and $3 \%$ sucrose, solidified with $0.6 \%$ agar, under $150 \mu \mathrm{mol} \mathrm{m} \mathrm{m}^{-2}, 16 \mathrm{~h}$ photoperiod, at $20^{\circ} \mathrm{C}+1-1^{\circ} \mathrm{C}$. In the last multiplication stage, half of the stock cultures were JA-pre-conditioned on the MS medium supplemented with $2.5 \mu \mathrm{M} \mathrm{JA}$ (JAPret). After the last multiplication, nodal explants were placed on tuberization media consisting of MS salts, vitamins, $8 \%$ sucrose and either $2.5 \mu \mathrm{M}$ JA (JAMed) or no JA, solidified with $0.6 \%$ agar. Cultures were incubated at $20^{\circ} \mathrm{C}$ under dark, or $8 \mathrm{~h}$ photoperiod, $50 \mu \mathrm{mol} \mathrm{m} \mathrm{s}^{-1}$, for 10 weeks. Amisk, Russet Burbank, Sangre and Umatilla Russet produced the highest number of microtubers per nodal cutting (1.0 - 1.7) and their tubers were also the largest with the highest percentage of microtubers $>0.1 \mathrm{~g}$ (70$85 \%$ ). Results with Shepody were inconsistent and Atlantic produced the lowest number of tubers per nodal cutting. Independently of the variety, less microtubers per explant with significantly lower average weight, were produced in dark treatments than under $8 \mathrm{~h}$ photoperiod. The effects of JA were variety specific, although the benefits were more pronounced in the dark than in the light treatments. The tested varieties could be divided into three groups. Amisk, Atlantic and Umatila Russet (group I) benefited from JA supplement to the tuberization medium, but not as the pre-conditioning treatment. In the dark, total tuber weight, and percentage and weight of microtubers $>0.1 \mathrm{~g}$ were significantly higher than in control or other JA treatments. None of these three varieties clearly benefited from any JA treatments under light. Russet Burbank (group II) and Sangre also benefited from the JA supplement in the dark, although stock plantlet conditioning was more effective than the JA supplement to the tuberization medium. Shepody (group III) did not show any benefits of JA on microtuberization, neither under dark or light conditions. Compared to the control and the individual JA treatments, the double treatment with JA (JAPret and JAMed) in light, significantly reduced production of microtubers in both Shepody and Russet Burbank, opposite to the group I varieties.
\end{abstract}

Key words: in vitro tuberization, jasmonic acid, photoperiod, potato microtubers

\subsection{Introduction}

More and more attention has been recently focused on a potential for a broader utilization of microtubers (in vitro produced small tubers) in certified seed potato production systems (Ranalli, 1997; Jimenez et al., 1999; Struik \& Wiersema, 1999; Yu 


\section{Chapter 6}

et al., 2000). The common constraints, poor tuber uniformity, small size, and low progeny yield, restricting the use of microtubers as propagules of choice (Estrada $e t$ al., 1986; Struik \& Lommen, 1990), are being to an extent overcome by manipulation of the tuberization conditions (Nowak \& Asiedu, 1992; Struik \& Wiersema, 1999) and the introduction of a bioreactor technology (Jimenez et al., 1999; Teisson \& Alvard, 1999; Yu et al., 2000). Microtubers can easily be produced in vitro and could be used in greenhouse production of minitubers (nuclear seed) at the start of seed programmes (Lommen, 1995). Microtubers have two important advantages over the plantlets: they are easy to store and easy to transport. Moreover, microtubers do not all have to be produced just before use (unlike plantlets), making it possible to evenly organize the laboratory production over time (Struik \& Wiersema, 1999). Throughout the year, an uneven distribution of work is a major problem in tissue culture laboratories producing plantlets for greenhouse plantings (Jensen, 1996).

In a recent study (Pruski et al., 2001), we have explored the potential for the use of jasmonic acid (JA) in the development of a simple and efficient protocol for commercial production of microtubers. Jasmonates, a group of growth regulators produced by plants exposed to stress and under senescence (Koda, 1997; Biondi, et al., 2000), are also highly effective inducers of tuberization (Van den Berg \& Ewing, 1991; Pelacho \& Mingo-Castel, 1991; Ravinkar et al., 1992). We have found, that JA conditioning of stock plants destined for taking explants for in vitro tuberization, or its addition to the tuberization medium, enhanced tuber size and uniformity (Pruski et al., 2001). The degree of the benefits of this treatment depended on light and media conditions. In the study outlined below, we have tested the effect of JA supplement in large scale tuberization experiments, conducted with six potato varieties, in the dark and under $8 \mathrm{~h}$ photoperiod.

\subsection{Materials and methods}

\section{In vitro culture}

Tissue cultured plantlets of six commercial potato varieties: Amisk (Ranger Russet), Russet Burbank, Umatilla Russet, Atlantic, Shepody and Sangre, derived from the potato germplasm bank at Crop Diversification Centre North, Edmonton, Alberta, Canada, were used as a source of virus-free material. Russet Burbank and Sangre were used in Experiment 1. Atlantic, Shepody, Russet Burbank, Amisk (Ranger Russet) and Umatilla Russet were used in Experiment 2. The plantlets were multiplied as singlenode explants. Stem cuttings with one leaf node were taken from six-week old in vitro plantlets and cultured on $50 \mathrm{ml}$ hormone-free medium, MS salts and vitamins 
(Murashige \& Skoog, 1962) (Sigma-Aldrich Canada Ltd., Oakville, Ont., Canada) in GA7 Magenta vessels (Magenta Corp., Chicago, IL, USA). Sucrose (3\%, w/v) was used as a carbon source and the media were solidified with $0.6 \%$ (w/v) agar (Difco, Detroit, MI, USA). All media were adjusted to $\mathrm{pH} 5.7$ before autoclaving. Sixteen (4×4) single-node explants were placed in each vessel. Cultures were incubated for 4 weeks in an environmental chamber (Conviron, Model TCR 144, Winnipeg, Manitoba, Canada) at $20^{\circ} \mathrm{C}+/-1^{\circ} \mathrm{C}$ temperature with $16 \mathrm{~h}$ photoperiod at $150 \mu \mathrm{mol} \mathrm{m} \mathrm{m}^{-2} \mathrm{~s}^{-1}$ mixed fluorescent (F40T12 tubes, General Electric (GE), USA) and incandescent illumination ( $40 \mathrm{~W}, \mathrm{GE}, \mathrm{USA}$ ). At the end of the 4 week period, the plantlets were cut into single-node explants and placed on fresh MS medium in GA7 Magenta jars for further multiplication. The process was repeated until the required number of plantlets for in vitro tuberization experiments was achieved. During the last transfer before in vitro tuberization experiments, single-node explants of all varieties were divided into two groups and transferred onto agar media. The two groups were: 1) the same MS medium as above (continuation of multiplication stage) and 2) the same MS medium as above supplemented with $2.5 \mu \mathrm{M}$ of jasmonic acid (JA) (Apex Organics Ltd., Leicester, UK) - this group of explants was labelled as JA pre-treated (JAPret). Both groups were incubated for 4 weeks under environmental conditions described above.

\section{In vitro tuberization}

Nodal cuttings from each group of plantlets produced during the multiplication stage were placed onto two types of tuberization media: 1) the same MS medium as in multiplication stage supplemented with $8 \%(w / v)$ sucrose and 2) the same MS medium as above supplemented with $2.5 \mu \mathrm{M}$ of JA and $8 \%(w / v)$ sucrose - this group was labelled as JA in Media (JAMed). The media were solidified with $0.6 \%(\mathrm{w} / \mathrm{v})$ agar and the $\mathrm{pH}$ was adjusted to 5.7 before autoclaving. When taking nodal explants from the four-week old plantlets grown on media with and without JA the apical and basal nodes were discarded. Fifteen (Experiment 1) and sixteen (Experiment 2) stem cuttings with one leaf were placed in each GA7 Magenta vessel on $75 \mathrm{ml}$ tuberization medium. Cultures were incubated at $20^{\circ} \mathrm{C}$ with 0 (darkness) and $8 \mathrm{~h}$ photoperiod at 50 $\mu \mathrm{mol} \mathrm{m} \mathrm{m}^{-1}$ mixed fluorescent/incandescent light for 10 weeks. After 10 weeks microtubers were harvested, the number and weight of microtubers produced per nodal cutting was recorded. Seven GA7 Magenta vessels ( 7 replicates) with 15 explants each were used in each treatment with both varieties in Experiment 1 studies. In Experiment 2, 32 GA7 Magenta vessels (32 replicates) with 16 explants each were used in each treatment with each of five varieties. 


\section{Chapter 6}

\section{Statistical analysis}

For each of the responses (weight per microtuber, and number of microtubers produced per vessel in both experiments, and percentage of microtubers $>0.1 \mathrm{~g}$ and number of microtubers $>0.1 \mathrm{~g}$ per vessel in Experiment 2), a four-factor (variety, JA pre-treatment (JAPret), JA in tuberization medium (JAMed), light treatment (Li)) factorial design was used. For each response, validity of the model assumptions (normal distribution and constant variance assumptions on the experimental error terms) was confirmed by examining the residuals as described in Montgomery (1997). For the responses with significant interactions, least square means comparisons of all treatment combinations were conducted to generate letter groupings. Since the experiments were conducted in a fully controlled environment growth rooms the $1 \%$ level of significance was chosen. Analyses were completed using SAS program (SAS Institute, 1999).

\subsection{Results}

All tested factors: variety, jasmonic acid presence in pre-treatment medium (JAPret), jasmonic acid presence in tuberization medium (JAMed) and light treatment exposure to light during tuberization $(\mathrm{Li})$ or dark, significantly affected the number of microtubers produced per vessel, their size and weight. Since the four-factor, Variety $\times \mathrm{JAPret} \times \mathrm{JAMed} \times \mathrm{Li}$ interaction, was significant in both experiments, only the means and means comparisons for the four-factor interactions are presented in Tables 1 and 2.

\section{Experiment 1}

Table 1 summarizes the results with Russet Burbank and Sangre. Both varieties responded similarly to applied light treatments. A short photoperiod treatment benefited the production of microtubers. Following the 10 week in vitro tuberization, both varieties produced significantly more microtubers per jar (a 2 to 3-fold increase) under $8 \mathrm{~h}$ photoperiod than in dark, when no JA was applied (Table 1). The difference was more pronounced in Russet Burbank than in Sangre. The average weight of Russet Burbank microtubers was also $2-3$ times higher when the tuberization was carried out under $8 \mathrm{~h}$ photoperiod than in dark. This effect was observed under all JA treatments. In the same as above treatments, Sangre produced only a 1.5 to 2 -fold increase in average weight of microtubers (Table 1).

In Russet Burbank, the highest number of microtubers per jar $(21.8=1.45$ per nodal 
Table 1. Experiment 1: Effects of photoperiod and jasmonic acid (JA) in pre-treatment (JAPret) and tuberization media (JAMed), on weight and the total number of microtubers produced per vessel of varieties Russet Burbank and Sangre. Least square means comparison of the treatment combinations of Cultivar $\times$ JAPre-treatment $\times$ JAinMedia $\times$ Light interaction.

\begin{tabular}{|c|c|c|c|c|c|}
\hline Cultivar & $\begin{array}{l}\text { JA } \\
\text { Pre-treated }\end{array}$ & $\begin{array}{l}\text { JA } \\
\text { in Media }\end{array}$ & Light & $\begin{array}{c}\text { Average weight } \\
\text { of one } \\
\text { microtuber } \\
{[\mathrm{g}]}\end{array}$ & $\begin{array}{l}\text { Total number of } \\
\text { microtubers per } \\
\text { vessel (from } 15 \\
\text { cuttings) }\end{array}$ \\
\hline \multirow[t]{8}{*}{ Russet Burbank } & No & No & 0 & 0.068 ef $^{*}$ & $5.8 \mathrm{f}$ \\
\hline & No & No & 8 & $0.278 \mathrm{a}$ & $21.8 \mathrm{a}$ \\
\hline & No & Yes & 0 & $0.072 \mathrm{ef}$ & $9.3 \mathrm{ef}$ \\
\hline & No & Yes & 8 & $0.151 \mathrm{c}$ & $18.0 \mathrm{ab}$ \\
\hline & Yes & No & 0 & $0.050 \mathrm{f}$ & $7.7 \mathrm{f}$ \\
\hline & Yes & No & 8 & $0.289 \mathrm{a}$ & $19.3 \mathrm{ab}$ \\
\hline & Yes & Yes & 0 & $0.055 \mathrm{f}$ & $13.9 \mathrm{~cd}$ \\
\hline & Yes & Yes & 8 & $0.116 \mathrm{~d}$ & $17.4 b c$ \\
\hline \multirow[t]{8}{*}{ Sangre } & No & No & 0 & $0.111 \mathrm{~d}$ & 8.3 ef \\
\hline & No & No & 8 & $0.181 \mathrm{bc}$ & $19.9 \mathrm{ab}$ \\
\hline & No & Yes & 0 & $0.106 \mathrm{~d}$ & $12.5 \mathrm{de}$ \\
\hline & No & Yes & 8 & $0.183 \mathrm{bc}$ & $9.3 \mathrm{ef}$ \\
\hline & Yes & No & 0 & $0.046 \mathrm{f}$ & $19.6 \mathrm{ab}$ \\
\hline & Yes & No & 8 & $0.102 \mathrm{de}$ & $20.3 \mathrm{ab}$ \\
\hline & Yes & Yes & 0 & $0.092 \mathrm{de}$ & $17.4 \mathrm{bc}$ \\
\hline & Yes & Yes & 8 & $0.199 \mathrm{~b}$ & $16.3 b c$ \\
\hline
\end{tabular}

* Least square means followed by the same letter are not significantly different from each other at the $1 \%$ level of significance.

cutting) was observed in treatments without JA and under $8 \mathrm{~h}$ photoperiod. Although no significant differences were observed in the number of microtubers per vessel in no JAPretreated/JA in Media (18.0 = 1.20 per cutting) and in JA Pretreated/no JA in Media (19.3 = 1.29 per cutting) treatment combinations under $8 \mathrm{~h}$ light, the numbers were slightly lower than in no JA treatments (Table 1). However, the average weight of one Russet Burbank microtuber was slightly higher (though not significantly) in JA Pretreatment/ No-JA in Media $(0.289 \mathrm{~g})$ than in No-JA treatment $(0.278 \mathrm{~g})$. Under $8 \mathrm{~h}$ photoperiod Sangre produced almost the same number of microtubers either from cuttings pre-treated with JA or without JA (20.3 vs 19.9), however, the average weight of microtubers was reduced in treatments with JA (Table 1). In both varieties, JA 


\section{Chapter 6}

significantly enhanced the production of microtubers in the dark. Both varieties showed a 2-fold increase in the number of microtubers per vessel in JA's presence. In the dark, Russet Burbank produced 5.8 microtubers per jar in no/no JA and 13.9 in yes/yes JA treatment combinations. Sangre produced similar results, 8.3 microtubers in no/no JA and 17.4 in yes/yes JA treatment combinations (Table 1). In the best treatment combinations (under $8 \mathrm{~h}$ light) the microtubers of variety Sangre were significantly smaller than those of Russet Burbank $(0.199 \mathrm{~g}$ and $0.289 \mathrm{~g}$, respectively); the total number of microtubers per jar was slightly lower in Sangre than in Russet Burbank $(20.3$ per jar $=1.35$ per nodal cutting and 21.8 per jar $=1.45$ per nodal cutting, respectively) although not significantly different (Table 1).

\section{Experiment 2}

Microtubers below $0.1 \mathrm{~g}$ are considered too small for greenhouse production of minitubers (nuclear seed tubers), thus the number and percentage of microtubers $>0.1$ g per vessel were also calculated (Table 2). Independently of the cultivar and JA treatment, light exposure gave significantly larger and more uniform tubers (Table 2). Similar to Experiment 1, the effects of JA were photoperiod and variety specific. Generally, the benefits, if any, were more pronounced in dark than under the $8 \mathrm{~h}$ photoperiod treatments. In general, the tested varieties could be divided into three groups; group I: Amisk, Atlantic and Umatilla Russet, group II: Russet Burbank, and group III: Shepody. Group I benefited from JA supplement to the tuberization medium in the dark, but not from JA as the pre-conditioning treatment. In all these three varieties, total tuber weight, and percentage and weight of microtubers over $0.1 \mathrm{~g}$ were significantly higher than in the control or other JA treatments. None of these three varieties clearly benefited from any JA treatment under light. In Atlantic, JA seemed to substitute for light treatment; the average weight of microtubers and the percentage of microtubers $>0.1 \mathrm{~g}$ were almost identical for no/no JA in light and no/yes JA in dark (Table 2). Russet Burbank also benefited from the JA supplement in the dark, although stock plantlet conditioning was more effective in the enhancement of the total tuber weight than the JA supplement to the medium. Under $8 \mathrm{~h}$ light, Russet Burbank produced $0.22 \mathrm{~g}$ microtubers either on JA tuberization media or from JA pre-treated nodal cuttings. It also produced the highest number of microtubers per jar $(25.6=1.7$ per nodal cutting) on media with JA from JA pre-treated microcuttings contrary to results in Experiment 1. Although the average weight of these tubers was significantly lower than in other treatments, it was still within an acceptable range, $0.177 \mathrm{~g}$. From all varieties tested, Russet Burbank produced the highest number of microtubers per jar $>0.1 \mathrm{~g}$ irrespective of JA treatment, however the percentage of microtubers $>0.1 \mathrm{~g}$ 
Table 2. Experiment 2: Light (Li) and jasmonic acid (JA) in stock plantlets pre-treatment (JAPret) and/or tuberization media (JAMed) effects on weight and number of microtubers produced per vessel, $\%$, and number of microtubers $>0.1 \mathrm{~g}$ per vessel. Least square means comparison of the treatment combinations of Cultivar $\times \mathrm{JAPret} \times \mathrm{JAMed} \times \mathrm{Lj}$ interaction.

\begin{tabular}{|c|c|c|c|c|c|c|c|}
\hline Cultivar & $\begin{array}{l}\text { JA } \\
\text { Pret }\end{array}$ & $\begin{array}{l}\text { JA } \\
\text { Med }\end{array}$ & $\begin{array}{l}\mathrm{Li} \\
{[\mathrm{hrs}]}\end{array}$ & $\begin{array}{l}\text { Avg. weight } \\
\text { of one } \\
\text { microtuber } \\
\text { [g] }\end{array}$ & $\begin{array}{l}\text { Number of } \\
\text { microtubers } \\
\text { per vessel }\end{array}$ & $\begin{array}{c}\% \\
\text { Micro- } \\
\text { tubers } \\
>0.1 \mathrm{~g}\end{array}$ & $\begin{array}{c}\text { Number of } \\
\text { microtubers } \\
>0.1 \mathrm{~g} \\
\text { per vessel }\end{array}$ \\
\hline \multirow[t]{8}{*}{ Amisk } & No & No & 0 & $0.082 \mathrm{ij}^{*}$ & $22.7 \mathrm{~b}$ & $39.5 \mathrm{de}$ & $8.7 \mathrm{~h}$ \\
\hline & No & No & 8 & $0.270 \mathrm{a}$ & $15.2 \mathrm{ef}$ & $85.2 \mathrm{a}$ & $13.4 \mathrm{~cd}$ \\
\hline & No & Yes & 0 & $0.144 \mathrm{~g}$ & $17.0 \mathrm{de}$ & $75.5 \mathrm{ab}$ & $13.2 \mathrm{~cd}$ \\
\hline & No & Yes & 8 & $0.211 \mathrm{de}$ & $19.2 \mathrm{~cd}$ & $69.7 b c$ & $13.6 \mathrm{~cd}$ \\
\hline & Yes & No & 0 & $0.094 \mathrm{hi}$ & $19.3 \mathrm{~cd}$ & $46.9 \mathrm{de}$ & $8.7 \mathrm{~h}$ \\
\hline & Yes & No & 8 & 0.220 cde & $14.6 \mathrm{ef}$ & $85.5 \mathrm{a}$ & $13.0 \mathrm{~cd}$ \\
\hline & Yes & Yes & 0 & $0.173 \mathrm{f}$ & $15.6 \mathrm{ef}$ & $77.0 \mathrm{ab}$ & $12.3 \mathrm{de}$ \\
\hline & Yes & Yes & 8 & $0.257 \mathrm{ab}$ & $16.5 \mathrm{e}$ & $79.8 \mathrm{ab}$ & $13.5 \mathrm{~cd}$ \\
\hline \multirow[t]{8}{*}{ Atlantic } & No & No & 0 & $0.067 \mathrm{ij}$ & $5.0 \mathrm{i}$ & $12.4 \mathrm{i}$ & 2.61 \\
\hline & No & No & 8 & $0.113 \mathrm{~h}$ & $16.5 \mathrm{e}$ & $45.0 \mathrm{de}$ & $7.8 \mathrm{hi}$ \\
\hline & No & Yes & 0 & $0.116 \mathrm{~h}$ & $11.1 \mathrm{fg}$ & $42.4 \mathrm{de}$ & $5.4 \mathrm{j}$ \\
\hline & No & Yes & 8 & $0.088 \mathrm{hi}$ & $13.1 \mathrm{f}$ & $32.9 \mathrm{ef}$ & $5.4 \mathrm{j}$ \\
\hline & Yes & No & 0 & $0.061 \mathrm{j}$ & $6.2 \mathrm{i}$ & $8.7 \mathrm{i}$ & $2.6 \mathrm{l}$ \\
\hline & Yes & No & 8 & $0.082 \mathrm{ij}$ & $8.0 \mathrm{hi}$ & $24.3 \mathrm{gh}$ & $3.6 \mathrm{kl}$ \\
\hline & Yes & Yes & 0 & $0.092 \mathrm{hi}$ & $9.3 \mathrm{gh}$ & $33.7 \mathrm{ef}$ & $4.5 \mathrm{jk}$ \\
\hline & Yes & Yes & 8 & $0.119 \mathrm{gh}$ & $11.2 \mathrm{fg}$ & $44.7 \mathrm{de}$ & $6.1 \mathrm{ij}$ \\
\hline \multirow[t]{8}{*}{ Russet Burbank } & No & No & 0 & $0.058 \mathrm{j}$ & $15.4 \mathrm{ef}$ & $22.3 \mathrm{gh}$ & $4.7 \mathrm{jk}$ \\
\hline & No & No & 8 & $0.195 \mathrm{ef}$ & $20.2 \mathrm{c}$ & $79.4 \mathrm{ab}$ & $16.0 \mathrm{a}$ \\
\hline & No & Yes & 0 & $0.088 \mathrm{hi}$ & $22.8 \mathrm{~b}$ & 36.5 ef & $8.6 \mathrm{~h}$ \\
\hline & No & Yes & 8 & $0.225 \mathrm{~cd}$ & $23.4 \mathrm{~b}$ & $78.0 \mathrm{ab}$ & $16.0 \mathrm{a}$ \\
\hline & Yes & No & 0 & $0.113 \mathrm{~h}$ & $12.2 \mathrm{f}$ & $48.0 \mathrm{~d}$ & $7.3 \mathrm{i}$ \\
\hline & Yes & No & 8 & $0.228 \mathrm{~cd}$ & $19.0 \mathrm{~cd}$ & $81.5 \mathrm{a}$ & $15.3 a b$ \\
\hline & Yes & Yes & 0 & $0.092 \mathrm{hi}$ & $22.6 \mathrm{~b}$ & $35.0 \mathrm{ef}$ & $8.3 \mathrm{hi}$ \\
\hline & Yes & Yes & 8 & $0.177 \mathrm{f}$ & $25.6 \mathrm{a}$ & $60.7 \mathrm{c}$ & $15.3 \mathrm{ab}$ \\
\hline \multirow[t]{8}{*}{ Shepody } & No & No & 0 & $0.064 \mathrm{j}$ & $5.2 \mathrm{i}$ & $11.0 \mathrm{i}$ & 2.71 \\
\hline & No & No & 8 & $0.230 \mathrm{~cd}$ & $17.6 \mathrm{de}$ & $83.7 \mathrm{a}$ & $14.2 \mathrm{bc}$ \\
\hline & No & Yes & 0 & $0.062 \mathbf{j}$ & $5.2 \mathrm{i}$ & $11.0 \mathrm{i}$ & 2.61 \\
\hline & No & Yes & 8 & $0.204 \mathrm{e}$ & $15.8 \mathrm{ef}$ & $78.2 \mathrm{ab}$ & $12.2 \mathrm{de}$ \\
\hline & Yes & No & 0 & $0.064 \mathrm{j}$ & $5.6 \mathrm{i}$ & $11.1 \mathrm{i}$ & 2.61 \\
\hline & Yes & No & 8 & $0.232 b c$ & 16.2 ef & $82.5 \mathrm{a}$ & $13.1 \mathrm{~cd}$ \\
\hline & Yes & Yes & 0 & $0.070 \mathrm{ij}$ & $5.6 \mathrm{I}$ & $14.3 \mathrm{hi}$ & 2.81 \\
\hline & Yes & Yes & 8 & $0.179 \mathrm{fg}$ & $14.8 \mathrm{ef}$ & $69.8 \mathrm{~b}$ & $10.6 \mathrm{fg}$ \\
\hline \multirow[t]{8}{*}{ Umatilla Russet } & No & No & 0 & $0.071 \mathrm{jj}$ & $13.9 \mathrm{f}$ & $29.5 \mathrm{fg}$ & $3.4 \mathrm{kl}$ \\
\hline & No & No & 8 & $0.249 \mathrm{ab}$ & $15.6 \mathrm{ef}$ & $79.0 \mathrm{ab}$ & $12.6 \mathrm{~cd}$ \\
\hline & No & Yes & 0 & $0.137 \mathrm{~g}$ & $15.9 \mathrm{ef}$ & $60.6 \mathrm{c}$ & $9.5 \mathrm{gh}$ \\
\hline & No & Yes & 8 & $0.230 \mathrm{~cd}$ & $14.2 \mathrm{f}$ & $83.2 \mathrm{a}$ & $12.3 \mathrm{de}$ \\
\hline & Yes & No & 0 & $0.075 \mathrm{ij}$ & $11.3 \mathrm{fg}$ & 32.7 ef & 2.91 \\
\hline & Yes & No & 8 & $0.243 b$ & $14.5 \mathrm{ef}$ & $84.6 \mathrm{a}$ & $12.7 \mathrm{~cd}$ \\
\hline & Yes & Yes & 0 & $0.092 \mathrm{hi}$ & $11.7 \mathrm{fg}$ & $44.8 \mathrm{de}$ & $4.6 \mathrm{jk}$ \\
\hline & Yes & Yes & 8 & $0.216 \mathrm{de}$ & $13.5 \mathrm{f}$ & $80.7 \mathrm{ab}$ & $11.3 \mathrm{ef}$ \\
\hline
\end{tabular}

* Least square means followed by the same letter are not significantly different from each other at the $1 \%$ level of significance. 
was the highest $(81.5 \%$ ) from microcuttings treated with JA (Table 2). Shepody, on the other hand, did not show any benefits of JA on in vitro tuberization, neither under dark or light conditions. The largest microtubers of Shepody came from the JAPret/no JAMed/light treatment (average $0.232 \mathrm{~g}$ each) showing also the highest percentage of microtubers $>0.1 \mathrm{~g}(82.5 \%)$, although the difference with no/no JA treatments in light was negligible (Table 2). Number of Shepody's microtubers produced per jar did not differ significantly between JA and no JA treatments either. The variety produced the largest differences in production of microtubers between JA/light and JA/no light treatments (Table 2). Compared to the control and the individual JA treatments, a double treatment with JA (JAPret and JAMed), in light, significantly reduced the production of microtubers $>0.1 \mathrm{~g}$ in both Shepody and Russet Burbank, contrary to the varieties of group I.

All three Russet varieties, Russet Burbank, Amisk (Ranger Russet) and Umatilla Russet, responded more favourably to in vitro tuberization than Atlantic and Shepody. Russet Burbank produced the highest number of microtubers per jar $(19.0-25.6)$ in all $8 \mathrm{~h}$ light treatment combinations (Table 2). This figure translates to $1.2-1.7$ microtubers per nodal cutting. Amisk (Ranger Russet) and Umatilla Russet produced slightly fewer microtubers than Russet Burbank. In Shepody, the number of microtubers per nodal cutting was around one in most of the $8 \mathrm{~h}$ light treatment combinations and did not differ from that of Umatilla Russet. Atlantic produced the lowest number of microtubers (much fewer than one per nodal cutting) in most of the treatments (Table 2). The $8 \mathrm{~h}$ photoperiod had also beneficial effect on weight of microtubers. The average weight was significantly higher in light treatments than in dark. The most dramatic differences were observed with Shepody (Figure 1C), particularly in percentage of microtubers larger than $0.1 \mathrm{~g}$. When tuberization was taking place under $8 \mathrm{~h}$ light about $70-83 \%$ of microtubers from all treatment combinations were $>0.1 \mathrm{~g}$. In dark, Shepody produced only $11-14 \%$ microtubers $>0.1 \mathrm{~g}$ (Table 2). All three Russet varieties responded similarly producing the largest in vitro tubers. Microtubers of $\mathrm{cv}$. Amisk had the highest average weight from all the varieties tested and the percentage of microtubers $>0.1 \mathrm{~g}$ varied from 70 to $85.5 \%$ (about 13 tubers per vessel) in all light treatment combinations. Umatilla Russet and Shepody also produced about 13 microtubers $>0.1 \mathrm{~g}$ per vessel, however, the average weights were lower. Russet Burbank produced the highest number of tubers $>0.1 \mathrm{~g}$ per vessel (about 16 = 1 microtuber per nodal cutting), however its tubers were slightly smaller than those of Amisk. Microtubers of cv. Atlantic were the smallest and the percentage and number of tubers $>0.1 \mathrm{~g}$ per vessel was also the lowest (Table 2). 


\subsection{Discussion}

Independently of the cultivar and the JA treatment, light exposure, similar to other studies (Dóbránszki \& Mandi, 1993; Nowak \& Asiedu, 1992; Pruski et al., 2001), gave significantly larger and more uniform tubers in both Experiment 1 and 2 studies (Tables 1 and 2, Figure 1C, D). The $0 \mathrm{~h}$ photoperiod (dark) was found unsuitable for in vitro tuberization since the number and weight of microtubers produced in dark
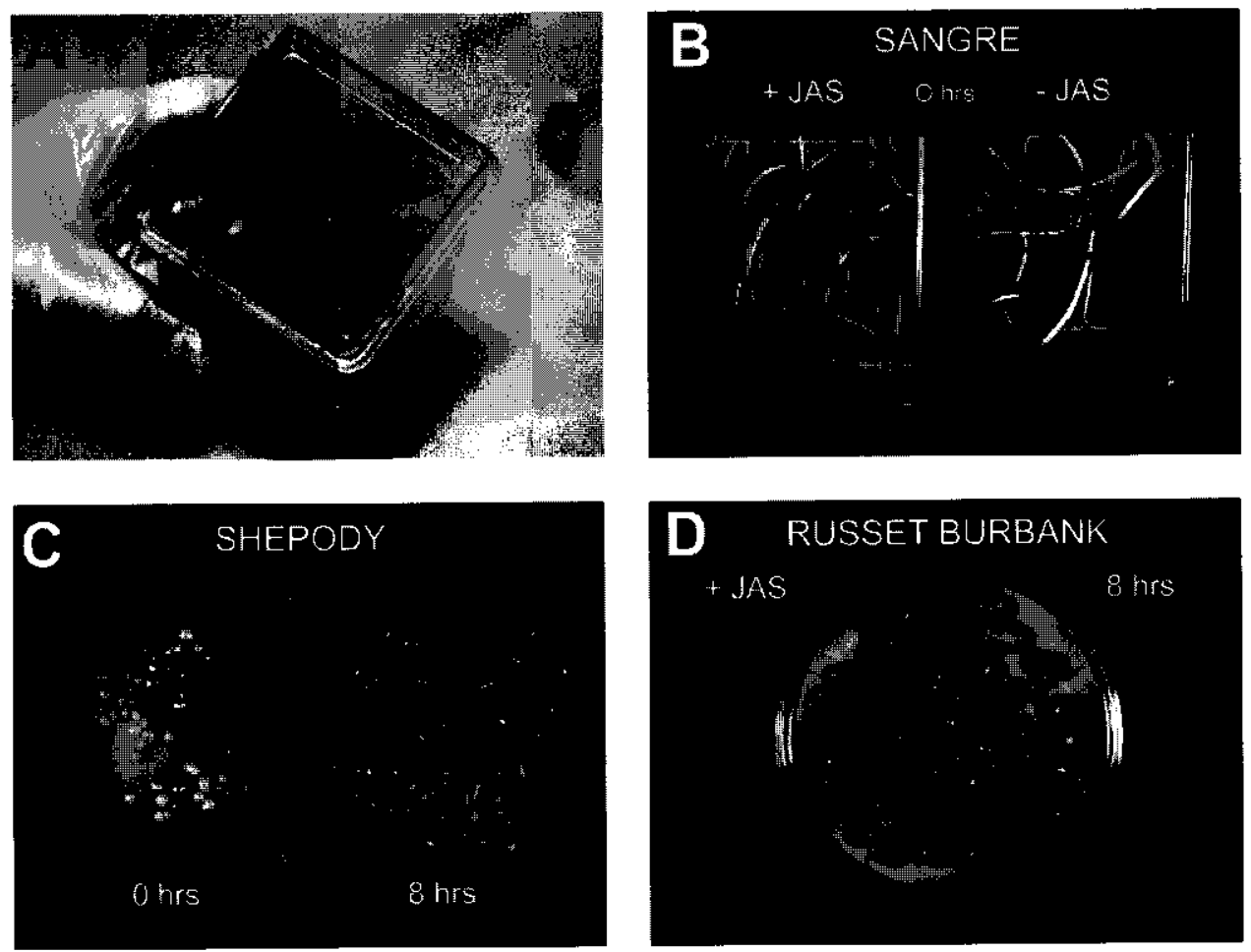

Figure 1. Production of microtubers in vitro.

A. Plantlets of Russet Burbank prepared for in vitro tuberization.

B. Microtubers of Sangre produced in dark $(0 \mathrm{~h}$ photoperiod) on media with (+JAS, left) and without (-JAS, right) $2.5 \mu \mathrm{M}$ jasmonic acid (JA).

C. Microtubers of Shepody produced in the dark (left) and under $8 \mathrm{~h}$ photoperiod (right) from JA pre-treated plantlets.

D. Microtubers of from stock plants pre-conditioned (JAPret) with $2.5 \mu \mathrm{M}$ JA under $8 \mathrm{~h}$ photoperiod on tuberization media without JA. 
treatments were significantly (in some varieties drastically) lower than in treatments with $8 \mathrm{~h}$ light. Garner \& Blake (1989) in their studies found the $8 \mathrm{~h}$ day length for the production of microtubers more suitable than darkness. Khuri \& Moorby (1996) reported a successful microtuber production of cvs. Estima and Cultra under short days. Ranalli (1997) stated that most varieties (probably all) give much better microtuber production in short days $(8 \mathrm{~h}$ ) than in complete darkness. Our results (Tables 1 and 2) also show significant differences between varieties in response to the photoperiod during in vitro tuberization. Production of microtubers in all three Russet varieties (Experiment 2) and in Sangre (Experiment 1) was superior to that of Shepody and Atlantic. Nowak \& Asiedu (1992) reported variety Atlantic being the slowest to tuberize from the six varieties they tested. The above conclusion can be extended to our results with Atlantic. On the other hand, in their studies (Nowak \& Asiedu, 1992), Atlantic produced significantly more large tubers in the dark than in light treatments and this observation contradicts our data for no/no JA treatment combination (Table 2). Jackson (1999) concluded that it is actually the length of the dark period rather than the light period that is important in inducing in vitro tuberization.

The effects of JA were light and variety specific. Generally, the benefits were more pronounced in the dark than light tuberization in both Experiment 1 and Experiment 2 studies. Experiment 1 results with Russet Burbank and Sangre clearly show the benefits of JA supplement when the tuberization was conducted in the dark (Table 1). Stimulatory effects of JAs on in vitro tuberization and on potato stem node cultures have been reported (Koda et al., 1991; Pelacho \& Mingo-Castel, 1991; Ravnikar et al., 1992; Pruski et al., 1993; Kreft et al., 1997; Pruski et al., 2001). JAs are involved in control of leaf senescence in potato which is closely associated with tuber induction (Van den Berg \& Ewing, 1991). The JA pre-treated nodal cuttings used in our experiments (particularly when the in vitro tuberization was taking place in the dark) may have possessed the signal to quickly induce tuberization and to produce more uniform and higher number of microtubers compared to untreated cuttings. Pelacho \& Mingo-Castel (1991) reported JA induction of tuberization in potato stolons cultured in vitro. On the other hand, Jackson (1999) reported that the JA or other JA-related compounds may be responsible for inducing/promoting in vitro tuberization, but the differences in endogenous levels of JA itself do not control tuberization. The JA may act by antagonizing the effect of gibberellic acid (GA), which levels decrease upon the photoperiodic induction of tuberization (Jackson, 1999).

Based on results from Experiment 2, the tested varieties were divided into three groups. Amisk, Atlantic and Umatilla Russet (group I) benefited from JA supplement to the tuberization medium in the dark, but not from JA in the pre-conditioning treatment (Table 2). However, none of these varieties clearly benefited from any JA 
treatments under light. On the other hand, the JA seemed to substitute for light in JA/dark treatment combination (Table 2). Russet Burbank (group II) also benefited from the JA supplement in the dark, although stock plantlet conditioning was more effective than the JA supplement to the medium. Shepody (group III), on the other hand, did not show any benefits of JA on in vitro tuberization, neither under dark or light conditions (Table 2).

From the six varieties tested, we found that all three Russet varieties (Russet Burbank, Umatilla Russet and Amisk) and Sangre responded positively to in vitro tuberization conditions and can be recommended for commercial production. Based on our data we cannot recommend Atlantic nor Shepody for this method. The production of microtubers in both varieties was low (especially Atlantic). Exposure to light $(8 \mathrm{~h}$ ) during tuberization was essential for the production of a sufficient number of microtubers per nodal cutting and the $8 \mathrm{~h}$ photoperiod can be recommended. Although, the $2.5 \mu \mathrm{M}$ JA supplement (in pre-treatment media (JAPret) or in tuberization media (JAMed)) had a beneficial effect in the dark production of microtubers (under $0 \mathrm{~h}$ light), the inconsistencies in results with Russet Burbank under $8 \mathrm{~h}$ light tuberization between studies in Experiment 1 and Experiment 2 need to be addressed. More studies are necessary to clearly determine benefits of JA supplement prior or during in vitro tuberization, before JA supplement is utilized in any commercial production of microtubers.

\section{References}

Biondi, S., S. Fornale, K.M. Oksman-Caldentey, M. Eeva, S. Agostani \& N. Bagni, 2000. Jasmonates induces over-accumulation of methylputrescine and conjugated polyamines in Hyoscyamus muticus L. root cultures. Plant Cell Reports 19: 691-697.

Dobránszki, J. \& M. Mandi, 1993. Induction of in vitro tuberization by short day period and dark treatment of potato shoots grown on hormone-free medium. Acta Biologica Hungarica 44: 411-420.

Estrada, R., P. Tovar, \& J.H. Dodds, 1986. Induction of in vitro tubers in a broad range of potato genotypes. Plant Cell, Tissue and Organ Culture 7: 3-10.

Garner, N. \& J. Blake, 1989. The induction and development of potato microtubers in vitro on media free of growth regulating substances. Annals of Botany 63: 663-674.

Jackson, S.D., 1999. Multiple signalling pathways control tuber induction in potato. Plant Physiology 119: 1-8.

Jensen, L.C., 1996. The small lab's perspective of technology used in commercial increase of Solanum tuberosum by micropropagation. In Vitro Cellular and Developmental Biology Plant 32: 34 (abstract).

Jimenez, E., N. Perez, N. de Feria, R. Barbon, A. Capote, M. Chavez, E. Quiala \& J. C. Perez, 


\section{Chapter 6}

1999. Improved production of potato microtubers using a temporary immersion. Plant Cell, Tissue and Organ Culture 59: 19-23.

Khuri, S. \& J. Moorby, 1996. Nodal segments or microtubers as explants for in vitro microtuber production of potato. Plant Cell, Tissue and Organ Culture 45: 215-222.

Koda, Y., 1997. Possible involvement of jasmonates in various morphogenic events. Physiologia Plantarum 98: 407-412.

Koda, Y., Y. Kikuta, H. Tazaki, Y. Tsuhino, S. Sakamura \& T. Yoshihara, 1991. Potato tuberinducing activities of jasmonic acid and related compounds. Phytochem. 30: 1435-1438.

Kreft, S., M. Ravinkar, P. Mesko, J. Pungercar, A. Umek, I. Kregar \& B. Strukelj, 1997. Jasmonic acid inducible aspartic proteinase inhibitors from potato. Phytochemistry 44: 1001-1006.

Lommen, W.J.M., 1995. Basic studies on the production and performance of potato minitubers. PhD thesis, Wageningen Agricultural University, The Netherlands, $181 \mathrm{pp}$.

Montgomery, D.C., 1997. Design and Analysis of Experiments. Fourth edition. Wiley, New York.

Murashige, T. \& F. Skoog, 1962. A revised medjum for rapid growth and bioassays with tobacco tissue cultures. Physiologia Plantarum 15: 473-497.

Nowak, J. \& S. Asiedu, 1992. Gelling agent and light effects on in vitro tuberization of potato varieties. American Potato Journal 69: 461-470.

Pelacho, A.M. \& A.M. Mingo-Castel, 1991. Jasmonic acid induces tuberization of potato stolon cultured in vitro. Plant Physiology 97: 1253-1255.

Pruski, K., J. Nowak \& T. Lewis, 1993. Jasmonates and photoperiod effect on microtuber production in two potato varieties. In Vitro Cellular and Developmental Biology - Plant 29: 69 (abstract).

Pruski, K, T. Astatkie \& J. Nowak, 2001. Jasmonate effects on in vitro tuberization and tuber bulking in two potato cultivars (Solanum tuberosum L.) under different media and photoperiod conditions. In Vitro Cellular and Developmental Biology - Plant (accepted).

Ranalli, P., 1997. Innovative propagation methods in seed tuber multiplication programmes. Potato Research 40: 439-453.

Ravinkar, M., B. Vilhar \& N. Gogala, 1992. Stimulatory effects of jasmonic acid on potato node and protoplast culture. Journal of Plant Growth Regulation 11:29-33.

SAS Institute Inc., 1999. SAS Online Doc@, Version 8. SAS Institute Inc., Cary NC.

Struik, P.C. \& W.J.M. Lommen, 1990. Production, storage and use of micro- and minitubers. Proceedings of the $11^{\text {th }}$ Triennial Conference of the European Association for Potato Research (EAPR), Edinburgh, UK, pp. 122-133.

Struik, P.C. \& S.G. Wiersema, 1999. Seed Potato Technology. Wageningen Pers, The Netherlands, $383 \mathrm{pp}$.

Teisson, C. \& D. Alvard, 1999. In vitro production of microtubers in liquid medium using 
Jasmonate effects on in vitro tuberization of different varieties temporary immersion. Potato Research 42:499-504.

Van den Berg, J.H. \& E.E. Ewing, 1991. Jasmonates and their role in plant growth and development with special reference to the control of potato tuberization: A review. American Potato Journal 68: 781-794.

Yu, W.C., P.J. Joyce, D.C. Cameron \& B.H. McCown, 2000. Sucrose utilization during potato microtuber growth in bioreactors. Plant Cell Reports 19: 407-413. 


\section{Chapter 7}

\section{Jasmonate as a potato plantlets and microtubers conditioner for greenhouse and field planting*}

* Pruski, K., T. Astatkie, T. Lewis, P. Duplessis, J. Nowak \& P.C. Struik, 2001. Jasmonate as a potato plantlet conditioner for: 1 . Greenhouse production of minitubers. American Joumal of Potato Research (to be accepted).

${ }^{*}$ Pruski, K., T. Astatkie, L. Stewart, P. Duplessis, J. Nowak \& P.C. Struik, 2001. Jasmonate as a potato plantlet conditioner for: 2. Field planting. American Journal of Potato Research (to be accepted). 


\title{
7. Jasmonate as a potato plantlets and microtubers conditioner for greenhouse and field planting
}

\begin{abstract}
A two-year study was conducted to determine the effects of jasmonic acid (JA) (during in vitro explant production and in vitro tuberization phases) on performance of microtubers in the production of minitubers (greenhouse) and Pre-elite seed tubers (field) in five potato cultivars. The microtubers were produced under short day $(8 \mathrm{~h}$ photoperiod) conditions and in darkness, from stock plantlets pre- and non-treated with JA, and on tuberization media with or without JA. Microtuber performance was compared with the industry standard, the in vitro plantlets. Plantlets of all five tested cultivars performed well in both, the greenhouse and in the field. Microtuber responses to JA varied with cultivar. Results obtained with microtubers of cultivars Amisk, Russet Burbank and Umatilla Russet were encouraging, with Shepody inconclusive, and Atlantic microtubers performed poorly in both, the greenhouse and the field. Microtubers obtained from explants taken from stock plantlets grown on medium supplemented with $2.5 \mu \mathrm{M} \mathrm{JA}$ (compared to no JA) produced better yieids of minitubers in the greenhouse in all tested cultivars. The results were comparable to those obtained with plantlets. In the field studies, the results were inconclusive; stock plantlets pre-treated with JA (prior to in vitro tuberization) enhanced the Pre-elite tuber production in Russet Burbank but significantly lowered it in Shepody. JA presence in media during in vitro tuberization significantly lowered production of Pre-elite tubers in the field. Exposure to $8 \mathrm{~h}$ light during in vitro tuberization resulted in microtubers performing significantly better in the greenhouse and in the field than microtubers produced in the dark. Dormancy release was the key factor influencing microtuber performance. Rindite proved to be very effective for microtubers used in greenhouse conditions. For microtubers used in the field, gibberellic acid (GA) gave slightly better results. JA conditioning of stock plants prior to taking explants for tuberization is being proposed as a treatment enhancing the quality of microtubers and their performance, particularly in the greenhouse production of minitubers.
\end{abstract}

Key words: in vitro tuberization, jasmonic acid, microtubers, minitubers, Pre-elite tubers, Rindite, Solanum tuberosum L.

Abbreviations: GA - gibberellic acid, JA - jasmonic acid, MS - Murashige \& Skoog's medium, PPFD - photosynthetic photon flux density

\subsection{Introduction}

In vitro plantlets (Jones, 1988; Lommen, 1995; Struik \& Wiersema, 1999) are commonly used for speeding up multiplication of disease-free material in elite seed potato programmes. After the final multiplication stage the plantlets are used for the 


\section{Chapter 7}

production of seed tubers. This step is usually carried out in greenhouses resulting in the production of minitubers (also called nuclear tubers). Additionally, the plantlets can also be used for the production of microtubers. Microtubers are produced in vitro and have a potential to be integrated into seed potato programmes (Lillo, 1989; Lommen, 1995; Khuri \& Moorby, 1996; Nasiruddin \& Blake, 1997; Kim et al., 1999; Struik \& Wiersema, 1999). In the light of new developments in methodologies for mass production of microtubers in bio-reactors ( $Y u$ et al., 2000), the propagule may prove as effective as plantlets. Microtubers are often considered as alternative to plantlets in germplasm storage and exchange (Estrada et al., 1986) and in the production of minitubers in greenhouses and/or Pre-elite tubers in the field (Ranalli et al., 1994; Ranalli, 1997; Coleman et al., 2001). At present, however, most of the commercial production of minitubers is still based on tissue culture plantlets. This is mainly due to the limited information on commercial laboratory production of microtubers, suitability of cultivars to specific microtuberization methods, and greenhouse and field performance comparison between microtubers and plantlets (Joung et al., 1993; Lê, 1999; Dobránszki et al., 1999). Both propagules, plantlets and microtubers, have a common deficiency: they require special attention after (trans)planting. Moreover, the microtubers vary in size, the length of their dormancy period, and their physiological age (Leclerc et al., 1995; Tábori et al., 1999; Coleman \& Coleman, 2000). Consequently, not all microtubers uniformly sprout and produce vigorous plants after planting.

Over the last decade several researchers observed that jasmonic acid (JA), a growth regulator produced by plants exposed to stress (Biondi et al., 2000), is highly effective in the induction of microtubers (Koda et al., 1991; Van den Berg \& Ewing, 1991; Pelacho \& Mingo-Castel, 1991; Ravnikar et al., 1992; Pruski et al., 1993; Kreft et al., 1997). In a recent study (Pruski et al., 2001), we have found that JA supplement less than $5 \mu \mathrm{M}$ in the plantlet multiplication medium generates plantlets with sturdier stems, better developed root system and a higher root/shoot biomass ratio compared to the plantlets grown on a conventional medium. Nodal explants taken from the JA conditioned plantlets also tuberized earlier and more uniformly, giving higher yield of microtubers than the controls. A similar stimulation of tuberization was achieved when JA was supplemented directly into the microtuberization media.

The objectives of the present study were: $(i)$ to compare greenhouse and field performance of the JA conditioned and non-conditioned plantlets and microtubers, and (ii) to evaluate responses of commonly grown commercial varieties to the JA conditioning. 


\subsection{Materials and methods}

The study was conducted at the tissue culture laboratory, greenhouses and field of the Crop Diversification Centre North $(\mathrm{CDCN})$, Alberta Agriculture Food and Rural Development, Edmonton, Alberta, Canada ( $53^{\circ} \mathrm{N}$ latitude, $113^{\circ} \mathrm{W}$ longitude), in 1998 and 1999. The cultivars studied were Atlantic (AT), Russet Burbank (RB) and Shepody (SH) in 1998, and Amisk - Ranger Russet (AM), Russet Burbank (RB) and Umatilla Russet (UM) in 1999.

\section{Plantlet multiplication and stock plants preparation for in vitro tuberization}

Plant material for all experiments was derived from the $\mathrm{CDCN}$ potato tissue culture bank.The plantlets were multiplied as single-node explants on $50 \mathrm{ml}$ MS (Murashige \& Skoog, 1962) media with standard vitamins (Sigma-Aldrich Canada Ltd., Oakville, Ont., Canada), in GA7 Magenta vessels (Magenta Corp., Chicago, IL, USA). Sixteen $(4 \times 4)$ single-node explants were placed in each vessel. Sucrose $\left(30 \mathrm{~g} \mathrm{l}^{-1}\right)$ was used as a carbon source and the media were solidified with $0.6 \%$ agar (Difco, Detroit, MI, USA). The $\mathrm{pH}$ of media was adjusted to 5.7 before autoclaving. Cultures were incubated for four weeks in an environmental chamber (Conviron, Model T144, Winnipeg, Manitoba, Canada) at $20^{\circ} \mathrm{C}+/-1^{\circ} \mathrm{C}$ temperature with $16 \mathrm{~h}$ photoperiod, $150 \mu \mathrm{mol} \mathrm{m} \mathrm{m}^{-2} \mathrm{~s}^{-1}$ mixed fluorescent (F40T12 tubes, General Electric (GE), USA) and incandescent ( $40 \mathrm{~W}, \mathrm{GE}, \mathrm{USA}$ ) illumination. At the end of the 4-wk period, the singlestem plantlets were cut into single-node explants and placed on a fresh MS medium in GA7 Magenta jars for further multiplication. The process was repeated until the required number of plantlets was achieved. During the last transfer before in vitro tuberization experiments, single-node explants of all cultivars were divided into two groups and transferred onto agar media: (i) the same MS medium as above (continuation of multiplication stage) and (ii) the MS medium supplemented with $2.5 \mu \mathrm{M} \mathrm{JA}$ (Apex Organics Ltd., Leicester, UK) - this group of explants was labelled as JA pretreated (JAPret). Both groups were incubated for 4 weeks under the conditions described above.

\section{Microtuberization}

Nodal explants were taken from four-week old plantlets grown on media with and without JA. Apical and basal nodes were discarded. Sixteen explants were placed in each GA7 Magenta vessel on $75 \mathrm{ml}$ tuberization medium (Figure 1A). Two media were used for the tuberization: (i) MS with $80 \mathrm{~g} \mathrm{l}^{-1}$ sucrose (no growth regulators) and 

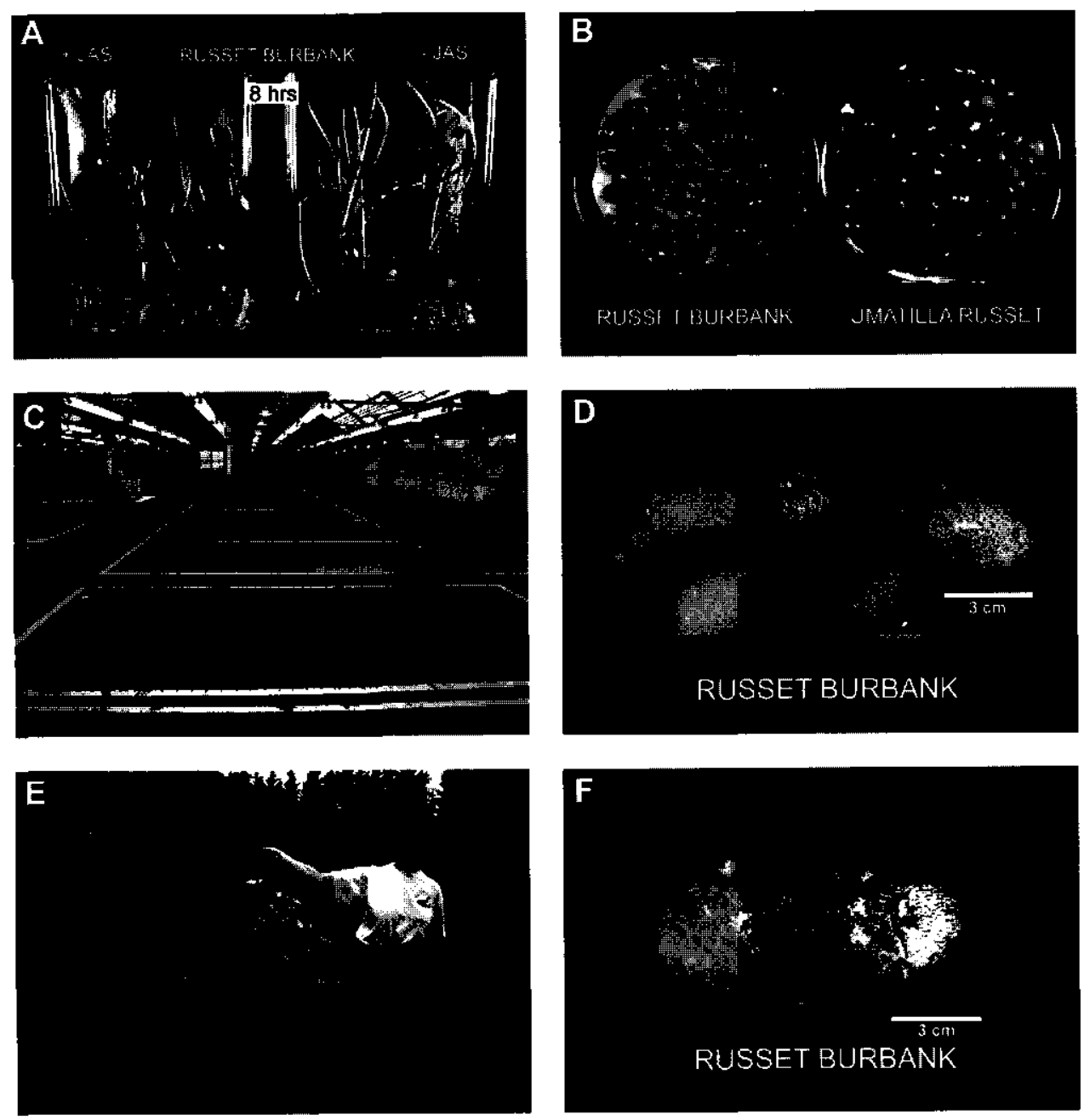

Figure 1. Microtubers in the greenhouse production of minitubers and in the field production of Pre-elite seed tubers.

A. Microtubers of Russet Burbank produced under $8 \mathrm{~h}$ photoperiod on media with (+JAS, left) and without (-JAS, right) $2.5 \mu \mathrm{M}$ jasmonic acid.

B. Microtubers of Russet Burbank and Umatilla Russet - cultivar difference.

C. Greenhouse benches for production of minitubers (CDCNorth, Edmonton).

D. Minitubers of Russet Burbank produced in the greenhouse from microtubers.

E. The plant of Russet Burbank (from plantlet) at harvest (September 24, 1999).

F. The Pre-elite tuber of Russet Burbank produced from microtubers. 
(ii) MS with $80 \mathrm{~g} \mathrm{l}^{-1}$ sucrose and $2.5 \mu \mathrm{M} \mathrm{JA}$ and (JA in Media (JAMed)). All media were solidified with $0.6 \%$ agar and $\mathrm{pH}$ adjusted as above. Cultures were incubated at $20^{\circ} \mathrm{C}$ in the dark $\left(0 \mathrm{~h}\right.$ photoperiod) and under $8 \mathrm{~h}$ photoperiod at $50 \mu \mathrm{mol} \mathrm{m} \mathrm{m}^{-2} \mathrm{~s}^{-1}$ mixed fluorescent/incandescent light, for 10 weeks. At harvest, the microtubers were grouped according to size and weight, and then kept in cold storage $\left(4^{\circ} \mathrm{C}\right)$, in sealed Petri dishes, for 12 weeks.

\section{Greenhouse production of mini (nuclear seed) tubers}

From plantlets. Four replicates of twenty plantlets per each cultivar were transplanted to the greenhouse benches (Figure 1C) filled with a 6 inches $(15 \mathrm{~cm}$ ) deep layer of PRO-Mix 'BX' (Premier Horticulture, Dorval, Quebec, Canada), a peat-based professional growing medium designed for cultivation of horticultural greenhouse plants (pH $5.5-6.0$, electric conductivity (EC) $1.5-2.0$ mmhos per $\mathrm{cm}, 75-85 \%$ sphagnum, perlite and vermiculite). Spacing used for planting was $3.5 \times 3.5$ inches ( 9 $\times 9 \mathrm{~cm}$ ). Planting was done the first week of July. Plants were grown for 16 weeks under standard greenhouse conditions $\left(24 / 18^{\circ} \mathrm{C}\right.$ day/night temperature and with $14 \mathrm{~h}$ photoperiod with supplemental lighting (FT72112/CW/NHO tubes, Philips, USA)). One week after planting to the greenhouse, the plantlets received 10-52-10 (NPK), water-soluble fertilizer (Plant-Prod, Brampton, Ontario, Canada) at the rate of $1.5 \mathrm{~g} \mathrm{l}^{-1}$. The fertilizer treatment continued for the next two weeks. Following these, plants were receiving 20-20-20 (NPK), water-soluble fertilizer (Plant-Prod, Brampton, ON, Canada) at the rate of $3 \mathrm{~g} \mathrm{l}^{-1}$ every second week ( 5 times), for 10 weeks. In between the fertilizer applications, plants were watered daily during hot weather and every second day in cooler weather. Plants were sprayed with Bravo to prevent and control Gray mold (Botrytis cinerea), approximately every 2 weeks from mid-July until late August. In week 14 in the greenhouse, the plants received plain tap water and water was withdrawn during the last week before harvest. Plots were harvested by hand, minitubers sorted by size and weight in three size categories: (i) 5 - $30 \mathrm{~mm}$, (ii) 30 - 60 $\mathrm{mm}$, and (iii) $>60 \mathrm{~mm}$, and placed in mesh bags in a cold room at $4^{\circ} \mathrm{C}$ for further use.

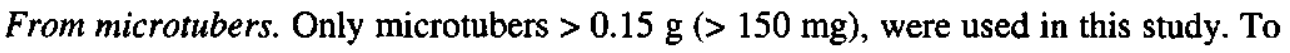
induce uniform sprouting, prior to the greenhouse planting microtubers were treated with: (i) $100 \mathrm{ppm}$ solution of gibberellic acid $\left(\mathrm{GA}_{3}\right)$ for $24 \mathrm{hrs}$ (1998 and 1999 studies), and (ii) Rindite, a mixture of ethylene chlorhydrin, ethylene bichloride and carbon tetrachloride, 7:3:1 v/v, respectively (Denny, 1945) (1999 studies only). Rindite concentration was $10 \mathrm{ml}$ per 101 of container volume. The microtubers were treated in an airtight container for $24 \mathrm{hrs}$ at $24^{\circ} \mathrm{C}$, in a chemical fume hood, to avoid 


\section{Chapter 7}

inhalation of toxic vapours. Following the Rindite treatment, microtubers were aerated prior to planting. Microtubers from each tuberization treatment were planted separately on greenhouse benches filled with PRO-Mix 'BX' as for plantlets. Microtubers were grown along with plantlets under the greenhouse conditions described above. Microtubers received 10-52-10 (NPK), fertilizer (the rate as for plantlets), two weeks after planting. All other treatments, spacing, fertilization, greenhouse maintenance practices, harvest, and data collection were the same as for plantlets.

\section{Field production of Pre-elite tubers}

From plantlets. Four replicates of twenty plantlets were used in each cultivar/treatment combination. In the 1998 studies, plantlets were directly planted from GA7 Magenta vessels to the field, the first week of June. In 1999, two methods of transplanting were used: (i) planting directly from the vessels to the field, and (ii) planting to Jiffy pellets ( 2 inches $(5 \mathrm{~cm}$ ) in diameter; Jiffy Products (NB) Ltd., Shippagan, NB, Canada) first, and grown in the greenhouse for one week prior to field transplanting, the first week of June. The field plots were $10 \mathrm{ft}(3 \mathrm{~m})$ long with 6 inches $(15 \mathrm{~cm})$ tuber spacing and 36 inches $(90 \mathrm{~cm}$ ) row spacing (field location/land description: NW-5-TR54-54-R23W4th meridian). Soil, a sandy loam with medium clay content ( $\mathrm{pH} 6.6$ ), was tilled and rows were made using the tuber unit potato planter at the center. Hilling and weed control were done by hand. Plots were fertilized based on recommendations for yield of 15 tons ( $t$ ) per acre ( $33 \mathrm{t}$ per ha). Soil samples were taken and analysed at Norwest Laboratories, Edmonton, Canada. Plots were irrigated as needed and treated with Bravo bi-weekly to control Early blight (Alternaria solani) and Late blight (Phytophthora infestans), from mid-July until late August. Tops were removed by hand just prior to harvest in the third week of September (both, 1998 and 1999 studies). The crop received a total of 1,398 corn heat units in 1998 and 1,200 in 1999. Tubers were sorted into the following categories: (i) $<48 \mathrm{~mm}$, (ii) $48-88 \mathrm{~mm}$ and (iii) $>88 \mathrm{~mm}$, and the number and weight of Pre-elite tubers produced per plantlet were recorded.

From microtubers. Similar to the greenhouse study only larger than $0.15 \mathrm{~g}$ (>150 mg) microtubers were used. Prior to field planting, the same dormancy breaking procedures were applied as to the microtubers used in the 1998 and 1999 greenhouse experiments. Microtubers from each tuberization treatment were planted separately. Twenty microtubers of each cultivar were planted per replicate using 4 replicates per treatment. In 1999 , only the microtubers produced under $8 \mathrm{~h}$ photoperiod were used. The same spacing and the same field maintenance practices (fertilizer rates, pest control) were applied to microtubers as to the plantlets. The performance of the plants derived 
from the microtubers was compared to the performance of the plants derived from plantlets. The yield structure was determined as above.

\section{Statistical design}

For the greenhouse production of minitubers, a four-factor (cultivar, JA pre-treatment, JA in tuberization medium, light $[\mathrm{h}]$ factorial design was used in the 1998 study and a five-factor (cultivar, JA pre-treatment, JA in tuberization medium, light [h], dormancy breaking treatment) in the 1999 study. For the field production of Pre-elite tubers, a four-factor factorial design was used in both studies; in 1998, cultivar, JA pretreatment, JA medium, light [h] and in 1999, cultivar, JA pre-treatment, JA in tuberization medium, dormancy breaking treatment. For each response (number, size and weight of minitubers (greenhouse) or Pre-elite tubers (field) per plantlet or per microtuber), validity of the model assumptions (normal distribution and constant variance assumptions on the experimental error terms) was confirmed by examining the residuals as described in Montgomery (1997). Since for most of the responses, normality assumption was not valid under the original scale, the square root transformation was used during analysis. The results were then transformed back to the original scale. For the responses with significant two or higher order interaction effects, least square means comparisons of all treatment combinations of the involved factors, starting with the highest order interaction, were conducted to generate letter groupings. Analyses were completed using SAS (SAS Institute, 1999).

\subsection{Results}

\section{Greenhouse studies: Production of mini (nuclear seed) tubers}

From plantlets. Table 1 summarizes the production of minitubers (nuclear seed tubers) from in vitro derived plantlets in both 1998 (Table 1A) and in 1999 (Table 1B) seasons using current industrial protocols (AAFC, 1996). Minitubers are small tubers that can be produced all year round in the greenhouse from in vitro propagated plantlets or microtubers planted in high density (Struik \& Lommen, 1990; Lommen, 1995). No significant differences were found in total yield of minitubers between varieties in either, 1998 or 1999. In 1998, Atlantic produced the highest number of minitubers (78.9, close to four minitubers per plantlet), almost doubling that of Russet Burbank (49.1) and Shepody (44.3), but most of the tubers were small and medium size, with about $43 \%$ in the $5-30 \mathrm{~mm}$ and about $54 \%$ in the $30-60 \mathrm{~mm}$ size categories (Table 1A). Atlantic also produced the highest weight in these size categories. Shepody 


\section{Chapter 7}

produced the highest weight $(1.467 \mathrm{~kg}$ per plot of 20 plantlets planted) of large minitubers. Although the total yield of Russet Burbank was not significantly different from that of the other tested cultivars, its tubers evenly fell into the $30-60 \mathrm{~mm}$ and $>60 \mathrm{~mm}$ categories, 0.442 and $0.561 \mathrm{~kg}$ per plot, respectively (Table 1A). Minitubers over $30 \mathrm{~mm}$ in diameter are preferable on the market. However, smaller sizes are also useful for further replanting in the in-house seed production. According to the current regulations, seed potato producers are allowed to plant two generations of seed tubers in the greenhouse without losing the minituber (nuclear seed) status.

Similarly to 1998, in the 1999 season, no significant differences were observed in total yield of minitubers per plot between cultivars (Table 1B). The total yield of Russet Burbank minitubers was almost two and a half times higher than in 1998, with the majority of tubers in $>60 \mathrm{~mm}$ size category. Amisk and Umatilla Russet produced about $35 \%$ of tubers in the $30-60 \mathrm{~mm}$ and about $30 \%$ in $>60 \mathrm{~mm}$ categories (Table 1B). The total yield (3.387 kg per plot) and number (72.5) of Umatilla Russet minitubers were the highest, although not significantly different from that of the other two varieties. In all three cultivars, only $15-25 \%$ of the minituber total yield was in $5-30$ mm size category (Table 1B).

Table 1. Production of minitubers from in vitro derived plantlets, using industry standards. Cultivars (CV): Amisk (AM), Atlantic (AT), Russet Burbank (RB), Shepody (SH), and Umatilla Russet (UM).

\begin{tabular}{|c|c|c|c|c|c|c|c|c|}
\hline \multicolumn{9}{|c|}{ A. 1998 season } \\
\hline $\mathrm{CV}$ & $\begin{array}{c}\text { Total } \\
\text { number of } \\
\text { minitubers } \\
\text { from } 20 \\
\text { plantlets } \\
\end{array}$ & $\begin{array}{c}\text { Number } \\
\text { of tubers } \\
\text { size } \\
5-30 \mathrm{~mm}\end{array}$ & $\begin{array}{c}\text { Nuinber } \\
\text { of tubers } \\
\text { size } \\
30-60 \\
\mathrm{~mm} \\
\end{array}$ & $\begin{array}{c}\text { Number } \\
\text { of tubers } \\
\text { size } \\
>60 \\
\mathrm{~mm}\end{array}$ & $\begin{array}{c}\text { Total yield } \\
\text { of mini- } \\
\text { tubers from } \\
20 \text { plantlets } \\
{[\mathrm{kg}]}\end{array}$ & $\begin{array}{c}\text { Yield of } \\
\text { tubers } \\
\text { size } \\
5-30 \mathrm{~mm} \\
{[\mathrm{~kg}]}\end{array}$ & $\begin{array}{c}\text { Yield of } \\
\text { tubers } \\
\text { size } \\
30-60 \mathrm{~mm} \\
{[\mathrm{~kg}]}\end{array}$ & $\begin{array}{c}\text { Yield of } \\
\text { tubers } \\
\text { size } \\
>60 \mathrm{~mm} \\
{[\mathrm{~kg}]}\end{array}$ \\
\hline AT & $78.9 \mathrm{a}^{*}$ & $34.1 \mathrm{a}$ & $42.7 \mathrm{a}$ & $2.0 \mathrm{c}$ & $1.529 \mathrm{a}$ & $0.207 \mathrm{a}$ & $1.062 \mathrm{a}$ & $0.185 \mathrm{~b}$ \\
\hline RB & $49.1 \mathrm{~b}$ & $14.2 \mathrm{~b}$ & $23.0 \mathrm{~b}$ & $11.5 \mathrm{~b}$ & $1.071 \mathrm{a}$ & $0.055 b$ & $0.442 \mathrm{~b}$ & $0.561 \mathrm{~b}$ \\
\hline SH & $44.3 \mathrm{~b}$ & $5.8 \mathrm{c}$ & $14.2 \mathrm{c}$ & $24.0 \mathrm{a}$ & $1.816 \mathrm{a}$ & $0.016 \mathrm{c}$ & $0.229 \mathrm{~b}$ & $1.467 \mathrm{a}$ \\
\hline \multicolumn{9}{|c|}{ B. 1999 season } \\
\hline $\mathrm{AM}$ & $65.5 \mathrm{a}$ & $20.7 \mathrm{a}$ & $21.7 \mathrm{a}$ & $23.0 \mathrm{a}$ & $2.475 \mathrm{a}$ & $0.067 \mathrm{a}$ & $0.472 \mathrm{~b}$ & $1.935 \mathrm{a}$ \\
\hline $\mathbf{R B}$ & $59.5 \mathrm{a}$ & $9.0 \mathrm{~b}$ & $23.5 \mathrm{a}$ & $27.0 \mathrm{a}$ & $2.662 \mathrm{a}$ & $0.033 \mathrm{~b}$ & $0.460 \mathrm{~b}$ & $2.165 \mathrm{a}$ \\
\hline UM & $72.5 \mathrm{a}$ & $13.0 \mathrm{ab}$ & $31.7 \mathrm{a}$ & $27.7 \mathrm{a}$ & $3.387 \mathrm{a}$ & $0.046 \mathrm{ab}$ & 0.907 a & $2.433 \mathrm{a}$ \\
\hline
\end{tabular}


From microtubers. In 1998, yield of minitubers obtained from microtubers was very low. This was very likely associated with an incomplete breaking of the microtubers dormancy prior to planting.

Table 2 summarizes the results of the production of minitubers from microtubers

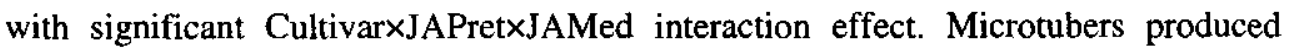
either from JA pre-treated stock plants or on JA containing media gave about $50 \%$ more minitubers in Shepody. This cultivar also produced the highest number of minitubers in $30-60 \mathrm{~mm}$ category and a few $>60 \mathrm{~mm}$ from JA pre-treated microtubers (Table 2). Similar to the production from plantlets, Atlantic minitubers were small with $65-75 \%$ in $5-30 \mathrm{~mm}$ size category. This cultivar did not produce minitubers $>60 \mathrm{~mm}$. Russet Burbank, however, gave almost three times more tubers from the microtubers produced without JA than with the JA treatments (Table 2). Since yields in 1998 were very low for all treatment combinations, they are not included the tables.

Table 2. Effects of JA treatments during the in vitro explant production and in vitro tuberization on production of minitubers from in vitro tubers in the greenhouse. Least square means comparison of the responses with significant cultivar, JA pre-treatment and JA in tuberization media interaction. Cultivars: Atlantic (AT), Russet Burbank (RB), Shepody (SH), 1998 season.

\begin{tabular}{|c|c|c|c|c|c|c|}
\hline Cultivar & $\begin{array}{c}\text { JA } \\
\text { pre- } \\
\text { treated }\end{array}$ & $\begin{array}{c}\text { JA } \\
\text { in } \\
\text { media }\end{array}$ & $\begin{array}{c}\text { Total number } \\
\text { of minitubers } \\
\text { per } 20 \\
\text { microtubers }\end{array}$ & $\begin{array}{c}\text { Number of } \\
\text { minitubers size } \\
5-30 \mathrm{~mm}\end{array}$ & $\begin{array}{c}\text { Number of } \\
\text { minitubers size } \\
30-60 \mathrm{~mm}\end{array}$ & $\begin{array}{c}\text { Number of } \\
\text { minitubers size } \\
>60 \mathrm{~mm}\end{array}$ \\
\hline AT & No & No & $1.93 \mathrm{ab}^{*}$ & $1.50 b c$ & $0.30 \mathrm{bc}$ & $0.00 \mathrm{~b}$ \\
\hline AT & No & Yes & $3.29 \mathrm{ab}$ & $2.39 \mathrm{bc}$ & $0.61 \mathrm{bc}$ & $0.00 \mathrm{~b}$ \\
\hline AT & Yes & No & $2.06 \mathrm{ab}$ & $1.48 \mathrm{bc}$ & $0.23 b c$ & $0.00 \mathrm{~b}$ \\
\hline AT & Yes & Yes & $4.36 a b$ & $2.95 \mathrm{ab}$ & $0.79 \mathrm{abc}$ & $0.00 \mathrm{~b}$ \\
\hline RB & No & No & $13.38 \mathrm{a}$ & $11.14 \mathrm{a}$ & $1.96 \mathrm{ab}$ & $0.27 \mathrm{a}$ \\
\hline RB & No & Yes & $1.14 \mathrm{~b}$ & $0.86 \mathrm{c}$ & $0.08 \mathrm{c}$ & $0.00 \mathrm{~b}$ \\
\hline RB & Yes & No & $4.08 \mathrm{ab}$ & $2.31 \mathrm{bc}$ & $0.93 \mathrm{ab}$ & $0.08 \mathrm{~b}$ \\
\hline RB & Yes & Yes & $4.62 \mathrm{a}$ & $3.13 \mathrm{ab}$ & $0.92 \mathrm{~b}$ & $0.01 \mathrm{~b}$ \\
\hline SH & No & No & $3.96 \mathrm{ab}$ & $1.18 \mathrm{bc}$ & $1.63 \mathrm{ab}$ & $0.71 \mathrm{a}$ \\
\hline SH & No & Yes & $6.17 \mathrm{a}$ & $2.06 \mathrm{bc}$ & $2.41 \mathrm{ab}$ & $1.19 \mathrm{a}$ \\
\hline SH & Yes & No & $6.65 \mathrm{a}$ & $1.25 \mathrm{bc}$ & $2.84 \mathrm{a}$ & $1.00 \mathrm{a}$ \\
\hline SH & Yes & Yes & $4.32 \mathrm{ab}$ & $1.25 \mathrm{bc}$ & $1.39 \mathrm{ab}$ & $0.68 \mathrm{a}$ \\
\hline
\end{tabular}

Means in the same column followed by different letters are significantly different at the $5 \%$ level of significance. 


\section{Chapter 7}

Microtubers produced under light were significantly better propagules than the microtubers produced in darkness. In all three tested cultivars, the total number of minitubers obtained from these microtubers (per plot, 20 planted) was 4 times higher, 7.85 vs 1.66, respectively (data not shown). All other characteristics (total yield and number of minitubers in 5-30,30-60 and $>60 \mathrm{~mm}$ ) were also $2-7$ times higher in production of minitubers from microtubers exposed to light during in vitro tuberization. Shepody produced the highest total yield of minitubers tubers followed by Russet Burbank and Atlantic (data not shown).

In 1999 season, the production of minitubers from microtubers was much higher than in 1998. All tested factors: cultivar (C), the presence of jasmonic acid in pretreatment medium and in the tuberization medium, the exposure to light during tuberization and the dormancy breaking treatment had significant effects on all response variables, namely the number and yield (weight in $\mathrm{kg}$ ) of minitubers produced per microtuber in different size categories. A three-factor interaction, cultivar, JA pre-treatment and JA in media was significant for the total number of minitubers, number of tubers $5-30 \mathrm{~mm}$ and $30-60 \mathrm{~mm}$ in diameter, and yield of tubers $30-60$ $\mathrm{mm}$. The results are summarized in Table 3. Although the three-factor interaction for total yield was not significant, its means comparison is presented in Table 3 for completeness. Amisk produced the highest number of minitubers (61.31) per plot of 20 microtubers (more than 3 minitubers per microtuber) derived from pre-treated with JA plantlets. In general, microtubers derived from explants taken from JA conditioned stock plants gave more minitubers than the microtubers from other treatments (for example the total yields in Russet Burbank and Umatilla Russet were the highest in this treatment, 0.859 and $0.879 \mathrm{~kg}$, respectively). Almost all tested response variables (parameters) were also the highest in JAPret-yes/JAMed-no treatment combinations (Table 3). Amisk numbers of minitubers derived from the microtubers were comparable to numbers obtained from plantlets (65.5 minitubers from 20 plantlets (Table 1B) and 61.31 from 20 microtubers derived from JA treated stock plants (Table 3)). Also, Amisk yield of minitubers in the $30-60 \mathrm{~mm}$ category was almost the same from plantlets (Table 1B) as from microtubers from the JA pre-treatment (Table 4), $0.472 \mathrm{vs}$ $0.446 \mathrm{~kg}$ per plot. Russet Burbank and Umatilla Russet produced fewer tubers from microtubers (Russet Burbank 44.62 per plot, 41.18 Umatilla Russet per plot (Table 3)) than from plantlets (RB 59.5 per plot, UM 72.5 per plot (Table 1B)). The column most to the right in Table 3 (the average of total yields) shows the benefits of pre-treatment with JA of stock plants before tuberization on yield of minitubers in Russet Burbank and Umatilla Russet.

Significant interactions between light exposure during in vitro tuberization, cultivar and jasmonate pre-treatment, and light, cultivar and jasmonate in media were observed 
Table 3. Effects of JA treatments during the in vitro explant production and in vitro tuberization on production of minitubers from in vitro tubers in the greenhouse. Least square means comparison of the responses with significant Cultivar, JA pre-treatment and JA in media interaction. Cultivars: Amisk (AM), Russet Burbank (RB), Umatilla Russet (UM), 1999 season.

\begin{tabular}{|c|c|c|c|c|c|c|c|}
\hline Cultivar & $\begin{array}{c}\text { JA } \\
\text { pre- } \\
\text { treated }\end{array}$ & $\begin{array}{c}\text { JA } \\
\text { in } \\
\text { media }\end{array}$ & $\begin{array}{c}\text { Total } \\
\text { number of } \\
\text { minitubers } \\
\text { per } 20 \\
\text { microtubers }\end{array}$ & $\begin{array}{c}\text { Number of } \\
\text { minitubers } \\
\text { size } \\
5-30 \mathrm{~mm}\end{array}$ & $\begin{array}{c}\text { Number of } \\
\text { minitubers } \\
\text { size } \\
30-60 \mathrm{~mm}\end{array}$ & $\begin{array}{c}\text { Yield of } \\
\text { minitubers } \\
\text { size } \\
30-60 \mathrm{~mm} \\
{[\mathrm{~kg}]}\end{array}$ & $\begin{array}{c}\text { Total yield } \\
\text { of mini- } \\
\text { tubers per } \\
20 \text { micro- } \\
\text { tubers [kg] }\end{array}$ \\
\hline $\mathrm{AM}$ & No & No & $50.94 \mathrm{abc}^{*}$ & $20.83 \mathrm{ab}$ & $15.62 \mathrm{bc}$ & $0.300 \mathrm{~cd}$ & $1.119 \mathrm{a}$ \\
\hline $\mathrm{AM}$ & No & Yes & $55.25 \mathrm{ab}$ & $22.40 \mathrm{ab}$ & $18.18 \mathrm{ab}$ & $0.417 \mathrm{ab}$ & $1.092 \mathrm{ab}$ \\
\hline $\mathrm{AM}$ & Yes & No & $61.31 \mathrm{a}$ & $24.02 \mathrm{a}$ & $21.56 \mathrm{a}$ & $0.446 a$ & $1.078 \mathrm{ab}$ \\
\hline AM & Yes & Yes & $49.69 \mathrm{bc}$ & $20.18 \mathrm{ab}$ & $16.56 b c$ & $0.332 b c$ & $0.849 \mathrm{abc}$ \\
\hline RB & No & No & $20.44 \mathrm{f}$ & $4.80 \mathrm{e}$ & $8.68 \mathrm{~d}$ & $0.160 \mathrm{e}$ & $0.409 \mathrm{~d}$ \\
\hline $\mathrm{RB}$ & No & Yes & $24.06 \mathrm{f}$ & $4.99 \mathrm{e}$ & $10.56 \mathrm{~d}$ & $0.234 \mathrm{de}$ & $0.573 \mathrm{~d}$ \\
\hline $\mathrm{RB}$ & Yes & No & $44.62 \mathrm{bcd}$ & $15.69 \mathrm{bc}$ & $16.56 \mathrm{bc}$ & $0.322 \mathrm{bcd}$ & $0.859 a b c$ \\
\hline $\mathrm{RB}$ & Yes & Yes & $17.87 \mathrm{f}$ & $3.57 \mathrm{e}$ & $6.87 \mathrm{~d}$ & $0.140 \mathrm{e}$ & $0.433 \mathrm{~d}$ \\
\hline UM & No & No & $35.62 \mathrm{de}$ & $9.48 \mathrm{de}$ & $15.62 b c$ & $0.337 \mathrm{bc}$ & $0.826 b c$ \\
\hline UM & No & Yes & $35.44 \mathrm{de}$ & $10.61 \mathrm{~cd}$ & $15.00 \mathrm{bc}$ & $0.343 \mathrm{bc}$ & $0.729 \mathrm{~cd}$ \\
\hline UM & Yes & No & $41.18 \mathrm{~cd}$ & $12.46 \mathrm{~cd}$ & $19.19 \mathrm{ab}$ & $0.415 \mathrm{ab}$ & $0.879 \mathrm{abc}$ \\
\hline UM & Yes & Yes & $33.25 \mathrm{ef}$ & $9.15 \mathrm{de}$ & $16.87 \mathrm{bc}$ & $0.360 \mathrm{abc}$ & $0.701 \mathrm{~cd}$ \\
\hline
\end{tabular}

* Means in the same column followed by different letters are significantly different at the $5 \%$ level of significance.

for minitubers $5-30 \mathrm{~mm}$ in diameter (Table 4). On average, Amisk produced significantly more minitubers in this category, 27.84 per plot (from 20 microtubers in JAPret per $8 \mathrm{~h}$ light treatment combination) than Russet Burbank, 8.64 per plot and Umatilla Russet, 11.43 per plot (Table 4). Similar trend was observed in JAMed per 8 $\mathrm{h}$ light treatment combination.

\section{Field production of Pre-elite tubers}

From plantlets. The production of Pre-elite seed tubers from in vitro derived plantlets is summarized in Tables 5A (1998) and 5B (1999). No significant differences were found in total yield of Pre-elite tubers between cultivars in either of the seasons, although the yields in 1998 seemed higher than in 1999. This was likely a result of the 


\section{Chapter 7}

Table 4. Effects of $\mathrm{JA}$ and light, during the in vitro phases of microtuber production, on yield and number of minitubers (size $5-30 \mathrm{~mm}$ ) produced from microtubers in the greenhouse. Least square means comparison of response variables with significant CultivarXJAPretreatment $\times$ Light, and Cultivar $\times$ Light $\times$ JAinMedia interaction. Cultivars: Amisk (AM), Russet Burbank (RB) and Umatilla Russet (UM), 1999 season.

\begin{tabular}{|c|c|c|c|c|c|c|c|}
\hline \multicolumn{5}{|c|}{ Cultivar $\times$ JAPre-treatment $\times$ Light } & \multicolumn{3}{|c|}{ Cultivar $\times$ Light $\times$ JAMedia } \\
\hline Cultivar ${ }^{* *}$ & $\begin{array}{c}\text { JA } \\
\text { pre- } \\
\text { treated }\end{array}$ & $\begin{array}{c}\text { Light }^{* *} \\
{[\mathrm{~h}]}\end{array}$ & $\begin{array}{c}\text { Number of } \\
\text { minitubers } \\
\text { size } \\
5-30 \mathrm{~mm}\end{array}$ & $\begin{array}{c}\text { Yield of } \\
\text { minitubers } \\
\text { size } \\
5-30 \mathrm{~mm}[\mathrm{~kg}]\end{array}$ & $\begin{array}{c}\text { JA } \\
\text { in } \\
\text { media }\end{array}$ & $\begin{array}{c}\text { Number of } \\
\text { minitubers } \\
\text { size } \\
5-30 \mathrm{~mm}\end{array}$ & $\begin{array}{c}\text { Yield of } \\
\text { minitubers size } \\
5-30 \mathrm{~mm} \\
{[\mathrm{~kg}]}\end{array}$ \\
\hline $\mathbf{A M}$ & No & $\mathbf{0}$ & $17.63 \mathrm{~b}^{*}$ & $0.077 \mathrm{a}$ & No & 19.08 bc & 0.089 a \\
\hline AM & No & 8 & $26.00 \mathrm{a}$ & $0.081 \mathrm{a}$ & No & $25.98 \mathrm{ab}$ & $0.090 \mathrm{a}$ \\
\hline $\mathbf{A M}$ & Yes & $\mathbf{0}$ & $16.95 \mathrm{~b}$ & $0.063 \mathrm{ab}$ & Yes & $15.60 \mathrm{~cd}$ & $0.052 \mathrm{c}$ \\
\hline AM & Yes & 8 & $27.84 \mathrm{a}$ & $0.090 \mathrm{a}$ & Yes & $27.85 \mathrm{a}$ & $0.081 \mathrm{ab}$ \\
\hline $\mathbf{R B}$ & No & $\mathbf{0}$ & $2.88 \mathrm{e}$ & 0.011 e & No & $5.38 \mathrm{fg}$ & 0.019 ef \\
\hline RB & No & 8 & $7.44 \mathrm{~d}$ & $0.024 \mathrm{de}$ & No & $14.68 \mathrm{~cd}$ & $0.047 \mathrm{~cd}$ \\
\hline $\mathbf{R B}$ & Yes & $\mathbf{0}$ & $8.47 \mathrm{~d}$ & $0.027 \mathrm{~d}$ & Yes & $5.23 \mathrm{fg}$ & 0.017 ef \\
\hline $\mathbf{R B}$ & Yes & 8 & $8.64 d$ & $0.030 \mathrm{~cd}$ & Yes & $3.37 \mathrm{~g}$ & $0.012 \mathrm{f}$ \\
\hline UM & No & $\mathbf{0}$ & $6.47 d$ & 0.022 de & No & $5.92 \mathrm{fg}$ & $0.022 \mathrm{de}$ \\
\hline UM & No & 8 & $14.37 \mathrm{bc}$ & $0.048 b c$ & No & $17.42 \mathrm{c}$ & $0.060 \mathrm{bc}$ \\
\hline UM & Yes & $\mathbf{0}$ & $10.42 \mathrm{~cd}$ & $0.038 \mathrm{~cd}$ & Yes & $10.79 \mathrm{de}$ & $0.038 \mathrm{~cd}$ \\
\hline UM & Yes & 8 & $11.43 \mathrm{bcd}$ & $0.040 \mathrm{bcd}$ & Yes & 8.99 ef & $0.031 \mathrm{de}$ \\
\hline
\end{tabular}

Means in the same column followed by different letters are significantly different at the $5 \%$ level of significance.

** This column is also for the Cultivar $\times$ Light $\times$ JAinMedia part of the table.

Bold rows - minitubers produced from the microtubers grown in the dark treatment.

lower number of corn heat units the crop received during 1999 growing season $(1,200$ units) comparing to 1998 (1,398 units). In 1998, Atlantic and Shepody produced the highest number of Pre-elite tubers (about 30\% more than Russet Burbank). Most of the Pre-elite tubers of Atlantic and Russet Burbank were in $48-88 \mathrm{~mm}$ size category, and that of Shepody were in $<48 \mathrm{~mm}$. Atlantic and Shepody also produced a few tubers in $>88 \mathrm{~mm}$ category, whereas in Russet Burbank the number of tubers and yield in this category were negligible (Table 5A). No significant differences in total yields between cultivars and in the number of tubers in $48-88 \mathrm{~mm}$ category were observed in 1999 (Table 5B). The plug method used in 1999 during transplanting plantlets to the field did not prove effective. Umatilla Russet produced the highest number of Pre-elite 
Table 5. Production of Pre-elite tubers from in vitro derived plantlets. Least square means comparison of Cultivar (1998), and CultivarxTransplanting Method (1999). Cultivars (CV): Atlantic (AT), Amisk (AM), Russet Burbank (RB), Shepody (SH), Umatilla Russet (UM).

\begin{tabular}{|c|c|c|c|c|c|c|c|c|}
\hline \multicolumn{9}{|c|}{ A. 1998 season } \\
\hline $\mathrm{CV}$ & $\begin{array}{c}\text { Total } \\
\text { number of } \\
\text { Pre-elite } \\
\text { tubers } \\
\text { from } 20 \\
\text { plantlets }\end{array}$ & $\begin{array}{c}\text { Number } \\
\text { of tubers } \\
\text { size } \\
<48 \mathrm{~mm}\end{array}$ & $\begin{array}{c}\text { Number } \\
\text { of tubers } \\
\text { size } \\
48-88 \\
\mathrm{~mm}\end{array}$ & $\begin{array}{c}\text { Number } \\
\text { of tubers } \\
\text { size } \\
>88 \mathrm{~mm}\end{array}$ & $\begin{array}{c}\text { Total yield } \\
\text { of Pre-elite } \\
\text { tubers from } \\
20 \text { plantlets } \\
\text { [kg] }\end{array}$ & $\begin{array}{c}\text { Yield of } \\
\text { tubers } \\
\text { size } \\
<48 \mathrm{~mm} \\
{[\mathrm{~kg}]}\end{array}$ & $\begin{array}{c}\text { Yield of } \\
\text { tubers } \\
\text { size } \\
48-88 \mathrm{~mm} \\
{[\mathrm{~kg}]}\end{array}$ & $\begin{array}{c}\text { Yield of } \\
\text { tubers } \\
\text { size } \\
>88 \mathrm{~mm} \\
{[\mathrm{~kg}]}\end{array}$ \\
\hline AT & $129.0 \mathrm{a}^{*}$ & $57.0 \mathrm{a}$ & $71.0 \mathrm{a}$ & $1.00 \mathrm{a}$ & $14.178 \mathrm{a}$ & $2.200 \mathrm{a}$ & $11.050 \mathrm{a}$ & $0.537 \mathrm{a}$ \\
\hline $\mathrm{RB}$ & $80.8 \mathrm{~b}$ & $33.6 \mathrm{~b}$ & $47.1 \mathrm{c}$ & $0.09 \mathrm{~b}$ & $12.238 \mathrm{a}$ & $1.604 \mathrm{~b}$ & $10.382 \mathrm{~b}$ & $0.061 \mathrm{c}$ \\
\hline SH & $113.2 \mathrm{a}$ & $61.5 \mathrm{a}$ & $51.2 \mathrm{~b}$ & $0.50 \mathrm{ab}$ & $13.985 \mathrm{a}$ & $2.195 \mathrm{a}$ & $11.223 \mathrm{a}$ & $0.330 \mathrm{~b}$ \\
\hline \multicolumn{9}{|c|}{ B. 1999 season } \\
\hline$\overline{\mathrm{AM}}$ & $59.6 \mathrm{c}$ & $20.1 \mathrm{c}$ & $38.3 \mathrm{a}$ & $\begin{array}{c}\text { No } \\
\text { tubers }\end{array}$ & $9.440 \mathrm{a}$ & $1.226 \mathrm{c}$ & $\begin{array}{r}\text { Jar } 7.146 a \\
\text { Plug } 8.480 a\end{array}$ & $\begin{array}{c}\text { No } \\
\text { tubers }\end{array}$ \\
\hline RB & $79.3 \mathrm{~b}$ & $41.7 \mathrm{~b}$ & $37.5 \mathrm{a}$ & $\begin{array}{c}\text { No } \\
\text { tubers }\end{array}$ & $9.022 \mathrm{a}$ & $2.241 \mathrm{~b}$ & $\begin{array}{r}\text { Jar 7.301a } \\
\text { Plug 4.711b }\end{array}$ & $\begin{array}{c}\text { No } \\
\text { tubers }\end{array}$ \\
\hline UM & $100.0 \mathrm{a}$ & 56.5 a & $43.5 \mathrm{a}$ & $\begin{array}{c}\text { No } \\
\text { tubers }\end{array}$ & $11.060 \mathrm{a}$ & $3.295 \mathrm{a}$ & $\begin{array}{r}\text { Jar } 8.400 \mathrm{a} \\
\text { Plug } 6.995 a\end{array}$ & $\begin{array}{c}\text { No } \\
\text { tubers }\end{array}$ \\
\hline
\end{tabular}

* Means within a column in each season followed by different letters are significantly different at the $5 \%$ level of significance.

tubers (100 per plot from 20 plantlets ( 5 per plantlet, about $20 \%$ more than Russet Burbank and 40\% more than Amisk). Most of the Umatilla Russet and Russet Burbank Pre-elite tubers were smaller than $48 \mathrm{~mm}$ in diameter. None of the three varieties tested, produced tubers larger than $88 \mathrm{~mm}$ (Table 5B). Most of the plants derived from plantlets produced excessive foliage (Figure 1E) with lower stem branching.

From microtubers. Similar to the greenhouse study, in the 1998 field experiments, the production of Pre-elite tubers from microtubers was low and erratic (Table 6). This outcome might have been caused by the incomplete break of their dormancy before planting. The effects of JA addition to the pre-treatment and to the tuberization media on the yield and number of Pre-elite tubers are shown in Tables 6 and 7. Yields of Atlantic were consistently very low, causing difficulty to meet normality assumptions of the statistical model. Consequently, this variety was excluded from data analysis.

Table 6 shows the effects of JA conditioning of stock plantlets where the nodal 


\section{Chapter 7}

Table 6. Effects of JA in microtuber pre-treatment media (JAPret) on field production of Preelite tubers in Russet Burbank (RB) and Shepody (SH). Least square means comparisons for the responses with significant Cultivar by JA pre-treatment interaction, 1998 season.

\begin{tabular}{lccccc}
\hline Cultivar & $\begin{array}{c}\text { JA } \\
\text { pre- } \\
\text { treatment }\end{array}$ & $\begin{array}{c}\text { Total number of } \\
\text { Pre-elite tubers per } \\
20 \text { microtubers }\end{array}$ & $\begin{array}{c}\text { Number of } \\
\text { Pre-elite tubers } \\
\text { size }<48 \mathrm{~mm}\end{array}$ & $\begin{array}{c}\text { Number of } \\
\text { Pre-elite tubers } \\
\text { size } 48-88 \mathrm{~mm}\end{array}$ & $\begin{array}{c}\text { Yield of } \\
\text { Pre-elite tubers } \\
\text { size }<48 \mathrm{~mm} \\
{[\mathrm{~kg}]}\end{array}$ \\
\hline RB & No & $35.38 \mathrm{~b}^{*}$ & $29.49 \mathrm{~b}$ & $5.88 \mathrm{~b}$ & $0.882 \mathrm{~b}$ \\
RB & Yes & $50.38 \mathrm{a}$ & $40.11 \mathrm{a}$ & $10.26 \mathrm{a}$ & $1.387 \mathrm{a}$ \\
SH & No & $47.69 \mathrm{ab}$ & $36.30 \mathrm{ab}$ & $11.39 \mathrm{a}$ & $1.185 \mathrm{ab}$ \\
SH & Yes & $39.75 \mathrm{ab}$ & $31.24 \mathrm{~b}$ & $8.51 \mathrm{ab}$ & $0.891 \mathrm{~b}$ \\
\hline
\end{tabular}

" Means in the same column followed by different letters are significantly different at the $5 \%$ level of significance.

Table 7. Effects of JA in tuberization media (JAMed) on field production of Pre-elite tubers in Russet Burbank (RB) and Shepody (SH). Least square means comparisons for the responses with significant Cultivar (CV) by JA in media interaction, 1998 season

\begin{tabular}{|c|c|c|c|c|c|c|c|}
\hline $\mathrm{CV}$ & $\begin{array}{c}\mathrm{JA} \\
\text { in } \\
\text { media }\end{array}$ & $\begin{array}{c}\text { Total } \\
\text { number of } \\
\text { Pre-elite } \\
\text { tubers per } \\
20 \text { micro- } \\
\text { tubers }\end{array}$ & $\begin{array}{l}\text { Number of } \\
\text { Pre-elite } \\
\text { tubers size } \\
<48 \mathrm{~mm}\end{array}$ & $\begin{array}{l}\text { Number of } \\
\text { Pre-elite } \\
\text { tubers size } \\
48-88 \mathrm{~mm}\end{array}$ & $\begin{array}{l}\text { Total yield } \\
\text { of Pre-elite } \\
\text { tubers per } \\
20 \text { micro- } \\
\text { tubers [kg] }\end{array}$ & $\begin{array}{c}\text { Yield of } \\
\text { Pre-elite } \\
\text { tubers size } \\
<48 \mathrm{~mm} \\
{[\mathrm{~kg}]}\end{array}$ & $\begin{array}{c}\text { Yield of } \\
\text { Pre-elite } \\
\text { tubers size } \\
48-88 \mathrm{~mm} \\
\text { [kg] }\end{array}$ \\
\hline RB & No & $54.3 \mathrm{a}^{*}$ & $41.8 \mathrm{a}$ & $12.4 \mathrm{a}$ & $3.654 \mathrm{a}$ & $1.732 \mathrm{a}$ & $1.922 \mathrm{ab}$ \\
\hline RB & Yes & $31.4 \mathrm{c}$ & $27.7 \mathrm{c}$ & $3.7 \mathrm{c}$ & $1.263 \mathrm{c}$ & $0.855 \mathrm{~b}$ & $0.408 \mathrm{c}$ \\
\hline SH & No & $40.7 \mathrm{bc}$ & $32.3 b c$ & $8.4 \mathrm{~b}$ & $2.935 \mathrm{~b}$ & $1.333 \mathrm{ab}$ & $1.430 \mathrm{~b}$ \\
\hline SH & Yes & $46.7 \mathrm{ab}$ & $35.2 \mathrm{~b}$ & $11.5 \mathrm{ab}$ & $3.422 \mathrm{ab}$ & $1.344 \mathrm{ab}$ & $2.078 \mathrm{a}$ \\
\hline
\end{tabular}

* Means in the same column followed by different letters are significantly different at the $5 \%$ level of significance.

cuttings were taken from to produce microtubers, which were later used for production of Pre-elite tubers on the field. The JA pre-treatment significantly enhanced the total number of Pre-elite tubers in Russet Burbank by approximately $40 \%$ but lowered it in Shepody by $17 \%$ (Table 6). In Russet Burbank, all the responses (total number of Preelite tubers, number of tubers $<48 \mathrm{~mm}$, number of tubers $48-88 \mathrm{~mm}$ and yield of tubers $<48 \mathrm{~mm}$ ) were significantly higher in the JA pre-conditioned treatments than in 
the no-JA control. The reverse was true in Shepody. In Russet Burbank, about 2.5 Preelite tubers were produced per microtuber in the JA pre-treatment $v s 1.8$ in no-JA (Table 6). On the other hand, the effect of JA in tuberization medium on the production of Pre-elite tubers in the field was opposite to that of JA pre-treatment. In Russet Burbank, the total number of Pre-elite tubers was about $42 \%$ and yield was about $65 \%$ lower than those from non-JA media (Table 7). Shepody, on the other hand, was either indifferent to or benefited from the JA treatment. In general, JA in tuberization media enhanced Shepody's Pre-elite tuber production by up to $45 \%$ (Table 7).

Exposure to light during in vitro tuberization had also a significant effect on the performance of the microtuber propagules in the field, in both cultivars. Responses were very similar to those in the greenhouse production of minitubers. Total number of Pre-elite tubers produced from microtubers ( 20 planted) treated with $8 \mathrm{~h}$ light was about 50 - 60\% higher than from the microtubers produced in dark, 52.54 and 34.06 respectively (data not shown). Similar results were recorded for total yield and yield, and number of $<48 \mathrm{~mm}$ in diameter tubers.

The results of our 1998 studies demonstrated that microtubers produced under $8 \mathrm{~h}$ photoperiod gave higher yields of minitubers and Pre-elite seed tubers. Consequently, only this kind of microtubers was used in the 1999 field planting. The overall production of Pre-elite tubers from microtubers in 1999 was more consistent than in 1998, mainly due to a more effective microtuber dormancy release with Rindite. Two twofactor interactions (Cultivar $\times J A$ in media and Cultivar $\times$ JAPretreatment) were significant for the total number and yield of Pre-elite tubers, and for the number and yield of Pre-elite tubers in $48-88 \mathrm{~mm}$ size category (Table 8). As in 1998, with the exception of Russet Burbank, the microtubers produced with JA in the tuberization medium gave fewer Pre-elite tubers than those produced without JA. Comparing to the control, the yield of Umatilla Russet was reduced the most (for example, by almost $90 \%$ in $48-88$ $\mathrm{mm}$ size category) (Table 8 ). On the contrary, microtubers produced from the JA conditioned Amisk stock plantlets gave up to $10 \%$ higher yield of Pre-elite tubers in the $48-88 \mathrm{~mm}$ category (Table 8 ). In Russet Burbank the yield was also slightly higher, $1.226 v s 1.200 \mathrm{~kg}$ in non JAPret. Although these results were not statistically significant, they correspond to the 1998 results in Russet Burbank.

\section{Microtuber dormancy release studies (1999 season)}

Dormancy release of microtubers prior to the greenhouse and field plantings had a profound impact on the production of minitubers in the greenhouse (Tables 9-11) and Pre-elite tubers in the field (Table 12).

Table 9 summarizes a significant Cultivar $\times$ Dormancy release treatment interaction 


\section{Chapter 7}

Table 8. Effects of JA pre-treatment during explant production and in vitro tuberization, and cultivar on the field production of Pre-elite tubers from microtubers. Least square means

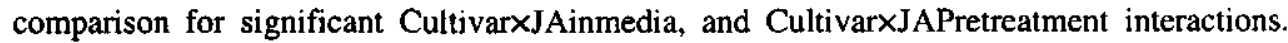
Cultivars (CV): Amisk (AM), Russet Burbank (RB), Umatilla Russet (UM), 1999 season.

\begin{tabular}{|c|c|c|c|c|c|c|c|}
\hline \multicolumn{6}{|c|}{ CultivarXJAMedia } & \multicolumn{2}{|c|}{$\begin{array}{c}\text { Cultivar } \times \text { JAPre- } \\
\text { treatment }\end{array}$} \\
\hline $\mathrm{CV}^{* *}$ & $\begin{array}{c}\text { JA } \\
\text { in } \\
\text { media }\end{array}$ & $\begin{array}{c}\text { Total } \\
\text { number of } \\
\text { Pre-elite } \\
\text { tubers per } 20 \\
\text { microtubers }\end{array}$ & $\begin{array}{l}\text { Number of } \\
\text { Pre-elite } \\
\text { tubers size } \\
48-88 \mathrm{~mm}\end{array}$ & $\begin{array}{c}\text { Total yield } \\
\text { of Pre-elite } \\
\text { tubers per } 20 \\
\text { microtubers } \\
\text { [kg] }\end{array}$ & $\begin{array}{c}\text { Yield of Pre- } \\
\text { elite tubers } \\
\text { size } \\
48-88 \mathrm{~mm} \\
{[\mathrm{~kg}]}\end{array}$ & $\begin{array}{r}\text { JA } \\
\text { pre- } \\
\text { treat- } \\
\text { ment } \\
\end{array}$ & $\begin{array}{c}\text { Yield of } \\
\text { Pre-elite } \\
\text { tubers size } \\
48-88 \mathrm{~mm} \\
{[\mathrm{~kg}]}\end{array}$ \\
\hline AM & No & $69.75 \mathrm{a}^{*}$ & $14.56 \mathrm{a}$ & $3.871 \mathrm{a}$ & $1.860 \mathrm{a}$ & No & $1.576 \mathrm{ab}$ \\
\hline $\mathrm{AM}$ & Yes & $55.62 \mathrm{ab}$ & $10.81 \mathrm{ab}$ & $3.061 \mathrm{~b}$ & $1.537 \mathrm{a}$ & Yes & $1.739 \mathrm{a}$ \\
\hline RB & No & $61.37 \mathrm{ab}$ & $10.06 \mathrm{ab}$ & $2.358 \mathrm{bc}$ & $1.115 \mathrm{ab}$ & No & $1.200 \mathrm{bc}$ \\
\hline RB & Yes & $58.75 \mathrm{ab}$ & $11.81 \mathrm{ab}$ & $2.588 \mathrm{bc}$ & $1.225 \mathrm{ab}$ & Yes & $1.226 \mathrm{~b}$ \\
\hline UM & No & $60.25 \mathrm{ab}$ & $6.56 \mathrm{~b}$ & $2.100 \mathrm{c}$ & $0.715 b$ & No & $1.021 \mathrm{c}$ \\
\hline UM & Yes & $42.00 \mathrm{~b}$ & $1.87 \mathrm{c}$ & $0.929 \mathrm{~d}$ & $0.053 \mathrm{c}$ & Yes & $0.976 \mathrm{c}$ \\
\hline
\end{tabular}

Means in the same column followed by different letters are significantly different at the $5 \%$ level of significance.

** Column also for the CultivarXJAPretreatment part of the table.

Table 9. Effects of dormancy breaking treatment, applied to microtubers prior to greenhouse planting, on production of minitubers in the greenhouse. Least square means comparison for significant Cultivar by Dormancy treatment interaction. Cultivars (CV): Amisk (AM), Russet Burbank (RB), Umatilla Russet (UM).

\begin{tabular}{llcccc}
\hline CV & $\begin{array}{c}\text { Dormancy } \\
\text { release } \\
\text { treatment }\end{array}$ & $\begin{array}{c}\text { Total number } \\
\text { of minitubers } \\
\text { from } 20\end{array}$ & $\begin{array}{c}\text { Number of } \\
\text { minitubers size } \\
\text { microtubers }\end{array}$ & $\begin{array}{c}\text { Total yield of } \\
\text { minitubers from } \\
200 \mathrm{~mm}\end{array}$ & $\begin{array}{c}\text { Yield of } \\
\text { minitubers }\end{array}$ \\
\hline AM & GA & $29.22 \mathrm{c}^{*}$ & $5.78 \mathrm{c}$ & $0.611 \mathrm{c}$ & $0.354 \mathrm{c}$ \\
AM & Rindite & $79.37 \mathrm{a}$ & $14.72 \mathrm{a}$ & $1.458 \mathrm{a}$ & $0.778 \mathrm{a}$ \\
RB & GA & $9.12 \mathrm{~d}$ & $0.84 \mathrm{~d}$ & $0.116 \mathrm{~d}$ & $0.040 \mathrm{~d}$ \\
RB & Rindite & $44.37 \mathrm{~b}$ & $10.12 \mathrm{~b}$ & $1.021 \mathrm{~b}$ & $0.598 \mathrm{ab}$ \\
UM & GA & $21.63 \mathrm{c}$ & $4.69 \mathrm{c}$ & $0.561 \mathrm{c}$ & $0.322 \mathrm{c}$ \\
UM & Rindite & $51.13 \mathrm{~b}$ & $7.31 \mathrm{c}$ & $1.007 \mathrm{~b}$ & $0.426 \mathrm{bc}$ \\
\hline
\end{tabular}

" Means in the same column followed by different letters are significantly different at the $5 \%$ level of significance. 
for the total number and yield of large minitubers. Microtubers treated with Rindite produced 2 - 5 times more minitubers than those treated with gibberellic acid $\left(\mathrm{GA}_{3}\right)$ in all three varieties. Also, total number and yield of minitubers $>60 \mathrm{~mm}$ in diameter was significantly higher from the microtubers treated with Rindite than with $\mathrm{GA}_{3}$. The largest difference was observed in Russet Burbank, which produced on average approximately 45 minitubers from 20 microtubers $(2.25$ per microtuber) treated with Rindite comparing to only 9 ( 0.45 per microtuber) from the $\mathrm{GA}_{3}$ treatment (Table 9 ). Amisk produced the highest total number of minitubers (79.37, almost 4 minitubers per one planted microtuber) among the tested varieties and the highest yield of minitubers $>60 \mathrm{~mm}$ (Table 9).

Jasmonic acid in Media $\times$ Light $\times$ Dormancy release treatment interaction was significant for total number and yield as well as for all size categories of minitubers (Table 10). Overall, Rindite treatment gave significantly higher tuber numbers and yields, irrespective of the JA presence in tuberization media and of the photoperiod. Microtubers treated with $\mathrm{GA}_{3}$ yielded significantly fewer minitubers than those treated with Rindite (Table 10). Exposure to light during the microtuber production phase had later on a significant effect on their performance in the greenhouse. Almost all parameters for all three cultivars were the highest for minitubers grown from microtubers produced under $8 \mathrm{~h}$ photoperiod with no JA in tuberization medium, coming from the Rindite dormancy release treatment (Table 10).

The results of the effect of JA conditioning of the stock plants, prior to taking explants for in vitro tuberization, combined with the exposure to light during the production of microtubers and with the dormancy release treatment are presented in Table 11. The JAPretreatment $\times$ Light $\times$ Dormancy release treatment interaction was significant for the total number and yield of minitubers, and for the yields in two size categories, $30-60 \mathrm{~mm}$ and $>60 \mathrm{~mm}$. All the responses for minitubers produced from Rindite treated microtubers were significantly higher than for those treated with GA. Exposure to light during the in vitro tuberization phase was much less pronounced in the greenhouse performance of microtubers produced from JA pre-treated plantlets (Table 11) than for microtubers coming from JA containing media (Table 10). In fact, light during the microtuberization step significantly lowered $(20-40 \%)$ number and yield of minitubers coming from JA conditioned microtubers subjected to Rindite dormancy release. On the contrary, GA-treated microtubers performed better when produced under $8 \mathrm{~h}$ light (Table 10). The microtubers from JAPret- $0 \mathrm{~h}$ light-Rindite treatment combination gave the highest number and yield of minitubers in the greenhouse (Table 11).

As opposed to the greenhouse study, in the field production of the Pre-elite tubers, $\mathrm{GA}_{3}$ treatment of microtubers was more effective than Rindite (Table 12). For all three 


\section{Chapter 7}

Table 10. Effects of JA in tuberization media, exposure to light during microtuber production and dormancy breaking treatment (applied to microtubers prior to greenhouse planting) on production of minitubers in three Russet cultivars in the greenhouse. Least square means comparison for all eight response variables (parameters) with significant JA in Media $\times$ Light $\times$ Dormancy breaking treatment interaction effect.

\begin{tabular}{|c|c|c|c|c|c|c|c|c|c|c|}
\hline $\begin{array}{l}\text { JA } \\
\text { in } \\
\text { media }\end{array}$ & $\begin{array}{c}\mathrm{Li} \\
{[\mathrm{h}]}\end{array}$ & $\begin{array}{l}\text { Dor- } \\
\text { mancy } \\
\text { release }\end{array}$ & $\begin{array}{l}\text { Total } \\
\text { number } \\
\text { of mini- } \\
\text { tubers } \\
\text { from } 20 \\
\text { micro- } \\
\text { tubers }\end{array}$ & $\begin{array}{c}\text { Number } \\
\text { of mini- } \\
\text { tubers } \\
\text { size } \\
5-30 \\
\text { mm }\end{array}$ & $\begin{array}{c}\text { Number } \\
\text { of mini- } \\
\text { tubers } \\
\text { size } \\
30-60 \\
\text { mm }\end{array}$ & $\begin{array}{l}\text { Number } \\
\text { of mini- } \\
\text { tubers } \\
\text { size } \\
>60 \mathrm{~mm}\end{array}$ & $\begin{array}{c}\text { Total } \\
\text { yield of } \\
\text { mini- } \\
\text { tubers } \\
\text { from } 20 \\
\text { micro- } \\
\text { tubers } \\
{[\mathrm{kg}]}\end{array}$ & $\begin{array}{c}\text { Yield of } \\
\text { mini- } \\
\text { tubers } \\
\text { size } \\
5-30 \\
\mathrm{~mm} \\
{[\mathrm{~kg}]}\end{array}$ & $\begin{array}{c}\text { Yield of } \\
\text { mini- } \\
\text { tubers } \\
\text { size } \\
30-60 \\
\mathrm{~mm} \\
{[\mathrm{~kg}]}\end{array}$ & $\begin{array}{c}\begin{array}{c}\text { Yield } \\
\text { of mini- } \\
\text { tubers }\end{array} \\
\text { size } \\
>60 \\
\mathrm{~mm} \\
{[\mathrm{~kg}]}\end{array}$ \\
\hline No & 0 & GA & $19.00 d^{*}$ & $5.27 \mathrm{~d}$ & $6.88 \mathrm{~cd}$ & $5.25 \mathrm{bc}$ & $0.523 c$ & $0.021 d$ & $0.142 c$ & $0.356 b c$ \\
\hline No & 0 & Rindite & $45.96 \mathrm{~b}$ & $14.34 b$ & $16.71 b$ & 8.33b & $0.940 b$ & $0.061 b$ & $0.357 b$ & $0.491 b$ \\
\hline No & 8 & GA & $28.33 c$ & $10.87 \mathrm{bc}$ & $10.75 \mathrm{c}$ & $4.29 \mathrm{~cd}$ & $0.539 \mathrm{c}$ & $0.040 \mathrm{bc}$ & $0.226 c$ & $0.264 \mathrm{~cd}$ \\
\hline No & 8 & Rindite & $76.13 a$ & $29.59 \mathrm{a}$ & $30.50 \mathrm{a}$ & $13.71 \mathrm{a}$ & $1.445 \mathrm{a}$ & $0.096 \mathrm{a}$ & $0.595 \mathrm{a}$ & $0.747 \mathrm{a}$ \\
\hline Yes & 0 & GA & $9.00 \mathrm{e}$ & $1.37 \mathrm{e}$ & 4.13d & $2.00 \mathrm{~d}$ & $0.233 d$ & $0.004 \mathrm{e}$ & $0.094 d$ & $0.129 \mathrm{e}$ \\
\hline Yes & 0 & Rindite & $70.00 a$ & $26.82 \mathrm{a}$ & $28.79 \mathrm{a}$ & 13.17a & $1.421 \mathrm{a}$ & $0.093 a$ & $0.609 \mathrm{a}$ & $0.714 a$ \\
\hline Yes & 8 & GA & $23.63 \mathrm{~cd}$ & $8.00 \mathrm{~cd}$ & $8.21 \mathrm{c}$ & $3.54 \mathrm{~cd}$ & $0.422 \mathrm{~cd}$ & $0.027 \mathrm{~cd}$ & $0.179 \mathrm{c}$ & $0.206 \mathrm{de}$ \\
\hline Yes & 8 & Rindite & $41.08 \mathrm{~b}$ & $15.31 \mathrm{~b}$ & $14.92 \mathrm{~b}$ & $7.67 \mathrm{~b}$ & $0.842 b$ & $0.048 \mathrm{~b}$ & $0.334 \mathrm{~b}$ & $0.45 \mathrm{lbc}$ \\
\hline
\end{tabular}

* Means in the same column followed by different letters are significantly different at the $5 \%$ level of significance.

Bold rows - minitubers produced from microtubers from the dark treatment.

Table 11. Effects of JA pre-treatment during explant production, light during in vitro tuberization and dormancy breaking treatment (applied to microtubers prior to greenhouse planting) on minituber production in three Russet cultivars, in the greenhouse. Least square means comparison for significant JA pretreatment $\times$ Light $\times$ Dormancy treatment interaction.

\begin{tabular}{|c|c|c|c|c|c|c|c|c|}
\hline $\begin{array}{c}\text { JA } \\
\text { pre- } \\
\text { treat }\end{array}$ & $\begin{array}{l}\mathrm{Li} \\
{[\mathrm{h}]}\end{array}$ & $\begin{array}{c}\text { Dormancy } \\
\text { release }\end{array}$ & $\begin{array}{c}\text { Total } \\
\text { number of } \\
\text { mini- } \\
\text { tubers }\end{array}$ & $\begin{array}{c}\text { Number of } \\
\text { minitubers } \\
\text { size } \\
30-60 \mathrm{~mm}\end{array}$ & $\begin{array}{c}\text { Number of } \\
\text { minitubers } \\
\text { size } \\
>60 \mathrm{~mm}\end{array}$ & $\begin{array}{c}\text { Total yield } \\
\text { of mini- } \\
\text { tubers } \\
{[\mathrm{kg}]}\end{array}$ & $\begin{array}{c}\text { Yield of } \\
\text { tubers size } \\
30-60 \mathrm{~mm} \\
{[\mathrm{~kg}]}\end{array}$ & $\begin{array}{c}\text { Yield of } \\
\text { tubers size } \\
>60 \mathrm{~mm} \\
{[\mathrm{~kg}]}\end{array}$ \\
\hline No & 0 & GA & $14.67 \mathrm{e}^{*}$ & $5.67 \mathrm{e}$ & $3.79 \mathrm{c}$ & $0.395 \mathrm{c}$ & $0.126 \mathrm{e}$ & $0.252 \mathrm{c}$ \\
\hline No & $\mathbf{0}$ & Rindite & $47.63 \mathrm{c}$ & $17.83 \mathrm{c}$ & $8.17 \mathrm{~b}$ & $0.959 \mathrm{~b}$ & $0.381 \mathrm{c}$ & $0.488 \mathrm{~b}$ \\
\hline No & 8 & GA & $25.42 \mathrm{~d}$ & $8.79 \mathrm{de}$ & $4.00 \mathrm{c}$ & $0.476 c$ & $0.182 \mathrm{de}$ & $0.256 \mathrm{c}$ \\
\hline No & 8 & Rindite & $60.13 a b$ & $23.50 \mathrm{~b}$ & $13.00 \mathrm{a}$ & $1.336 \mathrm{a}$ & $0.506 \mathrm{ab}$ & $0.754 \mathrm{a}$ \\
\hline Yes & 0 & GA & $13.33 \mathrm{e}$ & $5.33 \mathrm{e}$ & $3.46 \mathrm{c}$ & $0.361 \mathrm{c}$ & 0.111 e & $0.234 \mathrm{c}$ \\
\hline Yes & 0 & Rindite & $68.33 \mathrm{a}$ & $27.67 \mathrm{a}$ & $13.33 \mathrm{a}$ & $1.403 \mathrm{a}$ & 0.585 a & $0.718 \mathrm{a}$ \\
\hline Yes & 8 & GA & $26.54 \mathrm{~d}$ & $10.17 \mathrm{~d}$ & $3.83 \mathrm{c}$ & $0.484 \mathrm{c}$ & $0.223 \mathrm{~d}$ & $0.213 \mathrm{c}$ \\
\hline Yes & 8 & Rindite & $57.08 \mathrm{bc}$ & $21.92 \mathrm{~b}$ & $8.38 \mathrm{~b}$ & $0.951 \mathrm{~b}$ & $0.423 b c$ & $0.444 \mathrm{~b}$ \\
\hline
\end{tabular}

* See explanation Table 10. 
Table 12. Effects of JA in tuberization media and dormancy release treatments, applied to microtubers prior to field planting, on the field production of Pre-elite tubers from microtubers in three Russet cultivars. Least square means for responses with significant JA in media and dormancy breaking interaction effect.

\begin{tabular}{|c|c|c|c|c|c|c|}
\hline $\begin{array}{l}\mathrm{JA} \\
\text { in } \\
\text { media }\end{array}$ & $\begin{array}{l}\text { Dormancy } \\
\text { release }\end{array}$ & $\begin{array}{l}\text { Total number } \\
\text { of Pre-elite } \\
\text { tubers from } 20 \\
\text { microtubers }\end{array}$ & $\begin{array}{l}\text { Number of } \\
\text { Pre-elite } \\
\text { tubers size } \\
<48 \mathrm{~mm}\end{array}$ & $\begin{array}{l}\text { Number of } \\
\text { Pre-elite } \\
\text { tubers size } \\
48-88 \mathrm{~mm}\end{array}$ & $\begin{array}{l}\text { Total yield of } \\
\text { Pre-elite } \\
\text { tubers from } \\
20 \text { micro- } \\
\text { tubers [kg] }\end{array}$ & $\begin{array}{c}\text { Yield of } \\
\text { Pre-elite } \\
\text { tubers size } \\
48-88 \mathrm{~mm} \\
{[\mathrm{~kg}]}\end{array}$ \\
\hline No & GA & $69.25 \mathrm{a}^{*}$ & $56.87 \mathrm{a}$ & $12.37 \mathrm{a}$ & $3.299 \mathrm{a}$ & $1.562 \mathrm{a}$ \\
\hline No & Rindite & $58.33 \mathrm{ab}$ & $49.87 \mathrm{ab}$ & $8.41 \mathrm{~b}$ & $2.254 \mathrm{~b}$ & $0.861 \mathrm{~b}$ \\
\hline Yes & GA & $50.66 \mathrm{~b}$ & $44.12 \mathrm{~b}$ & $6.54 \mathrm{~b}$ & $1.992 \mathrm{~b}$ & $0.680 \mathrm{~b}$ \\
\hline Yes & Rindite & $53.58 \mathrm{~b}$ & $44.20 \mathrm{~b}$ & $9.33 \mathrm{ab}$ & $2.393 \mathrm{~b}$ & $0.801 \mathrm{~b}$ \\
\hline
\end{tabular}

" Means in the same column followed by different letters are significantly different at the $5 \%$ level of significance.

Russet varieties, the highest number and yield of Pre-elite tubers were obtained when the microtubers were soaked in $100 \mathrm{ppm}$ solution of gibberellic acid prior to field planting (Table 12). The yield and the number of Pre-elite tubers were significantly higher when the microtubers were produced on media without JA. For microtubers coming from JA tuberization media, there were no significant differences observed in all parameters measured, irrespective of the dormancy release treatment. Both, Rindite and GA treatments gave similar results (Table 12).

\subsection{Discussion}

Data presented in this study show that the greenhouse and field performance of microtubers was highly dependent on the potato cultivar, jasmonic acid (JA) conditioning of plantlets prior to in vitro tuberization, presence of $\mathbf{J A}$ in tuberization media, the photoperiod during tuberization and the dormancy release treatment. Optimizing these factors can lead to a successful use of microtubers in production of nuclear tubers, or if necessary in production of Pre-elite tubers in the field.

The three Russet cultivars, Amisk - Ranger Russet, Russet Burbank, and Umatilla Russet responded most favourably to the use of microtubers in production of nuclear seed in the greenhouse and also Pre-elite tubers in the field. Shepody needs more research to improve performance in both, the greenhouse and in the field. Microtuber performance of variety Atlantic was very poor during the course of this study, and the 
variety cannot be recommended for this method. An incomplete dormancy release of microtubers likely caused very low yields of mini- and Pre-elite tubers in the 1998 studies. Microtubers, after in vitro tuberization are generally very dormant and will not sprout unless stored for a long period, 4 months or more at low temperatures (Struik \& Wiersema, 1999). However, data obtained from the 1998 season were valuable in designing the continuation of experiments in 1999.

Jasmonic acid (JA), used as a conditioner in production of microtubers, proved to enhance performance of microtubers particularly in the greenhouse situation (Tables 2 and 3). Jasmonate pre-treatment of stock plants prior to taking nodal explants for tuberization, was an effective inducer of microtuber formation in Russet Burbank (Pruski et al., 2001). Plantlets pre-treated with JA produced more roots and in effect more microtubers compared to non-treated controls (Figure 1A). Stimulatory effects of JAs on in vitro tuberization and on potato stem node cultures have been also reported by Koda et al. (1991), Ravnikar et al. (1992) and others (Pruski et al., 1993; Kreft et al., 1997; Jackson, 1999). Data from our studies suggest that this conclusion could be extended to the performance of microtubers in the greenhouse. Also, JA presence in culture media during in vitro tuberization resulted in a higher number of minitubers produced from the microtubers. However, in the field studies, the results we obtained were inconclusive. Stock plants pre-treated with JA, before in vitro tuberization, enhanced the Pre-elite tuber production in the field in Russet Burbank but significantly lowered it in Shepody (Table 6). On the other hand, JA presence in media during the production stage of microtubers did not have any significant effect on their field performance (Table 8). Thus, at this stage of knowledge, we cannot recommend JA as a microtuber conditioner for direct field planting and production of Pre-elite seed. More studies are needed to improve transplant survival of microtubers on the field and yields of Pre-elite tubers.

Light $(8 \mathrm{~h})$ during tuberization was an important factor in producing microtubers which then performed well in the greenhouse and on the field. Microtubers produced in dark performed poorly. Microtubers derived from short photoperiod were greenish and seemed to be less juvenile than the tubers from dark treatments. Gopal et al. (1997) observed that such microtubers perform far better in the field or in the greenhouse than microtubers produced in darkness. Dobránszki \& Mandi (1993) reported induction of in vitro tuberization by short-day period of potato shoots grown on hormone-free media. Our observations (Tables 4, 10 and 11) showed a significant enhancement in microtuber performance (the microtubers produced under $8 \mathrm{~h}$ photoperiod) in both, greenhouse and field conditions.

As mentioned earlier, microtubers of the three Russet cultivars performed the best in the production of minitubers in the greenhouse. Also, their field performance was 
satisfactory. Only microtubers $>0.15 \mathrm{~g}$ (preferably $>0.2 \mathrm{~g}$; the larger the better) can be planted to the greenhouse or to the field. Results obtained with these microtubers (yield and the number of nuclear tubers from one microtuber) were comparable with results from plantlets particularly in greenhouse conditions (Tables 1 and 3). Figure 1D illustrates minitubers of Russet Burbank produced from microtubers in the greenhouse. The three Russet varieties produced more than $50 \%$ of minitubers in the $30-60 \mathrm{~mm}$ category. In commercial production, the larger minitubers are produced, the more attractive they become. Minitubers size $30 \mathrm{~mm}$ or larger are preferred on the market.

The key factor to a successful use of microtubers along with the plantlets in the greenhouse or in the field seemed to be the dormancy release. In general, the microtubers right after in vitro tuberization are very dormant (Struik \& Wiersema, 1999; Tábori et al., 1999). Recently, several researchers reported that dormancy of microtubers is cultivar dependent and is also affected by the photoperiod applied during in vitro tuberization (Tábori et al., 1999; Coleman \& Coleman, 2000). In the study reported here we used gibberellic acid and Rindite to release microtuber dormancy prior to planting. Rindite proved to be very effective in greenhouse conditions (Tables 9 - 11). In the field situation gibberellic acid gave slightly better results (Table 12). However, more studies are required to provide evidence that the product is safe to use with microtubers, since there is a controversy in literature. In general, Rindite is not recommended for breaking dormancy of microtubers. It is considered dangerous for microtubers, since decay may easily occur after such treatment due to the small size of microtubers (Ranalli, 1997; Struik \& Wiersema, 1999). In our experiments we did not observe any rot or decay of microtubers treated with Rindite, derived from $8 \mathrm{~h}$ light tuberization treatment. Some damage was observed in microtubers produced in dark $(0 \mathrm{~h}$ photoperiod) but it was considered minimal. Microtubers used in our studies were stored in a cooler for close to 12 weeks prior to planting, which provided enough time to develop adequate skin. Moreover, right after harvest and before cold storage, microtubers were placed into Petri dishes and left on the laboratory bench for $24 \mathrm{hrs}$ at room temperature to harden off. Also, only microtubers $>0.15 \mathrm{~g}$ were used in greenhouse and field plantings. The above conditions may have protected the microtubers from damages during Rindite application. A successful dormancy release of microtubers by Rindite was reported recently by Nasiruddin \& Blake (1997) and Kim et al. (1999).

The results suggest that the plantlets can be considered as a source of planting material in the field production of Pre-elite seed potato tubers. Figure 1F presents the Pre-elite tuber of Russet Burbank produced on the field from the microtubers. Struik \& Wiersema (1999) reported several successful studies on use of plantlets in direct field 
planting to produce Pre-elite tubers. The method, however, needs more research. Based on our data, only the microtuber propagule of Amisk, Russet Burbank and Umatilla Russet can be recommended for a commercial use in greenhouse production of minitubers. Microtubers of Russet Burbank and Umatilla Russet placed on $10 \mathrm{~cm}$ diameter Petri dishes are shown in Figure 1B. At this stage of knowledge, we cannot recommend microtubers for direct field planting and a commercial production of Preelite seed potato tubers.

More studies are needed to improve transplant survival of microtubers and yields of Pre-elite tubers produced from microtubers. Jasmonate pre-treatment of stock plants prior to taking nodal explants for tuberization was effective in enhancing yields of nuclear tubers from microtubers and can be of help in the commercial set-up, where microtubers are included in the production system. This conclusion can also be extended to JA presence in tuberization media. Thus, we can recommend the use of JA as a plantlet/microtuber conditioner in semi-controlled environments (greenhouses). Further investigation is needed in the dormancy release treatments for microtubers. Although Rindite provided an effective dormancy break of microtubers and significantly enhanced nuclear seed tuber production in the greenhouse, more studies would be beneficial on finding the optimal concentration of this product in relation to size of the microtubers, the condition of their skin and the storage history.

\section{References}

AAFC (Agriculture \& Agri-Food Canada), 1996. Propagation and initiation of single node cuttings of potato in vitro. Prepared by L.K. Douglass, Potato Propagation and Tissue Culture Laboratory, Potato Research Centre, AAFC, Fredericton, Canada, pp. 1-9.

Biondi, S., S. Fomale, K.M. Oksman-Caldentey, M. Eeva, S. Agostani \& N. Bagni, 2000. Jasmonates induce over-accumulation of methylputrescine and conjugated polyamines in Hyoscyamus muticus L. root cultures. Plant Cell Reports 19: 691-697.

Coleman, W.K. \& S.E. Coleman, 2000. Modification of potato microtuber dormancy during induction and growth in vitro and ex vitro. American Journal of Potato Research 77: 103 110.

Coleman, W.K., D.J. Donnelly \& S.E. Coleman, 2001. Potato microtubers as research tools: A review. American Journal of Potato Research 78: 47-55.

Denny, F.E., 1945. Synergistic effects of three chemicals in the treatment of dormant potato tubers to hasten germination. Contr Boyce Thompson Institute for Plant Research 14: 1-14.

Dobránszki, J. \& M. Mandi, 1993. Induction of in vitro tuberization by short day period and dark treatment of potato shoots grown on hormone-free medium. Acta Biologica Hungarica 44: 411-420.

Dobránszki, J., K.M. Tábóri \& A. Ferenczy, 1999. Light and genotype effects on in vitro 
tuberization of potato plantlets. Potato Research 42: 483-488.

Estrada, R., P. Tovar \& J.H. Dodds, 1986. Induction of in vitro tubers in a broad range of potato genotypes. Plant Cell, Tissue and Organ Culture 7: 3-10.

Gopal, J., J.L. Minocha \& J.S. Sidhu, 1997. Comparative performance of potato crops raised from microtubers induced in the dark versus microtubers induced in light. Potato Research 40: $407-412$.

Jones, E.D., 1988. A current assessment of in vitro culture, and other rapid multiplication methods in North America and Europe. American Potato Journal 65: 209-220.

Jackson, S.D., 1999. Multiple signalling pathways control tuber induction in potato. Plant Physiology 119: 1-8.

Joung, H., J.H. Jeon, S.W. Park \& H.S. Kim, 1993. The impact of mass-produced potato microtubers on Korean potato agriculture. American Potato Joumal 70: 819-820 (abstract).

Khuri, S. \& J. Moorby, 1996. Nodal segments or microtubers as explants for in vitro microtuber production of potato. Plant Cell, Tissue and Organ Culture 45: 215-222.

Kim, S.Y., J.K. Kim, K.H. Choi, Y.H. Joung \& H. Joung, 1999. Effects of Rindite on breaking dormancy of potato microtubers. American Joumal of Potato Research 76: 5-8.

Koda, Y., Y. Kikuta, H. Tazaki, Y. Tsuhino, S. Sakamura \& T. Yoshihara, 1991. Potato tuberinducing activities of jasmonic acid and related compounds. Phytochemistry 30: 14351438 .

Kreft, S., M. Ravinkar, P. Mesko, J. Pungercar, A. Umek, I. Kregar \& B. Strukelj, 1997. Jasmonic acid inducible aspartic proteinase inhibitors from potato. Phytochemistry 44: 1001-1006.

Leclerc, Y., D.J. Donnelly, W.K. Coleman \& R.R. King, 1995. Microtuber dormancy in three potato cultivars. American Potato Journal 72: 215-223.

Lillo, C., 1989. A simple two-phase system for efficient in vitro tuberization in potato. Norwegian Journal of Agricultural Sciences 3: 23-27.

Lê, C.L., 1999. In vitro microtuberization: An evaluation of culture conditions for the production of virus-free potatoes. Potato Research 42: 489-498.

Lommen, W.J.M., 1995. Basic studies on the production and performance of potato minitubers. PhD thesis, Wageningen Agricultural University, The Netherlands, $181 \mathrm{pp}$.

Montgomery, D.C., 1997. Design and Analysis of Experiments. Fourth edition. Wiley, New York.

Murashige, T. \& F. Skoog, 1962. A revised medium for rapid growth and bioassays with tobacco tissue cultures. Physiologia Plantarum 15: 473-497.

Nasinuddin, K.M. \& J. Blake, 1997. Effect of Rindite on storage behavior, dormancy break and sprout growth of potato microtubers (cv. Desiree). American Potato Journal 74: 325330.

Pelacho, A.M. \& A.M. Mingo-Castel, 1991. Jasmonic acid induces tuberization of potato 


\section{Chapter 7}

stolons cultured in vitro. Plant Physiology 97: 1253-1255.

Pruski, K., J. Nowak \& T. Lewis, 1993. Jasmonates and photoperiod effect on microtuber production in two potato cultivars. In Vitro Cellular and Developmental Biology - Plant 29: 69 (abstract).

Ranalli, P., 1997. Innovative propagation methods in seed tuber multiplication programmes. Potato Research 40: 439-453.

Ranalli, P., F. Bassi, G. Ruaro, P. del Re, M. di Candilo \& G. Mandolino, 1994. Microtuber and minituber production and field performance compared with normal tubers. Potato Research 37: 383-391.

Ravnikar, M., B. Vilhar \& N. Gogala, 1992. Stimulatory effects of jasmonic acid on potato node and protoplast culture. Journal of Plant Growth Regulation 11: 29-33.

SAS Institute Inc., 1999. SAS Online Doc@, Version 8. SAS Institute Inc., Cary NC.

Struik, P.C. \& W.J.M. Lommen, 1990. Production, storage and use of micro- and minitubers. Proceedings of the $11^{\text {th }}$ Triennial Conference of the European Association for Potato Research (EAPR), Edinburgh, UK, pp. 122-133.

Struik, P.C. \& S.G. Wiersema, 1999. Seed Potato Technology. Wageningen Pers, The Netherlands, 383 pp.

Tábóri, K.M., J. Dobránszki \& A. Ferenczy, 1999. Some sprouting characteristics of microtubers. Potato Research 42: 611-617.

Van den Berg, J.H. \& E.E. Ewing, 1991. Jasmonates and their role in plant growth and development with special reference to the control of potato tuberization: A review. American Potato Journal 68: 781-794.

Yu, W.C., P.J. Joyce, D.C. Cameron \& B.H. McCown, 2000. Sucrose utilization during potato microtuber growth in bioreactors. Plant Cell Reports 19: 407-413. 


\section{Chapter 8}

Microplantlets and microtubers in the seed potato production system of Alberta, Canada 


\section{Microplantlets and microtubers in the seed potato production system of Alberta, Canada}

\subsection{Potato production in Alberta - History}

Very little information is available about the early history of potato production in Alberta. Settlers/pioneers coming to the Province in late 1700, early 1800 presumably set a small-scale potato production, mainly in home and market gardens. Daniel Harman, the agent for the North West Trading Company post in Dunvegan (Peace River country, northern Alberta, Canada), wrote on October 3, 1810: “... we harvested the potatoes that were planted on May $10^{\text {th }}$ and found that the nine bushels planted produced 150 bushels ...". The above record is among the earliest in Alberta mentioning the potato crop (WCSH, 1956).

By the 1930s commercial potato production was well established and records of the Western Canadian Society for Horticulture (WCSH) show that in the Lethbridge (southern Alberta) area only, 2,430 ha (6,000 acres) of irrigated potatoes were grown in 1937. It was a record year and the crop averaged $14.2 \mathrm{tha}^{-1}\left(6.3 \mathrm{t} \mathrm{acre}{ }^{-1}\right)$ (Schaupmeyer, 1992). The certified seed production and grading regulations were implemented to Alberta during the 1930s and early 1940s. The table stock's quality improved, and export markets (mainly US) started to expand. In 1940s the industry was set back due to a severe outbreak of bacterial ring rot (Clavibacter michiganesis subsp. sepedonicus (Corynebacterium sepedonicum)). This damaged credibility and the established export markets for almost a decade. The mid 1950s brought back the quality, and credibility in Alberta potatoes had been re-established. Good publicity the Alberta potatoes received for their quality performance at the Toronto Royal Agricultural Fair (1955) brought back the old markets, opening also new ones (Schaupmeyer, 1992).

During the 1960s and 1970s major changes were made in management techniques, mechanization, storages, packaging facilities and in processing. In the 1970s, the Alberta seed potato programme implemented micropropagation for the production of minitubers and Pre-elite tubers, providing growers up to date with a continuous supply of highest quality, disease-free seed tubers (ATN\&HC, 1988). Just from 1985 to 1990 Alberta' potato growers produced between 220,000 and 300,000 tonnes of potatoes annually on 9,700 to 10,400 ha (Schaupmeyer, 1992). This figure doubled in 2000 (Section 1.2 of the thesis). 


\section{Chapter 8}

\subsection{Alberta seed standards and the Seed Potato Programme}

Certified, Foundation, Elite 4 or Elite 3 seed (Section 1.3 of the thesis) is used to produce commercial potatoes in Canada. This system is used in Alberta as well. These classes must meet the standards set out under the regulations for seed potato certification administered by the Canadian Food Inspection Agency (CFIA) of Agriculture Canada. To be certified, seed fields must be free from disease as determined by field inspection during the growing season. Since 1991 all seed lots must be tested for bacterial ring rot before they are sold to another grower or replanted by the seed grower. In 1990, potato growers in Alberta requested the Alberta government to pass legislation that would require all potato growers to plant certified seed starting in 1993. This legislation was passed in 1992, and anyone planting potatoes with the intention of selling them (no matter how small the area of production) is required to plant certified classes of seed since 1993 (Schaupmeyer, 1992).

The Alberta Seed Potato Programme was operating by Alberta Agriculture (Government of the Province of Alberta) out of Olds College (Olds, Alberta, Canada) since 1978. On April 1, 1988, the programme was transferred to the Alberta Tree Nursery and Horticulture Centre (ATN\&HC), Edmonton (now Crop Diversification Centre North-CDCN, AAFRD), taking advantage of additional greenhouse space and a well organized, fully functioning tissue culture laboratory. This move allowed the expansion of seed potato production to meet growing demands for nuclear stock (minitubers) (ATN\&HC, 1988). For several years, the ATN\&HC laboratory was the only producer and supplier of minitubers, and Pre-elite in the Province. The ATN\&HC was also producing Elite I but only of highly demanded cultivars, for example Russet Burbank, Sangre, Norchip. The tubers were then included into the seed system to produce further generations of seed tubers. The ATN\&HC production was meeting close to $100 \%$ demand of the Province, during that period. Table 1 provides a seed production summary by variety in 1988 (ATN\&HC, 1988). Since the quality of the Alberta seed tubers proved high on outside markets, the export sales of seed potatoes have steadily increased since 1976 when Alberta Agriculture (now AAFRD) started pursuing this market.

Table 2 illustrates production and export of seed potatoes from Alberta for 1976 1988 including the number of certified seed potato growers.

At present, Alberta seed potato growers continue to produce for domestic and export sales. The exports trend started in the 1970s continues. Alberta is now Canada's largest exporter of seed potatoes to the United States and also has a well developed export market into Mexico (Statistics Canada, 2001). Elite III production is generally sold to commercial growers in both Alberta and the Pacific North West. There are very 
Table 1. Elite Seed Potato Production at Alberta Tree Nursery \& Horticulture Centre in 1988 (ATN\&HC).

\begin{tabular}{|c|c|c|c|}
\hline Variety & $\begin{array}{l}\text { Number of } \\
\text { minitubers }\end{array}$ & $\begin{array}{c}\text { Number of } \\
\text { Pre-elite tubers }\end{array}$ & $\begin{array}{c}\text { Elite I } \\
{[\mathrm{t}]}\end{array}$ \\
\hline A69868-2 & 18 & 60 & - \\
\hline Atlantic & 1,000 & 350 & - \\
\hline Banana & 173 & - & - \\
\hline Butoche & 44 & - & - \\
\hline Bintje & 100 & - & - \\
\hline Carlton & 50 & 900 & - \\
\hline Cheroke & 10 & - & - \\
\hline Conestoga & 2,538 & 2,000 & - \\
\hline F76080 & 38 & - & - \\
\hline Jemseg & 40 & - & - \\
\hline Kennebec & 20 & 900 & - \\
\hline Min 9632 & 500 & - & - \\
\hline Monona & 1,200 & - & - \\
\hline Norchip & 2,000 & 4,700 & 4.0 \\
\hline Norgold Russet & 50 & 2,400 & 4.0 \\
\hline Norland & 1,000 & 3,300 & - \\
\hline Red Pontiac & 10 & 375 & - \\
\hline Russet Burbank & 30,000 & 60,000 & 50.0 \\
\hline Russet Norkotach & 2,000 & 11,000 & - \\
\hline Sangre & 3,000 & 3,000 & 18.0 \\
\hline Shepody & 2,000 & 1,700 & 0.4 \\
\hline Superior & 500 & 2,100 & 3.0 \\
\hline Viking & 50 & - & - \\
\hline Warba & 100 & 375 & - \\
\hline Wisc 848 & 400 & - & - \\
\hline Yukon Gold & 400 & 525 & 2.5 \\
\hline TOTALS & 44,240 & 93,685 & 81.9 \\
\hline
\end{tabular}

small amounts of lower generation seed produced in Alberta and it is rarely sold to commercial farms (Patricia Duplessis, pers. comm., April 2001).

The seed potato programme is still operating from the $\mathrm{CDCN}$ (previously ATN\&HC) site until now, however it has undergone major changes. During the 1990s, Alberta Agriculture made the decision to privatize services they were providing that 
Table 2. Alberta production and export of seed potatoes, 1976-1988 (ATN\&HC, 1988).

\begin{tabular}{lcccc}
\hline Year & $\begin{array}{c}\text { Number of seed } \\
\text { growers }\end{array}$ & $\begin{array}{c}\text { Seed potato area } \\
{[\mathrm{ha}]}\end{array}$ & $\begin{array}{c}\text { Production } \\
{[\mathrm{t}]}\end{array}$ & $\begin{array}{c}\text { Exports } \\
{[\mathrm{t}]}\end{array}$ \\
\hline 1976 & 18 & 222 & 4,636 & 0 \\
1977 & 16 & 512 & 6,909 & 78 \\
1978 & 13 & 561 & 9,955 & 210 \\
1979 & 14 & 466 & 10,455 & 414 \\
1980 & 15 & 483 & 13,455 & 3,258 \\
1981 & 19 & 593 & 13,273 & 3,630 \\
1982 & 18 & 739 & 14,136 & 4,249 \\
1983 & 23 & 971 & 21,818 & 6,228 \\
1984 & 33 & 1,295 & 22,500 & 9,514 \\
1985 & 37 & 1,675 & 30,310 & 10,488 \\
1986 & 37 & 1,792 & 36,838 & 11,258 \\
1987 & 35 & 1,619 & 45,000 & 14,289 \\
1988 & 31 & 1,644 & 46,057 & 18,759 \\
\hline
\end{tabular}

could be profitable to the private sector. One programme that they determined would be best served through the private industry was nuclear seed potato (minitubers) production. The provincial seed potato specialist co-operated with several growers and helped them establish private tissue culture laboratories and greenhouse operations. The provincial seed potato programme then began the process of phasing out minituber production and sales as the private sector capacity in these areas grew (Patricia Duplessis, pers. comm., April 2001). The number of private laboratories and greenhouses in Alberta has continued to grow as seed acreage has expanded. There are currently 8 private lab facilities that are certified by the Canadian Food Inspection Agency and in 2000 there were 14 private greenhouse facilities. The majority of these operations are owned by potato growers. Most of the greenhouse growers use the minitubers (nuclear tubers) in their own seed potato production systems, while some of the lab/greenhouse operations focus on plantlet and minituber sales only (Patricia Duplessis, pers. comm., April 2001).

Alberta Agriculture, now known as Alberta Agriculture, Food and Rural Development (AAFRD), supplies disease tested plantlets and nuclear stock material (occasionally minitubers) to the private facilities for a fee. They also offer technical support to the lab and greenhouse operators and ensure that the Seed Potato Repository contains the varieties that growers require to meet changing market demands. At present the repository contains more than 100 varieties (CDCN/S, 1999; Patricia Duplessis, pers. 
comm., April 2001). Some private growers and companies owe several of the newly acquired varieties. They determine whether their clones are to be distributed and where. Growers have all become aware of the Plant Breeder's Rights legislation and co-operate with breeders and agents to multiply and market these new varieties. The lab facility also provides plant material to private lab facilities to other Provinces, in Saskatchewan and Manitoba (Patricia Duplessis, pers. comm., April 2001). The Seed Potato Programme continues to work with growers to improve their greenhouse production practices.

The Alberta Potato Industry has undergone rapid change in the last 5 years. The location of two new processing plants in Southern Alberta has resulted in a dramatic increase in the Province's total potato acreage (see Section 1.2). Figures obtained from the Potato Growers of Alberta indicate that total potato acreage for the province has doubled since 1996 (Potato Growers of Alberta, 2000). The majority of this increase has been associated with so called "processing acreage"; it has increased by almost $60 \%$, although seed potato production has also seen a significant increase of approximately $30 \%$. The table stock acreage has declined due to growers converting to seed or processing production. There has been recent growth in the acreage of potatoes grown for speciality markets and this acreage is expected to increase (Patricia Duplessis, pers. comm., April 2001; Clive Schaupmeyer, pers. comm., February 2001).

The major varieties produced in the Province at present are Russet Burbank, Shepody, Russet Norkotah, FL varieties, Snowden, Atlantic, Norland and Bintje. Table 3 illustrates the area of major 10 varieties grown in Alberta in 2000 .

Table 3. Potato Crop Summary, Alberta, Canada, 2000. Major cultivars grown in Alberta grouped by hectares, variety and designation (Clive Schaupmeyer, pers. comm.; Statistics Canada, January 2001).

\begin{tabular}{lcccc}
\hline VARIETY & Processing [ha] & Seed [ha] & Fresh market [ha] & Total [ha] \\
\hline Russet Burbank & 9,209 & 1,912 & 200 & 11,321 \\
Shepody & 1,945 & 540 & 0 & 2,485 \\
Russet Norkotach & 0 & 668 & 868 & 1,536 \\
Ranger Russet & 317 & 586 & 0 & 903 \\
FritoLay varieties & 640 & 116 & 0 & 756 \\
Atlantic & 415 & 295 & 0 & 710 \\
Snowden & 473 & 100 & 0 & 573 \\
Norland & 0 & 167 & 247 & 414 \\
Bintje & 0 & 92 & 104 & 196 \\
Niska & 184 & undisclosed & 0 & 184 \\
\hline
\end{tabular}




\subsection{Microplantlets and microtubers in Alberta Seed Potato Programme}

Microplantlets or in vitro plantlets have been used in the Alberta Seed Potato Programme since its origin. In order to meet current market demands for seed, large quantities of plantlets are required in Alberta. The rapid multiplication is achieved by so called nodal cuttings. The steps used in the nodal cutting based multiplication system are CFIA (Canadia Food Inspection Agency) approved. They follow general procedures outlined by Struik \& Wiersema (1999) for production methods of in vitro plantlets, using the method of in vitro nodal cuttings:

1. Selection and treatment of source plants; these include:

- tubers or tuber discs with one eye (sprouted)

- stems harvested directly from the greenhouse

- in vitro plantlets.

2. Decontamination (disinfection) of stems; various methods including $70 \%$ ethanol and $10 \%$ aqueous solution of bleach (sodium hypochloride).

3. Initiation of in vitro cultures; stems are cut into pieces consisting of a stem part with one axial bud and placed in test tubes onto nutrient medium, MS (Murashige \& Skoog, 1962) with $30 \mathrm{~g} \mathrm{l}^{-1}$ sucrose and solidified with agar $7 \mathrm{~g} \mathrm{l}^{-1}$. Cultures are grown for 3 - 4 weeks in the controlled environment growth room at $21^{\circ} \mathrm{C}+/-1^{\circ} \mathrm{C}$ with $16 \mathrm{~h}$ photoperiod at $150 \mu \mathrm{mol} \mathrm{m} \mathrm{m}^{-2} \mathrm{~s}^{-1}$ usually mixed fluorescent and incandescent illumination.

4. Plantlets produced in Step 3 are cut into pieces called nodal cuttings (stem cuttings with one leaf node) and placed back onto MS medium, usually into Magenta GA7 (Magenta Corp., Chicago, IL, USA) vessels, but any kind of sterile jars can be used for further multiplication.

5. Step 4 is repeated until the required number of plantlets is achieved.

6. After the desired number of plantlets has been produced they are directly planted to the greenhouse benches.

The materials in Step 1 must be 'true-to-type' and be certified (tested for virus, bacterial diseases and other quarantine diseases). In Alberta, this step is carried out at the CDCN laboratory, Edmonton. As mentioned earlier (Section 8.2) the CDCN lab is supplying the Alberta seed potato growers with stock plantlets for fee. At present, a base for the Seed Potato Programme in Alberta is the in vitro plantlet. Between 300,000 to 400,000 plantlets are produced in Alberta annually. Most of the production is carried out in eight certified private laboratories.

In the 1970s and 1980s, microtubers (in vitro derived tubers) did not present any value in the Alberta Seed Potato Programme. Growers started using microtubers in their plantings on the experimental scale in early 1990s. The privatization of the 
Alberta Seed Potato Programme generated a new interest in this type of propagule among the owners of the new laboratories and the greenhouse growers. As mentioned in Chapter 1 (Section 1.4) more even distribution of the work load was needed in these labs and microtubers presented a logical choice. Also, among the seed potato growers there were a few producers who were interested in using microtubers for direct field planting (Author's notes, discussion with selected Alberta seed potato growers). Since many changes took place in the administration of the Alberta Seed Potato Programme in the mid 1990s and the demand for seed potato was growing steadily, the first draft of the project on effective production and utilization of microtubers in greenhouse and field plantings was prepared. It was positively received by the Potato Growers of Alberta (PGA) and resulted in a two-year study: "Potato microtubers in seed potato production in Alberta" - project \#97M071 sponsored by PGA and Alberta Agriculture Research Institute. Five major commercially grown cultivars were tested. In search of the optimum conditions for in vitro tuberization various techniques were applied (Chapter 6). Produced microtubers were tested in the greenhouse production of minitubers and in the field production of Pre-elite tubers. Microtuber performance was compared to that of plantlets. Results were encouraging, especially in greenhouse production of minitubers with the Russet varieties (Chapter 7). As a result, two laboratories included microtubers in their production schedule (at the experimental stage at the moment - D'nA Gardens, pers. comm., March 2001).

An almost two-fold increase in the potato acreage in Alberta, between 1998 and 2000 , put a significant pressure on seed potato producers. The market demand for high quality seed tubers also doubled. In order to maintain the seed supply, the seed potato growers started including microtubers into the system along with in vitro plantlets. Both types of propagules guarantee the production of high quality, disease-free minitubers (nuclear tubers) in greenhouses and/or in some cases Pre-elite tubers (direct field planting).

\section{References}

Alberta Tree Nursery \& Horticulture Centre (ATH\&HC), 1988. Seed Potato Program Horticulture Crop Development. Annual Report. Alberta Agriculture Food and Rural Development (AAFRD) Publication, Edmonton, Alberta, Canada, pp. 3-7.

Crop Diversification Centre North/South (CDCN/S), 1999. Seed Potato Program. Annual Report. Alberta Agriculture Food and Rural Development (AAFRD) Publication, Edmonton/Brooks, Alberta, Canada, pp. 25-27.

Murashige, T. \& F. Skoog, 1962. A revised medium for rapid growth and bioassays with tobacco tissue cultures. Physiologia Plantarum 15: 473-497.

Potato Growers of Alberta, 2001. The Alberta Potato Industry. Available from: 


\section{Chapter 8}

www.potatonet.com/intro.html [accessed May 10, 2001].

Schaupmeyer, C., 1992. Alberta Potato Production Guide. Alberta Agriculture Food and Rural Development (AAFRD) Publication, Brooks, Alberta, Canada, 79 pp.

Statistics Canada, 2001. Canadian Potato Production, January 2001. Agriculture Division.

Struik, P.C. \& S.G. Wiersema, 1999. Seed Potato Technology. Wageningen Pers, Wageningen, The Netherlands, $383 \mathrm{pp}$.

Western Canadian Society for Horticulture (WCSH), 1956. Development of Horticulture on the Canadian Prairies. 
Chapter 9

General discussion 


\section{General discussion}

\subsection{Introduction and objectives}

Over the last two decades, micropropagation technology became an inseparable part of the seed potato programmes around the world, providing disease-free propagules in the early phases of mass multiplication. In vitro produced plantlet is the base in the elite seed potato production systems, in the majority of the programmes. This thesis outlines improvements to micropropagation methods commonly used in commercial laboratories, with a special emphasis on the production of microtubers (small tubers produced in vitro). It is a common believe that these propagules are underutilized in the commercial seed potato production due to their small size $(0.02-0.70 \mathrm{~g}$ or $3-10$ $\mathrm{mm}$ in diameter) and lack of uniformity (Hussey \& Stacey, 1984; Estrada et al., 1986; Struik \& Lommen, 1990; Lê, 1999). Moreover, it is difficult to obtain more than one microtuber per plantlet or nodal explant (Struik \& Lommen, 1990; Struik \& Wiersema, 1999). The lack of uniformity in the microtuber induction and the bulking processes directly affects the length of their dormancy period as well as their physiological age (Leclerc et al., 1995; Tábori et al., 1999; Coleman \& Coleman, 2000). Consequently, not all microtubers uniformly sprout and produce vigorous plants after planting.

Three major steps are employed in the process of utilization of microtubers in either greenhouse production of minitubers (nuclear tubers), or Pre-elite seed tubers in the field: 1) in vitro plantlet multiplication via nodal cuttings, 2) microtuber production in vitro from nodal explants taken from in vitro plantlets, and 3) greenhouse planting of microtubers to produce minitubers, and/or field planting, where microtubers are used to produce conventionally sized Pre-elite tubers. All three steps have been subjects to the experiments described in Chapters 3 - 7, either published, in press, or submitted for publication by Pruski et al. (2000) and Pruski et al. (2001a, b, c, d), respectively. The first part of this general discussion goes through the micropropagation protocol for the production of in vitro plantlets, focusing on adjustments to the method for the quality improvement of plantlets and application of the method in areas where the aseptic conditions are difficult to maintain. It also discusses the optimal conditions for a short term, simple, in vitro storage of potato cultures. The second part of the discussion explores the in vitro tuberization methods. In search of the methods for the production of large and uniform microtubers, various components are being examined including: media, photoperiod, and the use of tuber inducing substances such as jasmonic acid (JA). It also discusses suitability of several varieties commercially grown in Canada to the in vitro tuberization method. The third part of the discussion focuses on perform- 


\section{Chapter 9}

ance of microtubers in the greenhouse production of minitubers and in the field production of Pre-elite tubers. In the last part of the general discussion, the possibilities of incorporating microtubers into the seed potato programmes are assessed, and the seed potato programme in the province of Alberta, Canada is described briefly. For the convenience of the reader, a few brief repetitions of methodology and results are also included.

\subsection{The production and storage of in vitro plantlets}

The in vitro plantlets used in the production of microtubers in all of the research experiments reported in this thesis were routinely multiplied in vitro via single node stem cuttings every few weeks. Plantlets were grown on MS (Murashige \& Skoog, 1962) media with standard vitamins. Sucrose $\left(30 \mathrm{~g} \mathrm{l}^{-1}\right)$ was used as a carbon source and the media were solidified with $0.6-0.7 \%$ agar. The $\mathrm{pH}$ of the media was adjusted to 5.7 before autoclaving. Cultures were incubated in an environmental chamber at $20^{\circ} \mathrm{C}+/-1^{\circ} \mathrm{C}$ temperature with $16 \mathrm{~h}$ photoperiod, $150 \mu \mathrm{mol} \mathrm{m}^{-2} \mathrm{~s}^{-1}$ mixed fluorescent (F40T12 tubes, General Electric (GE), USA) and incandescent (40W, GE, USA) illumination. At the end of the each growing period, the single-stem plantlets were cut into single-node explants and placed on a fresh MS medium in GA7 Magenta jars for further multiplication. The process was repeated until the required number of plantlets for in vitro tuberization experiments, photoautotrophic culturing and/or in vitro storage experiments, was achieved. The in vitro phase was not studied here as such, nor was the low-temperature storage of the in vitro stock material, since the procedures had already been developed (Goodwin et al., 1980; Hussey \& Stacey, 1981), optimised (Marinus, 1985) and successfully applied (AAFC, 1996) in the commercial production of in vitro plantlets and in conventional conservation of plant germplasm (Bessembinder et al., 1993; Withers \& Engelmann, 1998). However, the environmental conditions (for example $\mathrm{CO}_{2}$ enrichment and/or low red light) applied during the in vitro phase and/or in vitro low temperature storage may have a significant effect on the plantlet growth and the regeneration capacity of the stored cultures.

\section{Effects of $\mathrm{CO}_{2}$ enrichment on quality of plantlets (photoautotrophic cultures)}

The photoautotrophic micropropagation of potato cv. Russet Burbank investigated in this study, produced results which could be directly utilized in the commercial production of in vitro plantlets. A $20 \%$ increase in the number of nodes per stem (from 7.5 to 9.4 ) and a $50 \%$ increase in stem dry weight were observed in cultures grown on media with sucrose and in $\mathrm{CO}_{2}$ enriched atmosphere comparing to the conventionally 
micropropagated cultures or the cultures grown photoautotrophically on media without sucrose but in air supplemented with $1500 \mu \mathrm{CO}_{2} \mathrm{l}^{-1}$ (Pruski et al., 2001b). Stems of cultures grown on the media with sucrose and in $\mathrm{CO}_{2}$ enriched air almost doubled in length the stems of cultures from the other two treatments. This could have a significant impact on the multiplication rate at the early phase of in vitro production of plantlets. In this experiment, cultures derived from single node microcuttings were grown for four weeks on MS medium with or without sucrose $\left(30 \mathrm{~g} \mathrm{I}^{-1}\right)$ under conditions described above, with or without supplemental $\mathrm{CO}_{2}$ at $1500 \mu \mathrm{l} \mathrm{l^{-1 }}$. No significant differences were observed between Control (MS medium supplemented with sucrose, $30 \mathrm{~g} \mathrm{l}^{-1}$ ) and photoautotrophic cultures coming from MS medium with no sucrose grown under $1500 \mu \mathrm{ICO}_{2} \mathrm{I}^{-1}$. Photoautotrophic cultures produced stems averaging $43.3 \mathrm{~mm}$, with 7.58 nodes and weighing $9.2 \mathrm{mg}$ (dry), very similar to conventionally grown in vitro cultures ( $47.9 \mathrm{~mm}$ with 7.55 nodes, $9.7 \mathrm{mg}$ dry weight). These results suggest that growers (owners of the laboratories producing potato plantlets) may consider photoautotrophic culturing of potato in areas where the high sterility levels are difficult to maintain (Pruski et al., 2001b). In fact, some of the growers in the province of Alberta, Canada, started using this system successfully (D'nA Gardens, personal communication). Additionally, plantlets grown on regular media with sucrose benefited from the $\mathrm{CO}_{2}$ enriched atmosphere by improved quality, their size and biomass, speeding up the multiplication. Some of the benefits of the photoautotrophic cultures have been described earlier and include: the use of large size, loosely capped, vessels, reduction of microbial contamination, lower humidity inside vessels, and overall better plantlets' quality (Kozai et al. 1987; Fujiwara et al., 1995; Van Huylenbroeck \& Debergh, 1996).

\section{Sucrose and low light effects on in vitro cultures of potato during low temperature storage}

External conditions (environment in the growth-room) as well as the composition of the nutrient medium used for culturing the in vitro plantlets directly affect the biomass of these plantlets, their leaf area, stem length and the number of nodes. Similarly, during storage of cultures, the environmental conditions as well as the media components (particularly sucrose) have significant effects on quality of stored cultures and their regeneration capacity after storage. The study reported in this thesis was undertaken in order to develop a simple, inexpensive method for a short term (up to 12 weeks) storage of cultures, applicable and usable for small tissue culture laboratories. To stay competitive and to adjust propagation scheduling to the market demands, some of these laboratories in Western Canada store large stock cultures for various periods 


\section{Chapter 9}

of time, usually up to 3 months, either in refrigerators or small coolers. Common factors which need to be adjusted are: temperature, light illumination (photosynthetic photon flux density or PPFD), and medium composition (Kubota et al., 1995; Kubota \& Kozai 1994; Marino et al., 1985; Westcott, 1981a, b). In the study reported here, the cultures of potato variety Atlantic grown in vitro for 3 weeks under conditions described above were then stored for 6,9 and 12 weeks at $4^{\circ} \mathrm{C}$ under 0 (darkness) and $3 \mu \mathrm{mol} \mathrm{m} \mathrm{m}^{-2} \mathrm{~s}^{-1}$ PPFD (690 $\mathrm{nm}$ red light continuous illumination). Growth regulator free MS medium either with or without $30 \mathrm{~g} \mathrm{l}^{-1}$ sucrose was used to store the cultures. Tested factors were sucrose concentration, light and the length of the storage period and these all had an impact on shoot quality (fresh weight, length, number of nodes/leaves) and re-growth capacity (relative growth rate) of the cultures (Pruski $e t$ al., 2000). Sucrose in the medium was found essential for the low temperature maintenance of vigorous stock plants of potato, if stored for over 6 weeks. Low light significantly improved quality of the stored potato cultures (Pruski et al., 2000). The results indicate that growers can successfully use their existing facilities, small refrigerators and coolers with low light intensity, set at $4^{\circ} \mathrm{C}$, for a short-term storage of potato cultures.

\subsection{The production of potato microtubers}

Definition of the term microtuber is given in Section 1.7 of this thesis. Microtubers have different advantages: they are disease-free, are easy to store and to transport, and can be produced all year round. Unlike plantlets, microtubers do not all have to be produced just before use, making it possible to evenly organize the laboratory production over time (Struik \& Wiersema, 1999). In search of effective methods for the production of large, uniform microtubers which could be utilized in the seed potato programmes, a series of research experiments was designed. The production method for microtubers was further developed and studied by Pruski et al. (2001a, c). Special attention was paid to examining: 1) suitability of the media with agar (solid) $v s$ without agar (liquid), 2) effectiveness of jasmonic acid (JA) as media additive and/or preconditioner of microcuttings, during in vitro tuberization, 3) the light conditions (photoperiod) during the in vitro tuberization and 4) suitability of the most common, commercially grown (in Canada) varieties to this method. How these four factors may have affected the in vitro production of microtubers is discussed below.

\section{Suitability of the media (liquid vs solid) for the production of microtubers}

Preparation of plantlets for all in vitro tuberization experiments reported in this thesis 
is described in Section 9.2 of this chapter. The following procedures were used in all in vitro tuberization experiments presented in this thesis, unless indicated otherwise. During the last transfer before in vitro tuberization, single-node explants of the cultivars tested were divided into two groups and transferred onto agar media: 1) the same hormone-free MS medium as used in production of plantlets (continuation of the multiplication stage) and 2) the MS medium (with standard vitamins) supplemented with $2.5 \mu \mathrm{M} \mathrm{JA}$ (this group of explants was labelled as JA pre-treated (JAP or JAPret). Both groups were incubated for four weeks under the conditions described above in Section 9.2. Nodal explants (with one leaf) were taken from four-week old plantlets grown on media with and without JA, placed on MS tuberization media supplemented with $80 \mathrm{~g} \mathrm{l}^{-1}$ sucrose, with or without $2.5 \mu \mathrm{M}$ JA (this group was called JAM or JAMed) and with (solid)/without (liquid) $0.6 \%$ agar. Cultures were incubated at $20^{\circ} \mathrm{C}$ with 0 (darkness), 8 and $16 \mathrm{~h}$ photoperiod at $50 \mu \mathrm{mol} \mathrm{m} \mathrm{m}^{-2} \mathrm{~s}^{-1}$ mixed fluorescent/ incandescent light for 10 weeks. The liquid media and the $16 \mathrm{~h}$ photoperiod were used only in the first series of the in vitro tuberization experiments reported in Chapter 5. Overall, significantly better production of microtubers (number of tubers and weight) was observed on media solidified by agar than on liquid media (Chapter 5, Table 4; Pruski et al., 2001a). The agar media were then used in further in vitro tuberization experiments. The use of liquid media required a frequent addition of fresh medium (every week or two) during the tuberization period (Teisson \& Alvard, 1999). This was found inconvenient (especially in the commercial production) and the risk of contaminating the cultures was greatly increased. The two varieties tested in these experiments, Sangre and Russet Burbank, responded similarly to the applied treatments (Pruski et al., 2001a). Microtubers of both varieties averaged over $300 \mathrm{mg}$ in weight. Thus, for further experiments, only agar (solid) media were used. In the agar media sucrose was probably more stable than in the liquid media and this in turn was beneficial for tuberization. Sucrose content is crucial during the in vitro tuberization and $80 \mathrm{~g} \mathrm{l}^{-1}$ (8\%) was found optimal (Struik \& Lommen, 1990; Struik \& Wiersema, 1999). Sucrose is an important source of energy for tuberizing cultures. It affects the osmotic potential of the medium. Independently of other factors, sucrose at the optimum level (8\%) triggers the tuberization as well as positively affects the whole process in the later stages (Struik \& Wiersema, 1999).

\section{Possible effects of jasmonic acid (JA) as media additive and/or plantlet pre- conditioner on in vitro tuberization}

Results obtained in the first series of experiments indicate that explants (nodal cuttings) taken from stock plants grown on $2.5 \mu \mathrm{M}$ JA supplemented medium, 


\section{Chapter 9}

tuberized first, particularly in darkness (Pruski et al., 2001a). The most pronounced benefits of the JA pre-treatment were recorded under $16 \mathrm{~h}$ photoperiod, which is known to inhibit tuberization. Variety Sangre benefited from the JA pre-conditioning of stock plants more than Russet Burbank. Russet Burbank required JA supplement in tuberization media to reach the same degree of stimulation. Overall, microtubers produced either from JA pre-conditioned stock plants or on the JA containing tuberization media were more uniform and larger than from other treatments (Pruski et al., 2001a). Jasmonic acid was chosen as media additive in these studies since it has been found to induce tuberization in potato (Van den Berg \& Ewing, 1991; Pelacho \& Mingo-Castel, 1991; Koda et al., 1991; Ravnikar et al., 1992). More recent reports show that jasmonates play several physiological functions in plants, usually related to their stress adaptation and signalling in root-shoot communication (Koda, 1997; Jackson, 1999) which may be closely related to tuber initiation. The JA pre-treatment of nodal cuttings used in the experiments reported here may have a practical significance in triggering tuberization responses in commercial microtuber production systems. Microtuber initiation occurred within two weeks (with cv. Sangre in 10 days) after placing JA pre-treated microcuttings on tuberization media comparing to 3 weeks in the control treatments (Pruski et al., 2001a). The JA concentration used as medium supplement $(2.5 \mu \mathrm{M})$ for growing stock plants as explant donors for tuberization, did not have a detrimental effect on growth of plantlets, although it induced some symptoms of senescence (slight yellowing of leaves) after a 5 to 6-week-long exposure (Pruski et al., 2001a).

Further studies on effects of JA on the production of microtubers were extended to six varieties commercially grown in Canada (Pruski et al., 2001c). It was observed that effects of JA were variety specific, although the benefits were more pronounced in the dark than in the light treatments. According to the responses, the tested varieties were divided into three groups (Table 1). Table 1 summarizes all the responses to JA observed in the studies reported in the thesis. The results are compared with responses to GA found in literature. Amisk, Atlantic and Umatilla Russet (group I) benefited from JA supplement to the tuberization medium (JAMed), but not from JA when applied as a pre-conditioning treatment (JAPret). Total weight of microtubers, the percentage and weight of microtubers $>0.1 \mathrm{~g}$ were significantly higher than in control or in other JA treatments (Chapter 6, Table 2). However, none of these varieties clearly benefited from any JA treatments under light (Table 1).

Russet Burbank (group II) and Sangre also benefited from the JA supplement in the dark, although stock plantlet conditioning (JAPret) was more effective than the JA supplement to the tuberization medium (JAMed). This observation corresponds with the results of the first study with Russet Burbank and Sangre discussed in the previous 
Table 1. Summary of all the responses to JA observed in production of microtubers compared with expected responses (based on literature) to gibberellic acid (GA). Group I varieties: Amisk, Atlantic, Umatilla Russet; Group II varieties: Russet Burbank, Sangre; Group III varieties: Shepody. Abbreviations: $0 \mathrm{NS} / \mathrm{-NS} /+\mathrm{NS}$ - not significantly different/slightly lower/slightly better but not significantly different from control; --- - significantly lower than control; +++ - significantly better than control; JAP - JA pre-treatment, JAM - JA in media; RB - Russet Burbank.

\begin{tabular}{|c|c|c|c|c|c|c|c|c|}
\hline \multirow{2}{*}{ Response } & \multirow{2}{*}{ Group } & \multicolumn{2}{|c|}{ JAP } & \multicolumn{2}{|c|}{ JAM } & \multicolumn{2}{|c|}{ JAP+JAM } & \multirow{2}{*}{$\mathrm{GA}$} \\
\hline & & Light & Dark & Light & Dark & Light & Dark & \\
\hline Total & I & $-N S$ & $-N S$ & $+\mathrm{NS}$ & $+++^{*}$ & $-N S$ & $-\mathrm{NS}$ & 1. Inhibition of \\
\hline number & II & $-N S$ & $+++^{*}$ & $-N S$ & $+\mathrm{NS}$ & -NS & $+++{ }^{*}$ & microtuber \\
\hline of tubers & III & $-\mathrm{NS}$ & $+\mathrm{NS}$ & $-\mathrm{NS}$ & ONS & $-\mathrm{NS}$ & $+\mathrm{NS}$ & induction $^{* *}$ \\
\hline Number & I & $-\mathrm{NS}$ & $-\mathrm{NS}$ & $-\mathrm{NS}$ & $+++^{*}$ & $\ldots{ }^{*}$ & +++ & 2. Reduction or \\
\hline of tubers & II (RB) & $+\mathrm{NS}$ & $\ldots{ }^{*}$ & $+++^{*}$ & $+\mathrm{NS}$ & $-\mathrm{NS}$ & $--^{*}$ & inhibition of \\
\hline$>0.1 \mathrm{~g}$ & III & $-\mathrm{NS}$ & $-\mathrm{NS}$ & $\ldots{ }^{*}$ & $-\mathrm{NS}$ & $\ldots-^{*}$ & $+\mathrm{NS}$ & tuber formation $^{* *}$ \\
\hline Weight & $\mathrm{I}$ & $-\mathrm{NS}$ & ONS & $--^{*}$ & $+++^{*}$ & $-\mathrm{NS}$ & $+\mathrm{NS}$ & \\
\hline of one & II & $+++^{*}$ & $+\mathrm{NS}$ & $+\mathrm{NS}$ & $+\mathrm{NS}$ & +NS & $-\mathrm{NS}$ & 3. Tuberization \\
\hline tuber & III & $+\mathrm{NS}$ & ONS & $\ldots-^{*}$ & ONS & $\ldots{ }^{*}$ & $+\mathrm{NS}$ & \\
\hline
\end{tabular}

Significantly different at $1 \%$ level.

** References: Okazawa, 1967; Palmer \& Smith, 1970; Hussey \& Stacey, 1984; Xu et al., 1998; Coleman et al., 2001.

paragraph in this Section. Surprisingly, Shepody (group III) did not show any benefits of JA on microtuberization, neither under dark or light conditions (Table 1). Compared to the control and the individual JA treatments, the double treatment with JA (JAPret and JAMed) in light, generally reduced the production of microtubers (Table 1). As mentioned earlier, JA was found to act as a stimulant in the induction of tuberization in potato stolons cultured in vitro (Pelacho \& Mingo-Castel, 1991). On the other hand, Jackson (1999) reported that the JA or other JA-related compounds may be responsible for inducing or promoting in vitro tuberization, the differences in endogenous levels of JA itself do not control tuberization. In the results reported here, the JA seemed to substitute for light in JA/dark treatment combinations especially in variety Atlantic (Pruski et al., 2001c). The JA may possibly act by antagonizing the effect of gibberellic acid (GA), which levels decrease upon the photoperiodic induction of tuberization (Jackson, 1999). In all studies reported so far, GA inhibited tuber formation in vitro (Okazawa, 1967; Palmer \& Smith, 1970; Hussey \& Stacey, 1984; $\mathrm{Xu}$ et al., 1998). Depending on the concentration GA either totally inhibited, reduced 
or delayed tuberization (Palmer \& Smith, 1970; Garcia-Torres \& Gomez-Campo, 1973; Hussey \& Stacey, 1984; Xu et al., 1998). Based on the results from the in vitro tuberization experiments in this thesis, JA seems to act as an inducer of tuberization especially when the process takes place in dark (Table 1). It had opposite effect to GA by promoting tuberization.

The use of JA as a pre-treatment of nodal cuttings or in the tuberization medium may have practical implications in a commercial production of microtubers providing a degree of flexibility to the production systems of the propagules (both, plantlets and microtubers). Plantlets grown on the JA media had extensively branched, thicker than control plantlets' stems, with larger root system (Chapter 5, Figure 1), and higher root and shoot dry weight as well as root to stem biomass ratio (Chapter 5, Figure 2). JA also showed significant effects in triggering tuberization responses in the production of microtubers. Determining the preferences of different varieties to JA treatments (JA pre-treatment/JA in media) would enable the laboratory to direct the production of the propagules accordingly, steering towards the optimal results for each variety. Although in general JA can be recommended as a plantlet pre-conditioner in the production of microtubers, more studies are needed to determine the varietal preferences and the optimal conditions.

\section{Effects of photoperiod on the production of microtubers}

In the first series of experiments reported in the thesis (Chapter 5), three different photoperiods were studied: 0,8 , and 16 hours. The best production of microtubers was recorded under short days (SD, $8 \mathrm{~h}$ light) in all experiments reported here in most treatment combinations. Several researchers including Garner \& Blake (1989), Dobránszki \& Mandi (1993), Ranalli (1997) and Struik \& Wiersema (1999) reported the beneficial effects of SD on the induction of in vitro tuberization, tuber uniformity and their size. Khuri \& Moorby (1996) observed a successful microtuber production of varieties Estima and Cultra under SD. Ranalli (1997) stated that most varieties (probably all) give much better microtuber production in short days $(8 \mathrm{~h})$ than in complete darkness. From the data in Chapter 5 of this thesis, it was observed that the first tubers were induced in darkness, on explants from JA conditioned stock plants, although tuber bulking rates were lower in the darkness than under the short photoperiod. Tubers derived from the short photoperiod treatment were green and seemed to be less juvenile than the tubers from dark treatments (Pruski et al., 2001a). Gopal et al. (1997) observed that such microtubers perform better in the field or greenhouse conditions than microtubers produced in darkness. The $16 \mathrm{~h}$ photoperiod was inhibitory to the production of microtubers. In further studies (Chapter 6; Pruski et al., 
$2001 \mathrm{c}$ ), the production of microtubers was much better under short day conditions. Independently of the variety (six varieties tested), fewer microtubers per explant with significantly lower weights, were produced in dark treatments than under $8 \mathrm{~h}$ photoperiod. However, the results also showed significant differences between varieties in response to the photoperiod during in vitro tuberization. Production of microtubers in all three Russet varieties and in Sangre was superior to that of Shepody and Atlantic (Chapter 6, Tables 1 and 2). The results obtained in these studies, namely, SD photoperiod promoting tuberization, are consistent with the expected behaviour of the potato under field conditions. Plants grown in SD form tubers earlier than those kept in long days (Chapman, 1958; Slater, 1963). In some potato species (for example Solanum andigena), short photoperiods are an absolute requirement for tuber formation (Booth, 1959; Kumar \& Wareing, 1973). Field planting of potato (Solanum tuberosum) under SD promotes tuberization. Applying long photoperiod at late stages of growth is delaying tuber set and growth (Machackova et al., 1998). Although it delays tuberization, application of long days (LD) for a short period of time before tuberization enhanced the number, branching and the length of stolons resulting in higher number of tuber initials (Struik et al., 1988). When the short LD treatment was applied during and/or after tuberization, the tuber set and growth were delayed. Short LD treatment before tuberization did not affect yield but it shifted tuber size distribution towards the smaller sizes (Struik et al., 1988). Tubers form freely when plants are grown in SD and cool night temperatures, but no tubers are formed if the night temperature is high. Leaves perceive the photoperiod signal (Gregory, 1956) and many later reports suggest that the phytochrome is involved in perceiving the signal (Jackson et al., 1998; Jackson, 1999). Recent research suggests that the effect of photoperiod on tuber formation and development may be mediated by photoperiod-induced changes in hormone levels (Machackova et al., 1998). Numerous recent reports present the SD photoperiod $(8 \mathrm{~h})$ to be optimal for in vitro tuberization (Dobránszki et al., 1999; Lê, 1999; Ochotorena et al., 1999). In the studies presented in Chapters $5-7$, the exposure to SD during tuberization was essential for the production of a sufficient number of microtubers per nodal cutting and the $8 \mathrm{~h}$ photoperiod is being recommended.

\section{Variety and the in vitro tuberization}

The varietal differences in responses to in vitro tuberization have been reported earlier (Estrada et al., 1986; Nowak \& Asiedu, 1992; Pruski et al., 1993; Struik \& Wiersema, 1999). Six commercial varieties were tested in the experiments reported in this thesis. It was found that all three Russet varieties (Russet Burbank, Umatilla Russet and Amisk (Ranger Russet)) and Sangre responded positively to in vitro tuberization 


\section{Chapter 9}

conditions and can be recommended for commercial production (Pruski et al., 2001c). Based on data obtained during the series of experiments, varieties Atlantic and Shepody cannot be recommended (yet) for this method. The production of microtubers in both varieties was low (especially in Atlantic). Nowak \& Asiedu (1992) reported variety Atlantic being the slowest to tuberize from the six varieties they tested and the results reported here support this observation. Atlantic is a mid-season variety with a relatively long dormancy (during storage) and in the field situation is often very slow to emerge and then to tuberize which may explain its behaviour during in vitro tuberization. Results with Shepody were inconclusive and more research is needed to determine optimum conditions for in vitro tuberization of this variety. Shepody is also a mid-season variety with a strong apical dominance and in the field tends to produce very few stems yielding in effect very few large (often oversized) tubers. During the in vitro tuberization studies, the variety often produced large microtubers but in small numbers.

\subsection{Performance of microtubers in the commercial production of seed tubers}

In the experiments reported here, all microtubers used in greenhouse and field plantings were produced following the procedures outlined in Sections 9.2 and 9.3. Thus, the plantings were done with microtubers produced: 1) under $8 \mathrm{~h}$ photoperiod and in the dark, from 2) stock plantlets pre-treated with/without JA and grown on 3) tuberization media supplemented with/without JA. The performance of microtubers was compared to the industry standard, the performance of plantlets. For the reader's convenience, the results obtained in the greenhouse and in the field are discussed separately.

\section{Microtubers in the production of minitubers in the greenhouse}

Data obtained in this study show (Chapter 7, Pruski et al., 2001d) that the greenhouse performance of microtubers was highly dependent on the potato variety, jasmonic acid (JA) conditioning of plantlets prior to in vitro tuberization, presence of JA in tuberization media, the photoperiod during tuberization and the dormancy release treatment. Optimizing these factors can lead to a successful use of microtubers in production of minitubers (nuclear tubers). The three Russet cultivars, Amisk (Ranger Russet), Russet Burbank, and Umatilla Russet responded most favourably to the use of microtubers in production of minitubers in the greenhouse. Microtubers of variety Shepody produced inconclusive results and more research is needed to improve their performance in both, the greenhouse and in the field. Microtuber performance of variety Atlantic was very 
poor during the course of this study, and the variety cannot be recommended for this method. In the first year of the study (1998) difficulties with dormancy release of microtubers were experienced. This incomplete dormancy release of microtubers likely caused very low yields of minitubers and also Pre-elite tubers in 1998 studies. Microtubers, after in vitro tuberization are generally very dormant and will not sprout unless stored for a long period, four months or more at low temperatures (Struik \& Wiersema, 1999). However, data obtained from the 1998 season were valuable in designing the continuation of experiments in 1999.

Table 2 summarizes all the responses to JA in vitro treatments observed in the production of minitubers in the greenhouse. Similarly to Subsection Possible effects of jasmonic acid (JA) as media additive and/or plantlet pre-conditioner on in vitro tuberization (in Section 9.3), the results are compared with expected responses to GA found in literature. As mentioned earlier GAs are known to inhibit and often completely block tuberization. On the other hand, gibberellins proved to enhance stolon induction, elongation and branching (Vreugdenhil \& Struik, 1989). Inhibition of tuber induction as well as reduction in tuber dry matter and altered tuber size distribution (smaller grades) occurred in tubers treated at different times after planting with GA in pot experiments (Struik et al., 1989). Table 2 shows that pre-treatment (JAP) of stock plantlets with jasmonic acid (JA) resulted in microtubers which performed the best in production of minitubers in the greenhouse. It seems that JA was the most effective inducer of tuberization especially with Russet varieties. It had an opposite effect to GA by promoting tuberization. Total number and yield of minitubers in the three Russet varieties was the highest from minitubers produced from plantlets pretreated with JA (Table 2). Although most of the other responses were also better from JA treatments, there were no significant differences determined and these are marked in the Table as +NS. When two treatments, JAP and JAM were used together the total yield was significantly reduced, suggesting that a prolonged exposure to JA may inhibit tuber production (Table 2).

Jasmonic acid (JA), used as a conditioner in production of microtubers, proved to enhance performance of microtubers in the greenhouse situation (Chapter 7, Tables 2 and 3; Pruski et al., 2001d). Jasmonate pre-treatment of stock plants prior to taking nodal explants for tuberization, was an effective inducer of microtuber formation in Russet Burbank (Pruski et al., 2001a). Plantlets pre-treated with JA produced more roots and in effect more microtubers compared to non-treated controls. Stimulatory effects of JAs on in vitro tuberization were already discussed in the previous Section. Data from the studies reported here suggest that JA pre-treated microtubers performed better than JA non-treated propagules in the greenhouse. Amisk produced the highest number of minitubers (more than 3 minitubers per planted microtuber) derived from 


\section{Chapter 9}

pre-treated with JA plantlets comparing to the control (2.5 per microtuber) (Chapter 7, Table 3). The total yields in Russet Burbank and Umatilla Russet were the highest in this treatment, 0.859 and $0.879 \mathrm{~kg}$ per plot of 20 microtubers, respectively comparing

Table 2. Summary of all the responses to JA observed in greenhouse performance of microtubers compared with expected responses (based on literature) to gibberellic acid (GA). Russet varieties (Amisk - AM, Russet Burbank - RB, Umatilla Russet - UM) are placed in one group; other varieties: Atlantic - AT and Shepody - SH. Abbreviations: 0NS/-NS/+NS - not significantly different/slightly lower/slightly better but not significantly different from control; --- - significantly lower than control; +++ - significantly better than control; JAP - JA pre-treatment; JAM - JA in media.

\begin{tabular}{|c|c|c|c|c|c|}
\hline Response & Variety & JAP & JAM & JAP+JAM & GA \\
\hline $\begin{array}{l}\text { Total number of } \\
\text { minitubers per } \\
\text { plot }\end{array}$ & $\begin{array}{l}\text { AM,RB,UM } \\
\text { AT } \\
\text { SH }\end{array}$ & $\begin{array}{l}+++^{*} \\
+\mathrm{NS} \\
+++^{*}\end{array}$ & $\begin{array}{l}+\mathrm{NS} \\
+\mathrm{NS} \\
+++^{*}\end{array}$ & $\begin{array}{l}\mathrm{NS} \\
+\mathrm{NS} \\
+\mathrm{NS} \\
\end{array}$ & $\begin{array}{l}\text { Reduction and/or } \\
\text { inhibition of tuber } \\
\text { formation }\end{array}$ \\
\hline $\begin{array}{l}\text { Number of } \\
\text { minitubers } 5-30 \\
\text { mm per plot }\end{array}$ & $\begin{array}{l}\text { AM,RB,UM } \\
\text { AT } \\
\text { SH }\end{array}$ & $\begin{array}{l}+++^{*} \\
\text { ONS } \\
+\mathrm{NS}\end{array}$ & $\begin{array}{l}+\mathrm{NS} \\
+\mathrm{NS} \\
+\mathrm{NS}\end{array}$ & $\begin{array}{l}\ldots * \\
+\mathrm{NS} \\
+\mathrm{NS}\end{array}$ & $\begin{array}{l}\text { Increased number } \\
\text { of small tubers }\end{array}$ \\
\hline $\begin{array}{l}\text { Number of } \\
\text { minitubers } \\
30-60 \mathrm{~mm}\end{array}$ & $\begin{array}{l}\text { AM,RB,UM } \\
\text { AT } \\
\text { SH }\end{array}$ & $\begin{array}{l}+++^{*} \\
-\mathrm{NS} \\
+++^{*}\end{array}$ & $\begin{array}{l}+\mathrm{NS} \\
+\mathrm{NS} \\
+\mathrm{NS} \\
\end{array}$ & $\begin{array}{l}\text { ONS } \\
+\mathrm{NS} \\
-\mathrm{NS} \\
\end{array}$ & \\
\hline $\begin{array}{l}\text { Number of } \\
\text { minitubers }>60 \\
\text { mm per plot }\end{array}$ & $\begin{array}{l}\text { AM,RB,UM } \\
\text { AT } \\
\text { SH }\end{array}$ & $\begin{array}{l}+\mathrm{NS} \\
\text { No tubers } \\
+\mathrm{NS}\end{array}$ & $\begin{array}{l}\text {-NS } \\
\text { No tubers } \\
+\mathrm{NS} \\
\end{array}$ & $\begin{array}{l}\text { No tubers } \\
\text { No tubers } \\
+\mathrm{NS}\end{array}$ & \\
\hline $\begin{array}{l}\text { Total yield } \\
\text { of minitubers } \\
\text { per plot }\end{array}$ & $\begin{array}{l}\text { AM,RB,UM } \\
\text { AT } \\
\text { SH }\end{array}$ & $\begin{array}{l}++++^{*} \\
\text { Very low } \\
\text { Yields } \\
\end{array}$ & $\begin{array}{l}\text { +NS } \\
\text { Very low } \\
\text { Yields } \\
\end{array}$ & $\begin{array}{l}-^{*} \\
\text { Very low } \\
\text { Yields }\end{array}$ & $\begin{array}{l}\text { Inhibition of } \\
\text { tuber formation }\end{array}$ \\
\hline $\begin{array}{l}\text { Yield of tubers } \\
5-30 \mathrm{~mm} \\
\text { per plot }\end{array}$ & $\begin{array}{l}\text { AM,RB,UM } \\
\text { AT } \\
\text { SH }\end{array}$ & $\begin{array}{l}-\mathrm{NS} \\
\text { Very low } \\
\text { Yields }\end{array}$ & $\begin{array}{l}\text {-NS } \\
\text { Very low } \\
\text { Yields }\end{array}$ & $\begin{array}{l}\text {-NS } \\
\text { Very low } \\
\text { Yields }\end{array}$ & \\
\hline $\begin{array}{l}\text { Yield of tubers } \\
30-60 \mathrm{~mm} \\
\text { per plot }\end{array}$ & $\begin{array}{l}\text { AM,RB,UM } \\
\text { AT } \\
\text { SH }\end{array}$ & $\begin{array}{l}+++ \\
\text { Very low } \\
\text { Yields }\end{array}$ & $\begin{array}{l}+\mathrm{NS} \\
\text { Very low } \\
\text { Yields }\end{array}$ & $\begin{array}{l}\text {-NS } \\
\text { Very low } \\
\text { Yields }\end{array}$ & \\
\hline $\begin{array}{l}\text { Yield of tubers } \\
>60 \mathrm{~mm} \\
\text { per plot }\end{array}$ & $\begin{array}{l}\text { AM,RB,UM } \\
\text { AT } \\
\text { SH }\end{array}$ & $\begin{array}{l}\text {-NS } \\
\text { No tubers } \\
\text { V. low yield }\end{array}$ & $\begin{array}{l}-\mathrm{NS} \\
\text { No tubers } \\
\text { V. low }\end{array}$ & $\begin{array}{l}\text { No tubers } \\
\text { No tubers } \\
\text { V. low yield }\end{array}$ & \\
\hline
\end{tabular}

* Significantly different at $5 \%$ level.

** References: Okazawa, 1967; Hussey \& Stacey, 1984; Xu et al., 1998; Vreugdenhil \& Sergeeva, 1999; Coleman et al., 2001

${ }^{* * *}$ References: Struik et al., 1989; Vreugdenhil \& Sergeeva, 1999. 
to about $0.500 \mathrm{~kg}$ per plot in other treatments). Amisk numbers of minitubers derived from the microtubers were comparable to numbers obtained from plantlets (65.5 minitubers from 20 plantlets (Chapter 7, Table 1B) and 61.3 from 20 microtubers derived from JA treated stock plants (Chapter 7, Table 3). Also, Amisk yield of minitubers in $30-60 \mathrm{~mm}$ category was almost the same from plantlets (Chapter 7, Table 1B) as from microtubers from the JA pre-treatment (Chapter 7, Table 4), 0.472 vs $0.446 \mathrm{~kg}$ per plot. Russet Burbank and Umatilla Russet produced fewer tubers from microtubers (Russet Burbank 44.6 per plot, 43.1 Umatilla Russet per plot) than from plantlets (RB 59.5 per plot, UM 72.5 per plot (Chapter 7, Table 1B)) however still within the range acceptable for the commercial production (Pruski et al., 2001d).

Microtubers produced under light were significantly better propagules than the microtubers produced in darkness. In the 1998 season, in all three tested varieties (AT, $\mathrm{RB}, \mathrm{SH}$ ), the total number of minitubers obtained from these microtubers (per plot, 20 planted) was 3 times higher, 7.85 vs 2.56, respectively (Table 3 ). All other characteristics (total yield and number of minitubers in $5-30,30-60$ and $>60 \mathrm{~mm}$ ) were also 2 - 7 times higher in production of minitubers from microtubers exposed to light during in vitro tuberization. Shepody produced the highest total yield of minitubers

Table 3. Effects of Light ( $\mathrm{Li})$ during the in vitro tuberization on production of minitubers in the greenhouse. Single effect of light on 7 parameters for all three potato varieties: Atlantic (AT), Russet Burbank (RB) and Shepody (SH). Significant Variety $\times$ Light (V×Li) interaction for total yield of nuclear tubers only (right column).

\begin{tabular}{|c|c|c|c|c|c|c|c|c|c|}
\hline $\begin{array}{l}\mathrm{Li} \\
\text { [h] }\end{array}$ & $\begin{array}{l}\text { Total number } \\
\text { of nuclear } \\
\text { tubers (from } \\
20 \text { micro- } \\
\text { tubers) }\end{array}$ & $\begin{array}{c}\text { Number of } \\
\text { tubers } \\
5-30 \mathrm{~mm} \\
\text { diameter }\end{array}$ & $\begin{array}{l}\text { Number } \\
\text { of tubers } \\
30-60 \mathrm{~mm} \\
\text { diameter }\end{array}$ & $\begin{array}{l}\text { Number } \\
\text { of tubers } \\
>60 \mathrm{~mm} \\
\text { diameter }\end{array}$ & $\begin{array}{c}\text { Yield of } \\
\text { tubers } \\
5-30 \mathrm{~mm} \\
{[\mathrm{~kg}]}\end{array}$ & $\begin{array}{c}\text { Yield of } \\
\text { tubers } 30- \\
60 \mathrm{~mm} \\
{[\mathrm{~kg}]}\end{array}$ & $\begin{array}{c}\text { Yield of } \\
\text { tubers } \\
>60 \mathrm{~mm} \\
{[\mathrm{~kg}]}\end{array}$ & \multicolumn{2}{|c|}{$\begin{array}{c}\text { Total yield } \\
\text { of nuclear } \\
\text { tubers } \\
{[\mathrm{kg}]}\end{array}$} \\
\hline 0 & $2.56 \mathrm{~b}^{*}$ & $1.66 \mathrm{~b}$ & $0.56 \mathrm{~b}$ & $0.38 \mathrm{~b}$ & $0.01 b$ & 0.009 b & $\begin{array}{c}\text { No } \\
\text { tubers }\end{array}$ & $\begin{array}{l}\text { AT } \\
\text { RB } \\
\text { SH }\end{array}$ & $\begin{array}{l}0.08 \mathrm{c} \\
0.08 \mathrm{c} \\
0.09 \mathrm{c}\end{array}$ \\
\hline 8 & $7.84 \mathrm{a}$ & $3.68 \mathrm{a}$ & $2.07 \mathrm{a}$ & $2.89 \mathrm{a}$ & $0.08 \mathrm{a}$ & $0.035 \mathrm{a}$ & $0.18 \mathrm{a}^{* *}$ & $\begin{array}{l}\text { AT } \\
\text { RB } \\
\text { SH }\end{array}$ & $\begin{array}{c}0.17 b \\
0.20 b \\
0.48 a \\
\end{array}$ \\
\hline
\end{tabular}

Means within a column followed by different letters are significantly different at the $5 \%$ level of significance.

** Only Shepody produced some minitubers larger than $60 \mathrm{~mm}$ in diameter.

Bold row - minitubers produced from microtubers from the dark tuberization treatment. 


\section{Chapter 9}

followed by Russet Burbank and Atlantic. Similarly in 1999 season, microtubers produced under $8 \mathrm{~h}$ light gave significantly higher number and yield of minitubers in all three cultivars (Pruski et al., 2001d). Overall, light $(8 \mathrm{~h})$ during in vitro tuberization was an important factor (irrespective of other treatments) in producing microtubers which then performed well in the greenhouse. Microtubers produced in dark performed poorly (Pruski et al., 2001d).

Data obtained in the course of this study show that the key factor to a successful use of microtubers along with the plantlets in the greenhouse or in the field is the dormancy release. As mentioned earlier, the microtubers right after in vitro tuberization are very dormant (Struik \& Wiersema, 1999; Tábori et al. 1999). Recently, several researchers reported that dormancy of microtubers is cultivar dependent and is also affected by the photoperiod applied during in vitro tuberization (Tábori et al., 1999; Coleman \& Coleman, 2000). In the study reported here gibberellic acid (GA) and Rindite were used to release microtuber dormancy prior to planting. Rindite proved to be very effective in greenhouse conditions (Chapter 7, Tables $9-11$ ). However, more studies are required to provide evidence that the product is safe to use with microtubers, since there is a controversy in literature. In general, Rindite is not recommended for breaking dormancy of microtubers. It is considered dangerous for microtubers, since decay may easily occur after such treatment due to the small size of microtubers (Ranalli, 1997; Struik \& Wiersema, 1999). In the experiments included in this thesis, no rot or decay of microtubers treated with Rindite was observed when the propagules derived from $8 \mathrm{~h}$ light tuberization treatment. Some damage was observed in microtubers produced in dark ( $0 \mathrm{~h}$ photoperiod) but it was considered minimal. Microtubers used in these studies were stored in a cooler for close to 12 weeks prior to planting, which provided enough time to develop adequate skin. Moreover, right after harvest and before cold storage, microtubers were placed into Petri dishes and left on the laboratory bench for $24 \mathrm{hrs}$ at room temperature to harden off. Also, only microtubers $>0.15 \mathrm{~g}$ were used in greenhouse plantings. The above conditions may have protected the microtubers from damages during Rindite application. A successful dormancy release by Rindite was reported recently by Nasiruddin \& Blake (1997) for cultivar Désirée microtubers (Rindite application right after harvest) and Kim et al. (1999) for cultivars Atlantic, Kennebec, Lemhi Russet, Red Dale and Superior (Rindite application 2 weeks after harvest). Désirée, a long dormancy cultivar (Van Ittersum \& Scholte, 1993), also in vitro expresses long dormancy of microtubers (Nasiruddin \& Blake, 1997). Microtubers of Russet Burbank had the longest dormant period among the other cultivars tested (Leclerc et al., 1995). Field grown tubers of this variety also had the longest dormancy period (out of 10 varieties tested) and the slowest rate of sprouting after dormancy ended (Bogucki \& Nelson, 1980). Cho et al. 
(1983) observed that the dormant period is influenced by the maturity of tubers. This could be extended to microtubers as well (Leclerc et al., 1995; Kim et al., 1999). Differences in the dormancy breaking response treated by Rindite, observed among varieties (Kim et al., 1999), might be related to genetic characteristics of each variety. The Rindite treatment was the most effective for the Russet varieties, intermediate for Superior and least effective for Red Dale variety (Kim et al., 1999). In the studies reported in this thesis, all three Russet varieties responded well to Rindite dormancy release treatments. The earlier Rindite treatment was applied after harvest, the more damage, decay and loss of weight of microtubers were observed (Nasiruddin \& Blake, 1997; Kim et al., 1999).

Results from the above studies suggest that microtubers of the three Russet varieties (Amisk - Ranger Russet, Russet Burbank, Umatilla Russet) can be included along with in vitro plantlets in the commercial production of minitubers in greenhouses. All three varieties responded favourably to in vitro tuberization and also performed well in the greenhouse production of minitubers. The positive responses of Russet varieties to in vitro systems have been observed in several commercial laboratories in Canada (Shirlyn Coleman, personal communication; D'nA Gardens, personal communication). The Russet skin is an inherited characteristic and the few genes responsible for it, may have secondary (pleiotropic) effects making the variety more suitable for the in vitro system. As for other varieties, more studies are necessary to fine tune the conditions during the in vitro tuberization period and the dormancy release treatments before the method can be applied commercially.

\section{Microtubers in the production of Pre-elite tubers in the field}

Similarly to the greenhouse studies, results obtained with microtubers of cultivars Amisk, Russet Burbank and Umatilla Russet were encouraging, with Shepody inconclusive, and Atlantic microtubers performed poorly in the field (Pruski et al., $2001 \mathrm{~d})$. On the other hand the in vitro plantlets of all five tested cultivars performed well in the field. The results suggest that the plantlets can be considered as a source of planting material in the commercial field production of Pre-elite seed potato tubers (Chapter 7, Table 5A, B) if necessary and economically feasible. Struik \& Wiersema (1999) reported several successful studies on use of in vitro plantlets in direct field planting to produce Pre-elite tubers. In the studies reported here, in vitro plantlets outperformed microtubers in the production of Pre-elite tubers on the field. Yield and the number of Pre-elite tubers produced from microtubers were more than $50 \%$ lower than from plantlets.

Results obtained with direct planting of microtubers to the field (1998 studies) show 
that the JA pre-treatment significantly enhanced the total number of Pre-elite tubers in Russet Burbank by approximately $40 \%$ but lowered it in Shepody by $17 \%$ (Pruski et al., 2001d). In Russet Burbank, all the responses (total number of Pre-elite tubers, number of tubers $<48 \mathrm{~mm}$, number of tubers $48-88 \mathrm{~mm}$ and yield of tubers $<48 \mathrm{~mm}$ ) were significantly higher in the JA pre-conditioned treatments than in the no-JA control. The reverse was true in Shepody. In Russet Burbank, about 2.5 Pre-elite tubers (1998 studies) were produced per microtuber in the JA pre-treatment $v s 1.8$ in no-JA. However, when Pre-elite tubers were grown from microtubers produced on media containing JA the results were opposite to these obtained from JA pre-treated microtubers grown on JA-free media. In Russet Burbank, the total number of Pre-elite tubers was about $42 \%$ and yield was about $65 \%$ lower from the microtubers grown on the media containing JA than those from non-JA media (Chapter 7, Table 7). Shepody, on the other hand, was either indifferent to or benefited from the JA treatment. In general, JA in tuberization media enhanced Shepody's Pre-elite tuber production by up to $45 \%$. In the 1999 field studies, JA presence in media during in vitro tuberization significantly lowered production of Pre-elite tubers. As in 1998, with the exception of Russet Burbank, the microtubers produced with JA in the tuberization medium gave fewer Pre-elite tubers than those produced without JA. Comparing to the control, the yield of Umatilla Russet was reduced the most (for example, by almost $90 \%$ in the 48 - $88 \mathrm{~mm}$ size category). On the contrary, microtubers produced from the JA conditioned Amisk and Russet Burbank stock plantlets gave up to $10 \%$ higher number of Pre-elite tubers in the $48-88 \mathrm{~mm}$ category. Overall, the results were inconclusive; stock plantlets pre-treated with JA (prior to in vitro tuberization) enhanced the Preelite tuber production in some varieties but significantly lowered it in others (for example Shepody). Since the responses to JA, either in the tuberization media or as a stock plantlet conditioner, were variety specific, more experimental work is needed to determine suitability of the varieties to such treatment.

Exposure to light during in vitro tuberization had also a significant effect on the performance of the microtubers in the field, in all varieties. Responses were very similar to those in the greenhouse production of minitubers. Total number of Pre-elite tubers produced from microtubers ( 20 planted) treated with $8 \mathrm{~h}$ light was about 50 - 60\% higher than from the microtubers produced in dark, 52.54 and 34.06, respectively (Table 4). Similar results were recorded for total yield and yield, and number of $<48 \mathrm{~mm}$ in diameter tubers. Since the results from 1998 studies demonstrated that microtubers produced under $8 \mathrm{~h}$ photoperiod gave higher yields of Pre-elite seed tubers, consequently, only this kind of microtubers was used in the 1999 field planting. The result show that the $8 \mathrm{~h}$ light period during the in vitro tuberization can be recommended in the commercial settings, which would assure a good 
Table 4. Effects of light ( $\mathrm{Li})$ during in vitro tuberization on the number and yield of Pre-elite tubers in the field produced from microtubers. Least square means comparison for the significant single effect of light.

\begin{tabular}{|c|c|c|c|c|}
\hline $\begin{array}{l}\text { Light } \\
\text { [hrs] }\end{array}$ & $\begin{array}{l}\text { Total number of Pre- } \\
\text { elite tubers from } 20 \\
\text { microtubers per } \\
\text { varjety }\end{array}$ & $\begin{array}{l}\text { Number of tubers } \\
<48 \mathrm{~mm} \text { diameter } \\
\text { per variety }\end{array}$ & $\begin{array}{c}\text { Total yield of Pre-elite } \\
\text { tubers from } 20 \\
\text { microtubers per variety } \\
{[\mathrm{kg}]}\end{array}$ & $\begin{array}{c}\text { Yield of tubers } \\
<48 \mathrm{~mm} \text { diameter } \\
\text { per variety } \\
{[\mathrm{kg}]}\end{array}$ \\
\hline $\mathbf{0}$ & $34.06 \mathrm{~b}^{*}$ & $26.16 \mathrm{~b}$ & $1.476 \mathrm{~b}$ & $0.800 \mathrm{~b}$ \\
\hline 8 & $52.54 \mathrm{a}$ & $42.42 \mathrm{a}$ & $2.673 \mathrm{a}$ & $1.372 \mathrm{a}$ \\
\hline
\end{tabular}

${ }^{*}$ Means in the same column followed by different letters are significantly different at the $5 \%$ level of significance.

Bold row - minitubers produced from microtubers from the dark tuberization treatment.

performance of the microtubers in further production of minitubers and Pre-elite seed tubers.

As in the greenhouse situation, the dormancy release was the key factor influencing microtuber performance in the field. Rindite proved to be very effective for microtubers used in greenhouse conditions. For microtubers used in the field, gibberellic acid (GA) gave slightly better results (Pruski et al., 2001d). In all three Russet varieties, the highest number and yield of Pre-elite tubers were obtained when the microtubers were soaked in $100 \mathrm{ppm}$ solution of gibberellic acid prior to field planting. The yield and the number of Pre-elite tubers were significantly higher when the microtubers were produced on media without JA. For microtubers coming from JA tuberization media, there were no significant differences observed in all parameters measured, irrespective of the dormancy release treatment. Both, Rindite and GA treatments gave similar results.

As mentioned earlier, the production of Pre-elite tubers from microtubers (irrespectively of the treatment) was about $50 \%$ lower than those from in vitro plantlets. Taking this under consideration, at this stage of knowledge, microtubers cannot be recommended for direct field planting. More research is needed to improve their performance and determine suitability of the varieties to this method.

\subsection{Incorporating microtubers into a seed production programme: An assessment}

Potato microtubers of good size and quality can be produced reliably from in vitro propagated plantlets. However, application of microtubers in any of the seed potato 


\section{Chapter 9}

programmes, will only be successful if the microtubers will yield progeny tubers that are superior economically and in quality to tubers (minitubers or Pre-elite tubers) produced by existing technologies. In Western provinces of Canada, particularly in Alberta, the interest in a new type of the propagule is quickly growing among seed potato growers who are at the same time the owners of small tissue culture laboratories. Growers started using microtubers in their plantings on an experimental scale in the early 1990s. The privatization of the Alberta seed potato programme generated a new interest in this type of propagule among the owners of the new laboratories and the greenhouse growers. As mentioned in Chapter 1 (Section 1.4) and in Chapter 8 (Section 8.3) more even distribution of the workload was needed in these labs and microtubers presented a logical choice. An almost two-fold increase in the potato acreage in Alberta, between 1998 and 2000, put a significant pressure on seed potato producers. The market demand for high quality seed tubers also doubled. In order to maintain steady seed supply, the seed potato growers started including microtubers into the system along with in vitro plantlets. Both types of propagules guarantee the production of high quality, disease-free minitubers (nuclear tubers) in greenhouses and/or in some cases Pre-elite tubers (direct field planting). Technically it is possible to produce large numbers of microtubers throughout the year, store them in the cooler and plant them out accordingly to the schedule of the seed programme. However, before a large-scale application could be considered, more research is needed to determine suitability of the commercial varieties to the in vitro tuberization method and to improve the performance of microtubers, particularly in the field situation. Based on the data obtained in this study, microtubers of some varieties ('good performers') can be used, or even can be recommended to include them in the seed potato programme, in the greenhouse production of minitubers. Their performance was more than satisfactory and comparable with the industry standards, the plantlets. The others need more work on various aspect including tuberization conditions and the dormancy release methods.

\subsection{General assessment}

The various aspects of micropropagation technology discussed in this thesis show the importance of this technology for the seed potato programmes. As mentioned earlier, micropropagation became an essential part of any of the seed potato programmes around the world. The objectives of the research, although focused mainly on the needs of Western provinces of Canada (particularly Alberta), could be extended to any other area and any other laboratory associated with the seed potato programmes. Research on adjustments and improvements in the production of in vitro plantlets or in 
vitro storage of cultures have immediate practical implications to the production considerations and scheduling in small tissue culture laboratories. In vitro tuberization part of the research as well as work on performance of microtubers in the greenhouse and in the field provide a better understanding of the tuberization processes (including the effects of media, growth regulators and photoperiod) and their influence on further production of minitubers and Pre-elite tubers. The research described in this thesis, using advanced tissue culture techniques, may provide an evolutionary step in the seed potato production around the world.

\section{References}

AAFC (Agriculture \& Agri-Food Canada), 1996. Propagation and initiation of single node cuttings of potato in vitro. Prepared by L.K. Douglass, Potato Propagation and Tissue Culture Laboratory, Potato Research Centre, AAFC, Fredericton, Canada, pp. 1-9.

Bessembinder, J.J.E., G. Staritski \& E.A. Zandvoort, 1993. Long-term in vitro storage of Colocasia esculenta under minimal growth conditions. Plant Cell, Tissue and Organ Culture 33: 121-127.

Bogucki, S. \& D.C. Nelson, 1980. Length of dormancy and sprouting characteristics of ten potato cultivars. American Potato Journal 57: 151-157.

Booth, A., 1959. Some factors concerned in the growth of stolons in the potato. Journal of Linnean Society (Botanic) 56: 166-169.

Chapman, H.W, 1958. Tuberization in the potato plant. Physiologia Plantarum 11: 215-224.

Cho, J.L., W.M. Iritani \& M.W. Martin, 1983. Comparison of methods for measuring dormancy of potatoes. American Potato Journal 60: 169-177.

Coleman, W.K. \& S.E. Coleman, 2000. Modification of potato microtuber dormancy during induction and growth in vitro and ex vitro. American Journal of Potato Research 77: 103110.

Coleman, W.K., D.J. Donnelly \& S.E. Coleman, 2001. Potato microtubers as research tools: A review. American Journal of Potato Research 78: 47-55.

Dobránszki, J. \& M. Mandi, 1993. Induction of in vitro tuberization by short day period and dark treatment of potato shoots grown on hormone-free medium. Acta Biologica Hungarica 44: 411-420.

Dobránszki, J., K.M. Tábóri \& A. Ferenczy, 1999. Light and genotype effects on in vitro tuberization of potato plantlets. Potato Research 42: 483-488.

Estrada, R., P. Tovar, \& J. H. Dodds, 1986. Induction of in vitro tubers in a broad range of potato genotypes. Plant Cell, Tissue and Organ Culture 7: 3-10.

Fujiwara, K., S. Kira \& T. Kozai, 1995. Contribution of photosynthesis to dry weight increase of in vitro potato cultures under different $\mathrm{CO}_{2}$ concentrations. Acta Horticulturae 393: 119-126. 


\section{Chapter 9}

Garcia-Torres, L. \& C. Gomez-Campo, 1973. In vitro tuberization of potato sprouts as affected by ethrel and gibberellic acid. Potato Research 16: 73-79.

Garner, N. \& J. Blake, 1989. The induction and development of potato microtubers in vitro on media free of growth regulating substances. Annals of Botany 63: 663-674.

Goodwin, P.B., Y.C. Kim \& T. Adisarwanto, 1980. Propagation of potato by shoot-tip culture. 1. Shoot multiplication. Potato Research 23: 9-18.

Gopal, J., J.L. Minocha \& J.S. Sidhu, 1997. Comparative performance of potato crops raised from microtubers induced in the dark versus microtubers induced in light. Potato Research 40: 407-412.

Gregory, L.E., 1956. Some factors for tuberization in the potato plant. American Journal of Botany 43: 281-288.

Hussey, G. \& N.J. Stacey, 1981. In vitro propagation of potato (Solanum tuberosum L.). Annals of Botany 48: 787-796.

Hussey, G. \& N.J. Stacey, 1984. Factors affecting the formation of in vitro tubers of potato (Solanum tuberosum L.). Annals Botany 53: 565-578.

Jackson, S.D., 1999. Multiple signalling pathways control tuber induction in potato. Plant Physiology 119: 1-8.

Jackson, S.D., P. James, S. Prat \& B. Thomas, 1998. Phytochrome B affects the levels of graft-transmissible signal involved in tuberization. Plant Physiology 117: 29-32.

Khuri, S. \& J. Moorby, 1996. Nodal segments or microtubers as explants for in vitro microtuber production of potato. Plant Cell, Tissue and Organ Culture 45: 215-222.

Kim, S.Y., J.K. Kim, K.H. Choi, Y.H. Joung \& H. Joung, 1999. Effects of Rindite on breaking dormancy of potato microtubers. American Journal of Potato Research 76:5-8.

Koda, Y., 1997. Possible involvement of jasmonates in various morphogenic events. Physiologia Plantarum 98: 407-412.

Koda, Y., Y. Kikuta, H. Tazaki, Y. Tsuhino, S. Sakamura, \& T. Yoshihara, 1991. Potato tuber-inducing activities of jasmonic acid and related compounds. Phytochemistry 30: 1435-1438.

Kozai, T., Y. Iwanami \& K. Fujiwara, 1987. Environment control for mass propagation of tissue cultured plantlets. 1. Effects of $\mathrm{CO}_{2}$ enrichment on the plantlet growth during the multiplication stage. Plant Tissue Culture Letters 4: 22-26.

Kubota, C. \& T. Kozai, 1994. Low temperature storage for quality preservation and growth suppression of Broccoli plantlets cultured in vitro. HortScience 29: 1191-1194.

Kubota, C., G. Niu \& T. Kozai, 1995. Low temperature storage for production management of in vitro plants: effects of air temperature and light intensity on preservation of plantlet dry weight and quality during storage. Acta Horticulturae 393: 103-110.

Kumar, D \& P.F. Warreing, 1973. Studies on tuberization in Solanum andigena. I. Evidence for the existence and movement of a specific tuberization stimulus. New Phytology 73 : 
833-840.

Leclerc, Y., D.J. Donnelly, W.K. Coleman \& R.R. King, 1995. Microtuber dormancy in three potato cultivars. American Potato Joumal 72: 215-223.

Lê, C.L., 1999. In vitro microtuberization: an evaluation of culture conditions for the production of virus-free potatoes. Potato Research 42: 489-498.

Machackova, I., T. Konstantinova, L.I. Segeeva, V.N. Lozhnikova , S.A. Golyankovskaya, N.D. Dudko, J. Eder \& N.P. Aksenova, 1998. Photoperiodic control of growth, development and phytohormone balance in Solanum tuberosum L. Physiologia Plantarum 102: 272-278.

Marinus, J., 1985. "In Vitro" Multiplication of Potatoes: Description of Methods and Experience in The Netherlands. CABO, Wageningen, $21 \mathrm{pp}$.

Marino, G., P. Posati \& F. Sagrati, 1985. Storage of in vitro cultures of Prunus rootstocks. Plant Cell, Tissue and Organ Culture 5: 73-78.

Murashige, T. \& F. Skoog, 1962. A revised medium for rapid growth and bioassays with tobacco tissue cultures. Physiologia Plantarum 15: 473-497.

Nasiruddin, K.M. \& J. Blake, 1997. Effect of Rindite on storage behavior, dormancy break and sprout growth of potato microtubers (cv. Desiree). American Potato Joumal 74: 325330.

Nowak, J. \& S. Asiedu, 1992. Gelling agent and light effects on in vitro tuberization of potato varieties. American Potato Joumal 69: 461-470.

Ochotorena, M., I. Santamaria, L.M. Arregui \& A.M. Mingo-Castel, 1999. In vitro tuberisation of potato: the interaction of ancimidol and photoperiod. Potato Research 42: 601-606.

Okazawa, Y., 1967. Physiological studies on the tuberization of potato plants. Joumal Faculty of Agriculture of the Hokkaido University 55: 267-336.

Palmer, C.E. \& O.E. Smith, 1970. Effect of kinetin on tuber formation on isolated stolons of Solanum tuberosum L. cultured in vitro. Plant Cell Physiology 11: 303-314.

Pelacho, A.M. \& A.M. Mingo-Castel, 1991. Jasmonic acid induces tuberization of potato stolons cultured in vitro. Plant Physiology 97: 1253-1255.

Pruski, K., J. Nowak \& T. Lewis, 1993. Jasmonates and photoperiod effect on microtuber production in two potato varieties. In Vitro Cellular and Developmental Biology - Plant 29: 69 (abstract).

Pruski, K., T. Kozai, T. Lewis, T. Astatkie \& J. Nowak, 2000. Sucrose and light effects on in vitro cultures of potato (Solanum tuberosum L.), chokecherry (Prunus virginiana L.) and Saskatoon berry (Amelanchier alnifolia Nutt.) during low temperature storage. Plant Cell, Organ and Tissue Culture 63: 215-221.

Pruski, K., T. Astatkie \& J. Nowak, 2001a. Jasmonate effects on in vitro tuberization and tuber bulking in two potato cultivars (Solanum tuberosum L.) under different media and photoperiod conditions. In Vitro Cellular and Developmental Biology - Plant: in press. 


\section{Chapter 9}

Pruski, K, T. Astatkie, M. Mirza \& J. Nowak, 2001b. Photoautotrophic micropropagation of Russet Burbank potato (Solanum tuberosum L.). Plant Cell, Tissue and Organ Culture accepted.

Pruski, K., P. Duplessis, T. Astatkie, J. Nowak \& P.C. Struik, 2001c. Jasmonate effects on in vitro tuberization of potato (Solanum tuberosum $\mathrm{L}$.) varieties under light and dark conditions. Potato Research accepted.

Pruski, K., T. Astatkie, P. Duplessis, L. Stewart, J. Nowak \& P.C. Struik, 2001d. Jasmonate as a potato plantlets and microtubers conditioner for greenhouse and field planting. American Journal of Potato Research accepted after revision and splitting into two separate papers.

Ranalli, P., 1997. Innovative propagation methods in seed tuber multiplication programmes. Potato Research 40: 439-453.

Ravnikar, M., B. Vilhar \& N. Gogala, 1992. Stimulatory effects of jasmonic acid on potato node and protoplast culture. Journal of Plant Growth Regulation 11: 29-33.

Slater, J.W, 1963. Mechanism of tuber initation. In: J.D. Ivins \& F.L. Milthorpe (Eds.), The growth of the potato. Butterworths, London, pp. 114-120.

Struik, P.C., E. van Heusden \& K. Burger-Meyer, 1988. Effects of short periods of long days on the development, yield and size distribution of potato tubers. Netherlands Journal of Agricultural Science 36: 11-22.

Struik, P.C., G. Kramer \& N.P. Smit, 1989. Effects of soil applications of gibberellic acid on the yield and quality of tubers Solanum tuberosum L. cv. Bintje. Potato Research 32: 203208.

Struik, P.C. \& W.J.M. Lommen, 1990. Production, storage and use of micro- and minitubers. Proceedings of the $11^{\text {th }}$ Triennial Conference of the European Association for Potato Research (EAPR), Edinburgh, UK, pp. 122-133.

Struik, P.C. \& S.G. Wiersema, 1999. Seed Potato Technology. Wageningen Pers, Wageningen, The Netherlands, $383 \mathrm{pp}$.

Tábóri, K.M., J. Dobránszki \& A. Ferenczy, 1999. Some sprouting characteristics of microtubers. Potato Research 42: 611-617.

Teisson, C. \& D. Alvard, 1999. In vitro production of microtubers in liquid medium using temporary immersion. Potato Research 42: 499-504.

Van den Berg, J.H. \& E.E. Ewing, 1991. Jasmonates and their role in plant growth and development with special reference to the control of potato tuberization: A review. American Potato Journal 68: 781-794.

Van Huylenbroeck, J.M. \& P.C. Debergh, 1996. Physiological aspects in acclimatization of micropropagated plantlets. Plant Tissue Culture and Biotechnology 2: 136-141.

Van Ittersum, M.K. \& K. Scholte, 1993. Shortening dormancy of seed potatoes by haulm application of gibberellic acid and storage temperature regimes. American Potato Journal 
70: 7-19.

Vreugdenhil, D. \& P.C. Struik, 1989. An integrated view of the hormonal regulation of tuber formation in potato (Solanum tuberosum). Physiologia Plantarum 75: 525-531.

Vreugdenhil, D. \& L.I. Sergeeva, 1999. Gibberellins and tuberization in potato. Potato Research 42: 471-481.

Westcott, R.J., 1981a. Tissue culture storage of potato germplasm. 1. Minimal growth storage. Potato Research 24: 331-342.

Westcott, R.J., 1981b. Tissue culture storage of potato germplasm. 2. Use of growth retardants. Potato Research 24: 343-352.

Withers, L.A. \& F. Engelmann, 1998. In vitro conservation of plant genetic resources. In: A. Altman (Ed.), Agricultural Biotechnology, Marcel Dekker, Inc., New York, NY, pp. 57-88.

Xu, X., A.A.M. van Lammeren, E. Vermeer \& D. Vreugdenhil, 1998. The role of gibberellins, abscisic acid, and sucrose in the regulation of potato tuber formation in vitro. Plant Physiology 117: 557-584. 


\section{Summary}

Micropropagation (tissue culture propagation) has been widely used in seed potato production programmes over the last three decades. It practically solved the disease problems associated with the conventional seed production system providing the potato industries with high quality, disease/virus-free Elite plant material. It has also been widely accepted since it gives the possibility to produce large quantities of genetically uniform in vitro plant material (plantlets and microtubers) for seed tuber production (minitubers and Pre-elite tubers) within a short period of time and all year round.

The thesis outlines improvements to micropropagation methods commonly used in commercial laboratories, focusing on seed potato growers in Western Canada who either produce the tissue culture plant material themselves, or acquire it prior to planting.

This research project aimed on examining the possibilities of:

1. Improvements of in vitro plantlet multiplication via nodal cuttings with a focus on photoautotrophic growth;

2. Improvements in low-temperature, short-term in vitro storage of potato cultures;

3. Microtuber production in vitro from nodal explants, taken from in vitro plantlets, including testing of jasmonic acid (JA) as a tuber inducing agent and influence of three photoperiods during the tuberization period as well as examining suitability of several commercial potato varieties to the microtuberization method;

4. Greenhouse and/or field planting of microtubers to produce minitubers and/or Preelite tubers where the microtuber performance was compared to the industry standard, the plantlet;

5. The use of JA as a pre-conditioner for greenhouse and field planting of microtubers.

Multiplication of plantlets and in vitro storage of cultures. The photoautotrophic micropropagation of Russet Burbank variety investigated in Chapter 3 showed a usefulness of this technique for the small commercial laboratories where often the full sterility is difficult to maintain. Single node microcuttings were grown for four weeks on MS medium with or without sucrose $\left(30 \mathrm{~g}^{-1}\right)$ in the growth room at $21 / 19^{\circ} \mathrm{C}$ day/night temperature, with $16 \mathrm{~h}$ photoperiod at $150 \mu \mathrm{mol} \mathrm{m} \mathrm{m}^{-2} \mathrm{~s}^{-1}$ photosynthetic photon flux density (PPFD) mixed fluorescent/incandescent light, with or without supplemental $\mathrm{CO}_{2}$ at $1500 \mu \mathrm{l} \mathrm{l}^{-1}$. After four weeks, no significant differences were observed between control (MS medium supplemented with sucrose $\left(30 \mathrm{~g} \mathrm{l}^{-1}\right)$ and photoautotrophic cultures coming from MS medium with no sucrose grown under 
$1500 \mu \mathrm{l} \mathrm{CO}_{2} \mathrm{l}^{-1}$. Photoautotrophic cultures produced stems averaging $43.3 \mathrm{~mm}$, with 7.58 nodes and weighing $9.2 \mathrm{mg}$ (dry), very similar to conventionally grown in vitro cultures ( $47.9 \mathrm{~mm}$ with 7.55 nodes, $9.7 \mathrm{mg}$ dry weight). A $20 \%$ increase in the number of nodes per stem and a $50 \%$ increase in stem dry weight (doubled stem length) were observed in cultures grown on media with sucrose and in $\mathrm{CO}_{2}$ enriched atmosphere comparing to the conventional cultures or the cultures grown photoautotrophically. In conventional commercial settings, supplementing air in the growth room with $1500 \mu \mathrm{l}$ $\mathrm{CO}_{2} \mathrm{I}^{-1}$ could be beneficial for potato plantlet production since it significantly improved quality, size and biomass of produced plantlets, speeding up the multiplication.

Results obtained in the studies on low-temperature in vitro storage of cultures (Chapter 4) suggest the use of continuous low red light $\left(690 \mathrm{~nm}\right.$ ) at $3 \mu \mathrm{mol} \mathrm{m} \mathrm{m}^{-2} \mathrm{~s}^{-1}$ PPFD and $30 \mathrm{~g} \mathrm{l}^{-1}$ sucrose in the medium during the storage of potato cultures in order to have vigorous cultures, with a high capacity to re-grow. Cultures of cv. Atlantic grown in vitro for 3 weeks at $24 / 22^{\circ} \mathrm{C}, 16 \mathrm{~h}$ photoperiod, $150 \mu \mathrm{mol} \mathrm{m}^{-2} \mathrm{~s}^{-1}$ PPFD were placed in storage for 6,9 and 12 weeks at $4^{\circ} \mathrm{C}$ under 0 (darkness) and under low light. Growth regulators free MS medium either with or without sucrose was used to store the cultures. Although sucrose was essential for the low temperature maintenance of vigorous stock plants for either light treatment, low light significantly improved quality of the stored cultures if stored for more than six weeks. Since the commercial growers often need to store the cultures for short periods of time (due to production scheduling), installation of a simple low light device in the regular refrigerator would improve and maintain the high quality of the stored cultures.

The production of microtubers. The research on the production of microtubers (Chapters 5-6) examined the suitability of the culture media liquid $v s$ solid (agar), the importance of $8 \mathrm{~h}$ photoperiod (short days, SD) during the in vitro tuberization, benefits of use of jasmonic acid (JA) for tuberization and the varietal differences in responses to in vitro tuberization. The plantlets used in all in vitro tuberization experiments were routinely multiplied in vitro via single node stem cuttings every few weeks. During the last transfer before in vitro tuberization, half of the single-node explants of all the cultivars tested was placed on medium supplemented with $2.5 \mu \mathrm{M}$ JA (the group labelled JAP or JAPret) and incubated for four weeks under the conditions described for multiplication of plantlets. Nodal explants taken from the above plants (no JA and JAP) were used in tuberization experiments. Tuberization was performed on media with $8 \%\left(80 \mathrm{~g}^{-1}\right)$ sucrose, with or without $2.5 \mu \mathrm{M} \mathrm{JA}$ (the group labelled JAM or JAMed) and with (solid)/without (liquid) $0.6 \%$ agar. Cultures were incubated at $20^{\circ} \mathrm{C}$ with 0 (darkness), 8 and $16 \mathrm{~h}$ photoperiod at $50 \mu \mathrm{mol} \mathrm{m}{ }^{-2} \mathrm{~s}^{-1} \mathrm{PPFD}$ 
light for $10-11$ weeks. Overall, significantly better production of microtubers (number of tubers and weight) was observed on solid than on liquid media and under SD (Chapter 5). The agar media were then used in further in vitro tuberization experiments. Liquid media required a frequent addition of fresh medium during the tuberization and this was found inconvenient (additional work and increased risk of contamination). Also sucrose was probably more stable in agar medium than in the liquid and this in turn was beneficial for tuberization. Sucrose content, crucial during the in vitro tuberization was set at $8 \%$ (the optimal level) in all experiments following the recommendations found in literature.

From the three photoperiods studied $(0,8,16 \mathrm{~h})$, in the first series of experiments reported in the thesis the best production of microtubers was recorded under $8 \mathrm{~h}$ (SD). Although tuber bulking rates were lower in the darkness than under the SD, the first tubers were induced in darkness, on explants from JA conditioned stock plants. Tubers derived from SD were green and seemed less juvenile than the tubers from $0 \mathrm{~h}$ light. In further studies, it was observed that such microtubers performed better in the field or the greenhouse than microtubers produced in darkness. The $16 \mathrm{~h}$ photoperiod was inhibitory to the production of microtubers. In further studies, the production of microtubers was much better under SD than in darkness. Fewer microtubers per explant with significantly lower weights were produced in dark treatments than under SD (in all six varieties tested). There were significant differences observed between varieties in response to the photoperiod during in vitro tuberization. Production of microtubers in all three Russet varieties and in Sangre was superior to that of Shepody and Atlantic (Chapter 6). In the studies presented in Chapters 5 - 7, the exposure to SD during tuberization was essential for the production of a sufficient number of microtubers per nodal cutting and the $8 \mathrm{~h}$ photoperiod is being recommended.

Effects of jasmonic acid (JA) on in vitro tuberization of potato proved to be variety specific. In the first series of experiments (cvs Sangre and Russet Burbank), explants taken from stock plants grown on JA supplemented medium, tuberized first, particularly in darkness. The most pronounced benefits of the JA pre-treatment were recorded under $16 \mathrm{~h}$ photoperiod, which is known to inhibit tuberization. Overall, microtubers produced either from JA pre-conditioned stock plants or on the JA containing tuberization media were more uniform and larger than from other treatments. Studies with six commercial varieties (Chapter 6) examined the effects of JA in two independent experiments, under light $(8 \mathrm{~h})$ and dark $(0 \mathrm{~h})$ conditions. Amisk, Russet Burbank, Sangre and Umatilla Russet produced the highest number of microtubers per nodal cutting $(1.0-1.7)$ and their tubers were also the largest with the highest percentage of microtubers $>0.1 \mathrm{~g}(70-85 \%)$. Results with Shepody were inconsistent and Atlantic produced the lowest number of tubers per nodal cutting. The effects of JA were variety 


\section{Summary}

specific, whereas the benefits were more pronounced in the dark than in the light treatments. In Atlantic, the JA seemed to substitute for light during the $0 \mathrm{~h}$ photoperiod tuberization. According to the responses the tested varieties were divided into three groups. Amisk, Atlantic and Umatilla Russet (group I) benefited in the dark (significantly higher total tuber weight, percentage and weight of microtubers $>0.1 \mathrm{~g}$ ) from JA supplement to the tuberization medium, but not from the pre-conditioning treatment. However, none of these varieties clearly benefited from any JA treatments under light. Russet Burbank (group II) and Sangre also benefited from the JA supplement in the dark, although stock plantlet conditioning was more effective than the JA supplement to the tuberization medium. Shepody (group III) did not show any benefits of JA on microtuberization, neither under dark or light conditions. Compared to the control and the individual JA treatments, the double treatment with JA (JAPret and JAMed) in light, significantly reduced production of microtubers in both Shepody and Russet Burbank.

All three Russet varieties, Russet Burbank, Umatilla Russet, Amisk (Ranger Russet) and Sangre responded positively to in vitro tuberization and can be recommended for commercial production using this method. Varieties Atlantic and Shepody cannot be recommended (yet) for this method. The production of microtubers in both varieties was low (especially in Atlantic).

The performance of microtubers in the greenhouse and in the field. All microtubers used in this research (Chapter 7) were produced either under $8 \mathrm{~h}$ photoperiod or in darkness, from nodal cuttings pre-treated with/without JA on media supplemented with/without JA. The performance of microtubers was compared to the industry standard, the plantlet, in association with dormancy release methods.

In the greenhouse. Microtubers of the three Russet varieties performed best in the production of minitubers in the greenhouse. Shepody produced inconclusive results and more research is needed to improve performance of its microtubers in the greenhouse. Microtuber performance of variety Atlantic was very poor during the course of this study, and the variety cannot be recommended for this method. The greenhouse performance of microtubers was highly dependent on jasmonic acid (JA) conditioning of plantlets prior to in vitro tuberization, presence of $\mathrm{JA}$ in tuberization media, the photoperiod during tuberization and the dormancy release treatment. Although plantlets of all five tested cultivars performed well in the greenhouse, the microtuber performance was variety dependent, so were the responses to JA. Again, the three Russet varieties responded best to JA treatments. Total number and yield of minitubers in the three Russet varieties was the highest from minitubers produced from plantlets 
pre-treated with JA (Amisk produced more than 3 minitubers per microtuber, from JAPret plantlets comparing to 2.5 per microtuber without JA). The total yields in Russet Burbank and Umatilla Russet were also the highest in this treatment, 0.859 and $0.879 \mathrm{~kg}$ per plot of 20 microtubers, respectively comparing to about $0.500 \mathrm{~kg}$ per plot in other treatments. These data are comparable to numbers obtained from the industry standard (the plantlet), especially with variety Amisk. Also, Amisk yield of minitubers in $30-60 \mathrm{~mm}$ category was almost the same as from plantlets. JA conditioning of stock plants prior to taking explants for tuberization was beneficial for minituber production and it can be proposed as a treatment enhancing the quality of microtubers and their performance in the greenhouse production of minitubers.

Microtubers produced under light performed significantly better than those produced in darkness. In both seasons, 1998 and 1999, in all tested varieties, the total yield and number of minitubers in all size categories was $2-7$ times higher from microtubers exposed to light during in vitro tuberization. Overall, SD during in vitro tuberization was an important factor (irrespective of other treatments) in producing microtubers which then performed well in the greenhouse. Microtubers produced in dark performed poorly. Photoperiod effects during in vitro tuberization on microtubers performance are discussed in detail in Section 9.4 (Microtubers in the production of minitubers in the greenhouse) of the General Discussion. The $8 \mathrm{~h}$ photoperiod during in vitro tuberization is recommended.

The key factor to a successful use of microtubers for minituber production is dormancy release. Microtubers right after in vitro tuberization are very dormant. In this research gibberellic acid (GA) and Rindite were used to release microtuber dormancy prior to planting. Although Rindite proved to be very effective in greenhouse conditions, more studies are required to provide evidence that the product is safe to use with microtubers. Also, since Rindite is highly toxic to humans, safety measures have to be taken when handling the product. Often reported decay of microtubers after Rindite treatment did not occur in this research. No severe damage to microtubers treated with Rindite was observed when microtubers were from $8 \mathrm{~h}$ light tuberization treatment (minimal damage to tubers from the dark treatment). Rindite was applied only to microtubers which had well developed skin (after several weeks of storage) and only to microtubers $>0.15 \mathrm{~g}$. Rindite could be recommended for the dormancy release in the greenhouse production of minitubers, if used with caution.

In the field. Similar to the greenhouse studies, microtubers of cultivars Amisk, Russet Burbank and Umatilla Russet performed relatively well in the field, results with Shepody were inconclusive, and Atlantic microtubers performed very poorly in the field. However, the in vitro plantlets of all varieties performed well in the field. These 
results suggest that the plantlets can be considered as a source of planting material in the commercial field production of Pre-elite seed potato tubers (Chapter 7) if necessary and economically feasible. In this research, the in vitro plantlets clearly outperformed microtubers in the production of Pre-elite tubers on the field. Yield and the number of Pre-elite tubers produced from microtubers were less than $50 \%$ of these from plantlets.

In the 1998 field studies, the results with JA were inconclusive; stock plantlets pretreated with JA (prior to in vitro tuberization) enhanced the Pre-elite tuber production in Russet Burbank by approximately $40 \%$ but significantly lowered it in Shepody by 17\%. In Russet Burbank, all the responses (total number of Pre-elite tubers, number of tubers $<48 \mathrm{~mm}$, number of tubers $48-88 \mathrm{~mm}$ and yield of tubers $<48 \mathrm{~mm}$ ) were significantly higher in the JA pre-conditioned treatments than in the no-JA control. The reverse was true in Shepody. In the 1999 field studies, JA presence in media during in vitro tuberization significantly lowered production of Pre-elite tubers. Microtubers produced from the JA conditioned Amisk and Russet Burbank stock plantlets gave up to $10 \%$ higher number of Pre-elite tubers in the $48-88 \mathrm{~mm}$ category. Overall, the results were inconclusive. Since the responses to JA, either in the tuberization media or as a stock plantlet conditioner, were variety specific, more experimental work is needed to determine suitability of the varieties to such treatment.

Again, as in greenhouse studies, SD light during in vitro tuberization resulted in microtubers performing significantly better in the field than those in the dark. The dormancy release was also the key factor influencing microtuber performance. Total number of Pre-elite tubers produced from microtubers treated with $8 \mathrm{~h}$ light was about $50-60 \%$ higher than from the microtubers produced in dark. Only microtubers produced under SD light can be recommended to field plantings.

Although in the greenhouse situation Rindite proved to be very effective for microtuber dormancy release, in the field GA gave slightly better results (Chapter 7). In all three Russet varieties, the highest number and yield of Pre-elite tubers were obtained when the microtubers were soaked in $100 \mathrm{ppm}$ solution of gibberellic acid prior to field planting. The yield and the number of Pre-elite tubers were significantly higher when the microtubers were produced on media without JA. For microtubers coming from JA tuberization media, there were no significant differences observed in all parameters measured, irrespective of the dormancy release treatment. Both, Rindite and GA treatments gave similar results.

Since the production of Pre-elite tubers from microtubers (irrespectively of the treatment) was about 50\% lower than those from plantlets, at this stage of knowledge, the propagule cannot be recommended for direct field planting in the production of Pre-elite tubers. 
Incorporating microtubers into a seed production system. Technically it is possible to produce large numbers of microtubers throughout the year, store them in the cooler and plant them out accordingly to the schedule of the seed programme. However, before a large-scale application could be considered, more research is needed to determine suitability of the commercial varieties to the in vitro tuberization method and to improve the performance of microtubers, particularly in the field situation. Based on the data obtained in this research; only microtubers of the three Russet varieties (Amisk, Russet Burbank and Umatilla Russet) can be recommended to include them in the seed potato programme, in the greenhouse production of minitubers only. Their performance was more than satisfactory and comparable with the industry standards, the plantlets. The results were repetitive suggesting that they can be produced reliably from in vitro propagated plantlets. However, application of microtubers in any of the seed potato programmes, will only be successful if the microtubers will yield progeny tubers that are superior economically and in quality to tubers (minitubers or Pre-elite tubers) produced by existing technologies. As mentioned in Section 9.5, in Western provinces of Canada (Alberta in particular), the interest in this new type of the propagule is quickly growing among seed potato growers who are at the same time the owners of small tissue culture laboratories. This may justify incorporation of microtubers into the seed potato system. The economical situation in Alberta is also favourable for microtubers since the potato acreage doubled over the last two years and the production of plantlets is very seasonal. Microtubers can be produced throughout the year and stored in the cooler until required for planting. Thus, incorporation of microtubers (Russet varieties) in the Alberta seed potato programme for greenhouse production of minitubers can be recommended.

In conclusion. The objectives of the research, although focused mainly on the needs of Western provinces of Canada (particularly Alberta), could be extended to any other area and the laboratory associated with any given seed potato programme. The importance of micropropagation in the early phases of seed potato production has been documented in this thesis in regard to utilization of various techniques and the use of microtubers as a propagule of choice for production of elite material. These, in turn, could have immediate practical implications to the production considerations and scheduling in the tissue culture laboratories. Research work on performance of microtubers in the greenhouse and in the field may provide a better understanding of the tuberization processes and their influence on further production of minitubers and Pre-elite tubers. 


\section{Samenvatting}

Snelle vermeerdering door middel van weefselkweek wordt sinds 30 jaar algemeen toegepast in productieprogramma's van aardappelpootgoed. Snelle vermeerdering heeft voor een groot deel de ziekteproblemen in de pootgoedvermeerdering opgelost en voorziet de aardappelsector van kwalitatief hoogwaardig, ziekte- en virusvrij "Elite" plantmateriaal. De techniek vond ook snel ingang omdat zij de mogelijkheid biedt grote hoeveelheden genetisch uniform in vitro materiaal (in vitro plantjes en microknollen) voor pootgoedproductie (miniknollen en "Pre-elite" knollen) in korte tijd en gedurende het gehele jaar te produceren.

Dit proefschrift behandelt verschillende verbeteringen van de vermeerderingstechnieken zoals die gangbaar zijn in commerciële laboratoria. Het gaat daarbij uit van de situatie van pootgoedtelers in West-Canada, die zelf hun weefselkweekmateriaal produceren, dan wel zulk materiaal afnemen om het uit te planten (Hoofdstuk 2).

Het proefschrift beschrijft onderzoek naar de mogelijkheden van:

1. Verbeteringen van in vitro vermeerdering via bladknoopstekken met de nadruk op foto-autotrofe groei;

2. Verbeteringen van de tijdelijke in vitro opslag van aardappelcultures bij lage temperatuur;

3. In vitro productie van microknollen vanuit bladknoopstekken van in vitro plantjes; hierbij werd tevens getest in hoeverre jasmijnzuur (JA) kan worden benut als een stof waarmee de knolinductie kan worden bevorderd en werden de effecten van drie verschillende daglengtes gedurende de in vitro knolaanleg onderzocht. Tevens werd nagegaan welke commerciële rassen via een dergelijke vermeerderingsmethode op basis van in vitro knolaanleg goed konden worden vermeerderd.

4. Het poten van microknollen in de kas of het veld om miniknollen en/of "Pre-elite" knollen te produceren; hierbij werden de prestaties van de microknollen vergeleken met die van het normale uitgangsmateriaal, het in vitro plantje.

5. Het gebruik van JA als "pre-conditioner" voor het poten van microknollen in kas of veld.

Vermeerdering van in vitro plantjes en in vitro opslag van cultures. In Hoofdstuk 3 werd bij het ras Russet Burbank onderzocht in hoeverre het mogelijk was de vermeerdering in vitro foto-autotroof te laten plaatsvinden. Een dergelijke techniek kan waardevol zijn voor kleine commerciële laboratoria waar het niet altijd eenvoudig is om de gewenste steriele omstandigheden goed te handhaven. Microstekken met én knoop werden gedurende vier weken opgekweekt op standaard MS medium zonder of 
met (30 g per liter) sucrose in een kweekcel bij een dag/nachttemperatuur van $21 / 19^{\circ} \mathrm{C}$, een daglengte van 16 uur en een fotosynthetische foton flux dichtheid (PPFD) van $150 \mu \mathrm{mol} \mathrm{m}^{-2} \mathrm{~s}^{-1}$ op basis van een combinatie van TL- en gloeilamplicht, en met $\left(1500 \mu \mathrm{l} \mathrm{CO}_{2} \mathrm{l}^{-1}\right)$ of zonder extra $\mathrm{CO}_{2}$. Na vier weken werden geen significante verschillen gevonden tussen de controle (MS medium aangevuld met een sucroseconcentratie van $30 \mathrm{~g} \mathrm{l}^{-1}$ ) en foto-autotrofe cultures (MS medium zonder sucrose maar bij $1500 \mu \mathrm{l} \mathrm{CO}_{2} \mathrm{l}^{-1}$ ). Foto-autotrofe cultures produceerden stengels van gemiddeld 43,3 mm lengte, met 7,58 knopen en een drooggewicht van 9,2 mg. Deze waarden waren vrijwel gelijk aan die van de conventionele in vitro cultures (stengellengte 47,9 mm met 7,55 knopen, 9,7 mg drooggewicht). Bij de cultures op media met sucrose en tevens in $\mathrm{CO}_{2}$ verrijkte atmosfeer bleek het aantal knopen per stengel met $20 \%$ en het stengeldrooggewicht met $50 \%$ toegenomen bij een tweemaal zo lange stengel ten opzichte van de cultures die onder standaardomstandigheden of onder foto-autotrofe condities werden geproduceerd. In conventionele, commerciële situaties zou derhalve het verrijken van de lucht in de kweekcel met $1500 \mu \mathrm{CO}_{2} \mathrm{l}^{-1} \mathrm{de}$ productie van in vitro plantjes van de aardappel kunnen bevorderen. Een dergelijke behandeling verbeterde immers de kwaliteit, omvang en biomassa van de geproduceerde plantjes significant. Op deze wijze kan de vermeerdering worden versneld.

In Hoofdstuk 4 werd beschreven in hoeverre in vitro bewaring van cultures bij lage temperatuur mogelijk was. De resultaten gaven aan dat het gebruik van continu rood licht $(690 \mathrm{~nm})$ bij een lage intensiteit van $3 \mu \mathrm{mol} \mathrm{m}^{-2} \mathrm{~s}^{-1}$ PPFD en bij $30 \mathrm{~g} \mathrm{l}^{-1}$ sucrose in het medium gedurende de koude opslag van aardappelcultures nuttig kan zijn. Dergelijke condities zorgen er voor dat de cultures een grote groeikracht en een groot vermogen om hergroei te vertonen, behouden. Cultures van het ras Atlantic (in vitro gekweekt gedurende 3 weken bij $24 / 22^{\circ} \mathrm{C}$, een daglengte van 16 uur, en een PPFD van $150 \mu \mathrm{mol} \mathrm{m}^{-2} \mathrm{~s}^{-1}$ ) werden gedurende 6,9 of 12 weken bewaard bij $4^{\circ} \mathrm{C}$ in het donker of bij een laag lichtniveau. De cultures werden bewaard op MS medium dat vrij was van groeiregulatoren en dat wel of geen sucrose bevatte. Sucrose was essentieel voor het behoud van groeikracht bij lage temperatuur zowel in het donker als bij rood licht van lage intensiteit. Daarnaast gaf de behandeling met enig licht een significant betere kwaliteit van de opgeslagen cultures bij een bewaring van meer dan zes weken. Aangezien commerciële telers de cultures vaak vanwege hun productieschema's voor een korte periode moeten opslaan, zou het installeren van een eenvoudige lamp met een geringe lichtopbrengst in een standaard koelkast al kunnen leiden tot een verbetering en een handhaving van de hoge kwaliteit van de opgeslagen cultures.

De productie van microknollen. Het onderzoek naar de productie van microknollen 
(Hoofdstukken 5 en 6) had betrekking op de vergelijking tussen vloeibare en vaste media, het belang van een daglengte van 8 uur (korte dag, $\mathrm{KD}$ ) gedurende de knolaanleg in vitro, het effect van jasmijnzuur (JA) om de knolaanleg te bevorderen en de rasverschillen in in vitro knolaanleg. De in vitro plantjes die voor alle proeven inzake in vitro knolaanleg werden gebruikt, werden om de paar weken routinematig in vitro vermeerderd via éénknopige stengelstekken. Bij de laatste vermeerdering vóór de in vitro knolaanleg werden de in vitro plantjes van alle rassen opgekweekt op een medium dat al of niet was verrijkt met $2,5 \mu \mathrm{M} \mathrm{JA}$ (de behandeling die aangeduid werd als JAP of JAPret). Deze in vitro plantjes werden gedurende 4 weken geïncubeerd onder de omstandigheden die al eerder beschreven werden bij de behandeling van de vermeerdering van in vitro plantjes. Explantaten geproduceerd van deze aldus behandelde in vitro plantjes (geen JA of JAP) werden in de proeven aangaande de knolaanleg gebruikt. Knolaanleg vond plaats op media met $8 \%\left(80 \mathrm{~g} \mathrm{I}^{-1}\right)$ sucrose, zonder JA of met 2,5 $\mu \mathrm{M} \mathrm{JA}$ (deze behandeling werd aangeduid als JAM of JAMed) en met (vast medium) of zonder (vloeibaar medium) $0.6 \%$ agar. Cultures werden geïncubeerd bij $20^{\circ} \mathrm{C}$ met een daglengte van 0 (donker), $8(\mathrm{KD})$ of 16 uur (LD) bij een PPFD van $50 \mu \mathrm{mol} \mathrm{m} \mathrm{m}^{-2} \mathrm{~s}^{-1}$ gedurende $10-11$ weken. In het algemeen bleek de productie van microknollen significant beter (in termen van aantal en gewicht) op vast dan op vloeibaar medium en bij KD (Hoofdstuk 5). De media met agar werden gebruikt voor verdere experimenten aangaande in vitro knolaanleg. Bij vloeibare media was het nodig regelmatig vers medium toe te voegen gedurende de knolaanleg. Deze toedieningen werden als ongemakkelijk ervaren vanwege de extra benodigde arbeid, maar ook vanwege het extra risico op besmetting. Tevens was de sucrose waarschijnlijk stabieler in het vaste medium dan in het vloeibare medium en dit bevorderde de knolaanleg ook. Het sucrosegehalte is belangrijk gedurende de in vitro knolaanleg en werd in alle experimenten op het optimale niveau ( $8 \%$ volgens de literatuur) gebracht.

In de eerste reeks experimenten (Hoofdstukken 5 en 6) werden de effecten van verschillende daglengten $(0,8,16$ uur) nagegaan. De beste productie van microknollen bleek te worden gevonden bij 8 uur (KD). De knolgroeisnelheden in het donker waren lager dan onder $\mathrm{KD}$, maar de eerste knollen werden juist waargenomen in het donker, en wel aan explantaten afkomstig van in vitro plantjes, die met JA behandeld waren. Knollen, die onder KD waren gevormd, waren groen en leken minder juveniel dan de knollen afkomstig uit het donker. In latere studies werd waargenomen dat dergelijke $\mathrm{KD}$ microknollen beter presteerden in het veld of in de kas dan de microknollen die in het donker waren gevormd. Een daglengte van 16 uur belemmerde de productie van microknollen. In latere studies werd wederom waargenomen dat de productie van microknollen veel beter was onder KD dan in het donker. In het algemeen werden er 


\section{Samenvatting}

minder knollen per explantaat gevormd in het donker dan onder KD. Bovendien hadden de knollen bij alle onderzochte rassen een significant hoger gewicht onder KD. De rassen bleken echter verschillend te reageren op daglengte gedurende de in vitro knolaanleg. Verder bleek de productie van microknollen voor alle drie de Russet rassen en voor het ras Sangre veel beter dan de productie bij de rassen Shepody en Atlantic (Hoofdstuk 6). In de proeven die werden beschreven in de Hoofdstukken 5, 6 en 7 bleek derhalve het blootstellen aan een korte dag gedurende de knolaanleg essentieel te zijn voor de productie van voldoende microknollen per bladknoopstek. Daarom wordt een daglengte van 8 uur voor deze fase aanbevolen.

De effecten van jasmijnzuur (JA) op in vitro knolaanleg bij de aardappel bleken zeer rasspecifiek te zijn. In de eerste reeks experimenten (rassen Sangre en Russet Burbank), vormden de explantaten die afkomstig waren van plantjes die op met JA verrijkt medium waren opgekweekt het eerst knollen, vooral als de fase van knolaanleg in het donker plaatsvond. De effecten van de voorbehandeling met JA waren het meest uitgesproken bij een daglengte van 16 uur, die - zoals bekend - de knolvorming remde. In het algemeen bleken de microknollen die geproduceerd waren aan stekken die afkomstig waren van plantjes opgekweekt op met JA verrijkt medium en de microknollen die gevormd waren op medium dat met JA verrijkt werd tijdens de knolvorming, uniformer en groter dan de knollen van de andere behandelingen. Bij zes commerciële rassen werden de effecten van JA in twee onafhankelijke experimenten nader onderzocht (Hoofdstuk 6), zowel in het licht ( 8 uur) als in het donker (0 uur). Amisk, Russet Burbank, Sangre en Umatilla Russet produceerden de meeste microknollen per bladknoopstek $(1,0-1,7)$ en de knollen van deze rassen waren ook het grootst, zoals blijkt uit het feit dat ze de grootste fractie knollen zwaarder dan $0,1 \mathrm{~g}$ leverden $(70-85 \%)$. De resultaten voor het ras Shepody waren inconsistent; Atlantic produceerde de minste knollen per stek. De effecten van JA bleken rasspecifiek en het positieve effect van JA was sterker in het donker dan bij de behandelingen met licht. Bij Atlantic leek het erop alsof JA het lichteffect verving bij knolaanleg in het donker. Op basis van hun reacties konden de rassen in drie groepen worden onderverdeeld. Amisk, Atlantic and Umatilla Russet (groep I) hadden in het donker voordeel van een verrijking van het knolaanlegmedium met JA (significant hoger totaal knolgewicht, hogere beknollingsgraad en hoger percentage microknollen $>0,1 \mathrm{~g}$ ); deze rassen profiteerden echter niet van de "pre-conditioning"-behandeling. Geen van deze rassen uit groep I profiteerde duidelijk van welke JA behandeling dan ook als de knolvorming in het licht plaatsvond. Russet Burbank (groep II) en Sangre ondervonden ook voordeel van de verrijking met JA in het donker, hoewel de JA toediening aan in vitro plantjes effectiever was dan de verrijking met JA van het medium tijdens de knolaanleg. Shepody (groep III) vertoonde geen enkel positief effect van JA op de 
knolaanleg in vitro, niet in het licht, maar ook niet in het donker. Vergeleken met de controle en de enkelvoudige JA behandelingen, bleek de dubbele JA behandeling (JAPret en JAMed) in het licht de productie van microknollen significant te verlagen, zowel bij Shepody als bij Russet Burbank.

Alle drie de Russet rassen (Russet Burbank, Umatilla Russet en Amisk (Ranger Russet)) en Sangre bleken goed in staat in vitro knollen te vormen. Het kan daarom worden aanbevolen deze methode voor commerciële productie van deze rassen te gebruiken. De rassen Shepody en (vooral) Atlantic daarentegen bleken maar heel weinig microknollen te produceren onder deze omstandigheden. De voorgestelde methodiek is voor deze rassen dan ook ongeschikt.

Prestaties van microknollen in de kas en in het veld. Alle microknollen die werden gebruikt in dit deel van het onderzoek (Hoofdstuk 7) werden geproduceerd onder een daglengte van 8 uur of in het donker; het uitgangsmateriaal bestond uit microknollen die waren geproduceerd op media met of zonder JA vanuit bladknoopstekken die waren voorbehandeld met of zonder JA. De prestaties van de microknollen werden (bij verschillende methoden van kiemrustbreking) vergeleken met die van de standaard, namelijk in vitro plantjes.

In de kas. Microknollen van de drie Russet rassen gaven de beste prestaties te zien bij de productie van miniknollen in de kas. Shepody gaf onduidelijke resultaten en er is meer onderzoek nodig om de prestaties van microknollen van dit ras in de kas te verbeteren. De prestaties van microknollen van het ras Atlantic waren in deze studie slecht en het kan niet worden angeraden dit ras op deze manier te vermeerderen. De prestaties van microknollen hingen sterk af van de behandeling van in vitro plantjes met jasmijnzuur (JA) voorafgaand aan de knolaanleg in vitro, van de aanwezigheid van JA in het medium tijdens de knolaanleg, de daglengte gedurende de knolaanleg en de methode van kiemrustbreking. Hoewel plantjes van alle vijf de rassen die werden getest het goed deden in de kas, bleken de prestaties van de microknollen rasafhankelijk; ook de reacties op JA waren rasafhankelijk. Wederom bleken de Russet rassen het best op de JA behandelingen te reageren. De aantallen en opbrengsten aan miniknollen van de drie Russet rassen waren het hoogst indien de miniknollen werden geproduceerd met behulp van plantjes die waren voorbehandeld met JA (Amisk produceerde meer dan 3 minitubers per microknol van JAPret plantjes, vergeleken met 2,5 miniknollen per microknol zonder JA). De totale opbrengsten voor Russet Burbank en Umatilla Russet waren ook het hoogst voor deze behandeling $(0,859$ and $0,879 \mathrm{~kg}$ per veldje van 20 microknollen, vergeleken met ongeveer $0,500 \mathrm{~kg}$ per veldje voor de andere behandelingen. Deze gegevens zijn vergelijkbaar met de aantallen die behaald 
werden met de standaard (de plantjes), vooral bij het ras Amisk. Evenzo was bij het ras Amisk de opbrengst aan miniknollen in de categorie $30-60 \mathrm{~mm}$ ongeveer hetzelfde als die afkomstig van plantjes. De behandeling van de in vitro plantjes met JA voordat de explantaten daarvan werden geoogst om knollen te produceren bleek gunstig voor de productie van miniknollen. Deze methode kan worden aanbevolen teneinde de kwaliteit van microknollen alsmede hun prestaties bij de kasproductie van miniknollen te bevorderen.

Microknollen die in het licht werden geproduceerd deden het significant beter dan de microknollen die in het donker werden geproduceerd. In beide seizoenen, 1998 en 1999, en in alle geteste rassen, was de totale opbrengst en het aantal miniknollen in alle grootteklassen 2 - 7 keer hoger bij de microknollen die gedurende hun in vitro knolvorming aan het licht waren blootgesteld. Over het geheel genomen bleek de $\mathrm{KD}$ gedurende de in vitro knolaanleg een belangrijke factor (onafhankelijk van de andere behandelingen) bij het produceren van microknollen, en deze presteerden vervolgens ook goed in de kas. Microknollen die in het donker waren geproduceerd deden het slecht. De effecten van daglengte gedurende de in vitro knolaanleg op de prestaties van microknollen zijn in detail bediscussieerd in Sectie 9.4 (Microtubers in the production of minitubers in the greenhouse) van de algemene discussie. Een daglengte van 8 uur tijdens in vitro knolaanleg kan worden aanbevolen.

De sleutel tot succes bij het gebruik van microknollen voor de productie van miniknollen is de kiemrustbreking. Direct na in vitro knolaanleg zijn de microknollen nog diep in rust. In dit onderzoek werden gibberellinezuur (GA) en Rindite gebruikt om de kiemrust van microknollen te breken voordat ze werden gepoot. Hoewel Rindite zeer effectief bleek onder kascondities is meer onderzoek nodig om aan te tonen dat dit product veilig kan worden gebruikt bij microknollen. Aangezien Rindite zeer toxisch is voor de mens moeten er veiligheidsmaatregelen worden genomen bij het hanteren van het product. Het rotten van microknollen, zoals dat in de literatuur na gebruik van Rindite vaak wordt gerapporteerd, deed zich in dit onderzoek niet voor. De microknollen afkomstig van de behandeling met een daglengte van 8 uur tijdens de in vitro knolaanleg die vervolgens behandeld waren met Rindite, toonden geen zichtbare schade. Bij de microknollen die afkomstig waren van de donkerbehandelingen kwam slechts minimale schade voor. Rindite werd slechts toegepast op microknollen die reeds een goed ontwikkelde schil hadden (na verscheidene weken in de opslag) en zwaarder waren dan $0,15 \mathrm{~g}$. Indien het omzichtig gebruikt wordt, kan Rindite wel degelijk worden aanbevolen om de kiemrust van microknollen te breken.

In het veld. Net als in de experimenten onder kasomstandigheden, bleken microknollen van de rassen Amisk, Russet Burbank and Umatilla Russet het relatief 
goed te doen in het veld; de resultaten met Shepody waren wederom onduidelijk, en de microknollen van Atlantic deden het zeer slecht. Daarentegen deden de in vitro plantjes van alle rassen het goed in het veld. Deze resultaten suggereren dat de plantjes kunnen worden beschouwd als een bron van plantmateriaal voor de commerciële productie in het veld van "Pre-elite" aardappelpootgoed (Hoofdstuk 7) indien zulks noodzakelijk en economisch haalbaar is. In dit onderzoek, gaven de in vitro plantjes in het veld duidelijk betere opbrengsten aan "Pre-elite" knollen dan de microknollen. Opbrengsten en aantallen "Pre-elite" knollen geproduceerd door gewassen vanuit microknollen waren minder dan $50 \%$ van die van de gewassen vanuit in vitro plantjes.

In de veldproeven van 1998 waren de effecten van JA niet eenduidig. Indien de plantjes waren voorbehandeld met JA (voorafgaand aan de fase van in vitro knolvorming) werd de productie van "Pre-elite" knollen bij Russet Burbank met ongeveer $40 \%$ verhoogd, maar bij Shepody met $17 \%$ significant verlaagd. Bij Russet Burbank, waren opbrengstparameters (totaal aantal "Pre-elite" knollen, aantal knollen $<48 \mathrm{~mm}$, aantal knollen in de maat $48-88 \mathrm{~mm}$ en opbrengst knollen $<48 \mathrm{~mm}$ ) significant hoger voor de behandelingen met een JA pre-conditioning dan voor de behandelingen zonder JA. Het omgekeerde gold voor Shepody. In de veldproeven van 1999 verlaagde de aanwezigheid van JA in de media gedurende de in vitro knolaanleg de productie van "Pre-elite" knollen significant. Microknollen die werden geproduceerd aan stekken van in vitro plantjes die met JA geconditioneerd waren, gaven bij Amisk en Russet Burbank tot 10\% meer "Pre-elite" knollen in de maat 48 $88 \mathrm{~mm}$. Over het geheel genomen, waren de resultaten niet consistent. Omdat de reacties op JA, hetzij toegediend in de media voor knolaanleg hetzij toegediend aan de in vitro plantjes waarvan de explantaten waren genomen, rasspecifiek waren, is meer experimenteel werk nodig om vast te stellen welke rassen geschikt zijn om met deze methoden te worden vermeerderd.

Ook in het veld - net als in de kasproeven - gaven microknollen die onder korte dag gedurende de in vitro knolaanleg waren geproduceerd een betere prestatie dan de microknollen die in het donker waren geproduceerd. De kiemrustbreking was ook weer een cruciale factor voor de prestaties van de microknollen. Het totale aantal "Preelite" knollen dat gevormd werd bij gebruik van microknollen behandeld met een daglengte van 8 uur, was ongeveer 50 - 60\% hoger dan bij gebruik van microknollen geproduceerd in het donker. Alleen microknollen die onder KD zijn geproduceerd, kunnen worden aanbevolen voor het poten in het veld.

Hoewel onder de kascondities Rindite zeer effectief bleek te zijn in de kiemrustbreking van microknollen, gaf GA in het veld iets betere resultaten (Hoofdstuk 7). Bij alle drie de Russet rassen, werden de hoogste aantallen en opbrengsten van "Pre-elite" knollen verkregen als de microknollen werden ondergedompeld in een oplossing van 
$100 \mathrm{ppm}$ gibberellinezuur voordat de knollen in het veld werden gepoot. Opbrengst en aantal "Pre-elite" knollen waren significant hoger als de microknollen werden geproduceerd op media zonder JA. Voor de microknollen die afkomstig waren van knolaanlegmedia die verrijkt waren met JA, werden er geen significante verschillen gevonden voor enige waargenomen opbrengstparameter, ongeacht hoe de kiemrust was gebroken. Rindite en GA gaven over het algemeen vergelijkbare resultaten.

Aangezien de productie van "Pre-elite" knollen voor gewassen vanuit microknollen ongeacht de behandeling ongeveer $50 \%$ lager lag dan die voor gewassen vanuit in vitro plantjes, kan op dit moment niet worden aanbevolen microknollen direct in het veld te poten voor de productie van "Pre-elite" knollen.

Opnemen van microknollen in een systeem voor pootgoedproductie. Technisch is het mogelijk grote aantallen microknollen te produceren gedurende het gehele jaar. $\mathrm{Ze}$ kunnen koel bewaard worden en vervolgens worden uitgepoot volgens het schema van een pootgoedprogramma. Alvorens een toepassing op grote schaal kan worden overwogen, is evenwel nog wel meer onderzoek nodig om vast te stellen welke commerciële rassen geschikt zijn om in vitro knolproductie te realiseren en om de prestaties van deze microknollen, vooral in een veldsituatie, te verbeteren. Op basis van de onderzoeksresultaten in dit proefschrift kan alleen het gebruik van microknollen van de drie Russet rassen (Amisk, Russet Burbank en Umatilla Russet) in een pootgoedproductieprogramma aanbevolen worden, en dan alleen nog indien ze worden gebruikt voor de productie van miniknollen in de kas. De prestaties van de microknollen van deze rassen waren meer dan bevredigend en vergelijkbaar met die van de huidige standaard, de in vitro plantjes. De resultaten bleken reproduceerbaar en dat suggereert dat microknollen op een betrouwbare wijze kunnen worden geproduceerd met behulp van in vitro plantjes. Het benutten van microknollen in welk pootgoedprogramma dan ook zal echter alleen succesvol blijken indien microknollen dochterknollen opleveren die in economische zin of in kwaliteit superieur zijn aan de knollen (miniknollen of "Pre-Elite" knollen) die worden geproduceerd volgens de bestaande technologieën. Zoals vermeld in Sectie 9.5, groeit de belangstelling voor dit nieuwe type uitgangsmateriaal in de westelijke provincies van Canada (met name in Alberta) snel onder pootgoedtelers die tegelijkertijd kleine weefselkweeklaboratoria bezitten. Dit gegeven kan het opnemen van microknollen in het pootgoedsysteem rechtvaardigen. De economische situatie in Alberta is ook gunstig voor microknollen: het areaal aardappel is gedurende de laatste twee jaren verdubbeld en de productie van in vitro plantjes is nog steeds seizoensbepaald. Microknollen kunnen daarentegen het gehele jaar rond worden geproduceerd en vervolgens koel worden opgeslagen totdat ze moeten worden gepoot. Dus het opnemen van microknollen van Russet rassen in het 
pootgoedproductieprogramma van Alberta kan worden aanbevolen voor de kasproductie van miniknollen.

Slotopmerkingen. De doelstellingen van het onderzoek waren vooral gericht op de behoeften van de westelijke provincies van Canada, en met name Alberta. Toch kunnen de conclusies worden geëxtrapoleerd naar andere gebieden en laboratoria waarin vergelijkbare pootgoedprogramma's relevant zijn. Het belang van snelle vermeerdering in de vroege fasen van de pootgoedproductie is in dit proefschrift beschreven met betrekking tot de benutting van verschillende technieken en het gebruik van microknollen als uitgangsmateriaal voor de productie van elite materiaal. Deze technieken zouden op hun beurt onmiddellijk praktische implicaties kunnen hebben voor de overwegingen die bij de productie en de planning van weefselkweeklaboratoria een rol spelen. Onderzoek naar de prestaties van microknollen in de kas en in het veld kunnen een beter begrip opleveren van het proces van knolaanleg en de invloed daarvan op de verdere productie van miniknollen en "Pre-elite" knollen. 


\section{Curriculum vitae}

Krzysztof Wlodzimierz Pruski was born on September $13^{\text {th }} 1953$ in Lodz, Poland. He graduated from the Agricultural University in Warsaw (SGGW), Poland, with a BSc degree in 1975. He obtained his MSc in Entomology at the above-mentioned university in 1976. Following graduation, he worked as a manager of a greenhouse/ field operation until 1981, supervising the greenhouse production of several floral crops, propagation and production of ornamental shrubs and fruit trees, and field production of several vegetable crops. In 1982, he moved to Canada where in 1987 he obtained his second MSc degree in horticulture from the University of Alberta, Edmonton, Canada. Since then, he has been working as a tissue culture specialist with the Alberta Government (Alberta Agriculture Food \& Rural Development) at the Crop Diversification Centre North (CDCN) in Edmonton. In 1997, he organized (on the request of the Alberta horticulture industry) the entomology programme for horticulture crops. Currently, he is on a two-year educational leave from Alberta Agriculture working on his $\mathrm{PhD}$ degree at the Wageningen University and Research Centre. He is also employed as a research associate (research chair in potato physiology) at the Nova Scotia Agricultural College, Truro, NS, Canada, working closely with the potato industry in the region. 